\title{
Die Dogmatik des Verwaltungsrechts vor den Gegenwartsaufgaben der Verwaltung
}

1. Bericht von Professor Dr. Dr. h. c. Otto Bachof, Tübingen

\section{Inhalt}

Seite

1. Einleitende Bemerkungen zum Thema und zur Aufgabe der Dogmatik . . . . . . . . . . . . . . . . . . 194

2. Die Kritik an der Verwaltungsrechtslehre (Ưberbllck) . 199

3. Zur Kritik im einzelnen; eigene Stellungnahme . . . . 202

3.1. Rückständigkeit der verwaltungsrechtlichen Dogmatik? 202

3.2. Die Verfassungsabhängigkeit des Verwaltungsrechts . 204

3.3. "Obrigkeitsstaatliche Relikte“ . . . . . . . . . . . . 206

3.4. Der Uberhang liberal-rechtsstaatlicher Elemente . . . 207

3.4.1. Zum „liberalen Rechtsstaat“: Korrektur falscher Vorstellungen . . . . . . . . . . . . . . . . . 207

3.4.2. Die dogmatische Unterbilanz im Recht der Leistungsverwaltung . . . . . . . . . . . . . . . . .

3.5. Die „juristische Methode“; Verhältnis des Verwaltungsrechts zu den Sozialwissenschaften . . . . . . . . . 215

3.6. Formalismus, Positivismus, Begriffsjurisprudenz im Verwaltungsrecht? Vernachlässigung von Aufgaben und Zwecken? . . . . . . . . . . . . . . . . . . . . 218

3.7. Das verwaltungsrechtliche System . . . . . . . . . . 223

3.7.1. Die Systemkritik . . . . . . . . . . . . . . . . . . 223

3.7.2. Zum Systembegriff; äußeres und inneres System . . . 224

3.7.3. Aufgaben und Zwecke als systembildende Elemente des äußeren Systems? . . . . . . . . . . . . . . . . 225

3.7.4. dgl. des inneren Systems? . . . . . . . . . . . . . . . 228

4. Hinweise zum Umbau und Ausbau des verwaltungsrechtlichen Systems . . . . . . . . . . . . . . . . 230

4.1. Verwaltungsakt oder Rechtsgeschäft als Zentrum verwaltungsrechtlicher Dogmatik? . . . . . . . . . . 230

4.2. Die Vernachlässigung des Behörden- und Organisationsrechts .. . . . . . . . . . . . . 233

4.3. Die Rolle des besonderen Verwaltungsrechts . . . . . 235

4.4. Deutsches und europäisches Verwaltungsrecht . . . . 236

5. Zusammenfassung und Ausblick . . . . . . . . . . . 237

13 Veröffentl. Dt. Staatsrechtslehrer, Hett 30 


\section{Einleitende Bemerkungen zum Thema und zur Aufgabe der Dogmatik}

1.1. Noch rechtzeitig scheint sich der Vorstand des ihm in Bern erteilten Rates erinnert zu haben: keine Themen mehr zu stellen, deren Elemente durch das verfängliche Wörtchen "und" verknüpft seien"). So wurde aus dem Arbeitstitel „Die Aufgaben der Verwaltung, und' die Dogmatik des Verwaltungsrechts" die endgültige Fassung des Themas, die wenigstens deutlich macht, da $\beta$ von den Referenten nicht auch die in Speyer ${ }^{2}$ ) vermißte Lehre von den Staatsaufgaben überhaupt und von den Verwaltungsaufgaben insbesondere erwartet wird.

Gegenwartsaufgaben der Verwaltung? „Daseinsvorsorge“, "Sozialstaat", „Leistungsstaat", „Staat der Industriegesellschaft", „Verteilung" und „Umverteilung": das sind nur einige der Stichworte, die uns hier sofort einfallen und die gebotenen Assoziationen hervorrufen ${ }^{3}$ ).

Als der Vorsitzende mir den Auftrag des Vorstands übermittelte, bemerkte er, es solle "die Frage aufgeworfen werden, ob die Erfüllung von Verwaltungsaufgaben mit der herkömmlichen Dogmatik des Verwaltungsrechts auch in der Zukunft bewältigt werden kann, oder ob das Begriffsinstrumentarium unseres Verwaltungsrechts fortentwickelt werden muß". Das schien mir ein einigermaßen begrenztes Thema $z \mathfrak{u}$ sein. Je mehr ich mich in die Fragestellungen hineindachte, um so mehr schwand aber mein Vertrauen in die Begrenztheit und Begrenzbarkeit des Themas. Vollends ging es in die Brüche, als der Vorstand das Thema in einer Art von Nachhilfeunterricht mit den Referenten besprach. Sie hatten danach den Eindruck, daß so ziemlich nichts von dem Gesamtbereich unserer Wissenschaft aus dem Thema herausfalle. Unter den rund 40 Stichworten, die ich mir damals notiert habe, fehlen weder die Systemtheorie noch die Entscheidungstheorie, weder die Automatisierung noch die Datenverarbeitung, erscheinen die Demokratisierung wie das Verhältnis zu den Sozialwissenschaften, finden sich die Grenzziehung zwischen öffentlichem und privatem Recht, aber auch sehr viel speziellere Dinge wie Stabili-

1) Ipsen auf der Tagung 1969, VVDStRL 28, 244.

) Ossenbühl, VVDStRL 29, 150 ff., 204 (LS 6-8), 274 f.; ferner die Diskussionsbeiträge ebendort, insbes. S. $249 \mathrm{ff}$.

3) DaB auch die Erhaltung und Fortbildung des Rechtsstaats eine (gewissermaßen permanente) "Gegenwartsaufgabe" ist und bleibt, sollte über den "moderneren" Aufgaben nicht vergessen werden. Daran immer weder zu erinnerm, besteht angesichts der sich ausbreitenden Enklaven staatlich geduldeten Unrechts und damit Hand In Hand gehender Gewöhnung an einen Rechtsverfall AnlaB genug. 
tätsgesetz, konzertierte Alktion, Diskontsatzpolitik und Dienstpostenbewertung. Angesichts so vielfältiger und auch wohl unterschiedlicher Erwartungen blieb den Referenten nur übrig, selbst eine Auswahl zu treffen, über deren Berechtigung man sicher streiten kann.

\subsection{Einige thematische Eingrenzungen sind vorweg geboten.}

1.2.1. Ich beschränke mich auf die Dogmatik des deutschen Verwaltungsrechts. $\mathrm{Zu}$ einer Einbeziehung des schweizerischen und des österreichischen fühle ich mich weder hinreichend kompetent, noch ließe sich das zeitlich bewältigen. Vielleicht mögen unsere Kollegen aus jenen Ländern dazu in der Diskussion etwas sagen.

1.2.2. Das Thema fragt nach der Dogmatik des Verwaltungsrechts. Das treffende Wort Fritz Werners vom Verwaltungsrecht als "konkretisiertem Verfassungsrecht" 4 ) hat sich inzwischen herumgesprochen und wird mitunter - gewiß nicht im Sinne seines Erfinders - so mißverstanden, als sei das Verwaltungsrecht überhaupt nichts anderes und ermangele einer eigenständigen Bedeutung. Immerhin, seine durchgehende Abhängigkeit vom Verfassungsrecht besteht zweifellos, und heute mehr denn $\mathrm{je}^{\mathrm{s}}$ ). Es ist deshalb schwierig, unser Thema gegen die verfassungsrechtliche Dogmatik abzugrenzen. Es versteht sich von selbst, daß man in vielen Fragen des Verwaltungsrechts zu sehr unterschiedlichen Ergebnissen gelangen muß: je nachdem, ob man die Verwaltung als eine „eigenständige Staatsgewalt" in dem von Hans Peters") beschriebenen Sinne versteht, ausgestattet mit verfassungsrechtlich gewährleisteten Räumen freien und gerichtlich unüberprüfbaren Handelns; oder ob man - um eine äußerste Gegenposition zu kennzeichnen - mit Hans $H$. Rupp von einer verfassungsrechtlich geforderten durchgängigen Gesetzesgebundenheit der Verwaltung nebst lückenloser Gerichtskontrolle ausgeht, wobei die ganze Ermessenslehre als ein rechtsstaatswidriges Relikt des vorigen Jahrhunderts erscheint $t^{7}$ ); oder ob man gar der Regierung die Funktion des Regierens bestreitet $\left.{ }^{8}\right)$. Man mag dazu

4) DVB1. 1959, 527.

5) Dazu schon Bachof, JZ 1957, 335 (= Verfassungsrecht, Verwaltungsrecht, Verfahrensrecht i. d. Respr. d. BVerwG, Bd. I, 3. Aufl. 1966, S. 7).

*) Hans Peters, Die Verwaltung als eigenständige Staatsgewalt (Rektoratsrede), 1965, passim.

7 Hans Heinrich Rupp, Ermessensspielraum und Rechtsstaatlichkeit, NJW 1969, 1273 ff., insb. 1278 a. E.

8) So Hans Heinrich Rupp, Einige wichtige Entscheidungslinien 1. d. Rspr. des Zweiten Senats des BVerfG (in: Das Bundesverfas- 
stehen wie man will: solche Thesen werden jedenfalls nicht dadurch überzeugender, da $B$ man die Gegenmeinung in die „Rumpelkammer der deutschen Verfassungsgeschichte“ verweist $\left.{ }^{p}\right)$. Unsere Vorgänger waren gewi ${ }^{2}$ nicht dümmer als wir, und es war keineswegs alles nur zeitgebunden, was sie gedacht und geäußert haben. Vor allem aber beruhen solche Abwertungen der Vergangenheit nicht selten auf falschen Darstellungen und verkürzten Uberlieferungen früherer Verhältnisse ebenso wie früherer Lehrmeinungen. Gerade über das letzte Drittel des 19. Jahrhunderts, in dem die Dogmatik unseres Verwaltungsrechts entscheidend geprägt wurde, sind schiefe Vorstellungen weit verbreitet. Ich werde nicht umhinkönnen, einige in unserer Zunft gängige Legenden zu zerstören. Wer sich dadurch getroffen fühlt, möge sich durch mein Eingeständnis besänftigen lassen, daß ich auch mich nicht frei von der Schuld weiß, überkommene Ansichten ungeprüft weitergegeben zu haben $\left.{ }^{10}\right)$.

sungsgericht 1951-1971, 1971, S. 121 ff.), S. 152. Da Rupp in der Diskussion (unten $\mathbf{S}$. 339) meinte, ich habe ihn falsch zitiert, sei die Stelle hier angeführt. Sie lautet: „Noch immer sind Theorien im Umlauf, die der vom sog. monarchischen Prinzip geprägten deutschen Staatslehre der konstitutionellen Monarchie des vorigen Jahrhunderts entlehnt sind und der Regierung - im organisatorischen Sinn - auch die Funktion des Regierens - im Sinne des government - zuerkannt wissen möchten." Ich vermag zwischen „Funktion des Regierens" und "government" keinen wesentlichen Unterschied zu sehen und meine deshalb, daß der Sinn des Wiedergegebenen auch ohne den (zugegeben: verdeutlichenden) Zusatz des government kein anderer geworden ist. Wenn Rupp jetzt in seinem Diskussionsbeitrag erklärt, er habe gesagt, „es seien immer noch Thesen im Umlauf, die allein der Regierung im organisatorischen Sinn das Regieren im Sinne des angelsächsischen government zuerkannt wissen möchten", so ist demgegenüber festzustellen, daß sich weder an der oben zitierten Stelle noch an der fast inhaltsgleichen Stelle DVBI. 1971, 671 die doch wohl entscheidende Einschränkung „allein" findet. Ich wüßte auch nicht, wer die so eingeschränkte These heute noch vertreten sollte.

9) Rupp aaO., im Anschluß an die in N. 8 zit. Stelle. Rupp steht damit durchaus nicht allein. Rechtsinstitute und Rechtsanschauungen, die auf früheren Epochen beruhen, werden heute oft schon deshalb abgelehnt oder mindestens als verdächtig angesehen, weil sie durch solche Herkunft "belastet" sind. Das ist angesichts der deutschen Geschichte der letzten 100 Jahre gewiß nicht unverständlich, sollte aber nicht zu voreiligen Pauschalurteilen führen.

$\left.{ }^{10}\right)$ So hält meine früher (Ubber einige Entwicklungstendenzen im gegenwärtigen deutschen Verwaltungsrecht, in: Staatsbürger und Staatsgewalt, 1963, Bd. II S. 3 ff.) entwickelte Sicht des Systems Otto Mayers einer neuerlichen Uberprüfung nicht in allen Punkten stand; das gilt insb. für die Stellung und Bedeutung des Verwaltungsaktes in diesem System. Dazu nachstehend im Text S. 213. 
Trotz der Verfassungsabhängigkeit des Verwaltungsrechts muß ich mich im wesentlichen auf die verwaltungsrechtliche Dogmatik beschränken, sonst würde das Thema uferlos. Insbesondere muß ich - die damit in Kauf genommene Verkürzung ist mir bewußt - darauf verzichten, auf das für das Verwaltungsrecht zentrale Verhältnis von Gesetz und Verwaltung näher einzugehen. Es wurde von unserer Vereinigung erst auf der Würzburger Tagung (1965) eingehend erörtert ${ }^{11}$ ), und es war kaum die Meinung des Vorstandes, dasselbe Thema unter einem anderen Titel nochmals behandeln zu lassen.

1.2.3. Das Thema zielt auf die Dogmatik des Verwaltungsrechts. Es wäre reizvoll gewesen, vorweg den Fragen nach der Bedeutung, nach den Möglichkeiten und nach den Grenzen dogmatischer Betrachtungsweise - in der Jurisprudenz überhaupt wie im Verwaltungsrecht speziell - grundsätzlich nachzugehen; die Beschäftigung mit dem Thema hat mir hier manche für mich neuen Einsichten vermittelt. Aber auch insoweit war Beschränkung unerläßlich. Ich muß deshalb auf eine "theoretischen Vorgabe", wie sie Herr Häberle an den Anfang seines gestrigen Referates gestellt hat, verzichten und mich statt dessen mit ganz wenigen Bemerkungen begnügen, die - vorwiegend durch Zitate - meinen eigenen Standpunkt erkennen lassen. Auf Leitsätze zu diesem Teil meines Berichts habe ich wegen seines kursorischen Charakters verzichtet.

$\mathrm{Da} \beta$ die Dogmatik im Verwaltungsrecht einen legitimen Platz habe, wird in dem Thema offensichtlich vorausgesetzt. Mit Recht. Rechtswissenschaft „ist systematisch oder sie ist nicht" ${ }^{12}$ ). Rechtsdogmatik aber ist nichts anderes als systematische Rechtswissenschaft ${ }^{13}$ ). Sie ist „ein kontingentes Gefüge (,Lehrgebäude') von juristischen Sätzen und Regeln, die unabhängig vom Gesetz allgemeine Anerkennung und Befolgung beanspruchen" ${ }^{\text {"14)}}$ ). Ihre Leistung besteht vornehmlich dar-

11) Vgl. die Referate (von Klaus Vogel und Roman Herzog) und die Diskussion zum Thema "Gesetzgeber und Verwaltung", VVDStRL 24, $125 \mathrm{ff}$.

${ }^{12}$ ) So ein viel zitiertes Wort von Hans J. Wolff, Typen im Recht und in der Rechtswissenschaft, Studium generale 1952, S. $195 \mathrm{ff}$, 205.

19) So Raiser, DRiZ 1968, 98. Raiser hat nur deshalb Bedenken, den Ausdruck "Rechtsdogmatik" durch den für treffender gehaltenen Ausdruck "systematische Rechtswissenschaft" zu ersetzen, weil das als Vorentscheidung im Methodenstreit zwischen "Systemdenken" und "Problemdenken" mißverstanden werden könnte.

14) Wieacker, Zur praktischen Leistung der Rechtsdogmatlk, in: Hermeneutik und Dialektik, Festschrift für H. G. Gadamer, 1970, Bd. 2 S. 311 ff., hier S. 319; ähnlich Esser, Vorverständnis und Methodenwahl in der Rechtsfindung, 1970, S. $90 \mathrm{f}$. 
in, „die Entscheidung nach nicht jeweils neu aufzurollenden rechtspolitischen, sondern positiv dogmatisierten Gesichtspunkten" zu ermöglichen ${ }^{15}$ ); sie ist "eine heuristische Methode der Entscheidungsfindung, bei der gewisse Begriffsspeicherungen die Möglichkeit angemessener Urteilsbildung eröffnen ${ }^{\text {"15 }}$ ). Sie hat damit eine wichtige Entlastungsfunktion für den rechtsanwendenden Juristen. Diese Funktion kann sie nur erfüllen, wenn sie sich ihrer Praxisbezogenheit bewußt und in diesem Sinne "rechtsdogmatische Praxislehre"10) bleibt. Die Dogmatik wird gesteuert und muß auf ihre Brauchbarkeit für Konfliktlösungen stets von neuem überprüft und ggf. korrigiert werden durch rechtspolitische Uberlegungen; sie wird bestimmt „durch die Vorauswahl einsichtiger Gerechtigkeitskriterien und sachlich überzeugender Lösungsgesichtspunkte ${ }^{(17}$ ).

An Angriffen, die der Rechtsdogmatik ihre Existenzberechtigung absprechen, hat es freilich nie gefehlt und fehlt es auch heute nicht ${ }^{18}$ ). Ich kann mich mit ihnen nicht näher befassen. Soweit nicht unter dem Deckmantel eines Kampfes gegen die Dogmatik in Wirklichkeit viel weitergehende Attacken gegen die Rationalität des Rechts geritten und utopische Modellvorstellungen einer "Welt ohne Zwänge“ propagiert werden, beruht die Ablehnung der Dogmatik wohl meist auf einer Verkennung der Vorläufigkeit des Wahrheitsgehalts juristischer Dogmen, die ja anders als theologische keine Unumstößlichkeit beanspruchen ${ }^{19}$ ); nicht selten rennen ihre Gegner offene Türen ein, indem sie sich gegen ein längst überholtes Verständnis des juristischen Systems als eines axiomatisch-deduktiven richten, während das System nach heutigem Verständnis ${ }^{20}$ ) nur als ein axiologisches oder teleologisches begriffen werden kann.

\footnotetext{
15) Esser aaO. S. 89 bzw. S. 92.

10) Klaus König, Erkenntnisinteressen der Verwaltungswissenschaft (Schriftenreihe der Hochschule Speyer Bd. 46), 1970, S. 75. Vgl. dazu auch Brohm, Strukturen der Wirtschaftsverwaltung (res publica Bd. 21), 1969, S. 36 ff.; hier auf S. 37 die berechtigte Warnung, „in der Rechtsdogmatik die Differenzierungen immer weiter voranzutreiben": „Man läuft sonst nämlich Gefahr, die Uberschaubarkeit der Dinge und damit ein wesentliches Element der Rechtssicherheit aufzugeben."

i7) Esser aaO. S. 7.

10) Vgl. aus vielen nur: Egon Schneider, DRiZ 1968, 47 und Rasehorn, Krttische Justiz 1969, 273 tf. Zum ersten s. die Antwort von Raiser, DRiZ 1968, 98, zum zweiten Esser aaO. S. 99 mit N. 66.

10) Vgl. Raiser aaO.

80) Ich folge hierin Canaris, Systemdenken und Systembegriff in der Jurisprudenz (Schriften zur Rechtstheorie Heft 14), 1969, passim, insb. S. $46 \mathrm{ff}$.
} 
Wenngleich mein Bericht also die Legitimität dogmatischer Betrachtungsweise voraussetzt, so kann die Frage nach dem Stellenwert und nach den Grenzen einer solchen nicht ganz ausgeklammert werden; wird doch u. a. die Dogmatik dafür verantwortlich gemacht, durch ihre Einseitigkeit zur Vernachlässigung anderer Bezüge des Verwaltungsrechts - besonders seiner historischen, soziologischen und politischen - geführt zu haben. Darüber hinaus kann in diesem Referat aber nicht gegangen werden. Ich kann das Thema also nicht etwa, wie $H$. $H$. Kupp es in einem soeben erschienenen Aufsatz $z^{21}$ ) als allein "sinnvoll“ bezeichnet hat, „im Sinne einer Infragestellung nicht nur der Dogmatik des Verwaltungsrechts, sondern des Verwaltungsrechts selbst" behandeln. Das wäre in einer Stunde nicht zu bewältigen, wäre $\mathrm{m}$. E. aber auch keine "satzungskonforme" Interpretation des Themas mehr. Ebensowenig 'kann mein Ehrgeiz dahin gehen, einer so weitgehenden und gewiß sehr bedenkenswerten These nachzugehen, wie sie Klaus Königg") formuliert hat: die Verwaltungsrechtslehre stehe gegenwärtig "vor einer Umformulierung ihres Wissenschaftsprogramms“.

\section{Die Kritik an der Verwaltungsrechtslehre (Uberblick)}

$\mathrm{Da}$ der Vorstand sich zur Wahl unseres Themas gedrängt sah, kann nicht verwundern angesichts der vielfachen Kritik, der sich die Verwaltungsrechtsiehre von außen wie aus dem eigenen Kreise ausgesetzt sieht. Glaubt man diesen Stimmen, so befindet sie sich in einem wahrhaft schrecklichen Zustand. $\mathrm{DaB}$ sie sich „in einer Sackgasse befinde(t)“ und „seit Jahrzehnten erstarrt" sei" ${ }^{20}$ ); daß sie 20 Jahre nach dem Inkrafttreten des Grundgesetzes „den Proze $B$ der Vergangenheitsbewältigung“ -- verstanden als Bewältigung des rechtsdogmatischen Nachlasses aus der Epoche der konstitutionellen Monarchie - immer noch nicht habe abschließen können ${ }^{24}$ ); daß sie sich immer noch mühe, „den Fesseln des von Otto Mayer vor mehr als einem Dreivierteljahrhundert kunstvoll geknüpften dogmatischen Begriffsnetzes zu entrinnen “25): das sind nur einige Äußerungen aus jüngerer Zeit, die hier stellvertretend für einen vielstimmigen Chor stehen mögen. Ich werde mich mit solcher Kritik eingehend befassen müssen; ich halte sie in den meisten Punkten für falsch, schon in ihren leicht widerlegbaren tatsächlichen Prämissen. Darüber mögen die eigenen weiterführenden An-

\footnotetext{
21) DVBl. 1971, 669 If., hier S. 669 re.

2 ) AaO. S. 213.

25) Franz Mayer, Allgemeines Verwaltungsrecht, 1970, S. 18.

24) Friauf, Der Staat, Bd. 9 (1970) S. 223.

25) Walter Schmidt, AöR Bd. 96 (1971) S. 321.
} 
sätze vielleicht zu kurz kommen; ohne gründliche Diagnose kann man aber keine Therapie verordnen. -

Die „Mängelrügen" gegenüber der heutigen Verwaltungsrechtslehre lassen sich im wesentlichen - vereinfachend, keineswegs erschöpfend und sich $z$. T. überschneidend - in etwa folgende Gruppen zusammenfassen ${ }^{20}$ ):

2.1. Die Verwaltungsrechtsdogmatik sei, vor allem im Vergleich zur Dogmatik des Zivilrechts, wenig durchgebildet und insofern rückständig. Dabei wird für diesen Rückstand teils (und am häufigsten) die relative Jugend sowohl der Rechtsmaterie selbst wie ihrer Wissenschaft verantwortlich gemacht ${ }^{27}$ ), teils der ständige Fluß der Gesetzgebung ${ }^{28}$ ) oder gar deren angebliche Ungereimtheit ${ }^{20}$ ), gelegentlich aber auch Unvermögen oder mangelndes Selbstbewußtsein der Rechtslehre ${ }^{\text {so }}$ ).

2.2. Die Einsicht in die Verfassungsabhängigkeit des Verwaltungsrechts habe sich mit jahrzehntelanger Verzögerung erst jetzt durchgesetzt, sie habe das überkommene „verfassungsrechtlich neutrale" Instrumentarium des Verwaltungsrechts als ungeeignet für die Bewältigung sozialordnungsgestaltender Aufgaben erwiesen, zugleich aber zahlreiche Fundamente unseres Verwaltungsrechts unsicher gemacht ${ }^{31}$ ).

2.3. Jenes Instrumentarium sei - so meinen andere Kritiker - gerade nicht verfassungsrechtlich neutral, sondern als typische Hervorbringung des konstitutionellen Staates diesem

20) Für jeden Punkt des nachfolgenden Katalogs ließe sich eine Fülle von Belegstellen anführen. Ich beschränke mich auf wenige Außerungen aus jüngerer Zeit. Doch sei darauf hingewiesen, daß viel von der heutigen Kritik sich im Aufsatz schon in Erich Kaufmanns bekannten Beitrag "Verwaltung, Verwaltungsrecht" in Stengel-Fleischmann, Wörterbuch des Deutschen Staats- und Verwaltungsrechts, Bd. 3, 1914, S. $688 \mathrm{lf}$., insb. S. $716 \mathrm{ff}$., findet.

27) Z. B. Külz, DOV 1961, 104; Werner, Verh. des 43. Dt. Juristentages 1960, Bd. I Teil 2 B S. 28 f.; Baring in: Staatsbürger und Staatsgewalt, 1963, Bd. II S. $46 \mathrm{f}$.

20) Werner aaO. S. 28.

20) Renck NJW 1971, 1552: Verwaltungsrecht ein "Wust von Zufälligkeiten und Ungereimtheiten" - ein Urteil, das den Schwierigkeiten einer vor ständig wechselnde und expandierende Aufgaben sozialer Gestaltung gestellten Gesetzgebung offenbar nicht gerecht wird.

so) Kïlz aaO. S. 105.

s1) Friauf aaO. S. 224. Friauf spricht freilich nicht von der „Verfassungsabhängigkeit" des Verwaltungsrechts, sondern von der "untrennbaren Wechselbeziehung" zwischen beiden Rechtsgebieten. Gemeint ist damit wohl dasselbe. Denn wenngleich die Beziehung zwischen Verfassungs- und einfachem Recht nicht auf einer Einbahnstraße verläuft, so ist die Einwirkung des ersten auf das zweite doch ungleich stärker als umgekehrt. 
verhaftet, es konserviere daher wesentliche Elemente desselben; dabei wird teils mehr das Fortwirken monarchisch-obrigkeitsstaatlicher Elemente behauptet ${ }^{32}$ ), teils wird

2.4. eine einseitig liberal-rechtsstaatliche Ausrichtung der überkommenen Lehre bemängelt ${ }^{33}$ ).

2.5. Das Verwaltungsrecht habe seit und mit der von Otto Mayer zum Sieg geführten „juristischen Methode“ die Bezüge zur Verwaltungswirklichkeit und zu den Nachbarwissenschaften, vor allem zur Verwaltungslehre, verloren ${ }^{34}$ ).

2.6. Die Dogmatik des Verwaltungsrechts sei formal, begriffsjuristisch, zweckentleert ${ }^{35}$ ).

2.7. Insbesondere richte sich seine Systembildung fälschlich an den Rechts- und Handlungsformen der Verwaltung aus statt an deren Zwecken und Aufgaben ${ }^{36}$ ).

2.8. Die Verwaltungsrechtsdogmatik habe die Akzente falsch gesetzt, sie kreise um ein falsches Begriffszentrum („Offentliche Gewalt", „Verwaltungsakt ${ }^{\text {(37) }}$, habe außerdem wichtige Bereiche des allgemeinen Verwaltungsrechts (z. B. das Organisationsrecht $t^{38}$ ) wie vor allem des besonderen Verwaltungsrechts ${ }^{39}$ ) vernachlässigt. Sie habe so die neuen sozialstaatlichen Aufgaben nicht in den Griff bekommen; es fehle etwa an einer

37) So insb. Hans Heinrich Rupp, Grundfragen der heutigen Verwaltungsrechtslehre, 1965, passim; ders., DVBl. 1971, 670; zustimmend Friauf, Der Staat Bd. 9 (1970) S. 223 ff. Vgl. auch Renck, JuS 1971, $77 \mathrm{ff}$. (insb. S. 82).

39) Badura, Verwaltungsrecht im liberalen und im sozialen Rechtsstaat (Recht und Staat Heft 328), 1966, passim; ders., Das Verwaltungsrecht des liberalen Rechtsstaates (Göttinger Rechtswiss. Studien Bd. 66), 1967, passim.

s4) Am temperamentvollsten immer noch Nass, Verwaltungsreform durch Erneuerung der Verwaltungswissenschaft, 1950; aus neuerer Zeit vgl. W. Thieme, Verwaltungslehre, 1967, S. 24 H.; Menger, Die Verwaltung Bd. 1 (1968) S. $478 \mathrm{ff}$.

25) Badura, Verwaltungsrecht im liberalen und im sozialen Rechtsstaat S. $16 \mathrm{ff}$.; Walter Schmidt, AöR Bd. 96 (1971) S. $321 \mathrm{ff}$.

so) Badura aaO. S. $20 \mathrm{ff}$.

37) Vgl. hierzu schon E. Kaufmann aaO.; kritisch gegenüber der zentralen Stellung des Verwaltungsaktes Henke VVDStRL 28, 157 ff.; vgl. auch Rüfner, ebendort S. $204 \mathrm{f}$. mit weit. Nachw.; Badura, DOUV 1968, 452; Ossenbiihl, DOV 1971, 515 N. 18. Zacher, Die Sozialversicherungen als Teil des öffentlichen Rechts (in: Sozialrecht und Sozialpolitik, Festschrift für Kurt Jantz, 1968, S. 29 ff.), S. 38, spricht gar vom "Verwaltungsakt ..., der gemeinhin wie ein begriffsjuristischer Popanz in der Mitte des Systems des Verwaltungshandelns steht".

29) Forsthoff, Lehrbuch des Verwaltungsrechts Bd. 1, 9. Aufl. 1966, S. 400; Stern, JZ 1962, 301; Blumenwitz, AöR Bd. 96 (1971) S. 161.

s9) Badura, DOV 1968, 454. 
dogmatischen Bewältigung der Subventionen ${ }^{40}$ ), der Umverteilung ${ }^{11}$ ), der Planung ${ }^{42}$ ), des Bildungswesens, usw.

3. Zur Kritik im einzelnen; eigene Stellungnahme

\subsection{Ist die verwaltungsrechtliche Dogmatik rückständig?}

Es steht gewiß außer Frage, daß das Verwaltungsrecht dem Zivilrecht keine auch nur ähnlich ausgefeilte Dogmatik an die Seite zu stellen hat. Daß allein das schon ein Zeichen von „Rückständigkeit" sei, scheinen diejenigen zu meinen, die jene Feststellung mit dem geringen Alter unserer Disziplin entschuldigen wollen. In Wirklichkeit beruht jener Sachverhalt aber viel weniger auf der meist dafür verantwortlich gemachten Jugend des Verwaltungsrechts - das doch als Hausdomäne differenziertester Dogmatik geltende Strafrecht reicht in seinen wesentlichen Anknüpfungspunkten ja auch kaum hinter das Jahr 1871 (StGB) zurück - als vielmehr auf seinen Gegenständen. Wieacker ${ }^{43}$ ) hat jüngst sehr eindrucksvoll die These belegt, je "elementarer" das Verhältnis des Gesetzgebers zu seiner Aufgabe sei, je unmittelbarer er politische und soziale Wertungskonflikte zu entscheiden habe, um so weniger lasse das Gesetz Raum für eine eigenständige Dogmatik; weshalb die eigentliche Domäne der Dogmatik das Zivilrecht sei und bleibe, während ihr im Verfassungsrecht, im Recht der Arbeit, der sozialen Sicherheit u. a. m. nur ein geringer Raum eröffnet sei. So betrachtet, ist auch das Verwaltungsrecht gewiß kein besonders günstiges Feld für die Dogmatik. Seine Verzweigung in zahlreiche Einzelgesetze, deren breite stoffliche Streuung, die weitgehende Determinierung durch politische Entscheidungen und durch Zweckmäßigkeitsgesichtspunkte, der rasche Wandel der Gesetzgebung, nicht zuletzt die Aufsplitterung in Bundes- und in Landesrecht: das alles verringert die Möglichkeit dogmatischer Bearbeitung und Erschließung. Solche Gesetze eröffnen sich eher topischem Denken; wobei ich, ohne das hier ausführen zu können, mit einer offenbar im Vordringen begriffenen Ansicht ${ }^{44}$ ) davon ausgehe, daß zwischen topischem und Systemdenken kein unüberbrückbarer Gegensatz besteht, beide sich vielmehr ergänzen müssen.

Sicher spielt auch das Fehlen einer Kodifikation des allgemeinen Verwaltungsrechts eine Rolle. Das Verhältnis zwischen gesetzlicher Positivierung und Dogmatik ist freilich ambivalent.

\footnotetext{
40) Henke aaO. S. 2421.

1) Zacher, VVDStRL 28, 236.

6) Wolff, Verwaltungsrecht I, (8. Aufl. 1971), S. $346 \mathrm{ff}$.

4) AaO. (N. 14) S. 316.

4) Kriele, Theorie der Rechtsgewinnung, 1967, S. 150; Esser, aaO.

(N. 14) S. 153; Canaris aaO. (N. 20) S. 151.
} 
Es gibt gesetzesfreie Dogmatiken - Wieacker ${ }^{45}$ ) verweist auf die vorkodifikatorische Dogmatik des europäischen ius commune und es gibt gesetzesabhängige Dogmatiken. $\mathrm{Ob}$ und wieweit Kodifikation Dogmatik hindert oder fördert, hängt entscheidend von der Art der gesetzlichen Regelung ab; insbesondere davon, ob der Gesetzgeber seinerseits im Bezugssystem einer schon ausgebildeten Dogmatik bleibt ${ }^{40}$ ) oder nicht.

Unsere verwaltungsrechtliche Dogmatik ist in weitgehender Unabhängigkeit vom Gesetz entstanden. Zwar haben Otto Mayer und seine Vorgänger (insb. F. F. Mayer ${ }^{47}$ ) ihr Anschauungsmaterial den damals schon recht zahlreichen Verwaltungsgesetzen entnommen, sie haben an Abgaben- und Polizeigesetze, an positives Wegerecht, Wasserrecht, Kommunalrecht u. a. m. angeknüpft. Jedoch hat Otto Mayer bei den Begriffen und Instituten, mit denen er die Vielfalt der empirischen Erscheinungen zu ordnen suchte, beträchtliche Anleihen beim französischen Verwaltungsrecht, anfangs auch beim deutschen bürgerlichen Recht gemacht; er hat diese Leihgaben mit souveräner Unbekümmertheit in sein Verwaltungsrecht transponiert. Viel davon war auch, wie er selbst bekundet hat, „eignes Gewächs" ${ }^{\text {"48 }}$ ), beruhend auf gründlicher Verwaltungserfahrung u. a. als Beigeordneter und Vizebürgermeister von Straßburg"t).

Die von ihm entwickelten Begriffe und Institute sind nicht nur erstaunlich rasch von Lehre und Rechtsprechung aufgegriffen, sondern auch in die Gesetzgebung übernommen worden; sie haben sich dort weitgehend bis heute gehalten. Stern ${ }^{\text {so }}$ ) hat im Jahre 1962 in einer sorgfältigen Untersuchung der Bundesgesetzgebung „eine erfreuliche Ubereinstimmung in der Erhaltung und Verwendung der überkommenen Grundsätze und Institutionen des allgemeinen Verwaltungsrechts durch den Gesetzgeber des besonderen Verwaltungsrechts" feststellen können - unbeschadet vieler vermeidbarer, meist mehr ter-

4) AaO. S. $317 \mathrm{f}$.

c) Wie das z. B. bei den großen zivilrechtlichen Kodifikationen des 19. Jahrhunderts der Fall war: Wieacker aaO. S. 318.

17) Grundsätze des Verwaltungsrechts mit besonderer Rucksicht auf gemeinsames deutsches Recht, 1862.

6) Deutsches Verwaltungsrecht, 1. Bd., 2. Aufl. 1914, S. IX.

4) Dazu Otto Mayers lesenswerte Autoblographie in Planitz, Die Rechtswissenschaft der Gegenwart in Selbstdarstellungen (Bd. 1) 1924, S. $153 \mathrm{ff}$., hier S. $166 \mathrm{ff}$. Mayer war in StraBburg Leiter der Baupolizei und des Wegewesens, dann der "sozialen Verwaltung" (sic!).

so) Das allgemeine Verwaltungsrecht in der neueren Bundesgesetzgebung, JZ 1962, 265 ff. und $297 \mathrm{ff}$;; das Zitat steht auf S. 302. 
minologischer als sachlicher Ungereimtheiten als Folge mangelnder Koordinierung der Gesetze.

3.2. Im Gegensatz zu oft gehörten Behauptungen ist die Einsicht in die Verfassungsabhängigkeit des Verwaltungsrechts alles andere als neu. Auch Otto Mayer hat sie gekannt und nachdrücklich betont. Wer ihm unter Berufung auf sein ebenso oft zitiertes wie mißverstandenes Wort „Verfassungsrecht vergeht, Verwaltungsrecht besteht ${ }^{\text {"s51 }}$ ) etwas anderes unterstellt, muß sich den Verdacht gefallen lassen, von seinem ganzen Werk nichts als diesen einen Satz zu kennen. Ubrigens hatte schon ein halbes Jahrhundert zuvor Lorenz von Stein ${ }^{32}$ ) ganz Ähnliches gesagt: „Es liegt tief im Wesen der Verwaltung, daß ihre Kategorien nicht wie die der Verfassung wechseln, weder an sich noch im positiven Recht". Darin liegt die durchaus richtige Erkenntnis, daß „das Verwaltungsrecht durch eine Staatsumwälzung nicht so unmittelbar, nicht als Ganzes und nicht in einem einzigen Augenblick aus den Angeln gehoben [wird] wie die Verfassung; aber um so sicherer und nachhaltiger bewirkt eine Änderung der Grundlagen der Staatsund Gesellschaftsordnung auch eine allmähliche und kontinuierliche Umbildung des Verwaltungsrechts" ${ }^{453}$ ). Mit dieser Reduzierung auf den gemeinten Sinn hat jener Ausspruch auch heute noch seine Berechtigung, er enthält sogar mehr als nur „ein Körnchen Wahrheit"s4). Die grundsätzliche Abhängigkeit

si) VR 1. Bd. 3. Aufl., 1924, Vorwort.

32) Gegenwart und Zukunft der Rechts- und Staatswissenschaft Deutschlands, 1876, S. 25. Den Hinweis auf diesen Ausspruch Steins verdanke ich Hans Schneider. - Mayers Verhältnis zu Steins Werk war zwiespältig und wechselnd: zwar kritisch, aber im ganzen anerkennend in VR Bd. 1, 1. Aufl. S. 17; wenig freundlich (,blühender Bombast") bei Planitz aaO. S. 163. - Mayer war, wie kaum ein anderer, "ein Mensch mit seinen Widersprüchen", temperamentvoll, engagiert, mitunter ungerecht in seinem Urteil, witzig und überspitzt in seinen Formulierungen. Er hat sich aber auch nie gescheut, Ansichten zu revidieren und Irrtümer zuzugeben. In einem solchen Werk Fehler und Widersprüche nachzuweisen ist leicht, das Herausgreifen einzelner Zitate ohne Sicht auf das Ganze wenig beweiskräftig. Zu Mayers Werk und Persönlichkeit vgl. Walter Jellinek, Verwaltungsrecht, 3. Aufl. 1931 (Neudruck 1966), S. 106, und die dort angegebenen Besprechungen und Würdigungen; ferner Dennewitz, Die Systeme des Verwaltungsrechts, 1948, S. 122 If.; Forsthoff, aaO. (N. 38) S. 49 ff.

ss) Bachof, Uber einige Entwicklungstendenzen im gegenwärtigen deutschen Verwaltungsrecht (in: Staatsbürger und Staatsgewalt, 1963, Bd. 2 S. 3 ff.), S. 3. - Uber die Situationsbedingtheit von Mayers Wort vgl. Menger, Der Staat, Bd. 1 (1962) S. $360 \mathrm{f}$.

B4) Stern, aaO. S. 302. - Auch Erich Kaufmann (Verwaltungsarchiv Bd. 30, 1925, S. 390 u. 400) hat dem Wort zugestimmt, sogar Otto Mayer vorgeworfen, es seinerseits nicht genügend beachtet zu 
des Verwaltungsrechts von der Verfassung aber war Mayer völlig selbstverständlich. Ausgangspunkt seines Lehrgebäudes ist der gewaltenteilende "Verfassungsstaat", von dem er sagt: „Der Inbegriff der Regeln, nach welchen er eingerichtet ist, heißt Verfassungsrecht. Wir werden sehen, wie gerade an den damit gegebenen Unterscheidungen innerhalb der obersten $\mathrm{Ge}-$ walt unser ganzes Verwaltungsrecht hängt ${ }^{\alpha s 5}$ ).

Die Kenntnis dieser Zusammenhänge durchzieht die Literatur des Kaiserreichs wie der Weimarer Zeit. So schreibt z. B. Fleiner 1928 im Vorwort zur 8. Auflage seiner "Institutionen“, vermutlich in betonter Wendung gegen das mißverständliche Otto-Mayer-Wort: „Die Neugestaltung des Verfassungsrechts hat in Deutschland einen starken Einfluß auch auf das Verwaltungsrecht ausgeübt. Alte Rechtsinstitute haben einen veränderten Sinn bekommen, und neue Probleme sind aufgetaucht, die eine selbständige wissenschaftliche Behandlung erfordern ${ }^{\text {(s) }}$ ).

Nicht die Verfassungsabhängigkeit des Verwaltungsrechts, auch nicht die Einsicht in dieses Verhältnis ist also neu. Was hingegen wirklich neu, erst seit und mit dem Grundgesetz eingetreten ist, das ist die ständige unmittelbare Konfrontation allen Verwaltungshandelns mit der Verfassung, ist die nur noch begrenzte Möglichkeit einer Deckung der Verwaltung durch das einfache Gesetz. Das ist ein Umstand, auf den wohl Dürig ${ }^{57}$ ) zuerst hingewiesen hat. Einige Stichworte dazu mögen hier genügen: Art. 1 Abs. 3 GG; richterliches Prüfungsrecht; verfassungskonforme Auslegung. Das Ausma $\beta$ der Verfassungsabhängigkeit des Verwaltungsrechts ist damit freilich ganz außerordentlich gestiegen.

Man wird nun aber nicht behaupten können, daß Rechtsprechung und Lehre sich dieser gesteigerten Verfassungsabhängigkeit und der durch sie gestellten Aufgabe entzogen hätten. Die Einwirkungen der Verfassung auf verwaltungsrechtliche Normen, Institute und Begriffe sowie deren verfassungskonforme Fortbildung und Umbildung sind das tägliche Brot besonders der Judikatur. Eher wird hier zu viel des Guten als zu wenig

haben. Interessant ist die Bemerkung Kaufmanns, jener Ausspruch sei "auch von Otto Mayer zitiert" worden (aaO. S. 390); demnach scheint er überhaupt schon älter zu sein, worauf auch die Anführungszeichen bei $O$. M. hindeuten.

ss) VR, 1. Aufl. 1. Bd., S. 3 f. - Hervorhebung der Schlußworte von mir.

s6) Institutionen des deutschen Verwaltungsrechts, 8. Aufl. 1928, Vorwort (S. V).

s7) JZ 1953, 195; näher dazu Bachof, VVDStRL 12 (1954) 50 If. 
getan: oft erfolgt auch dann ein voreiliger Rückgriff auf die Verfassung, wenn dazu wegen einer ausreichenden einfachgesetzlichen Regelung kein Anlaß besteht.

3.3. Das Vorhandensein solch grundsätzlicher Einsicht in die Verfassungsabhängigkeit des Verwaltungsrechts widerlegt freilich noch nicht die Behauptung, unser heutiges Verwaltungsrecht und seine Lehre seien von der Verfassungslage und vom Staatsverständnis der konstitutionellen Monarchie geprägt, sie seien es geblieben und verharrten noch in den alten Verkrustungen; das gebräuchliche Instrumentarium des Verwaltungsrechts sei demnach nicht neutral, erst recht aber dem demokratischen und sozialen Rechtsstaat des Grundgesetzes nicht zugewandt.

Wenden wir uns zunächst den behaupteten „obrigkeitsstaatlichen Relikten" zu, so wird wohl niemand bestreiten wollen, daß das Verwaltungsrecht des Kaiserreichs, in geringerem MaBe auch dasjenige der Weimarer Republik und in nicht unerheblichen Restbeständen noch das Recht der Jahre nach 1945 manche obrigkeitsstaatlichen Elemente aufwies. Sie sind aber inzwischen längst abgebaut, und zwar gründlich und höchst effektiv; hier werden nur noch Nachhutgefechte geführt. Ich meine, es lohnt einfach nicht mehr, darüber noch viel zu reden. Wer freilich nur eine mehr oder minder totale gesetzliche Bindung der Verwaltung als rechtsstaatlich und als demokratisch anzuerkennen vermag, wird das bestreiten. Hier scheiden sich in der Tat die Geister. Wollte ich dem nachgehen, so wären wir mitten in der Diskussion der Würzburger Tagung, die ich nicht neu aufrollen kann.

Als wichtige Stationen eines Abbaus obrigkeitsfixierter Dogmatik seien nur - abgesehen von der auf Schritt und Tritt sich bemerkbar machenden Grundrechtsbindung - erwähnt: die veränderte Sicht des Staat-Bürger-Verhältnisses (Subjektstellung, nicht mehr Objektstellung des Bürgers), wie sie vor allem in einer Umgestaltung früherer Rechtsreflexe in subjektive Rechte sowie in einer anderen Interessenwertung zahlreicher Rechtsnormen zum Ausdruck kommt; die gegenständliche Erweiterung und gleichzeitige Rangerhöhung des Verhältnismäßigkeitsprinzips; die erweiterte Anerkennung von Entschädigungs- und Folgenbeseitigungsansprüchen; die Einschränkung des Verwaltungsermessens in Verbindung mit der Entwicklung und Anerkennung eines Anspruchs auf rechtsfehlerfreie Ermessensentscheidung; nicht zuletzt die rechtliche Durchdringung vormals als "rechtsfrei" erachteter sog. "Innenräume“ der Verwaltung, hier vor allem des sog. besonderen Gewaltver- 
hältnisses und speziell des Anstaltsnutzungsverhältnisses. Von der „großen Lücke im System der rechtsstaatlichen Verwaltung " (Forsthoff ${ }^{\text {s8 }}$ ), von dem "vorrechtsstaatlichen Urwald" (Herbert Krüger ${ }^{30}$ ) kann heute wohl ernstlich nicht mehr die Rede sein, nicht zuletzt dank der Rodungsarbeiten, die Krüger selbst und Ule seinerzeit in den Mainzer Referaten ${ }^{80}$ ) geleistet haben; hier bleibt nur noch einiges Unterholz wegzuschlagen.

3.4. Ganz anders verhält es sich mit der Behauptung, unser Verwaltungsrecht, sein Instrumentarium und seine Dogmatik seien von Anbeginn an einseitig liberal-rechtsstaatlich ausgerichtet gewesen und seien es bis heute geblieben. Hier stoßen wir auf recht komplexe Zusammenhänge. Paradoxerweise wird die Behauptung durch den Untersuchungsbefund im wesentlichen bestätigt, obwohl ihre gängigen Prämissen falsch sind.

3.4.1. Spätestens seit Forsthoffs Schrift „Die Verwaltung als Leistungsträger" ${ }^{\text {(01) }}$ gilt es in unserem Fach als ausgemacht, die Dogmatik des deutschen Verwaltungsrechts entstamme einer Époche des einseitig freiheitsverbürgenden, des sog. „liberalen“ oder „bürgerlichen" Rechtsstaats, sie sei durch diese ihre Entstehungszeit entscheidend geprägt. Forsthoff selbst sagt darüber: „... die Systembildung der Verwaltungsrechtswissenschaft [beschränkte sich] wesentlich auf den Teil des Verwaltungsrechts ...., den wir heute als Eingriffsverwaltung bezeichnen ... Diese Systembildung, mehr noch: die ihr zugrunde liegende Bindung der Verwaltung an das Gesetz, wurde erst ermöglicht durch eine substantielle Beschränkung der Verwaltungsfunktionen, ich meine die Eliminierung des Wohlfahrtszwecks" ${ }^{\text {c2 }}$ ). Hans Peters hat das anders, und wie ich meine rich-

58) AaO. (N. 38) S. 51, in bezug auf Otto Mayer. Mayer selbst sagte vom Anstaltsnutzungsverhältnis, es trage „mit voller Absichtlichkeit nicht das Gepräge des Rechtsstaates". Merkwürdig 1st dabei, daB nicht nur dieser Satz erstmals in der 2. Aufl. des VR (Bd. 2, 1917, S. 494; ebenso 3. Aufl., 1924, S. 284) erscheint, sondern daß auch der Sache nach das Anstaltsnutzungsverhältnis in der 1. Aufl. (Bd. 2 S. 318 ff.) noch ungleich rechtsstaatlicher gesehen war, mit subjektivem öffentlichem Recht auf Zulassung, Bindung des Anstaltsträgers nicht nur an eine rechtssatzmäßige, sondern auch an eine als Dienstvorschrift erlassene Anstaltsordnung, usw. Allerdings sind solche Bindungen $z$. $T$. auch in den späteren Auflagen erhalten geblieben, in gewissem Widerspruch zu jener drastischen Erklärung. Vgl. dazu auch Forsthoff aaO. S. 53 Fußn. 1.

so) VVDStRL 15 (1957) S. 109.

00 Das besondere Gewaltverhältnis, aaO. (N. 59) S. 109 tf. bzw. S. $133 \mathrm{ff}$.

11) 1938; das erste und das vierte Kapitel der Schrift sind neu veröffentlicht in: Forsthoff, Rechtsfragen der leistenden Verwaltung (res publica Bd. 1) 1959, S. $22 \mathrm{ff}$.

o2) Rechtsfragen der leistenden Verwaltung S. 50. 
tiger, gesehen. In der von ihm mitherausgegebenen letzten Auflage (1930) des seinerzeit berühmten „Hue de Grais“, des Handbuchs der Verfassung und Verwaltung in Preußen und dem Deutschen Reiche - mit seinen 25 Auflagen für die Praxis der deutschen Verwaltung übrigens weit wichtiger geworden als die Mehrzahl aller Lehrbücher -, stellt er Rechtszweck und Wohlfahrtszweck des Staates gleichberechtigt nebeneinander, und zum ersteren schreibt er: „Die auf liberalen Grundsätzen fußende Rechtsstaatstheorie sah hierin den einzigen Zweck des Staats; Gegensatz: Wohlfahrtsstaat. Schon die Präambel zur RV 1871 erkannte das Deutsche Reich als Wohlfahrtsstaat an. ${ }^{\text {"6s }) ~} \mathrm{Daß}$ das keine falsche Sicht ex post war, zeigen Gesetzgebung, Rechtsprechung und Schrifttum aus jener Zeit ${ }^{\text {t4 }}$; stellvertretend stehe auch hier der Hue de Grais. Schon in der 1881 erschienenen 1. Auflage des Werkes ${ }^{65}$ ) schreibt der Verfasser: "Der Staat hat für das wirtschaftliche Wohlergehen seiner Angehörigen zu sorgen, da die Bedingungen hierzu dem Einzelnen vielfach nicht erreichbar sind." $\left.{ }^{80}\right)$ Eingehend legt er dar, wie die liberale Bewegung damals schon ihren Höhepunkt überschritten hatte: "Doch auch diese auf wirtschaftliche Freiheit und Selbsttätigkeit gerichtete Bewegung hatte ihre Grenzen. Die aus den Fesseln des Polizeistaats erlöste wirtschaftliche Tätigkeit durfte nicht nach der anderen Seite hin dem starren Rechtsstaat verfallen, der nur den Rechtsschutz gewährt, alle Wohlfahrtszwecke dagegen von sich weist. Die Erfahrungen der jüngsten Zeit haben unsere wirtschaftliche Bewegung, die bereits diesen äußersten Zielen sich zu nähern begann, wieder in natürlichere Bahnen gelenkt. Die vermehrten Bedürfnisse des heutigen Lebens stellen Anforderungen, die nur vom

w) Graf Hue de Grais - Peters, Handbuch der Verfassung und Verwaltung in Preußen und dem Deutschen Reiche, 25. Aufl. 1930, S. 1 N. 2.

4) Man macht sich heute freilich kaum mehr die Mühe, zu diesen Quellen vorzustoßen, sondern begnügt sich in der Regel mit der Weitergabe vorgefundener Urteile, die sich dann oft noch von Autor zu Autor vergröbern.

as) Graf Hue de Grais, Handbuch der Verfassung und Verwaltung in Preußen und dem Deutschen Reiche, 1882. Das Auffinden dieser 1. Auflage verursachte erhebliche Schwierigkeiten, da sie laut späteren Auflagen im Jahr 1881 erschienen, unter diesem Jahr aber nicht katalogisiert ist. Tatsächlich muß sie schon 1881 erschienen sein, da sich in diesem Jahr bereits eine Rezension findet (im Centralblatt für Rechtswissenschaft I. Bd., 1881, S. 79 f.); die schlechte Sitte der Vordatierung durch geschäftstüchtige Verleger ist also auch nicht neu!

0) AaO. S. 346; Ahnliche Ausführungen finden sich auch zu Unterricht und Bildung, S. 331. 
Staate mit seinen umfassenderen und wirksameren Mitteln gehörig erfüllt werden können . . . Unserer Gesetzgebung ist damit ein sozialpolitischer Charakter aufgeprägt . . . Die Sozialgesetzgebung bildet somit keinen für sich abgeschlossenen Teil der allgmeinen Gesetzgebung, sondern kommt in größerem oder geringerem Umfange in den verschiedensten $Z$ weigen derselben zur Geltung. ${ }^{\text {“77) }}$ Diese grundsätzliche Beurteilung der Staatsaufgaben wird vollinhaltlich bestätigt durch diejenigen Abschnitte des Werkes, die sich im einzelnen mit der Gesetzgebung und Verwaltung der "Wirtschaftspflege“, „Wohlstandspflege" und "Kulturpflege" befassen und die in den folgenden Auflagen einen immer breiteren Raum einnehmen. $\mathrm{Zu}$ dem (als einem der Beispiele der Sozialgesetzgebung angeführten) Steuerrecht wird ausgeführt: „Auch hier hat die neuere Zeit den volkswirtschaftlichen und sozialen Gesichtspunkt gegen den finanziellen mehr in den Vordergrund gerückt." ${ }^{\text {(68) }}$ Die Rechtsprechung jener Epoche bestätigt das. Nicht nur Umverteilung, sondern auch sozial- und wirtschaftspolitische Lenkung werden als (ggf. sogar alleiniger!) Steuerzweck anerkannt: Ein Urteil des Reichsgerichts aus dem Jahre 1901 führt zu einer kommunalen Zweigstellensteuer aus: „Der Versuch des Klägers, den Charakter der Abgabe als der einer Steuer mit der Ausführung zu beseitigen, da $B$ nach der eigenen Angabe der Beklagten der Schutz der kleinen Gewerbetreibenden gegen die übermächtige Konkurrenz der Großbetriebe den Zweck der Abgabe bilde, und daß tatsächlich jedenfalls der sozialpolitische Zweck in erster Linie stehe, der finanzielle, wenn ein solcher überhaupt vorhanden sei, zurücktrete, trägt in den Begriff der Steuer, wenigstens im Sinne der geltenden Reichs- und Landesgesetze, ein ihm fremdes negatives Erfordernis hinein. ${ }^{\text {(Bo }}$ )

Die vorhin zitierten Äußerungen von Hue de Grais stammen - ich wiederhole es - aus dem Jahre 1881; das war 15 Jahre vor dem Erscheinen der 1. Auflage von Otto Mayers Deutschem

07) AaO. S. 348 f.; Sperrung im Original.

8 ) AaO. S. 162; Sperrung im Original.

0) RGZ 49, 66 (70). Das Urteil ist nicht zuletzt deshalb bemerkenswert, weil das RG schon im Jahre 1901 reine Lenkungssteuern offenbar als ganz unproblematisch ansah, während das BVerfG noch im Jahre 1954 eine ausführliche Widerlegung ihrer behaupteten Unzulässigkeit für notwendig erachtete: BVerfGE 3, 407 (435 1.). Fleiner (Institutionen des Deutschen Verwaltungsrechts, 3. Aufl. 1911, S. 390 mit N. 4) bezeichnete die Auffassung des RG als "in Judikatur und Literatur herrschend", obgleich er selbst ihr widersprach. Der von Häberle (oben S. 140 Leitsatz 47) angesprochene Wandel der Funktion der Steuer "von der bloß tiskalischen Mittelbeschaffung zur Durchsetzung politischer Zwecke" ist also schon sehr früh erfolgt. 
Verwaltungsrecht! Aber auch Mayer sah die Dinge nicht anders. Nach eigener Bekundung ${ }^{70}$ ) bilden den "Kern" seines „Systems der einzelnen Rechtsinstitute" nicht etwa die heute oft dafür angesehenen Institute der Polizeigewalt und der Finanzgewalt - die er dem Kern nur "vorausnimmt" -, sondern "das Rechtsgebiet der öffentlichen Unternehmungen und Anstalten“; "den Schluß" macht dann das Recht der besonderen juristischen Personen. Freilich: er hat „davon abgesehen, diese Gruppierungen durch besondere Uberschriften hervorzuheben; dergleichen wird dann leicht überschätzt ${ }^{\text {(771)}}$. Auch Erich Kaufmann, gleichermaßen ein großer Bewunderer wie scharfer Kritiker Mayers $^{22}$ ), urteilt im Jahre 1925, das ganze Werk gruppiere sich von Auflage zu Auflage „mit wachsender Deutlichkeit um den Begriff der öffentlichen Unternehmung“; der gesamte 2. Band könnte eigentlich die Uberschrift „Das Recht der öffentlichen Unternehmung" führen ${ }^{73}$ ). Schon in der 1 . Auflage erwähnt Mayer als Beispiele solcher Unternehmungen Straßen und Kanäle, Eisenbahnen, Schiffahrtsunternehmen, Fost, Banken, Sparkassen und andere Kreditinstitute, Landesmeliorationen. Schlachthäuser, kommunale Versorgungseinrichtungen, Fürsorge, Sozialversicherung, Krankenhäuser, öffentliche Bäder, Universitäten, Schulen und Akademien, Theater, Museen und manches andere. Ein Staat, der solche Aufgaben in die Hand nahm, war gewiß kein nur freiheitsbewahrender „liberaler Rechtsstaat ${ }^{* 74)}$.

70) VR 3. Aufl. 1. Bd., S. 21 f.

11) Heute wird man diese Zurückhaltung bedauern müssen, denn inzwischen wird "dergleichen" ohne entsprechende Uberschriften offenbar gar nicht mehr zur Kenntnis genommen! Für den nur noch die Uberschriften konsumierenden "eiligen Leser" ist es symptomatisch, daB Autoren in jüngster Zeit sogar mit den Uberschriften allein auskommen zu können glauben.

7g) Vgl. einerseits Verwaltungsarchiv Bd. 30 (1925) S. 391: Mayer habe durch seine Vernachlässigung der spezifischen geschlchtlichen Uberlieferungen und der besonderen Grundauffassungen von Staat und Recht in Deutschland "unser deutsches Verwaltungsrecht entstellt und denaturiert"; andererseits aaO. S. $378 \mathrm{f}$.: "Wenn diese Fähigkelt, die leitenden Grundsätze aus dem Stoffe "des Rechts herauszufühlen, von ihnen aus den inneren Zusammnehang des Rechtssystems zu erkennen und die Begriffe und Rechtssätze als wirkliche Wesen anzuschauen und hinzustellen, den großen Juristen ausmacht, dann gehört Otto Mayer zu den größten." Dort auch die Würdigung des $n$ künstlerischen Elementes", des glänzenden Stiles, der Klarheit und der Anschaulichkeit seiner Darstellung.

72) AaO. S. 387.

7i) Dieser schon sehr umfangreichen Tätigkeit des Staates auf dem Gebiet der Sozialordnung wird Forsthoff (Der Staat der Industriegesellschaft, 1971, S. 76 f. N. 10) kaum gerecht, wenn er meint, weder ubersehen noch verkannt zu haben, „daß es schon vor 
Sehr genau gesehen war auch, daß es sich bei diesen Unternehmungen um etwas grundsätzlich anderes handelte als um den Bereich der "obrigkeitlichen" - wir würden heute sagen: "Eingriffs"- - Verwaltung ${ }^{75}$ ). "Ganz anders geartet stellt sich das Rechtsinstitut [des öffentlichen Unternehmens ${ }^{76}$ )] von vornherein dar, als die im ersten Buche unseres besonderen Teiles betrachteten Erscheinungen ${ }^{77}$ ). Ein neues Gebiet von Rechtsformen der Verwaltung tut sich damit auf . . . In Polizeigewalt und Finanzgewalt stand der Staat als reine Obrigkeit über dem Wechsel und der Mannigfaltigkeit des Lebens der Gesellschaft, diesem folgend mit seinen Maßregeln und sich ihm anschließend, um es in Ordnung zu halten und um die Geldmittel daraus zu ziehen, die es ihm greifbar macht. Jetzt tritt er selbst in dieses Leben der Gesellschaft ein, mitten unter die Einzelnen, ... die er in ihrem Dasein und Wirtschaften bald fördert, bald in Anspruch nimmt. Er erscheint jetzt als der große Unternehmer, um ins Werk zu setzen, was zur Befriedigung allgemeiner Interessen dient, als der intendant géneral, wie ein französischer Schriftsteller ihn treffend bezeichnet hat. Das Verwaltungsrecht legt damit jene starre Einseitigkeit ab, bei welcher dem Einzelnen immer nur Befehl, Auflage, Zwang entgegentrat, und alles was ihm etwa gewährt wurde, nichts weiter war, als ein Nachlassen der Gewalt. Es wird jetzt gegeben wie genommen, Ausgleichsmaßregeln knüpfen sich an das eine, wie an das andere ... Ein frei bewegliches Verkehrsrecht schmiegt sich den einzelnen öffentlichen Unternehmungen an nach ihren Bedürfnissen und Zwecken, wie im Zivilrecht der Wirtschaft der Einzelnen ... Daß aber hier ein öffentliches Unternehmen in Frage ist, ein Unternehmen, in welchem ein Stück öffentlicher Verwaltung erscheint, das gibt dem Rechtsinstitut seine Eigenart. Offentlich-rechtlich sind im Zweifel die Beziehungen, die von hier aus mit den Einzelnen sich knüpfen ... "78).

Diese Korrekturen am oft verzeichneten Bilde Otto Mayers und seiner Lehren wollen gewiß weder als Apologie derselben noch gar als Aufforderung der Rückkehr zu ihnen verstanden werden. Jene Lehren waren, wenn auch nicht nur, so doch in erheblichem Maße Ausdruck ihrer Zeit. Die unsere braucht

der industriellen Entfaltung in den Städten Wasserleitungen und Müllabtuhr gegeben hat und manches andere, das jetzt unter dem Begriff Daseinsvorsorge zu fassen ist."

75) Zur Problematik des Ausdrucks "Eingriffsverwaltung" 8. unten S. 227.

70) Die Ausdrücke "Unternehmen" und "Unternehmung" wechsein, sie werden synonym gebraucht.

77 Das sind Polizeigewalt und Finanzgewalt.

78) VR 1. Aufl. 2. Bd., S. 4 f. - „Im Zweifel“: dazu unten S. 221. 
ihr eigenes Recht und ihre eigene Dogmatik - ohne daß man deshalb freilich alles unbesehen über Bord werfen sollte, nur weil es einer früheren Zeit enstammt.

Ebensowenig will ich mit den Korrekturen, die ich an verbreiteten Vorstellungen vom Staat und von der Verwaltung des ausgehenden 19. Jahrhunderts vornehmen zu müssen glaubte, die grundsätzliche Richtigkeit der Sicht Forsthoffs in Frage stellen, der den Wandel der Staatsaufgaben und damit des Staates selbst vom liberalen zum sozialen Staat mit seinen Begriffen „Daseinsvorsorge“ und "Leistungsverwaltung“ verdeutlicht und erstmals nachdrücklich ins allgemeine Bewußtsein gehoben hat. Ich stimme auch seiner Wertung zu, daß es sich hierbei um einen „Umschlag aus der Quantität in die Qualität" handelt ${ }^{79}$ ). Das allerdings mehr aus der Perspektive des einzelnen im Blick auf die radikale Schrumpfung des vom Menschen „beherrschten" Lebensraumes im Verhältnis zu seinem „effektiven “ Raum $^{80}$ ), als auch der Perspektive des Staates, dessen leistende und lenkende Tätigkeit die ordnende und freiheitsbewahrende wohl stets - jedenfalls schon oder wieder zur Zeit der Entstehung unserer Verwaltungsrechtsdogmatik an Umfang weit übertroffen hat. Worum es mir hier geht, das ist nur eine Korrektur der gängigen Ansichten über die Dimensionen dieses Wandels und über seine zeitliche Fixierung. Es ist nicht richtig, daß die Sozialordnung noch bis zum 1 . Weltkrieg „allenthalben als eine vorausgesetzte Gegebenheit behandelt" wurde und daß erst mit diesem Kriege eine grundsätzliche Änderung eingetreten sei $^{\text {(11)}}$ ); freilich hat sich diese Änderung mit und seit dem 1. Weltkrieg rasant beschleunig ${ }^{62}$ ).

3.4.2. Obwohl also der deutsche Staat stets in erheblichem Umfange Wohlfahrtsstaat war, stimmt der Befund, das verwaltungsrechtliche Instrumentarium sei von Anfang an schwerpunktmäßig auf die Eingriffs- und nicht auf die Leistungsverwaltung ausgerichtet; hier gab es in der Tat von Anfang an und gibt es noch heute die von Ossenbühl gerügte „dogmatische

7) Forsthoff, Der Staat der Industriegesellschaft, S. 76 f. N. 10.

so) So die treffenden Formulierungen Forsthoffs, Rechtsfragen der leistenden Verwaltung S. 25; ders., Der Staat der Industriegesellschaft S. 75 l.

81) So Forsthoff, Lehrbuch, 9. Aufl., S. 61.

82) Das hat Otto Mayer (VR, Vorwort von 1923 zur 3. Aufl.) nicht mehr richtig gesehen; insbesondere hat er die Dauerhaftigkeit vieler kriegswirtschaftlicher Maßnahmen sowie deren grundsätzliche Bedeutung für eine Ausweitung der Staatsaufgaben verkannt. Vgl. dazu auch Rüfner, Formen öffentlicher Verwaltung im Bereich der Wirtschaft, 1967, S. 124 N. 100. 
Unterbilanz ${ }^{\left({ }^{88}\right)}$. Zwar finden sich schon bei Otto Mayer nicht wenige Begriffe und Institute der Leistungsverwaltung, vor allem im Zusammenhang mit der Nutzung öffentlicher Unternehmen und Anstalten sowie öffentlicher Sachen; andere Begriffe und Institute sind insoweit unspezifisch, d. h. für Eingriffs- und Leistungsverwaltung gleichermaßen verwendbar. Es ist auch nicht so, daß sein System vorwiegend an obrigkeitlichen Handlungsformen oder gar am Verwaltungsakt ausgerichtet gewesen wäre. So rügt er die ,altertümliche Gleichsetzung" des (im Gesetz vorgegebenen) Begriffes „öffentliche Gewalt" mit „Befehl und Zwang“. Der Begriff selbst schmeckt ihm freilich „nach der Anschauungsweise der polizeistaatlichen Zeit, die Offentlichrechtliches sich nur denken konnte in der plumpen Gestalt von Befehl und Zwang. Wir haben gelernt, es auch in feineren Ausgestaltungen der öfentlichen Gewalt wiederzuerkennen, in allerlei Fürsorge, Geben und Nehmen und Dienstleistung." ${ }^{44}$ ) Die Rechtfigur des Verwaltungsaktes wird von ihm ungleich sparsamer verwendet als wir das heute tun ${ }^{85}$ ); ganz fern ist ihm und auch noch seinen Nachfolgern die erst nach 1945 eingetretene (und inzwischen wieder rückläufige) Ausuferung jenes Begriffes auf alle nur denkbaren Bekundungen der Verwaltung ${ }^{80}$ ).

Dennoch: Es ist nicht zu verkennen, daß die auf die Leistungsverwaltung bezogenen Begriffe und Institute im System Mayers relativ farblos und unscharf geblieben sind. Sie haben sich auch in der Folgezeit nicht in gleicher Weise durchgesetzt, sie sind nicht annähernd in gleicher Weise ausgebaut und verfeinert worden wie das am Schutz von Freiheit und Eigentum ausgerichtete Instrumentarium des gewaltenteilenden Rechtsstaats. Das hat verschiedene Gründe. Die hier genannten erheben keinen Anspruch auf Vollständigkeit.

Entscheidend ist wohl in erster Linie, daß die allgemeine StoBrichtung der Staats- und Verwaltungsrechtslehre jener Zeit gegen den Obrigkeitsstaat („Polizeistaat") ging. Den Rechtsstaat galt es zu sichern und auszubauen, den Obrigkeitsstaat zurückzudrängen. Der Rechtsstaat ist für Otto Mayer -

83) DOV 1971, 515.

94) VR 3. Aufl. 2. Bd., S. 294 f. mit N. 23.

85) So sind bei ihm z. B. weder die Zulassung zur Anstaltsnutzung noch die Widmung einer öffentlichen Sache Verwaltungsakte, vielmehr tatsächliche Handlungen mit rechtlicher Wirkung. Dennewitz, aaO. (N. 52) S. 140, weist zutreffend darauf hin, daß Mayer den Verwaltungsakt "nur auf etwa zehn Seiten“ behandelt habe.

8e) Dazu unten S. 231. 
nicht nur für ihn - schlechthin "das Neue ${ }^{(87)}$ ), der Polizeistaat der unermüdlich zu bekämpfende "große Gegner" ${ }^{\text {(88)}) . ~ D e n n ~ m i t ~}$ dem gewaltenteilenden Verfassungsstaat ist der Rechtsstaat noch nicht vollendet: "man verlangt dazu einen ,inneren Ausbau der Verfassung'. Mit der Errichtung der Verfassung ist das, was den Rechtsstaat ausmacht, noch nicht gegeben; es

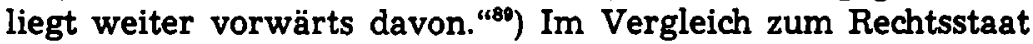
ist ihm der Wohlfahrtsstaat gewiß nicht weniger wichtig - gegen eine solche Annahme spricht schon der weit größere Umfang der einschlägigen Ausführungen -, aber im Grunde unproblematisch, deshalb besonderer Institutionen und Sicherungen weit weniger bedürftig.

An dieser Grundsituation hat sich in der Folgezeit wenig geändert. Der Weimarer Staat hatte hinreichenden Anlaß, sich von den monarchisch-obrigkeitsstaatlichen Relikten weiter abzusetzen, und nach 1945 galt es erst recht, einen inzwischen bis zur Perversion gediehenen Obrigkeitsstaat zu überwinden. Darin scheint mir auch einer der Gründe dafür zu liegen, weshalb die deutschen Verfassungen in erstaunlicher Kontinuität ihren Schwerpunkt auf den Rechtsstaat und nicht auf den Sozialstaat gelegt haben; das gilt $\mathrm{m}$. E. auch - hier unterscheide ich mich wohl von der gestern von Herrn Häberle vorgetragegenen Sicht ${ }^{00}$ ) - für die Weimarer Verfassung. Der Rechtsstaat war in Deutschland das oft in Frage gestellte, immer wieder zu verteidigende oder neu zu erkämpfende Gut; auch heute ist er ja von neuem gefährdet. Der Wohlfahrtsstaat war weit mehr das Selbstverständliche und Gegebene, gewiß stets Unfertige und weiter Auszubauende, aber er hatte und hat keinen prinzipiellen Gegner. Die sozialstaatliche Problematik hat - als Problematik - erst sehr spät die sie verdienende Beachtung gefunden, hervorgerufen durch die wachsende Einsicht in mit dem Machtzuwachs des Verteilerstaates verbundenen Freiheitsgefährdungen.

Einen weiteren Grund sehe ich in der schwerpunktmäßigen Ausrichtung der Verwaltungsgerichtsbarkeit auf die Eingriffsverwaltung. Solange nach dem vorherrschenden Enumerationsprinzip nur Teilbereiche der Verwaltung - und zwar im wesentlichen eben die als besonders schutzwürdig angesehenen

\footnotetext{
7) VR 1. Aufl, 1. Bd., S. 54.

*) So noch in der 3. Aufl. 1. Bd., S. 114.

89) VR 1. Aufl. 1. Bd., S. 62.

$\left.{ }^{\circ}\right)$ Oben S. 93, und S. 138 Leitsatz 35. Die „sozialen“ Grundrechte der WRV haben teils wegen ihrer Unbestimmtheit, teils wegen der die Grundrechtsdogmatik beherrschenden Programmsatztheorle nur geringe Bedeutung erlangt.
} 
Bereiche der Eingriffsverwaltung - justitiabel waren, bestand offenbar auch für die Lehre kein besonderer Anreiz zur Befassung mit den ausgesparten Materien der Leistungsverwaltung. Verstärkt wurde und wird diese Zurückhaltung wohl durch die mangelnde Verwaltungserfahrung vieler Hochschullehrer, die sie dazu treibt, ihren Stoff im sehr einseitigen Material ge-

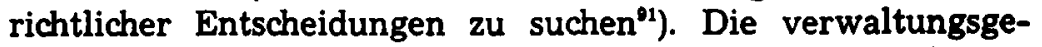
richtliche Generalklausel hat diese Einseitigkeit zwar theoretisch behoben, de facto aber gibt es nach wie vor weite Teile der leistenden und lenkenden Verwaltung, die aus Gründen, auf die ich hier nicht eingehen kann, selten vor Gericht gelangen.

Endlich (aber es gibt sicher noch weitere Gründe) sind Anlage und Ausrichtung unserer Studien- und Prüfungsordnungen gleichfalls seit eh und je einseitig auf die Gebiete der klassischen Eingriffsverwaltung ausgerichtet gewesen. $\mathrm{Ob}$ die gegenwärtigen „Reformen“ darin eine Besserung bringen, wird abzuwarten sein.

Ergebnis dieser Entwicklung ist jedenfalls ein starkes Defizit der Lehre hinsichtlich der Befassung mit der leistenden und lenkenden Verwaltung, und als Folge davon ein Zurückbleiben ihrer dogmatischen Bewältigung. Gewiß ist hier in den letzten Jahren ein gewisser Wandel eingetreten. Planung, Subventionen, Wirtschaftsaufsicht wie die Wirtschaftsverwaltung überhaupt, Bildungsrecht und Sozialversicherungsrecht sind nur einige Stichworte, um Forschungseinrichtungen aufzuzeigen, die in den letzten Jahren zunehmend in den Vordergrund getreten sind. Aber hier bleibt noch viel zu tun.

3.5. Die von Otto Mayer zum Erfolg geführte sog. „juristische Methode" des Verwaltungsrechts besteht darin, die den verschiedenen Verwaltungszweigen gemeinsamen Institute und Begriffe herauszuarbeiten; sie zielt auf ein „System der einzelnen Rechtsinstitute“08); sie hat eine "Lehre von den Rechtsformen der öffentlichen Verwaltung " hervorgebracht"s). Sie lehnt es ab, in ihrer Darstellung und Systematisierung der an

\footnotetext{
11) Dazu folgende Lesefrucht: „Kein akademischer Lehrer sollte, wenn er nicht selbst aus der Verwaltung hervorgegangen ist, ohne eine derartige praktische Schulung [scll.: als Verwaltungsrichter] das Wagnis der Vorlesung über Verwaltungsrecht unternehmen; denn in keiner Vorlesung Ist das bloße Gesetzes- und Bücherstudieren ohne Kenntnis des wirklichen Lebens verhängnisvoller als im Verwaltungsrecht." So Philipp Zorn, bel Planitz aaO. (N. 49) S. 228.
}

9) Otto Mayer, VR 3. Aufl. 1. Bd., S. 21.

it) Erich Kaufmann, VerwArch. Bd. 30 (1925), S. 386. 
den einzelnen Verwaltungszweigen orientierten älteren Staatswissenschaft $\mathrm{zu}$ folgen, wie das zunächst auch manche Verwaltungsrechtslehrbücher taten, als letztes das von Georg Meyer in der Bearbeitung von Franz Dochow"). Otto Mayer hielt solche Darstellungen übrigens für durchaus nützlich ${ }^{95}$ ). Er wehrte sich nur gegen die Alleinherrschaft jener Methode, eine Alleinherrschaft der seinigen hat er nicht erstrebt. Daß es dennoch zu einer weitgehenden Verdrängung der staatswissenschaftlich orientierten Darstellungen des Verwaltungsrechts und - was viel gravierender ist - der Staatswissenschaften selbst samt der Verwaltungslehre gekommen ist und daß letztere als Lehrfach völlig verschwand, war in der "juristischen Methode" an sich nicht angelegt. Die Ursache dieser Entwicklung liegt wohl zuvorderst in der positivistischen Grundhaltung jener Zeit $\left.{ }^{\infty}\right)$. Im Effekt hat die so bewirkte, einseitig juristische Betrachtungsweise der Verwaltung zu einer Verarmung nicht nur der Verwaltungswissenschaften insgesamt, sonder auch speziell des Verwaltungsrechts geführt, sie hat es von wichtigen Erkenntnisquellen abgeschnitten ${ }^{07}$ ).

$\mathrm{Da} B$ die Verwaltung Gegenstand sehr verschiedener Wissenschaften ist und sein $m u B^{98}$ ) und da $\beta$ ihre einseitig juristische Betrachtungsweise heute der Vergangenheit angehört, das ist eine Feststellung, die auch unter Juristen wohl keinen Widerspruch mehr finden wird. Die Konsequenzen - etwa für die Ausbildung der künftigen Verwaltungsbeamten - werden freilich nur sehr zögernd gezogen.

\footnotetext{
94) Meyer-Dochow, Lehrbuch des deutschen Verwaltungsrechts, 4. Aufl. $1913 / 15$.

${ }^{\text {Pis }) ~ N o c h ~ i n ~ d e r ~ 3 . ~ A u f l . ~ d e s ~ V R ~(1 . ~ B d . ~ S . ~ 19) ~ m e i n t ~ e r: ~ „ T r e f f l i c h e ~}$ Lehrbücher des deutschen und des einzelstaatlichen Verwaltungsrechts entstanden in dieser Form und werden noch weiter-entstehen." Mit dieser Prognose hat er sich freilich geirrt.

Po) Nicht freilich Otto Mayers! Dazu unten S. 218 f. Daß Mayer über die Verwaltungslehre - weniger als solche, als über diejenige seiner Zeit - recht abschätzig urteilte, mag freilich bei dem großen Einfluß seiner Meinungen mit zum Verschwinden der Disziplin belgetragen haben.

07) Freilich sollte man nicht übersehen: Otto Mayer und seine Nachfolger haben die Bühne niemals mit solcher Ausschließlichkeit beherrscht, wie das retrospektiv einer Fachwissenschaft erscheinen mag, die nur an den von ihr hervorgebrachten Produkten miBt. Eine Vielzahl von umfangreichen, auf hohem Niveau stehenden Handbüchern, Wörterbüchern und Großkommentaren des Verwaltungsrechts, denen heute wenig Gleichwertiges an die Seite zu stellen ist, hat bis zum Beginn der nationalsozialistischen Xra die Praxis der Verwaltung und die Verwaltungsrechtsprechung, mittelbar über diese auch die Lehre, in nicht geringem Maße mitgeprägt.

98) Dazu 2. B. Püttner, Die Verwaltung, Bd. 4 (1971), S. 102.
} 
Schwieriger ist es, das richtige Verhältnis des Verwaltungsrechts zu den anderen verwaltungsbezogenen Wissenschaften zu bestimmen. Die neueren Darstellungen des Verwaltungsrechts bemühen sich - unter grundsätzlichem Festhalten an der juristischen Methode -, die Erkenntnisse vor allem der Sozialwissenschaften wieder in stärkerem Maße zu berücksichtigen. Mit vollem Recht! Wenn es, nach der treffenden Feststellung Ludwig Raisers ${ }^{00}$ ), Aufgabe der Rechtsdogmatik u. a. ist, „den Normenbestand des geltenden Rechtes in seinen verschiedenen Dimensionen verstehen zu lehren, und zwar im blick auf seine geschichtlichen, ideologischen, gesellschaftlichen und politischen Bestimmungsfaktoren sowie auf seine Wirkung im Rechtsleben, ... und die Fortentwicklung dieses Normenbestandes im Wandel der gesellschaftlichen Verhältnisse und der Wertvorstellungen durch Beobachtung, Klärung und Anregung zu erleichtern": dann darf von solcher Einbeziehung außerrechtlicher Bestimmungsfaktoren gewiß ein Rechtsgebiet nicht ausgenommen werden, dessen Gegenstand so sehr mitten im politischen und sozialen Spannungsfeld steht wie gerade die Verwaltung.

Merkwürdigerweise wird das ausgerechnet von einem führenden Vertreter der Verwaltungswissenschaften bestritten: Luhmann ${ }^{100}$ ) erkennt das Verdienst der juristischen Methode bei der Normeninterpretation zwar ausdrücklich an, meint jedoch, ihre Erkenntnisse sollten "dann aber auch im Sinne der Wiener Schule methodenrein erarbeitet werden. Ein Hineinmischen sozialwissenschaftlicher Erkenntnisse in die juristischen Auslegungs- und Entscheidungsverfahren würde dem Sinn der Arbeitsteilung von Sozialwissenschaft und Entscheidungslogik widersprechen und das Entscheiden mit einer Komplexität überlasten, der es nicht gerecht werden kann". Der „Einbau von empirisch unzureichend abgesicherten sozialwissenschaftlichen Aussagen in das Verwaltungsrecht" sei typisch für das Lehrbuch Forsthoffs $\left.{ }^{1004}\right)$. - Ich halte das für falsch. Ein

99) DRiZ 1968, 98.

100) Theorie der Verwaltungswissenschaft, 1966, S. $21 \mathrm{t}$.

${ }^{1002}$ ) AaO. S. 22 N. 20 . Forsthoff, Rechtsstaat im Wandel, S. 165 N. 30 , argumentiert seinerseits ähnlich gegenübër einer am Wert orlentierten geisteswissenschaftlichen Auslegung der Verfassung: „Die Gefahr solcher der Philosophie entlehnter methodischer Aushilfen besteht natürlich in einem Abgleiten in den Dilettantismus, da Juristen insgemein keine gelernten Philosophen sind.“ Dazu aber die treffenden Bemerkungen von Wimmer, Materiales Verfassungsrecht (Forschungen aus Staat und Recht 15), 1971 S. 71: „Die zunehmende Absolutierung wissenschaftlicher Arbeitsteilung macht heute jeden Versuch einer interdisziplinären Gesamtschau verdäch- 
Methodensynkretismus ist sicher abzulehnen; die Rechtswissenschaft muß eine normative Wissenschaft bleiben. Aber der Rückgriff auf die Erkenntnisse anderer Wissenschaften und die Verarbeitung derselben durch die Jurisprudenz ist noch kein Synkretismus. Der Hinweis auf die mangelnde „Absicherung“ ist gewiß bedenkenswert. Ich meine jedoch, es sei für den Juristen unausweichlich, sich diesem Risiko zu stellen und den gefahrvollen Weg zwischen Scylla und Charybdis zu steuern: zwischen dem Verzicht auf Fremderkenntnisse und damit eimem Verlust an Wirklichkeitsbezug einerseits, und einer unkritischen Ubernahme solcher Fremderkenntnisse und damit einer Auslieferung an den Irrtum (oder an Schlimmeres) andererseits $\left.{ }^{101}\right)$. Das ist eine Aufgabe, vor der der Jurist nicht erst seit heute steht ${ }^{102}$ ), mag auch die immer weitere Auffächerung der für den einzelnen unüberschaubar gewordenen Wissenschaften die Schwierigkeiten und Gefahren gesteigert haben ${ }^{103}$ ). Wollte der Jurist sich weigern, gelegentlich auch ohne Netz zu arbeiten, so müßte er vor seiner Aufgabe kapitulieren.

Näher kann ich auf diese Fragen nicht eingehen; ich kann es auch deshalb bei diesen knappen Andeutungen belassen, weil Herr Brohm sich dazu äußern wird.

3.6. Die Dogmatik des Verwaltungsrechts hat - wie sollte es auch anders sein - den jeweiligen Zeitströmungen Rechnung getragen, wie diejenige anderer Rechtsgebiete auch; sie war positivistisch mit dem Positivismus, begriffsjuristisch mit der Begriffsjurisprudenz. Jedoch sind wichtige Besonderheiten zu vermerken. Otto Mayers starker Einfluß hat hier noch lange nachgewirkt. Kennzeichnend für sein Lehrgebäude sind eine

tig und liefert inn dem Vorwurf des Methodensynkretismus oder des Dilettantismus aus. Die Nachteile eines mehr und mehr am Detall haftenden, den Bezug zu den umliegenden Forschungsgebieten verlierenden Wissenschaftsbetriebes sollten allerdings nicht übersehen werden."

101) Auf diese Gefahren weist Püttner aaO. S. 102 ff. mit Recht hin, wobel er als "fatalsten Punkt" den heute allenthalben unternommenen Versuch bezeichnet, „politische Forderungen und Programme als gesicherte wissenschaftliche Erkenntnisse auszugeben und sie damit als unbedingt durchsetzungswürdig hinzustellen." Hier ist in der Tat äußerste Wachsamkeit geboten.

107) Man denke etwa an die Abhängigkeit juristischer Entscheldungen von medizinischen, psychiatrischen, technischen usw. Gutachten.

105) Das gilt mutatis mutandis wohl für das Verhältnis aller Wissenschaften zuelnander. Interdisziplinäre Zusammenarbeit kann heute nur noch sehr beschränkt in gemeinsamer Erarbeitung von Erkenntnissen bestehen, sie ist weithin auf die - auf eigene Prüfung verzichtende (verzichten müssende) - Ubernahme "anerkannter" Ergebnisse anderer Wissenschaftszweige angewiesen. 
unhistorische und antipositivistische Grundhaltung $\left.{ }^{104}\right)$, das Bemühen um kategoriale Begriffe und um Ordnung des Rechtsstoffes nach diesen, als Folge davon viel Konstruktion und ein hohes Maß an Abstraktion. Das alles wird aber nie Selbstzweck - dazu war Mayer viel zu sehr Pragmatiker -, sondern steht stets im Dienste praktisch brauchbarer, "vernünftiger" Ergebnisse ${ }^{105}$ ). In seinem "Glauben an die Macht allgemeinerer Rechtsideen, die in den Mannigfaltigkeiten des wirklichen Rechts zur Erscheinung und Entfaltung kommen, zugleich aber auch ihrerseits in der Geschichte sich wandeln und fortschreiten" ${ }^{100}$ ), in seinem Bekenntnis zu dem „Vernünftigen“, das "hinter allen Rechtseinrichtungen steht" und deshalb den "Maßstab" für sie hergeben $m u B^{107}$ ), in seinem Bemühen um "die überpositiven, aus der Natur der Sache und aus dem Wesen des Rechts fließenden, wenn man will: die naturrechtlichen Wahrheiten ${ }^{\text {"108) }}$ ) steht

104) Er ist für beides oft getadelt worden. $\mathrm{DaB}$ er die historisch gewachsenen "oft tief in den Jahrhunderten" wurzelnden, spezifisch deutschen Institute des Verwaltungsrechts ignoriert habe, hat ihm besonders $E$. Kaufmonn (VerwArch. aaO. S. 390) vorgehalten. Ungenügende Berücksichtigung des positiven Rechts oder gar eigenmächtiges Hinwegsetzen über dasselbe ist ihm immer wieder vorgeworten worden, so z. B. von Bühler (VerwArch. Bd. 27, 1919, S. 286), demzufolge Mayer "sozusagen ein Durchschnittsverwaltungsrecht für die deutschen Staaten gibt, das genau so überhaupt nirgends gilt". Vgl. auch Labands Kritik an der von Mayer behaupteten Eigenständigkeit des Verwaltungsrechts (AöR Bd. 2, 1887, S. $149 \mathrm{lf}$, insb. S. $155 \mathrm{f}$.) und dazu Forsthoff, Lehrbuch 9. Aufl. S. $53 \mathrm{f}$. Eine ausdrückliche Rüge, für mangelnden Positivismus auch bei Dennewitz aaO. (N. 52) S. 151.

Mayer hat übrigens die "Schwäche" seiner Lehre, die in dem weitgehenden Abstrahieren "vom positiven Recht lag, ausdrücklich „bekannt", seinen Kritikern jedoch entgegengehalten: „Nach allen Entgegnungen scheint es mir aber immer noch, daB man nur die Wahl hat zwischen ihr und gänzlicher Zerfahrenhelt" (AöR Bd. 16, 1901 , S. 65 f. mit N. 29). In der Tat: ohne sein mitunter etwas gewaltsames Hinwegsetzen über liebgewordene Traditionen und einzelstaatliche Spezialitäten hätte er niemals ein "deutsches" Verwaltungsrecht schreiben können, sondern vielleicht ein solches von Reuß-Greiz, von Reuß-Gera-Schleiz, usw. Der Erfolg hat ihm Jedenfalls recht gegeben!

$\left.{ }^{105}\right)$ Mayer selbst hat sich oft in diesem Sinne geäußert. Bezelchnend ist etwa die folgende Stelle auf S. 160 seiner Autoblographie (N. 49): "Nach ein paar Jahren . . . kam eben doch wieder das Bedürtnis über mich nach rein wissenschaftlicher Tätigkeit . . . Für die Behandlungsweise hatte ich aber jetzt eine ganz andere Form gewonnen. In der Wirklichkeit des Rechtslebens war mir ja auch der Sinn aufgegangen für die lebendige Gliederung, in welcher die verschiedenen Rechtsinstitute vom Gesetzgeber, bewußt oder unbewußt, gedacht waren. Die galt es zu erkennen und aufzuweisen."

19) VR 2. Aufl. 1. Bd. S. VIII. 107) AöR Bd. 16 S. 66.

100) So E. Kaufmann, VerwArch. Bd. 30 S. 401. 
sein Denken sowohl in der Tradition Hegels ${ }^{109}$ ) wie des rationalen Naturrechts ${ }^{10}$ ).

Merkwürdig ist die verbreitete Ansicht, in diesem System sei für die Zwecke und Aufgaben der Verwaltung kein Raum ${ }^{111}$ ). Dies Mißverständnis ist vielleicht dem Umstand zuzuschreiben, daß Mayer es ausdrücklich ablehnte, sein Lehrbuchsystem an ihnen, nach Art der Einteilungen der "staatswissenschaftlichen" Methode, auszurichten, vielmehr die den einzelnen Verwaltungszweigen gemeinsamen Begriffe und Rechtsinstitute zur Grundlage seines Systems machte: dies eben die sog. „juristische Methode". Jedoch spielen die Zwecke eine um so gröBere, ja geradezu beherrschende Rolle bei der Bildung eben dieser Institute und Begriffe sowie bei der Zuweisung der empirischen Erscheinungen zu einer bestimmten Kategorie von ihnen, und damit zugleich für die konkreten Rechtsfolgen, die aus einer solchen Zuweisung gezogen werden. Die Zwecke und die Aufgaben bestimmen und begrenzen z. B. die öffentliche Anstalt und die Anstaltsordnung wie das besondere Gewaltverhältnis überhaupt ${ }^{112}$ ). Auf den „besonderen Zweck“, dem eine öffentliche Sache zu dienen bestimmt ist, kommt es „ganz und gar an"113): im Gegensatz zum Zivilrecht, von dem der Autor meint, daß ihm „die Sachen ebenso formal gleich [sind] wie die Rechtssubjekte. Es nimmt keine Rücksicht auf ihren Zweck “119).

109) Mayer schreibt im unmittelbaren Anschluß an das im Text vor N. 106 wiedergegebene Zitat: „Es hängt bei mir wohl mit Hegelischer Rechtsphilosophie zusammen, vielleicht auch noch mit ganz Unjuristischem, mußte aber schon recht stark sein, daß ich es wagen konnte, solchen Ideen auch in dem zerfahrenen und unfertigen deutschen Verwaltungsrecht nachzugehen, um sie herauszuheben und aufzuweisen." $\mathrm{Zu}$ Hegels Einfluß ferner die Autobiographie $S .155 \mathrm{f}$. und $E$. Kaufmann aaO. S. $380 \mathrm{ff}$.

$\left.{ }_{110}\right)$ Auch dazu E. Kaufmann aaO. S. 401 f. und bei StengelFleischmann (N. 26) Bd. 3 S. 717.

111) Sie findet sich schon bei E. Kaufmann (in Stengel-Fleischmann aaO. S. 717), der Mayer eine „scharfe Ablehnung jedes Blickes auf die den abstrakten Rechtsbegriffen zugrunde liegenden Lebensverhältnisse" vorwirft und von der Wissenschaft fordert, "die Beziehungen zwischen dem sozialen Leben, seinen Zwecken und Aufgaben zu den Rechtsbegriffen in den Bereich ihrer Forschung und Betrachtung zu ziehen". Gerade das hat Mayer aber weit mehr als die meisten seiner Zeitgenossen getan!

119) Vgl. z. B. VR 3. Aufl. 1. Bd. S. 102, 2. Bd. S. 268 1f., insb. S. 270,273 f., $277,286$.

119) AöR Bd. $16 \mathrm{~S}$. $66 \mathrm{f}$. - Hier auf S. 66-86 die wohl gründlikste Analyse von Verwaltungszwecken, die Mayer durchgeführt hat. Nicht nur die Unterscheidung zwischen öffentlichen und privaten Sachen, sondern auch die Unterteilung der ersteren wird ausschließlich anhand ihrer jeweiligen Zweckbestimmung vorgenommen. 
Ganz auf dieser Linie liegt auch die ebenso grundsätzliche wie modern anmutende Erkenntnis: "die Tätigkeit des Staates für seine Zwecke ist von Natur öffentliche Verwaltung "114) auch dann, wenn der Staat sich dabei des Privatrechts bedient, was Mayer an sich als systemwidrig und nur ausnahmsweise kraft Tradition ${ }^{115}$ ) oder positiven Rechts für zulässig erachtet; die später aufgekommene Vorstellung beliebiger Austauschbarkeit von öffentlichem und privatem Recht ist ihm ganz fremd. Bei den privatrechtlichen Tätigkeiten des Staates unterscheidet er - das könnte heute geschrieben $\operatorname{sein}^{116}$ ) zwischen 1. den „öffentlichen Anstalten mit privatrechtlicher Nutzungsordnung"117), 2. den "fiskalischen“ oder "privatwirtschaftlichen" Unternehmen ${ }^{118}$ ), und schließlich 3. den privatrechtlichen Hilfsgeschäften der Verwaltung ${ }^{19}$ ). Staatliche und städtische Theater, Gasanstalten, Wasserleitungen, Reichsbank u. a. werden in die erste ${ }^{120}$ ), staatliche Brauereien, Forsten, Lotterien und Zinshäuser in die zweite ${ }^{212}$ ), Ankauf von Futtermitteln für das Heer, Miete eines Gerichtsgebäudes usw. in die dritte Kategorie ${ }^{122}$ ) gewiesen.

Sehr fern lag Mayer auch die Begriffsjurisprudenz. Er hat über die "Scholastik“, wie er sie nannte ${ }^{125}$ ), gespottet. Konstruktionen sind ihm nie Selbstzweck, sondern nur Mittel zur sachgerechten Problembewältigung $\left.{ }^{124}\right)$.

114) VR 3. Aufl. 2. Bd. S. 274.

115) "geschichtlich gewordene, tatsächlich in Geltung stehende Auffassungen", aaO. S. 275.

116) Vgl. die bekannte Einteilung von Siebert, Privatrecht im Bereich öffentlicher Verwaltung (in: Festschrift für Hans Niedermeyer, 1953, S. $214 \mathrm{ff}$.), S. $220 \mathrm{ff}$.

117) AaO. S. 272, 274, 276.

118) AaO. S. 274, 276.

119) S. 272 f. Der Ausdruck kommt zwar nicht vor, wohl aber die Sache: „Sodann ist es möglich, daß eine richtige öffentliche Anstalt nebenbei für die Beschaffung und Besorgung ihrer Mittel in Bezlehungen sich begibt, die ganz dem gewöhnlichen privatwirtschaftlichen Verkehr angehören, mag ihre eigentliche Aufgabe noch so entschieden die hoheitliche Natur der staatlichen Willensäußerung bekunden."

120) AaO. S. 274 f. N. 11.

121) S. 272,274 f. N. 11.

122) S. 273.

129) Z. B. AöR Bd. 16 S. 65.

124) So vertrat er z. B. in der Frage, ob der Tarif für die Anstaltsnutzung durch Verwaltungsakt festgesetzt oder durch Vertrag vereinbart werde, die erste Ansicht; er meinte aber, die Notwendigkeit, sich dieser Auffassung zu fügen, bestehe hier nicht so unmittelbar, weil man mit der anderen Ansicht zum nämlichen Ergebnis komme: „Es ist mehr eine Frage der juristischen Architektonik und als solche von verhältnismäBig geringerer Bedeutung" (VR 1. Aufl. 2. Bd. S. 341). 
$\mathrm{DaB}$ man ausgerechnet von Otto Mayer meinen konnte, sein Formalismus habe die Zwecke des Verwaltens aus dem Recht und der Rechtsbetrachtung vertrieben, für diese Zwecke sei in seinem System kein Raum, seine Methode sei formalistisch und nicht teleologisch gewesen, das ist angesichts des vorstehenden Befundes nur schwer verständlich. Es mag sich $z$. T. aus dem erwähnten hohen Abstraktionsgrad seiner Begriffe erklären, welche die sie prägenden und in sie aufgenommenen Zwecke nur dem genauen Kenner noch ersichtlich werden lassen. Das gilt für sein Lehrbuch mehr als für seine Monographien, und innerhalb des Lehrbuchs besonders für den „Allgemeinen Teil“.

Von alldem ist außerdem später manches verschüttet worden. Fritz Fleiners und Walter Jellineks Lehrbücher - um nur zwei besonders wichtige herauszugreifen - waren in ihrer Grundhaltung mehr positivistisch. Das erste besticht zwar durch knappe und präzise Formulierungen, erkauft das aber mit einem Verlust an Anschaulichkeit; von den bei Mayer immer noch durchscheinenden Zwecken des Verwaltungshandelns ist wenig mehr geblieben: es ist zwar noch dasselbe Gerippe, aber es fehlt das Fleisch. Jellineks Darstellung dagegen ist zwar äußerst anschaulich, aber mit vielen begriffsjuristischen Konstruktionen behaftet ${ }^{128}$ ). Auch die Rechtsprechung hat sich nicht immer auf der anfänglichen Höhe gehalten, gerade sie tendierte später mehr und mehr $\mathbf{z u}$ begriffsjuristischem Argumentieren und tut das - nicht selten zu Lasten des Ergebnisses - leider zum Teil noch heute. Das ist freilich keine Besonderheit der Verwaltungsrechtsprechung.

Alles in allem darf aber vom Verwaltungsrecht gesagt werden, daß seine Dogmatik die Zwecke seiner Normen und Institute sowie die Aufgaben der Verwaltungsträger niemals aus den Augen verloren hat. Sie hat sich - vielleicht gerade dank der Notwendigkeit ständiger Auseinandersetzung mit neuen Materien und Problemen - wirklichkeitsnäher gehalten als die Dogmatik mancher anderer Rechtsgebiete. Die Entwicklung seiner Institute und Begriffe war und blieb im wesentlichen final, die Auslegung seiner Normen teleologisch.

125) Frellich ist Konstruktion auch bei Jellinek nie Selbstzweck. Ganz Im Gegenteil: ihm ging es stets nur um das gerechte und vernünftige Ergebnis, gerade $\mathrm{lhm}$ zuliebe hat er oft zu recht gewagten Konstruktionen gegriffen. So hat er die Begriffsjurisprudenz gewissermaßen mit ihren eigenen Waffen geschlagen: eine thm selbst wohl unbewußte Uberlistung des Zeitgeistes; denn solches Konstruleren um der guten Sache willen bereitete Ihm höchsten GenuB, und nle wäre er auf den Gedanken gekommen, daß mit selnen Konstruktionen das Gesetz umgangen werde. 
Soweit die Behauptung, die Dogmatik des Verwaltungsrechts sei formal, zweckentleert und begriffsjuristisch, auf seine Institute und Begriffe zielt, stehe ich nicht an zu erklären: diese Behauptung ist schlicht falsch.

3.7. Wie aber steht es mit der Systembildung? Ist nicht wenigstens ihr gegenüber der Vorwurf berechtigt, sie vernachlässige Aufgaben und Zwecke ${ }^{128}$ ) des Verwaltungshandelns zugunsten vordergründiger Rechtsformen?

3.7.1. In diese Richtung zielt vor allem die Kritik Badu$\left.r a s^{127}\right)$. Eine konsequente Ersetzung der Systemidee des liberalen durch diejenige des sozialen Rechtsstaates müsse die Theorie der Verwaltung, statt aus einem „Positivismus der Rechtsformen", „auf der Basis der nicht weiter auflösbaren Verwaltungszwecke der Gefahrenabwehr, Abgabenerhebung, Leistung und Lenkung entwickeln".

Auch Forsthoff kritisiert das System: „Die Frage stellen, ob das wissenschaftliche System des Verwaltungsrechts, über das wir heute verfügen, der Wirklichkeit der modernen Verwaltung noch entspricht, heißt sie verneinen ${ }^{\text {"128) }}$. An anderer Stelle schreibt er: „Die Tatsache, daß die leistende Verwaltung mit zunehmendem Gewicht neben die Eingriffsverwaltung getreten ist, zwingt zu einer Revision der ganz auf den Eingriff in die Privatsphäre abgestellten überkommenen Systematik des Verwaltungsrechts" $\left.{ }^{(189}\right)$. Tadelnd wird vermerkt, noch habe die Verwaltungsrechtswissenschaft die ihr gestellte Aufgabe kaum erkannt ${ }^{130}$. Zugleich bekennt der Autor freilich, er habe die an sein Lehrbuch geknüpften Erwartungen, „daß es, auf dem Begriff der Daseinsvorsorge aufbauend, ein neues System der Verwaltungsrechtswissenschaft bieten würde", enttäuschen müssen: das dem Rechtsstaat und damit der Gewährleistung der gesetzmäßigen Freiheit zugeordnete System des Verwaltungsrechts mit seiner spezifischen Begrifflichkeit sei der modernen wohlfahrtsfördernden Verwaltung inkongruent; denn seine Ausbildung habe die Eliminierung der Wohlfahrtsförderung gerade vorausgesetzt ${ }^{128}$ ). Wieder anderwärts lesen wir, daß "sich die festgelegten Formen der rechtsstaatlichen Verwaltung nicht verändern lassen, ohne das gesamte Strukturgefüge des Rechtsstaats ins Wanken zu bringen"1181). Gerade die-

120) Beide Ausdrücke werden in diesem Zusammenhang meist synonym gebraucht, was freilich ungenau ist.

127) So Badura, Verwaltungsrecht im liberalen und im sozialen Rechtsstaat, S. 22 f.

128) Rechtsfragen der leistenden Verwaltung, S. 52.

129) Lehrbuch, 9. Autl., S. 341.

1s0) Lehrbuch S. 55.

131) Rechtstragen, S. 11 . 
sen Rechtsstaat aber gelte es „um der unverzichtbaren Dienste willen, die er heute und wohl auch für die absehbare Zukunft leistet, in der grundlegend veränderten Wirklichkeit fungibel $z u$ halten $\left.{ }^{(132}\right)$.

Ich gestehe, ich komme hier nicht ganz mit. Wie soll man das in seiner Widersprüchlichkeit verstehen? Eine Aufgabe, die äußerst dringlich, zugleich jedoch von vornherein unlösbar ist? Oder liegt der Ton vielleicht darauf, daß es nicht gelingen könne, Eingriffs- und Leistungsverwaltung in einem System zu vereinigen $\left.{ }^{139}\right)$ ? Wären also zwei getrennte Systeme die Lösung? Darauf könnte ich angesichts der engen Verflechtungen und Uberschneidungen von Eingriffs- und Leistungsverwaltung nur antworten: Die Frage stellen heißt sie verneinen.

3.7.2. Mir scheint, daß diesen (und weiteren) Kritiken am „System" mangelnde Klarheit über den Systembegriff zugrunde liegt; genauer: daß die verschiedenen Systembegriffe nicht auseinandergehalten werden. Das juristische System ist, nach der immer noch treffenden Definition Savignys ${ }^{134}$ ), „der innere Zusammenhang, welcher alle Rechtsinstitute und Rechtsregeln zu einer großen Einheit verknüpft". Einheit und Ordnung sind seine konstituierenden Elemente ${ }^{135}$ ). Man muB indessen unterscheiden: zunächst zwischen dem System der Gegenstände und dem System der Erkenntnisse, anders ausgedrückt zwischen dem objektiven (oder realen) und dem wissenschaftlichen System. Dabei muß das wissenschaftliche System dem objektiven folgen, will es diesem nicht Gewalt antun. Ja, ein wissenschaftliches System ist ohne ein vorgegebenes objektives gar nicht möglich. Wo das (geschriebene oder ungeschriebene) Recht die als Grundlage eines Systems unerläßliche Einheit und Ordnung nicht besitzt, ist auch eine rechtswissenschaftliche Systembildung nicht sinnvoll. Allerdings kann das wissenschaftliche System dazu beitragen, Brüche im objektiven System mit allerlei Interpretationskünsten zu überbrücken, sie zu harmonisieren; dem sind freilich Grenzen gesetzt ${ }^{130}$ ). Auch findet eine Rückkopplung vom wissenschaftlichen zum objektiven System statt: nicht nur durch Aufgreifen wissen-

192) Forsthoff, Rechtsstaat im Wandel, 1964, S. 9; vgl. auch S. 7, wo F. die Bewahrung des Rechtsstaats als den Kern seiner Konzeption bezeichnet.

133) So anscheinend in Rechtsfragen, S. 53.

124) System des heutigen Römischen Rechts, Bd. 1, 1840, S. 214.

195) Canaris, aaO. (N. 20) S. 12.

136) Eindeutige Rechtswegregelungen z.B. können durch keine Interpretation wegdisputiert werden, mögen sie noch so systemwidrig und im Ergebnis schädlich sein. 
schaftlicher Erkenntnisse seitens des Gesetzgebers, sondern mehr noch durch die im Wechselspiel von Lehre und Rechtsprechung ständig erfolgende Rechtsfortbildung; dafür bietet das allgemeine Verwaltungsrecht als ein Gebiet weithin ungeschriebener Normen besonders günstige Voraussetzungen.

Innerhalb des wissenschaftlichen oder Erkenntnissystems muß man, im Anschluß an die bekannte Unterscheidung Philipp Hecks ${ }^{137}$ ), weiter unterteilen in das „äußere“ System, das „im Darstellungsinteresse . . . durch Bildung von Ordnungsbegriffen, Einteilungen, Reihenfolge der Erörterung usw. "128) gebildet wird, und das "innere" System als "den sachlichen Zusammenhang zwischen den hervorgebrachten Gedanken", "die immanente Ordnung “130), oder - mit der treffenden Formulierung von Larenz ${ }^{140}$ ) - „als Ausdruck einer dem Recht als Ganzen immanenten Einheit des Sinns". Als ein wissenschaftliches System im strengen Sinne, jedenfalls als ein "dogmatisches", kann wohl nur das innere bezeichnet werden.

3.7.3. Würde die Forderung, das verwaltungsrechtliche System an den Zwecken und Aufgaben der Verwaltung auszurichten, sich nur auf das äußere System beziehen, so ließe sich darüber reden. Freilich könnte eine so systematisierende Darstellung nur neben eine Darstellung nach den Rechtsformen treten, nicht diese ersetzen. Denn wenn sich auch viele Gesetzesmaterien des besonderen Verwaltungsrechts schwerpunktmäßig der einen oder anderen Aufgabe zuordnen lassen mögen, so gilt das angesichts der vielfachen Uberschneidungen und Verflechtungen eben auch nur schwerpunktmäßig. Wenn z. B. die Einkommensteuer Aufwendungen für den sozialen Wohnungsbau berücksichtigt, so zielt das uno actu auf Mittelbeschaffung, soziale Umverteilung, Leistung (durch Verschonung) und Lenkung (durch Anreiz). Außerdem läßt sich eine Aufgabenzuordnung überhaupt nur für die Rechtsmaterien des besonderen Verwaltungsrechts durchführen, nicht aber z. B. für ein allgemeines Verwaltungsverfahrensgesetz. Die Begriffe und Institute des allgemeinen Verwaltungsrechts sind durchweg nicht an einzelne Aufgabenbereiche gebunden und lassen sich auch nicht daran binden. Sicher gibt es auch aufgabenspezifische Begriffe und Institute, etwa im Polizei-, Abgaben- oder Subventionsrecht. Aber gerade die das innere System verklammernden und überhaupt erst als System konstituierenden Begriffe sind unspezifisch. Sie liegen auch - wie

\footnotetext{
137) Begriffsbildung und Interessenjurisprudenz, 1932, S. 139 ff.

159) AaO. S. 142.

130) AaO. S. 143.

100) Methodenlehre der Rechtswissenschaft, 1960, S. 133.
} 
Sterns Untersuchung ${ }^{141}$ ) zeigt - als unspezifische der Gesetzgebung, also dem „objektiven System“, zugrunde.

Eine an Zwecken und Aufgaben orientierte Darstellung neben einer solchen der "Rechtsformen" ist freilich sinnvoll, ja notwendig. Sie hat nicht nur eine didaktische, sondern auch eine kritische Funktion, indem sie das Erfordernis zweckorientierter Interpretation und Rechtsfortbildung verdeutlicht; insoweit wirkt sie dann auch auf das innere System ein ${ }^{12}$ ). In die Richtung solcher Darstellungsweise weist $\mathrm{z}$. B. das Lehrbuch von Hans $J$. Wolff ${ }^{145}$ ), wenn es, neben manchen anderen Einteilungen, auch eine Einteilung der Verwaltung nach der "Qualität" der verwaltenden Tätigkeiten - in früheren Auflagen hieb es: nach ihrem „Gehalt"144) - bringt und hierbei zwischen ordnender, leistender, Abgaben- sowie Bedarfsverwaltung unterscheidet ${ }^{14}$ ), und wenn es an späterer Stelle ${ }^{106}$ ) anhand solcher Einteilungskriterien einige für die ordnende und für die leistende Verwaltung jeweils besonders typische Rechtsgebiete behandelt, die dann auch neben unspezifischen etliche typenspezifische Institute und Begriffe aufweisen. Ubrigens halte ich weder diese Einteilung Wolffs noch die Aufzählung Baduras ${ }^{147}$ ) für vollständig. Bei Badura fehlt der von Wolff als „Bedarfsdeckung“, von Köttgen ${ }^{168}$ ) als „Intendanturaufgaben" bezeichnete Bereich. Wolff hat - ohne mich überzeugenden Grund - die in früheren Auflagen enthaltene „verteilende Verwaltung" wieder gestrichen ${ }^{169}$ ). Solches Schwanken

14) Vgl. N. 50.

168) Das hat z. B. der Ubergang von der "staatswissenschaftlichen“ zur "juristischen" Methode in der Darstellung des Verwaltungsrechts gezeigt: zunächst nur ein Wandel des äußeren Systems, hat er gleichwohl entscheidend auf das innere eingewirkt.

16) Verwaltungsrecht I, 8. Aufl. 1971, S. $18 \mathrm{f}$.

140) Verwaltungsrecht $I, 6$. Aufl. 1965, S. $16 \mathrm{f}$.

145) Wolff selbst scheint das treilich nicht als eine Unterscheidung nach Zwecken und Aufgaben anzusehen, da er (Verwaltungsrecht I 8. Aufl. S. 19) meint: "Die öffentliche Verwaltung oder andere Verwaltungen lassen sich als solche weder durch thre Zwecke noch durch die Art der Aufgabenerfüllung noch durch Tätigkeitsmerkmale des Verwaltenden bestimmen oder unterscheiden, well diese fast stets vielfältig sind." Was aber ist sonst das Unterscheidungskriterium? "Qualität" ist m. E. ein nichtssagender Ausdruck. Ubrigens sind Uberschneidungen und Randunschärfen kein Grund gegen Kategorienbildung!

146) Verwaltungsrecht III, 2. Aufl. 1967, S. 1-229.

147) S. oben S. 223 mit N. 127.

16) Deutsche Verwaltung, 3. Aufl. 1944, S. 141.

160) Verwaltungsrecht I, 8. Aufl., S. 19. Der Begriff der verteilenden Verwaltung wird hier aufgegeben, „da er weniger auf den Tätigkeitsgehalt als auf den Verwaltungszweck abstellt". Das tun aber 
in den Einteilungskriterien wie in den Bezeichnungen weist übrigens darauf hin, wie unscharf letzten Endes diese ganzen Kategorien sind. Bei den sie kennzeichnenden Begriffen handelt es sich um beschreibende, nicht um definierende Begriffe. Für sie gilt dasselbe wie für den Begriff der "Daseinsvorsorge", von dem Ossenbüh $l^{150}$ ) zutreffend gesagt hat, er sei erstens ein soziologischer und zweitens ein heuristischer Begriff, aber kein Rechtsbegriff. Forsthoff ${ }^{151}$ ) selbst hat jüngst von der Daseinsvorsorge gesagt, sie sei im Begriffssystem der rechtsstaatlichen Verfassung von vornherein nicht unterzubringen; der Begriff gehöre den Staatswissenschaften an, wie sie im 18. Jahrhundert verstanden wurden. Den ,juristischen Sinn“, den Forsthoff dem Begriff trotzdem - in einer früheren Äußerung ${ }^{152}$ ) - beimißt, soll darin bestehen, "das mit der Daseinsvorsorge bezeichnete öffentlichrechtliche Element im Vollzug privatrechtlich gewährter Leistungen faßbar zu machen". Solcher juristische Sinn soll dem Begriff gewiß nicht abgesprochen werden; aber diese Sinnfunktion ist eben eine heuristische, und darüber hinaus wohl auch eine hermeneutische und kritische, aber keine dogmatische und systematische. "Ordnende“, "leistende“, "lenkende", "austeilende" und "umverteilende" Verwaltung sind gleichfalls heuristische Begriffe; auch ihnen mag man eine gewisse hermeneutische und kritische Funktion zusprechen, aber sie werden dadurch nicht zu Rechtsbegriffen. Sie bleiben letztlich im Bereich des äußeren Systems.

Erst recht gilt das für das gängige Begriffspaar „Eingriffsund Leistungverwaltung". $\mathrm{DaB}$ sich das Verwaltungsrecht mit dieser Unterscheidung ,in zwei Teile von je ausgeprägter struktureller Eigentümlichkeit" zerlegen lasse ${ }^{158}$ ), muß ich nachdrücklich bestreiten. Auch wenn man von der Inkongruenz der Begriffsbildungen absieht - einmal ist die Tätigkeitsform, einmal der Tätigkeitsgehalt begriffsbildendes Merkmal ${ }^{154}$ ) und wenn man also den Begriff der "Eingriffsverwaltung" als für den der "ordnenden Verwaltung “ stehend nimmt ${ }^{135}$ ), auch

die anderen dort verwendeten Begriffe $m$. E. nicht minder, vgl. N. 145.

130) DOV 1971, 516.

181) Der Staat der Industriegesellschaft, S. 77.

163) Rechtstragen der leistenden Verwaltung, S. 10.

159) Rechtsfragen S. 51.

1si) Wolff, Verwaltungsrecht III S. 124; Badura, Verwaltungsrecht im liberalen und im sozialen Rechtsstaat, S. 22; Brohm aaO. (N. 16), S. 49.

150) Ich behalte im folgenden den Begriff „Eingriffsverwaltung ${ }^{4}$ bel. Es empfiehlt sich im allgemeinen nicht, gebräuchliche Begriffe auswechseln und durch vermeintlich treffendere ersetzen 24 wol- 
dann verbinden, überschneiden und durchdringen sich sowohl die so bezeichneten Aufgabenbereiche wie die in ihnen verfolgten Zwecke und schließlich die dafür eingesetzten Handlungsformen und Mittel in derart mannigfacher Weise, daß eine auch nur halbwegs konturenscharfe rechtliche Strukturierung nach solchen Gesichtspunkten unmöglich ist ${ }^{15 \mathrm{~F}}$ ).

3.7.4. Damit sind wir aber schon beim inneren System. Die Forderung nach einer zweck- und aufgabenorientierten Systembildung zielt ja auch keineswegs nur auf das äußere System, sondern - mindestens auch, oder sogar primär - auf das innere. Wenn Badura ${ }^{157}$ ) Köttgens "Deutsche Verwaltung" als "die erste systematische Behandlung des Verwaltungsrechts" bezeichnet, „die die neuen Wirklichkeiten des Verwaltens in einem einheitlichen Zusammenhang $z u$ erfassen trachtet, dabei die ,Aufgaben der Verwaltung' und die ,Rechtsformen des Verwaltungshandelns' klar trennt und beide in einer je spezifischen Begrifflichkeit einzufangen sucht", so liegt darin die Behauptung einer schon einmal geglückten Bildung eines inneren Systems mit Hilfe der Aufgaben der Verwaltung, und es liegt darin doch wohl zugleich eine Aufforderung zur Nachfolge. Nun hat aber Köttgen - entgegen Baduras Ansicht gerade keine "spezifische Begrifflichkeit" für die Aufgaben entwickelt, und er hat das $\mathrm{m}$. E. auch gar nicht beabsichtigt. So führt $\mathrm{er}^{158}$ ) z. B. zu den rechtlichen Formen, in denen sich die staatliche Lenkung vollziehe, aus: sie seien "dem jeweiligen Gegenstande angepaßt und daher außerordentlich mannigfaltig"; verwaltungsrechtlich vollziehe sich die Lenkung vor allem über Zulassungsordnungen und mancherlei Ge- und Verbote, wie sie seit langem im Polizeirecht entwickelt worden seien. Von einem aufgabenspezifischen Instrumentarium ist also keine Rede. Im übrigen ist die aufgabenorientierte Darstellung bei Köttgen nur eine neben anderen; die Einteilung nach den Aufgaben ist und bleibt hier eine des äußeren Systems.

Daß und warum ich Zwecke und Aufgaben der Verwaltung nicht als tragfähige Grundlage für das innere System erachten

len. Abgesehen von der geringen Aussicht eines solchen Unterfangens hat es oft mehr Verwirrung als Klärung zur Folge.

$\left.{ }^{156}\right)$ So können Leistungen z. B. im einen Fall zweckerfüllend sein, Im anderen Fall nur Mittel zur Erfüllung weiterer Zwecke, etwa sozialer Gestaltung oder wirtschaftlicher Lenkung, sie erhalten damit instrumentalen Charakter. Dafür lassen sich zahlreiche Belspiele, z. B. im Wirtschaftsverwaltungsrecht, finden.

${ }^{157}$ ) Verwaltungsrecht im liberalen und im sozialen Rechtsstaat, S. 20.

160) AaO. S. 167 \&. 
kann, sollte aus meinen Bemerkungen zum äußeren schon deutlich geworden sein: Auf Begriffen, die keine hinreichend bestimmbare rechtliche Aussagekraft besitzen und die eben deshalb keine Rechtsbegriffe sind, läßt sich ein Rechtssystem nicht errichten. Welche Fehldeutungen sich ergeben, wenn man solche Begriffe als Rechtsbegriffe mißversteht, zeigt das mit Recht viel kritisierte Urteil des BGH vom 23. 9. 1969 mit dem Satz: "Alles, was funktionell zur Daseinsvorsorge gehört, ist nach Grundsätzen des öffentlichen und nicht des privaten Rechts zu beurteilen. ${ }^{159}$ ) Das Urteil steht damit nicht allein ${ }^{100}$ ).

Damit soll nicht gesagt werden, jene zweck- und aufgabenorientierten Begriffe und Einteilungen seien für das innere Rechtssystem wertlos; im Gegenteil, ihre heuristische, hermeneutische und kritische Funktion ist durchaus wichtig. So hat die Erkenntnis der besonderen Kategorie des Verwaltungsprivatrechts und seiner Bedeutung und so hat überhaupt die ganze systematische Einteilung in obrigkeitliches, schlichthoheitliches, verwaltungsprivatrechtliches, privatwirtschaftlich-fiskalisches Verwaltungshandeln sowie in Hilfsgeschäfte der Verwaltung ${ }^{161}$ ) - hierbei handelt es sich in der Tat um Rechtsbegriffe - von den Begriffen der Daseinsvorsorge und der Leistungsverwaltung entscheidende Impulse empfangen. Ähnliches gilt für die wachsende Einsicht in die Relativität der Unterscheiclung zwischen öffentlichem und Privatrech $t^{182}$ ), die zwar als solche von der Gesetzgebung vorgegeben und deshalb von der Dogmatik zugrundezulegen ist, deren früher oft unterstellter Absolutheitscharakter jedoch nicht vom Gesetz gefordert ist und deshalb durch eine zweckorientierte Interpretation korrigiert werden kann -

Ich ziehe die Folgerung: Der oft geforderte "Neubau" des verwaltungsrechtlichen Systems, als Auswechselung seiner tragenden begrifflichen und institutionellen Fundamente verstanden, ist weder erforderlich noch auch nur möglich. Denn - darin stimme ich ganz mit dem Urteil Franz Mayers ${ }^{103}$ ) überein:

159) BGHZ 52, 325 (329). Dazu Ossenbühl, DOV 1971, 517; Emmerich, JuS 1970, 332 ff. Die Berufung des Urteils auf Forsthoff und Wolff entbehrt der Grundlage.

$\left.{ }^{160}\right)$ Nachweise bei Püttner, Die öffentlichen Unternehmen, 1969, S. 54 f.; Ossenbühl, DOV 1971, 517 N. 50.

16i) Vgl. Siebert aaO. (N. 116) S. 219 ff., insb. $221 \mathrm{f}$.

16:) Dazu insb. Bu!linger, Offentliches Recht und Privatrecht (res publica Bd. 17), 1968, passim.

163) Neuzeitliche Entwicklung der öffentlichen Verwaltung (in: Verwaltung - Eine einführende Darstellung; in Verbindung mit Erich Becker und Carl Hermann Ule herausgegeben von Fritz Morstein Marx, 1965, S. 2 ff.) S. 15. 
"Auch die Leistungsverwaltung des sozialen Rechtsstaats ist auf alle elementaren Grundsätze des Rechtsstaats hin angelegt; lediglich die Schwerpunkte des Verwaltungshandelns wie des gesamten Verwaltungsgeschehens sind anders verteilt". Deshalb bleibt die Verwaltung, auch in ihren leistenden, lenkenden und verteilenden Aufgabenbereichen, auf das rechtsstaatliche Instrumentarium angewiesen. Die Verlagerung der Schwerpunkte des Verwaltungsgeschehens erfordert aber eine Verschiebung der Akzente und eine andere Verteilung der Gewichte innerhalb des rechtlichen Systems, zugleich dessen Befreiung von überholten Bestandteilen und seine Erweiterung durch neue; also einen kontinuierlichen „Umbau“ des Systems $s^{104}$ ), eine ständige kritische Uberprüfung und Fortentwicklung desselben. Das ist freilich eine mühevolle, niemals abreiBende Arbeit; sie ist weit weniger spektakulär, verspricht dafür aber einen ungleich gröBeren Erfolg als die gewollte Suche nach einem neuen System.

4. In welche Richtung solche Bemühungen um einen Umbau und Ausbau unseres verwaltungsrechtlichen Systems gehen müssen, das kann ich, an die knappe Zeit gebunden, nur noch in einer der Sache wenig angemessenen Kürze andeuten.

4.1. Als Zentralbegriff dieses Systems wurde und wird z. T. heute noch der Verwaltungsakt angesprochen ${ }^{105}$ ). Ich möchte hier nicht erörtern, ob der Ausdruck "Zentralbegriff" richtig gewählt ist, noch kann ich mich mit der in der Rechtstheorie jüngst wieder viel diskutierten Frage auseinandersetzen, welches letztlich die einheitsstiftenden Kriterien eines Rechtssystems sind: ob oberste Werte, Rechtsgrundsätze, Prinzipien, grundlegende Rechtssätze, Institute, allgemeine Rechtsbegriffe, oder was sonst $\left.{ }^{186}\right)$. Was mit der Kennzeichnung als Zentralbegriff gemeint ist, dürfte klar sein: daß nämlich der Verwaltungsakt der wichtigste, das System weithin beherrschende Be-

104) Ein solcher Umbau ist seit 1945 schon weitgehend erfolgt. Vgl. dazu Bachof, Uber einige Entwicklungstendenzen (N. 10), S. 7. Manche Säulen des überlieferten Lehrgebäudes haben sich in der Zwischenzelt aber doch wohl als tragfähiger erwiesen, als es mir damals schlen.

165) Nur noch selten wird dem Begriff der "öffentlichen Gewalt" diese Rolle zugewiesen; was übrigens (nur) dann auf dasselbe hinausläuft, wenn man diesen Begriff in seinem - schon von Otto Mayer bekämpiten - ursprünglichen Sinn von obrigkeitlicher Befehls- und Zwangsgewalt versteht; denn eben sle manifestiert sich in der verbindlichen Entscheidung, die der Verwaltungsakt beinhaltet.

106) Dazu z. B. Canaris, aaO. (N. 20) S. 46 fl., mit welt. Nachw. 
griff, das mit ihm bezeichnete Institut das beherrschende Institut sei.

Nun hat das, bei aller Bedeutung, die dem Verwaltungsakt bei und seit Otto Mayer zukam, schon für dessen Zeit und noch für die Zeit bis zum 2. Weltkrieg nicht gestimmt, jedenfalls nicht in dem heute vielfach angenommenen Ausmaß. Das hoffe ich gezeigt $\mathrm{zu}$ haben, womit ich zugleich eine eigene frühere Âußerung ${ }^{107}$ ) korrigiere. Es stimmt indessen für die Jahre nach dem 2. Weltkrieg, hervorgerufen durch eine schwerpunktmäßig am Verwaltungsakt ausgerichtete Regelung des Rechtsschutzes. Die außerordentliche und in vieler Hinsicht wenig vorteilhafte Abhängigkeit des materiellen Verwaltungsrechts von verfahrensrechtlichen Gestaltungen hat sich selten so deutlich gezeigt wie hier. Wo kein Verwaltungsakt, da kein Rechtsschutz: so wurden die einem aktionenrechtlichen Denken verhafteten Verwaltungsgerichtsgesetze der Jahre 1946 ff., ob zu Recht oder Unrecht, fast allgemein und insbesondere von den Gerichten verstanden, und nur daraus sind die Wucherungen des Verwaltungsaktes zu erklären ${ }^{108}$ ). Verdrängt wurde damit die Einsicht, $\mathrm{da} B$ der Verwaltungsakt nur eine Momentaufnahme innerhalb sich entwickelnder Beziehungen darstellt; daß er ein Rechtsverhältnis begründet, verändert oder beendet, und da $B$ dieses Rechtsverhältnis für eine materiellrechtliche Betrachtungsweise viel wichtiger und interessanter ist als der Verwaltungsakt zumal es ja zahlreiche Verwaltungsrechtsverhältnisse gibt, die auf ganz andere Weise begründet, verändert oder beendet werden als durch Verwaltungsakte. Daraus allein wird schon deutlich, daß das Rechtsverhältnis ein viel umfassenderes Institut ist als der Verwaltungsakt. Wenn ein Begriff und wenn ein Institut eine beherrschende, meinetwegen auch "zentrale" Stellung im Verwaltungsrecht einzunehmen verdienen, so ist es das Rechtsverhältnis; wobei, wie auf unserer Berner Tagung zutreffend betont wurde ${ }^{100}$ ), dem Dauerrechtsverhältnis eine besondere Bedeutung zukommt. Im übrigen decken sich meine Auffassungen zum Rechtsverhältnis weitgehend mit den von Henke in Bern vorgetragenen, insbesondere was die Notwendigkeit einer Ausmerzung des "Gewaltverhältnisses" betrifft" ${ }^{170}$ ).

Die Rechtsprechung hat inzwischen - nicht zuletzt in Auswirkung der VwGO von 1960 - den Verwaltungsaktbegriff wieder eingeschränkt und begonnen, dem Rechtsverhältnis ei-

107) Uber einige Entwicklungstendenzen, S. 5 .

100) Zu dieser Entwicklung vgl. Bachof, Uber einige Entwicklungstendenzen, S. $8 \mathrm{ff}$.

109) Rïfner, VVDStRL 28, 215 Æf.; Scheuner, ebenda S. 232.

170) VVDStRL 28, $156 \mathrm{ff}$. 
nen breiteren Platz einzuräumen $\left.{ }^{171}\right)$. In dieser Richtung muß sie durch die Lehre nachhaltig unterstützt werden ${ }^{172}$ ). Nur von solchem Ansatzpunkt aus läßt sich die Einseitigkeit des Denkens in Verwaltungsakten überwinden; nur so können auch andere Institute und Handiungsformen ihren legitimen Platz in der Dogmatik einnehmen; nur so lassen sie sich in jener Mannigfaltigkeit entwickeln und ausbauen, deren das Verwaltungsrecht bedarf, um allen Aufgaben der Verwaltung gerecht zu werden. Das gilt z. B. für den verwaltungsrechtlichen Vertrag, für das schlichte Verwaltungshandeln, für die Zusage (die als Verwaltungsakt $\mathrm{zu}$ werten keineswegs überzeugend ist), für die einseitige Willenserklärung Privater gegenüber der Verwaltung, für die Garantenstellung, für die Plangewährleistung und für vielles andere mehr.

Eine Eliminierung des Verwaltungsaktes aus dem Verwaltungsrecht oder auch nur aus der Leistungsverwaltung will ich damit gewiß nicht befürworten. Der Verwaltungsakt ist auch in der Leistungsverwaltung ein notwendiges Institut; die Gründe dafür - vornehmlich Konkretisierung, Stabilisierung, KlarS. 10 .

171) Nachweise bei Bachof, Uber einige Entwicklungstendenzen,

$\left.{ }^{172}\right)$ Die Lehre hat - 2. T. schon vor der VwGO - bereits in dieser Richtung gewirkt. Dabei handelt es sich einerseits um Außerungen, die - ohne grundsätzliche Stellungnahme zum Rechtsverhältnis als solchem - Verwaltungsrechtsverhältnisse in bestimmten Sachbereichen bejahen; vgl. etwa Ipsen, VVDStRL 11, 129 ff.: die Plangewährleistung entspringe der Erkenntnis, daß jede Lenkung und Planung ein zweiseitiges Rechtsverhältnis entstehen lasse; ders., Offentliche Subventionierung Privater, 1956, S. 61 ff: "Subventionsverhältnis" ( = "Subventions-Rechtsverhältnis", so ausdrücklich VVDStRL 25, 300). Zum anderen handelt es sich um Arbeiten besonders aus jüngerer Zeit, die einer stärkeren Betonung und Nutzbarmachung des Rechtsverhältnisses im Verwaltungsrecht ausdrücklich und grundsätzlich das Wort reden: so insbesondere für das Steuerrechtsverhältnis Bühler-Strickrodt, Steuerrecht Bd. I, 3. Aufl. 1960, S. 347 ff.; für das Subventionsrechtsverhältnis, aber darüber hinaus allgemein Zacher, VVDStRL $25,325 \mathrm{ff}$., insb. $\mathrm{s}$. 332 ff. mit N. 116; grundsätzlich und allgemein auch Henke VVDStRL 28, $156 \mathrm{ff}$; vor allem für das Schuldverhältnis Simons, Leistungsstörungen verwaltungsrechtlicher Schuldverhältnisse (Schriften zum öff. Recht Bd. 45), 1967, passim, insb. S. 49 ff.; dgl. Papier, Die Forderungsverletzung im öffentlichen Recht (Schriften zum öff. Recht Bd. 136), 1970, passim, insb. S. 17 ff.; vgl. ferner Oldiges, Grundlagen eines Plangewährleistungsrechts, 1970, S. 138 ff. Zahlreich sind auch die Äußerungen, die eine Ausweitung und Aufwertung des Rechtsverhältnisses aus prozessualer Sicht befürworten; vgl. hierzu nur aus jüngster Zeit Renck, JuS 1970, 113; Siemer, Normenkontrolle durch Feststellungsklage? (Schriften zum Prozeßrecht Bd. 20), 1971, S. 26 ff. 
stellung - sind gleichfalls in Bern erörtert worden $^{173}$ ), ich brauche sie nicht zu wiederholen. Es geht auch hier nur um die richtigen Relationen.

4.2. Das Gesagte bedarf aber einer wichtigen Einschränkung. Wenn das Rechtsverhältnis nach gängiger Ansicht eine rechtlich geordnete Beziehung von Personen zu anderen Personen $^{174}$ ) ist, so fallen Beziehungen innerhalb der Verwaltung nur dann darunter, wenn die beteiligten Organe verschiedenen Rechtssubjekten angehören. Beziehungen zwischen Organen ein und derselben Person lassen sich mit dem Begriff des Rechtsverhältnisses hingegen nicht erfassen - es sei denn, man wäre bereit, diesen Begriff über die im Zivilrecht entwickelte und ihm von daher zugewiesene Bedeutung hinaus zu erstrekken, wogegen ich keine grundsätzlichen Bedenken hätte; das kann ich hier nicht erörtern ${ }^{175}$ ). Wichtiger als diese terminologische Zuordnungsfrage ${ }^{178}$ ) ist auch etwas anderes: Das ganze Behörden- und Organisationsrecht ist seit eh und je von der verwaltungsrechtlichen Dogmatik vernachlässigt worden. Das geht schon auf Otto Mayer zurück, der die "Behördenordnung“ als ein dem Verwaltungsrecht „etwas fremdes Element" betrachtete und sie zusammen mit dem Verfassungsrecht das "deutsche Staatsrecht" bilden lassen wollte ${ }^{177}$ ) - wo sie denn freilich auch keinen rechten Platz gefunden hat. Im Grunde lag dieser Hinausweisung der Verwaltungsorganisation aus dem Verwaltungsrecht, wie Erich Kaufmann ${ }^{278}$ ) richtig gesehen hat,

173) Zur Konkretisierung und zur Stabilisierung insb. Rüfner, VVDStRL 28, 205; zur Klarstellung Vogel ebenda S. 269.

174) Oder - was nicht unbestritten ist, aber hier außer Betracht bleiben kann - zu Sachen.

175) Dazu sei darauf hingewiesen, daß man ja Regelungen zwischen Behörden ein und desselben Rechtsträgers (z. B. Kündigungsgenehmigungen oder -verweigerungen des Arbeitsministeriums gegenüber anderen Landesbehörden nach dem Schwerbeschädigtengesetz) auch nicht mehr schlechthin vom Begriff des Verwaltungsaktes ausnimmt.

${ }^{176)} \mathrm{Ob}$ es sich dabei nut um ein terminologisches Problem handelt, muß freilich bezweifelt werden. Die Terminologie ist in der Regel Ausdruck einer zuvor (oft unbewuBt) getroffenen Sachentscheidung, wie sie umgekehrt die Sachentscheidung auch zu präjudizieren vermag.

177) VR 3. Aufl. 1. Bd., S. $16 f$.

178) VerwArch. Bd. 30, 397. Die Stelle ist so lesenswert, daß ein Teil hier wörtlich wiedergegeben sei: „Ob für bestimmte Verwaltungsaufgaben die Behörden der ,allgemeinen Verwaltung' oder Behörden einer Spezialverwaltung zuständig sind, in welchem Verhältnis die allgemeinen und besonderen Verwaltungsbehörden zueinander stehen, ob die allgemeinen Verwaltungsbehörden nach Art des französischen Präfekten oder nach der des preußischen Regierungspräsidenten organisiert sind, in welchem Umfang das büro- 
ein „zu enger Begriff vom Recht" zugrunde. Bestärkt wurde diese auch in der Folgezeit und bis heute nicht behoben ${ }^{179}$ ) Vernachlässigung des Organisationsrechts durch die Ausgestaltung unserer Verwaltungsgerichtsbarkeit. Da die Gerichte sich überwiegend mit dem Staat-Bürger-Verhältnis zu befassen haben, und da nun einmal auch die Lehre sich vorzugsweise der von den Gerichten behandelten Materien anzunehmen pflegt, sind die Probleme der Organisation und der Struktur der Verwaltung nahezu ganz außer Sicht geraten. Es ist bezeichnend, daß sie auch heute noch fast nur dann erörtert werden, wenn sie unmittelbare Rückwirkungen auf das Staat-Bürger-Verhältnis haben, wie z. B. im Falle des Zusammenwirkens mehrerer Behörden beim Erlaß eines Verwaltungsaktes. Wie hilflos man anderen organisationsrechtlichen Problemen gegenübersteht, wenn sie unerwartet einmal auftauchen, zeigen einige jüngere Entscheidungen zu Fragen der Aufsicht, insbesondere zur ministeriellen Aufsicht über die Hochschulen, in denen die Mannigfaltigkeit der Bedeutungen und der Funktionen von „Aufsicht" nicht erkannt wird. Ein anderes Beispiel ist die fehlende Einsicht in die juristische Relevanz der Zusammensetzung von Verwaltungsgremien. Es ist z. B. für die Frage, ob die Ermächtigungsschranken des Art. 80 GG analog auf Satzungen anzuwenden sind, durchaus nicht gleichgültig, ob die Satzung von einem demokratisch gewählten und legitimierten Ortsgesetzgeber erlassen wird, oder aber von dem ernannten Leiter einer nur aus $Z$ weckmäßigkeitsgründen rechtlich verselbständigten, im übrigen aber behördenähnlich strukturierten Anstalt. Es ist auch für Fachaufsicht, Rechtsaufsicht und gerichtliche Kontrolle nicht gleichgültig, daß der Bebauungsplan vom Gemeinderat und nicht von einer bürokratisch organisierten Behörde beschlossen wird. Es ist schließlich nicht gleichgültig, wenn Verwaltungsgremien in ihrer Zusammensetzung auf einen Ausgleich pluralistischer Kräfte der Gesellschaft angelegt sind, oder wenn sie - beides kommt oft zusammen - sich aus besonders sachverständigen Personenkreisen zusammensetzen. Die Erwägungen solcher Gremien (Rundfunkräte, Ausschüsse

kratische und das kollegiale Prinzip oder eine Mitwirkung von Laien durchgeführt ist, ob Hoheits- und fiskalische Verwaltung bei den einzelnen Verwaltungszweigen derselben Behörde oder getrennten Behörden überwiesen sind, Art und $\mathrm{MaB}$ der Dekonzentration, Art und Umfang der Dezentralisation auf kommunale oder sachliche Selbstverwaltungskörper, deren Ausstattung mit Hoheitsrechten, Vermögen und Finanzgewalt, das Zusammenspielen zwischen Staatsverwaltung und Selbstverwaltung, das alles sind echte Rechtsprobleme der öffentlichen Verwaltung."

17i) Dazu die in N. 38 genannten Autoren. 
der Filmbewertungsstelle, Bundesprüfstelle usw.) können von einer ganz anders zusammengesetzten Kontrollinstanz nur in begrenztem Umfange ohne Schaden für die mit der personellen Zusammensetzung des Organs bezweckte Funktion ersetzt werden. Ich will damit nicht behaupten, daß demokratische oder pluralistische Organe keiner Rechtskontrolle bedürften, oder gar daß Rechtskontrolle gegen demokratische und gesellschaftliche Kontrolle austauschbar sei. Aber gewisse Relationen bestehen hier zweifellos, schon weil der Gesetzgeber so zusammengesetzten Gremien größere Freiheit für die Gestaltung, für das Ermessen und für ihre Wertungen einzuräumen pflegt und auch einräumen muß als bürokratisch organisierten Behörden. Diese Zusammenhänge sind bisher, vor allem in der Judikatur, noch so gut wie gar nicht erkannt worden ${ }^{170 \%}$ ). Nur wo das Zauberwort "Wahl" auftaucht, ist das anders. Ob z. B. bei der Wahl eines Bürgermeisters, sei es durch die Bevölkerung oder den Gemeinderat, der geeignetere Bewerber dem weniger geeigneten unterlegen ist, das ist bisher von den Gerichten - zum Glück! - noch nicht nachgeprüft worden. Warum eigentlich nicht? Gilt hier Art. 33 Abs. 2 GG etwa nicht? Natürlich gilt die Vorschrift hier auch; aber der richterlichen Zurückhaltung liegt die richtige Einsicht zugrunde, daß ein Wahlgremium eben etwas anderes ist als eine ernennende Behörde. Dann aber ist nicht einzusehen, warum nicht auch in anderen Fällen die Besetzung eines Organs rechtlich relevant sein soll.

4.3. Auch das besondere Verwaltungsrecht ist von der Dogmatik lange Zeit hindurch stiefmütterlich behandelt worden: jedenfalls auf den Gebieten, die nicht - wie Polizeirecht, $\mathrm{Be}-$ amtenrecht und Kommunalrecht - gängiger Stoff der Rechtsprechung, des Schrifttums und des akademischen Unterrichts waren und sind. Vernachlässigt wurden also gerade die im besonderen Maße sozialstaatsbezogenen Bereiche; insofern deckt sich diese Feststellung 2 . T. mit der vorhin erörterten dogmatischen Unterbilanz der Leistungsverwaltung. Welche wichtigen Anregungen das allgemeine vom besonderen und das besondere vom allgemeinen Verwaltungsrecht empfangen kann, haben erst vor kurzem die Berner Erörterungen zum Recht der sozialen Sicherung ${ }^{109}$ ) wieder deutlich gemacht. Erfreulicherweise sind in den letzten Jahren eine ganze Reihe monographischer Arbeiten vor allem zum Wirtschaftsverwaltungsrecht,

1709) Slehe jetzt aber BVerwG vom 16. 12. 1971, JZ 1972, 204 if. mit Anm. von Bachof.

109) Die Rechtsformen der sozialen Sicherung und das Allgemeine Verwaltungsrecht, Referate (von Henke und Rufner) und Diskussion, VVDStRL 28, $149 \mathrm{ff}$. 
aber auch zum Kulturverwaltungsrecht und zum Sozialverwaltungsrecht erschienen. Nur auf dem Wege solcher monographischer Erschließung und Durchforstung scheint es mir möglich zu sein, die für jene Gebiete spezifischen dogmatischen Begriffe und Institute $z u$ finden und auszubilden. Die Wissenschaft muB sich auch hier frei machen von ihrer traditionellen Abhängigkeit in der Wahl ihrer Arbeitsgebiete von den Schwerpunkten der Rechtsprechung und des akademischen Unterrichts.

4.4. Ich könnte damit meinen Rundgang beschließen, läge mir nicht daran, wenigstens als Merkposten noch eine bisher unerwähnt gebliebene dogmatische Aufgabe anzuführen: das ist die Einbeziehung des europäischen Rechts in unsere Utberlegungen. Das Recht der Europäischen Gemeinschaften ist im wesentlichen Verwaltungsrecht, vornehmlich Wirtschaftsverwaltungsrecht. In ihm fließen Rechtsgedanken der französischen, der deutschen, der italienischen und etlicher weiterer Rechtsordnungen zusammen, es strahlt seinerseits in diese nationalen Rechtsordnungen aus. Beides gilt nicht nur für die Rechtsetzung, sondern auch für die Interpretation der Normen, für ihre dogmatische Erfassung und Systematisierung. Das einzige französische Mitglied unserer Vereinigung, Michel Fromont, ein guter Kenner gleichermaßen des französischen wie des deutschen öffentlichen Rechts und verdienstvoll durch seine diesbezüglichen rechtsvergleichenden Arbeiten, hat dargestellt, wie sich das Gemeinschaftsrecht nach und nach von den nationalen Rechtsordnungen und -vorstellungen gelöst und verselbständigt, dabei aber doch zugleich dieselben verarbeitet und integriert hat ${ }^{181}$ ); wobei der Europäische Gerichtshof sich, nachdem anfangs die Rechtsprechung des französischen Conseil d'Etat dominierte, später auch deutschen Einflüssen zunehmend öffnete. Unterschiedliche Auffassungen etwa über den Verwaltungsakt, seine Rechtswidrigkeit und deren Folgen, über die Ermessensfehler der deutschen und das détournement de pouvoir der französischen Lehre müssen in der europäischen Rechtsprechung ausgeglichen werden. Davon können die nationalen Dogmatiken nicht unberührt bleiben. Man kann sich wohl kaum vorstellen, daß auf lange Sicht eine deutsche, eine französische, eine italienische usw. und überdies noch eine gemeineuropäische Dogmatik des Verwaltungsgeschehens unvermittelt nebeneinander bestehen könnten. Fromont hat auch darauf hingewiesen, in welch starkem Maße sich die vom französischen und vom deutschen Recht gefundenen Lösungen im Ver-

181) Fromont, Rechtsschutz gegenüber der Verwaltung in Deutschland, Frankreich und den Europäischen Gemeinschaften, 1967; dort insb. Teil II, S. 141 ff.; vgl. auch die Schlußfolgerung S. 275. 
waltungsrecht, ungeachtet unterschiedlicher methodischer Ansätze, schon in den vergangenen Jahrzehnten immer mehr aufeinander $\mathrm{zu}$ bewegt haben $\left.{ }^{182}\right)$. Diese Entwicklung wird durch das Gemeinschaftsrecht beschleunigt werden. Wir dürfen daran nicht vorbeigehen.

\section{Zusammenfassung und Ausblick}

Ich komme zum Ende: Wenn man die dogmatische Arbeit der Nachkriegsjahre unvoreingenommen betrachtet, so darf wohl, ungeachtet mannigfacher und sicher auch begründeter Kritik im einzelnen, gesagt werden, daß sie nicht erfolglos war. Es handelt sich dabei m. E. um erheblich mehr als nur um „Füllund Filigranarbeit"183). Die allgemeinen Lehren sind nicht nur fortentwickelt, sondern in entscheidenden Punkten umgestaltet worden, und zwar im steten Blick auf die Leitidee des sozialen Rechtsstaats und in steter Bemühung um die Lösung konkreter Sachprobleme. Die Bereiche des besonderen Verwaltungsrechts und ihre speziellen Fragestellungen sind in zunehmendem Maße in Angriff genommen worden.

Es kann hier nicht darum gehen, ob die angebotenen Lösungen, etwa für die Bestandskraft und die Rücknahme von Verwaltungsakten, ob die Lehre vom Verwaltungsakt mit Drittwirkung, von der Selbstbindung durch Verwaltungsübung oder durch Verwaltungsvorschriften, ob die Zweistufenlehre, ob eine Rechtsfigur wie der Plangewährleistungsanspruch, ob die neueren Konstruktionen im Staatshaftungs-, Entschädigungs- und Folgenbeseitigungsrecht - die Reihe könnte noch lange fortgesetzt werden - ob dies alles schon richtige oder gar endgültige Lösungen sind. Die dogmatische Bewältigung neuer Probleme braucht ihre Zeit, sie braucht Geduld und Ausdauer. Irrwege und Umwege sind dabei unvermeidbar, Fertiges wird sich nur selten aufweisen lassen. Heute schon eine durchgebildete Dogmatik etwa der Planung oder der Subventionen zu erwarten, hieße die Komplexität solcher Probleme gründlich verkennen. Fast jedes wichtige neue Verwaltungsgesetz - als Beispiel aus jüngster Zeit möge das Städtebauförderungsgesetz dienen - wirft auch eine Fülle neuer dogmatischer Probleme auf. Der „Eindruck einer heillosen Verwirrung“, von dem

182) AaO. S. 138 ff. Es kommt in diesem Zusammenhang nicht darauf an, ob man Fromonts Sicht in allen Punkten zustimmt; Ich würde hier manche Vorbehalte machen. Die Tendenz jedenfalls ist richtig beobachtet.

I83) H. H. Rupp, DVBl. $1971,669$. 
jüngst mehrfach gesprochen wurde ${ }^{184}$ ), ist weit weniger der Dogmatik des Verwaltungsrechts als ihren im ständigen Fluß befindlichen Gegenständen anzulasten. An solchem Wandel wird sich auch künftig nichts ändern. Nie wird der Verwaltungsrechtler ähnliche Ruhelagen - und handele es sich auch nur um eine relative Ruhe - vorfinden wie der Zivilist oder wie der Strafrechtler. Das ist unsere Last, aber auch der Reiz unseres Faches.

Lassen Sie mich ganz zum Schluß noch ein Zitat vervollständigen. Ich habe vorhin ${ }^{185}$ ) Fleiners Vorwort zur 8. Auflage seiner „Institutionen“ aus dem Jahre 1928 erwähnt, wo er von dem starken Einfluß des neuen Verfassungsrechts auf das Verwaltungsrecht spricht, von der dadurch bedingten Sinnwandlung alter Rechtsinstitute und vom Auftauchen neuer Probleme für die Wissenschaft. In dieser Auflage, so fährt er fort, sei der Versuch unternommen worden, „das Neue organisch mit den bewährten Grundsätzen des Deutschen Verwaltungsrechts zu verbinden". Ich meine, eben darin besteht auch die Aufgabe der verwaltungsrechtlichen Dogmatik unserer Zeit!

184) Ossenbithl DOV 1971, 513 (speziell für Lehre und Rechtsprechung zum Verwaltungsprivatrecht), im AnschluB an Emmerich, JuS 1970, 333.

18s) Oben S. 205 mit N. 56. 
Leitsätze des Berichterstatters über:

\section{Die Dogmatik des Verwaltungsrechts vor den Gegenwartsaufgaben der Verwaltung}

I.

1. Das Verwaltungsrecht ist im Vergleich zu anderen Rechtsgebieten dogmatisch wenig ausgeformt. Das ist keine durch sein geringes Alter bedingte Rückständigkeit, sondern liegt an seinem Gegenstand.

2. Die Aufteilung des Verwaltungsrechts auf zahlreiche (Bundes- und Landes-)Gesetze, deren breite stoffliche Streuung, ihre Determinierung durch politische und durch Zweckmäßigkeitsgesichtspunkte, ihre Situationsgebundenheit und ihr rascher Wandel erschweren eine dogmatische Erschließung. Solche Gesetze eröffnen sich eher topischem als systematischem Denken.

3. Auch das Fehlen einer Kodifizierung der allgemeinen Lehren des Verwaltungsrechts mag die dogmatische Arbeit behindert haben. Das Verhältnis von Dogmatik und Gesetz ist aber ambivalent; Kodifikation kann die Dogmatik ebenso hindern vie fördern.

4. Die Dogmatik des deutschen Verwaltungsrechts ist in weitgehender Unabhängigkeit vom Gesetz entstanden. Ihre Begriffe und Institute wurden von Otto Mayer teils in Anlehnung an das französische Verwaltungsrecht, teils an das deutsche bürgerliche Recht, weitgehend aber in schöpferischer Konstruktion als "eignes Gewächs" entwickelt. Sie bestimmen bis heute nicht nur Rechtsprechung und Lehre, sondern auch die Gesetzgebung.

II.

5. Die heute viel berufene Verfassungsabhängigkeit des Verwaltungsrechts bestand von Anfang an, sie wurde stets gesehen und beachtet. Das Grundgesetz hat diese Abhängigkeit jedoch verstärkt; es hat zu einer unmittelbaren Konfrontation allen Verwaltungshandelns mit der Verfassung geführt, die ihm die Deckung durch das einfache Gesetz entzieht (Art. 1 III GG; verfassungskonforme Auslegung; richterliches Prüfungsrecht). 
III.

6. Die dem Verwaltungsrecht aus seiner Entstehungszeit anhaftenden „obrigkeitsstaatlichen Relikte“ sind seit 1945 konsequent abgebaut worden. Das kann nur bestritten werden, wenn man allein eine gesetzliche Totalbindung der Verwaltung als rechtsstaatlich und als demokratisch anerkennen will. Das damit angesprochene Thema "Gesetzgeber und Verwaltung" (Tagung Würzburg 1965) kann in diesem Bericht nicht abermals erörtert werden.

\section{IV.}

7. Die Dogmatik des deutschen Verwaltungsrechts war stets und ist bis heute schwerpunktmäßig am Rechtsstaat und nicht am Sozialstaat ausgerichtet. Die Dogmatik der (hier weit verstandenen) "Leistungsverwaltung" weist deshalb eine beträchtliche Unterbilanz auf. Die zur Erklärung dieses Befundes üblicherveise angeführten Gründe reichen jedoch nicht aus.

8. Falsch ist insbesondere die gängige Behauptung, die Dogmatik des deutschen Verwaltungsrechts entstamme einer Epoche des einseitig freiheitsverbürgenden (liberalen oder bürgerlichen) Rechtsstaats. Der deutsche Staat war stets in erheblichem Umfange Wohlfahrtsstaat. Die auf Zurückdrängung wohlfahrtsstaatlicher Zivecke gerichtete Bewegung hatte zur Zeit Otto Mayers längst ihren Höhepunkt überschritten und einer gegenläufigen Bewegung Platz gemacht.

9. Mittelpunkt von Otto Mayers System war nach seiner eigenen Bekundung wie nach dem tatsächlichen Befund weder die Polizei- noch die Finanzgeualt, sondern das Recht der öffentlichen Unternehmungen. Offentliche Gewalt und Verwaltungsakt spielten hier keine beherrschende Rolle. Die „Förderung von Dasein und Wirtschaften der einzelnen" war als Aufgabenbereich und nach den Rechtsformen klar von der ordnenden (obrigkeitlichen) Verwaltung unterschieden.

10. Für die Vernachlässigung der Dogmatik sozialstaatsbezogener Verwaltungstätigkeiten war vor allem die Stoßrichtung der Staats- und Verwaltungsrechtslehre der konstitutionellen Monarchie verantwortlich. Ihr Ziel war der Ausbau des Rechtsstaats, ihr Gegner der Obrigkeitsstaat („Polizeistaat"). Der Sozialstaat ("Wohlfahrtsstaat") war relativ unproblematisch, zwar unfertig und ausbaubedürftig, aber ohne prinzipielle Gegnerschaft; seine dem Machtzuwachs entspringenden Freiheitsgefährdungen wurden erst spät erkannt.

11. An dieser Grundsituation hat sich in der Folgezeit wenig geändert. Daraus erklärt sich auch, daß die deutschen Verfas- 
sungen ihren Schwerpunkt kontinuierlich auf die rechtsstaatlichen Elemente gelegt haben.

12. Beigetragen zur dogmatischen Vernachlässigung der Leistungsverwaltung haben die schwerpunktmäßige Ausrichtung des Rechtsschutzes auf die Eingriffsverwaltung sowie die einseitige Anlage und Ausrichtung der Studien- und Prüfungsordnungen.

$\checkmark$.

13. Die sog. „juristische Methode" des Verwaltungsrechts hat $z u$ einer Verdrängung von Staatswissenschaften und Verwaltungslehre aus Wissenschafi und Unterricht geführt. Das war von ihren Verfechtern weder beabsichtigt noch in ihr angelegt. Diese Entwicklung ist vorwiegend eine Folge der positivistischen Grundhaltung der domaligen Zeit. Die Einseitigkeit juristischer Betrachtungsweise der Verwaltung hat das Verwaltungsrecht von wichtigen Erkenntnisquellen abgeschnitten und so zu seiner Verarmung geführt.

14. Die Bemühungen um eine Wiedereinbeziehung sozialwissenschaftlicher Erkenntnisse in das Verwaltungsrecht sind zu begrüßen. Der Vorwurf, ein Hineinmischen sozialwissenschaftlicher Erkenntnisse in die juristischen Auslegungs- und Entscheidungsverfahren widerspreche dem Sinn der Arbeitsteilung von Sozialwissenschaften und Entscheidungslogik (Luhmann), ist unbegründet.

VI.

15. Die Dogmatik des Verwaltungsrechts war in ihrem ursprünglichen Ansatz weder formal noch zweckentleert noch begriffsjuristisch. Im Gegenteil: seine Begriffe und Institute sind von Otto Mayer im ständigen Blick auf die Zwecke des Verwaltungshandelns und auf die Aufgaben der Verwaltungsträger entwickelt worden.

16. Die Dogmatik des Verwaltungsrechts hat zwar im weiteren Verlauf den Zeitströmungen Rechnung getragen, sie hat ihre zweckorientierte Grundhaltung aber im wesentlichen durchgehalten.

17. Der Ansicht, das "System" des Verwaltungsrechts orientiere sich fälschlich an den Rechts- und Handlungsformen der Vervaltung statt an ihren Zwecken und Aufgaben, liegt eine ungenügende Unterscheidung der verschiedenen Systembegriffe zugrunde. $Z u$ unterscheiden sind das "objektive" und das "wissenschaftliche" System (System der Gegenstände und System der Erkenntnisse), und innerhalb des wissenschaftlichen das "äußere" und das „innere" System (System der Darstellung und System der immanenten Sinneinheit). 
18. Eine Ausrichtung des äußeren Systems an Zwecken und Aufgaben der Verwaltung ist sinnvoll und nützlich, aber nur in Ergänzung und nicht als Ersatz einer Ausrichtung an den Rechtsformen. Eine zweck- und aufgabenorientierte Darstellung hat nicht nur didaktischen, sondern auch kritischen Wert; sie kann damit das innere System beeinflussen.

19. Für das innere System sind zweck- und aufgabenorientierte Kategorien nicht brauchbar. Solche Einteilungen besitzen wegen der mannigfachen und unauflösbaren Verflechtungen aller Zwecke und aller Aufgaben keine hinreichende Konturenschärfe und deshalb keinen rechtlichen Aussagewert.

20. Daseinsvorsorge, ordnende, leistende, lenkende, austeilende und umverteilende Verwaltung sind heuristische Begriffe, aber keine Rechtsbegriffe. Sie haben neben ihrer heuristischen eine hermeneutische und eine kritische Funktion - darin besteht ihr "juristischer Sinn" - aber keine dogmatische und sysytematische Bedeutung.

21. Das gilt erst recht von dem Begriffspaar "Eingriffs- und Leistungsverwaltung". Auch wenn man von der Inkongruenz der Begriffsbildung absieht, so lassen sich Eingriffs- (= ordnende) und Leistungsverwaltung weder nach Zwecken und Aufgaben noch nach dem Instrumentarium einigermaßen deutlich scheiden. Eine Zerlegung des Verwaltungsrechts „in zwei Teile von je ausgeprägter struktureller Eigentümlichkeit" (Forsthoff) läßt sich anhand jener Unterscheidung nicht vornehmen.

22. Ein „Neubau“ des verwaltungsrechtlichen Systems, verstanden als Auswechslung seiner tragenden begrifflichen und institutionellen Fundamente, ist demnach weder geboten noch auch nut möglich. Die Verwaltung des sozialen Rechtsstaats bleibt, auch in ihren leistenden, lenkenden und verteilenden Aufgabenbereichen, auf die elementaren Grundsätze des Rechtsstaats und damit auch auf dessen Instrumentarium angewiesen. Möglich und zugleich geboten ist aber eine andere Verteilung der Gewichte innerhalb des Systems, seine Befreiung von überholten und seine Erweiterung um neue, den Aufgaben des Sozialstaats angemessene Bestandteile.

VII.

23. Der Verwaltungsakt ist (erst) nach 1945 unter dem Einfluß eines aktionenrechtlich orientierten Rechtsschutzsystems zum "Zentralbegriff" des deutschen Verwaltungsrechts geworden. Diese Einseitigkeit verwaltungsaktfixierten Denkens hat aufgabengerechte Lösungen oft erschwert, wennn nicht unmöglich gemacht. 
24. Insbesondere wurde die Einsicht verdrängt, daß der Verwaltungsakt innerhalb sich entwickelnder Beziehungen nur eine Momentaufnahme darstellt. Viel wichtiger ist das durch ihn - aber auch durch andere Handlungen der Verwaltung oder des einzelnen - begründete, veränderte oder beendete Rechtsverhältnis. Diesem kommt die bisher vom Verwaltungsakt eingenommene Schlüsselstellung zu. Besondere Beachtung verdient dabei das Dauerrechtsverhältnis.

25. Deshalb ist die von der Rechtsprechung seit der VwGO begonnene Aufwertung des Rechtsverhältnisses von der Lehre nachdrücklich zu unterstützen. Nur von diesem Ansatzpunkt aus lassen sich Handlungsformen und Institute in jener Mannigfaltigkeit entwickeln, deren das Verwaltungsrecht bedarf, um allen Aufgaben der Verwaltung gerecht zu werden (verwaltungsrechtlicher Vertrag, schlichtes Verwaltungshandeln, $\mathrm{Zu}$ sage, einseitige Willenserklärung Privater, Garantenstellung, Plangewährleistung u. a. m.).

26. Die Innenbeziehungen der Verwaltung lassen sich nach dem herkömmlichen Verständnis nur dann als Rechtsverhältnis begreifen, wenn die beteiligten Verwaltungsorgane verschiedenen Rechtsträgern angehören. Da es sich bei diesen Beziehungen um echte Rechtsbeziehungen handelt, ist zu überlegen, ob der Begriff des Rechtsverhältnisses, wie er im Zivilrecht entwickelt ist und verstanden wird, für das Verwaltungsrecht nicht zu eng ist.

27. Wichtiger als diese (nur terminologische?) Zuordnungsfrage ist die Aufgabe, den bisher vernachlässigten Innenbeziehungen der Verwaltung, insbesondere dem Behörden- und Organisationsrecht, mehr Aufmerksamkeit zu schenken. Bisher finden diese Beziehungen in der Regel nur dann Beachtung, wenn sie unmittelbare Auswirkungen auf das Staat-BürgerVerhältnis haben, wie z. B. das Zusammenwirken mehrerer Behörden beim Erlaß eines Verwaltungsaktes.

28. So fehlt es $z$. B. an einer genügenden dogmatischen Bewältigung der "Aufsicht" in ihren verschiedenen Bedeutungen und Funktionen. Ebenso fehlt die Einsicht in die Rechtserheblichkeit von Struktur und Zusammensetzung der Verwaltungsorgane: Kollegien, die demokratisch gewählt oder personell auf Ausgleich pluralistischer Kräfte der Gesellschaft angelegt sind oder die einen speziellen Sachverstand repräsentieren, funktionieren anders als bürokratische Behörden; ihre Entscheidungen können nicht in gleicher Weise nachvollzogen und durch Aufsichtsbehörden oder Gerichte ersetzt werden wie die Entscheidungen jener. 
VIII.

29. Die dogmatische Durchdringung des besonderen Verwaltungsrechts hat darunter gelitten, daß sich die Wissenschaft in der Wahl ihrer Arbeitsgebiete zu stark von den Schwerpunkten der Rechtsprechung und des akademischen Unterrichts abhängig gemacht hat. Dadurch sind die in besonderem Maße sozialstaatsbezogenen Rechtsgebiete, insbesondere das Wirtschafts-, das Kultur- und das Sozialverwaltungsrecht, erst spät von der Dogmatik entdeckt worden. Nur durch eine verstärkte Bemühung um diese Bereiche kann es gelingen, die ihnen spezifischen Begriffe und Institute zu erarbeiten und sie in das Systemganze einzufügen.

IX.

30. Das (Verwaltungs-)Recht der europäischen Gemeinschaften verdient stärkere Beachtung. In ihm fließen Rechtsgedanken der verschiedenen nationalen Rechtsordnungen zusammen, wie es umgekehrt in diese Ordnungen ausstrahlt. Einheitliches Recht erfordert auch eine einheitliche Dogmatik.

$X$.

31. Die Dogmatik des Verwaltungsrechts ist unter dem Grundgesetz im Blick auf die Leitidee des sozialen Rechtsstaats kontinuierlich fortentwickelt worden. Das geschah vornehmlich im Bemühen um die Lösung konkreter Sachprobleme. Die Wissenschaft muß diesen Weg selbstkritisch, beharrlich und geduldig weitergehen; nur er verspricht Erfolg. Fritz Fleiners Forderung von einst gilt heute unverändert: "das Neue organisch mit den bewährten Grundsätzen des Deutschen Verwaltungsrechts zu verbinden". 


\section{Die Dogmatik des Verwaltungsrechts vor den Gegenwartsaufgaben der Verwaltung}

2. Mitbericht von Professor Dr. Winfried Brohm, Bielefeld*)

\section{Inhalt}

Inhalt
I. Rechtsdogmatik und sozialer Wandel . . . . . . . . . .
1. Die Funktion der Rechtsdogmatik . . . . . . . . .
2. Norm- und Wirklichkeitsbezug der Rechtsdogmatik.
3. Rechtsdogmatik und Rechtspolitik. Grenzen der Fort-
entwicklung der Rechtsdogmatik . . . . . . . . .

Seite

246

246

249

251

II. Vom punktuellen Vollzug zum gestaltenden Verwaltungshandeln. Die Lage der verwaltungsrechtlichen Dogmatik heute . . . . . . . . . . . . . . . . . . . . . .

1. Die Eigentümlichkeiten der überkommenen verwaltungsrechtlichen Dogmatik

2. Die historische Bedingtheit der herkömmlichen Dogmatik

3. Anpassung und Anpassungsfähigkeit der Dogmatik an die "Leistungsverwaltung" . . . . . . . . . . 257

4. Die neue Situation . . . . . . . . . . . . . . 258

III. Das Handein der Verwaltung und seine Wirkung im "gesellschaftlichen" Bereich

1. Hoheitskompetenz und öffentliches Recht . . . . . . 263

2. Vorbehalt des Gesetzes und „demokratische Rückkoppelung" . . . . . . . . . . . . . . . . . 266

3. "Eingriff" und "Rechtsbeeinträchtigung“. Ausweitung des subjektiven öffentlichen Rechts .. . . 271

4. Gestaltungsfunktion und Handlungsmaßstäbe . . . . 274

5. Beteiligung der Betroffenen am Verwaltungsverfahren 279

6. Verwaltungsakt und Rechtsnorm. Der Verwaltungsakt als „Entscheidung“ . . . . . . . 281

IV. Die Entscheidungsbildung innerhalb der Verwaltung als Prozeß . . . . . . . . . . . . . . . . . . . 289

1. Die dogmatische Erfassung der Entscheidungsstufen . 289

2. Das Problem der Beleihung bei der Entscheidungsbildung

") Die in eckige Klammern gesetzten Ausführungen wurden aus Zeltgruinden nicht vorgetragen. Angesichts der Welte des Themas mußte auf einen auch nur annähernd nach Vollständigkeit strebenden Zitierapparat verzichtet werden. 
V. Zielbestimmung und Koordination in einer pluralistischen

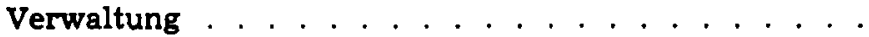

1. Das hierarchische Modell und seine Schwächen. Aufsicht und "politischer Kontrollbegriff“ . . . . . . 293

2. Formen der Kooperation und der Selbststeuerung . . 295

3. Die Systemfunktion des Rechts und der Gerichtsbarkeit 298

- Die systemtheoretische Bedeutung der Ausdehnung des subjektiven öffentlichen Rechts . . . . . . .

- Klagemöglichkeiten von Verbänden und Kompetenzinhabern ............ . 300

4. Möglichkeiten der Rückkoppelung . . . . . . . . . . 302

v1. Schlußbemerkung . . . . . . . . . . . . . . . . . 304

I.

1. Uberprüft man die verwaltungsrechtliche Dogmatik auf ihre Bewährung vor den Gegenwartsaufgaben der Verwaltung, so muß man sich zunächst Klarheit darüber verschaffen, welche Funktion der Dogmatik zukommt und in welchem Maße sie angesichts der Veränderungen in der sozialen Umwelt fortentwickelt werden kann'). Das soll hier nur kurz zur Kennzeichnung der eigenen methodischen Position geschehen.

Von einem strukturell-funktionalen Ansatz ${ }^{2}$ ) her kann man die Rechtsdogmatik als ein innersystematisch erarbeitetes Gefüge juristischer Begriffe, Institutionen, Grundsätze und Regeln verstehen, die als Bestandteil der positiven Rechtsordnung unabhängig von einer gesetzlichen Fixierung allgemein Anerkennung und Befolgung beanspruchen"). [Die Rechtsdogmatik

1) Diese Fragen wurden erstaunlicherweise bislang gerade in den dogmatischen Fächern wenig reflektiert. Das beklagt allgemein für die Rechtswissenschaft auch Franz Wieacker, Zur praktischen Lelstung der Rechtsdogmatik, in: Hermeneutik und Dialektik, Festschrift für H. G. Gadamer, Bd. II, Tübingen 1970, S. 311 ff. (313 f.).

2) Inwieweit die herkömmliche strukturell-funktionale Theorie in eine funktional-strukturelle Theorie umgearbeitet werden muB, um die Vorordnung des Strukturbegriffes vor den Funktionsbegriff zu vermeiden und so Strukturen schlechthin problematisieren und die Sinnfrage stellen zu können, kann hier dahingestellt bleiben. Im übrigen vermag auch eine fortentwickelte strukturell-funktionale Theorie diese Leistungen zu erbringen. Zur Streitfrage vgl. Niklas Luhmann, Soziologische Aufklärung, Soziale Welt 18 (1967), S. 97 ff., jetzt in: Soziologische Aufklärung, Aufsätze zur Theorie sozialer Systeme, 2. Aufl., Opladen 1971, S. 66 If. (78); ders., Soziologle als Theorie sozialer Systeme, ebd., S. 113 t.; ders., Legitimation durch Verfahren, Neuwied 1969, S. 41 f.; Walter Schmidt, Aufklärung durch Sozlologie, neue politische literatur 1971, S. 340 ff. (347).

) Diese Umschreibung hält sich an Formulierungen von Theodor Geiger, Vorstudien elner Soziologle des Rechts, Kopenhagen 1947, S. 9 ff. und Theodor Viehweg, Zwel Rechtsdogmatiken, in: Ulrich 
impliziert also mit ihren Formen und Typiken Wertungen, die als "ratio iuris" die "ratio legis" der einzelnen gesetzlichen Regelung übergreifen.]

Der Vorteil dogmatischer Festlegungen liegt darin, daß die grundsätzlichen Sach- und Wertungsfragen nicht bei jeder Rechtskonkretisierung erneut aufgeworfen und durchdiskutiert werden müssen'). (Dazu wäre der einzelne in der Praxis des täglichen Rechtslebens auch gar nicht imstande. Denn die menschliche Fähigkeit, eine größere Zahl von Beurteilungsgesichtspunkten als Variable zugleich zu berücksichtigen und miteinander abzuwägen, ist äußerst gering). Insofern ist der Weg über die Dogmatik schlechthin unvermeidlich").]

Allerdings darf diese „Entlastungsfunktion ${ }^{47}$ ) nicht als "Reflexionsverbot" aufgefaßt werden. Die Dogmatik vermag mit

Klug (Hrg.), Philosophie und Recht, Festschrift für C. A. Emge, Wiesbaden 1960, S. 106 ff. (106 f.). - Der Begriff und Insbesondere auch seine Abgrenzung zur Rechtstheorie und Methodologie ist in der Literatur nicht eindeutig. Vgl. etwa $F$. Wieacker, Rechtsdogmatik, S. 319 m. zahlr. w. N. in Anm. 22 ebd.; ergänzend Josef Esser, Vorverständnis und Methodenwahl in der Rechtsfindung, Frankfurt/M. 1970, S. $87 \mathrm{ff}$.; Th. Viehweg, Zwei Rechtsdogmatiken, S. $106 \mathrm{f}$. - Hier wird mit Dogmatik sowohl das Erarbeiten allgemeiner Rechtsbegriffe, allgemeiner Rechtsgrundsätze und einzelner Rechtsregeln verstanden wie auch das Ergebnis dieser Arbeit, nämlich diese Begriffe und Prinzipien selbst. Im selben Sinne zählt auch Hans $J$. Wolff, Rechtsgrundsätze und verfassungsgestaltende Grundentscheidungen als Rechtsquellen, in: Gedächtnisschrift für Walter Jellinek, München 1955, S. 33 ff. (40), die allgemeinen Rechtsgrundsätze hierher, jedenfalls soweit sie "besondere Rechtsgrundsätze" sind, die aus der positiven Rechtsordnung entwickelt werden. Im Hinblick auf die Leistung der Dogmatik als "Denkschema" kann man diese als eine heuristische Methode der Entscheidungsfindung bezeichnen (J. Esser, Vorverständnis, S. 92. Zu dieser Streitfrage vgl. auch $F$. Wieacker, Rechtsdogmatik, S. 333). Gegenüber der Rechtsdogmatik erscheint die Rechtstheorie als kritische Metatheorie.

1) J. Esser, Vorverständnis, S. 88 f.; entsprechend zum Systemdenken: Claus-Wilhelm Canaris, Systemdenken und Systembegriff in der Jurisprudenz, entwickelt am Beispiel des deutschen Privatrechts, Berlin 1969, S. 83.

3) Darauf weist in einem anderen Zusammenhang in Vermittlung amerikanischer Untersuchungen zutreffend Niklas Luhmann, Theorle der Verwaltungswissenschaft, Köln 1966, S. 47 und passim, hin.

ๆ) Vgl. J. Esser, Vorverständnis, S. 91; Erich Rothacker, Die dogmatische Denkform in den Geisteswissenschaften und das Problem des Historismus, Akademie der Wissenschaften und der Literatur, Abhandlungen der geistes- und sozialwissenschaftlichen Klasse, 1954 (Heft 6), S. 243 fl. (264).

7 Die von Arnold Gehlen vertretene These von der "Entlastungsfunktion der Institutionen" läßt sich aus ihrem philosophisch-an- 
ihren Typisierungen und Generalisierungen nicht alle Sachverhalte zu erfassen. Sie hat "Regelcharakter", so daß in singulären Fällen auf die dahinterstehenden Prinzipien und Wertungen selbst zurückgegriffen werden muß $B^{8}$ ).

Bleibt man sich dieser Tatsache bewußt, dann kann die Fechtsdogmatik nicht in formale Begriffskonstruktionen abgleiten; sie vermag vielmehr unkontrollierbare subjektive Wertungen zurückzudrängen und hat damit eine rationalisierende Funktion. [Sie dient der Rechtssicherheit und der generalisierenden Tendenz des Gerechtigkeitsgebotes ${ }^{\circ}$ ). Soll in einem konkreten Fall von den Fixierungen der Dogmatik abgewichen werden, so bedarf dies der besonderen Rechtfertigung und $\mathrm{Be}-$ gründung.]

Diese rationalisierende Funktion darf nicht nur punktuell, im Hinblick auf die Einzelentscheidung gesehen werden. Denn mit der Zuordnung gesetzlicher Vorschriften und mit der Herausarbeitung übergreifender Rechtsgrundsätze legt die Dogmatik „innere Zusammenhänge“ dar ${ }^{10}$ ) und ermöglicht damit eine auf die Einheit der Rechtsordnung hin argumentierende Rechtskonkretisierung ${ }^{11}$ ), ohne damit $\mathrm{zu}$ einem geschlossenen und umfassenden System führen zu müssen ${ }^{12}$ ). [Ein so verstandenes systematisierendes Denken, das die teleologisch erfaßbaren $\mathrm{Zu}$ sammenhänge herausarbeitet, ist heute um so mehr geboten, als die Einheit der Rechtsordnung durch Maßnahmegesetze und punktuelle Wertungen des Gesetzgebers in zunehmendem

thropologischen Kontext lösen; sie gilt auch hier. Dazu Im einzelnen Martin Kriele, Theorie der Rechtsgewinnung, entwickelt am Problem der Verfassungsinterpretation, Berlin 1967, S. $262 \mathrm{~m}$. Anm. 42.

8) Dazu im einzelnen Winfried Brohm, Strukturen der Wirtschaftsverwaltung, Stuttgart 1969, S. 36 f.; vgl. auch C.-W. Canaris, Systemdenken, S. 50. Im Unterschied zum Zivilrecht ist im öffentlichen Recht dieser Zusammenhang der Dogmatik mit den sozialen Interessen- und Wertungskonflikten in starkem MaBe erhalten geblieben. Dazu F. Wieacker, Rechtsdogmatik, S. 316.

) C.-W. Canaris, Systemdenken, S. 84.

10) Dazu auch C.-W. Canaris, Systemdenken, S. 37 f., 86 if.

11) Insofern tendiert die Dogmatik unausweichlich zum "System"; man darf dieses nur nicht in einem formal-logischen Sinne verstehen, sondern muß es als "innere Zuordnung" begreifen, die teleologisch erfaßbar ist. Vgl. C. $W$. Canaris, Systemdenken, S. 40 II., 86 ff. und passim; J. Esser, Vorverständnis, S. 81, 96; F. Wieacker, Rechtsdogmatik, S. 319.

12) Ein teleologisch erfaßbares "exiologisches" System kann kle1nere Ableitungszusammenhänge oder umfassendere Relationen darstellen. In jedem Falle ist es modifizierbar und entwicklungsfähig, also "offen". Zum Begriff des "offenen Systems" in diesem Sinne und mit anderen Bedeutungsinhalten vgl. C.-W. Canaris, Systemdenken, S. $61 \mathrm{ff}$. 
Maße gefährdet ist. Die Dogmatik gibt die Möglichkeit, in den Grenzen der Interpretation ${ }^{19}$ ) immer wieder auf dieses Ziel hinzuarbeiten ${ }^{14}$ ).]

Durch allgemeine Rechtsbegriffe und Rechtsgrundsätze verschafft die Rechtsdogmatik dem Rechtsanwender dabei eine größere Freiheit gegenüber dem Wortlaut des einzelnen Gesetzes. Auf diese Weise wird das System flexibler und vermag leichter neu auftretende Interessen- und Wertungskonflikte zu erfassen ${ }^{15}$ ).

Voraussetzung dafür ist, daß die Dogmatik selbst hinreichend flexibel bleibt, neu auftretende Konfliktslagen registriert und sich entsprechend der zunehmenden Umweltkomplexität weiter differenziert. Diese Rückkoppelung und Verbesserung ist deshalb möglich, weil sich die Dogmatik in der praktischen Rechtskonkretisierung laufend zu bewähren hat. So lassen sich notwendige Abweichungen von den hergebrachten Fixierungen registrieren und $u$. $U$. als neue Formen und Grundsätze generalisieren ${ }^{10}$.

2. [Die Forderung, die Dogmatik des Verwaltungsrechts flexibel zu halten und im Hinblick auf Veränderungen in der sozialen Umwelt und neue Aufgaben der Verwaltung fortzuentwickeln, versteht sich nicht von selbst. Schließlich ist die Rechtsdogmatik als Bestandteil der positiven Rechtsordnung am geltenden Recht orientiert; sie ist "Normwissenschaft". Faktische Gegebenheiten und Veränderungen scheinen daher aus

19) Dazu unten Nr. 3 dieses Abschnitts. - Inwieweit Systembrüche unter dem Gesichtspunkt des Willkürverbotes als verfassungswidrig anzusehen sind, kann hier nicht erörtert werden.

14) Anders J. Esser, Vorverständnis, S. 82 f. m. Anm. 37, der von seinem "vernunftrechtlichen" Verständnis her gerade hier keine Möglichkeiten für die Dogmatik sieht. Angesichts der Notwendigkeit, die ökonomischen und gesellschaftlichen Abläufe zu regulferen und soziale Konflikte laufend auszugleichen, bestimmen „MaBnahmegesetze“ immer mehr das Bild des öffentlichen Rechts. Aus diesem Blickfeld heraus ergibt sich, daß man mit den Klagen uber diese Entwicklung nur einer unwiderruflichen Vergangenheit nachtrauert. Die Dogmatik muß gerade hier ihre Bewährungsprobe bestehen. (Zu einer positiveren Sicht der Maßnahmegesetze vgl. auch Friedrich Kübler, Juristenausbildung im Zielkonflikt, Konstanzer Universitätsreden, Konstanz 1971, S. 14).

15) Vgl. auch F. Wieacker, Rechtsdogmatik, S. 318.

10) Dieses Rückkoppelungsverfahren, das eine autonome Verbesserung und Verfeinerung der Selektionsleistung ermöglicht, übersleht Niklas Luhmann, Zweckbegriff und Systemrationalität, TUbingen 1968, S. 229, Anm. 90, wenn er das "feed back" nur als Kontrollmechanismus für "Zweck-", nicht aber für "Konditionalprogramme" gelten lassen will. 
ihrem Arbeitsfeld auszuscheiden; sie sind Gegenstand der Wirklichkeitswissenschaften; ergeben sich hier bestimmte Normen, dann besitzen diese allenfalls gesellschaftliche Geltung, nicht aber rechtliche Verbindlichkeit ${ }^{17}$ ). Dazu bedarf es nach dem Grundgesetz der Legitimation durch die zur Rechtsetzung berufenen Instanzen. Diese können die sich aus den Fakten ergebenden Normen akzeptieren, sie können aber auch versuchen, sie zu modifizieren oder zu bekämpfen. Darin liegt die Leitfunktion des Rechts.

Dennoch sind die faktischen Gegebenheiten und ihre Entwicklung für die Rechtsdogmatik nicht ohne Belang.] Die neuere Methodendiskussion hat klargestellt, daß eine gesetzliche Vorschrift im allgemeinen nicht schon aus ihrem Normtext heraus verstanden und auf den Einzelfall angewandt werden kann. Sie erfährt vielmehr ihren Sinngehalt erst aus dem jeweiligen Sachverhalt, der seinerseits in seinen relevanten Daten wiederum von der Norm bestimmt wird ${ }^{18}$ ). [Das zeigt sich bei der Vorbewertung des Sachverhalts wie der anzuwendenden Norm. Der gesetzesanwendende Jurist muß erst aus der Vielzahl der Vorschriften diejenige Norm auswählen, die ihrem Sinne nach auf den zur Entscheidung stehenden Fall zutrifft; dabei entscheidet er auch gleichzeitig darüber, welche Einzelheiten des Sachverhaltes für die Entscheidung erheblich sind und welche als irrelevant erscheinen ${ }^{10}$ ). Oft hat er dabei die anzuwendende Norm erst aus der Vielzahl der gesetzlichen Regelungen für den konkreten Fall zu bilden. Sucht er die gesetzlichen Vorschriften teleologisch zu interpretieren und die Intention des Gesetzes optimal zu verwirklichen, so muß er wissen, bei welcher Aus-

17) Vgl. dazu im einzelner, Hans Ryffel, Rechts- und Staatsphilosophie, Neuwied 1969, S. 46, 73 ff. und passim.

18) Dazu im einzelnen mit unterschiedlicher Akzentuierung: Josef Esser, Grundsatz und Norm in der richterlichen Fortbildung des Privatrechts, Tübingen 1956; ders., Vorverständnis; $M$. Kriele, Theorie der Rechtsgewinnung; Friedrich Müller, Normstruktur und Normativität, Berlin 1966; F. Wieacker, Rechtsdogmatik; H. Ruffel, Rechts- und Staatsphilosophie, S. $53 \mathrm{ff}$. Vgl. hierzu aus der umfangrelchen und kontroversen Methodendiskussion weiter auch: Peter Lerche, Stil, Methode, Ansicht. Polemische Bemerkungen zum Methodenproblem, DVBl. 1961, S. 690 ff.; Ernst Forsthoff, Die Umbildung des Verfassungsgesetzes, jetzt in: Rechtsstaat im Wandel, Stuttgart 1964, S. 147 ff.; Alexander Hollerbach, Auflösung der rechtsstaatlichen Verfassung?, AöR 85 (1960), S. 241 ff.; Roman Schnur, Die normative F.raft der Verfassung, DVBl. 1960, S. $123 \mathrm{ff}$.

19) M. a. W.: Die Norm ist eine "wirklichkeitsgeprägte und Wirklichkeit prägende“ Regelung. Vgl. F. Müller, Normstruktur, S. 28, 131 und passim. 
legung er in der sozialen Wirklichkeit die Wirkung erzielt, die das Gesetz bezweckt ${ }^{20}$ ).]

Dieser Zusammenhang von Normprogramm und Sachstruktur gilt auch für die Rechtsdogmatik; denn sie steht mit ihren Typisierungen als "genereller Konkretisierung" gleichsam zwischen Gesetz und Konkretisierung im Einzelfall ${ }^{21}$ ), [bildet also eine Vorstufe der Gesetzesanwendung in der Einzelentscheidung. Soll das Recht in den jeweils neuen Konfliktsituationen seinem Sinne nach zur Wirksamkeit gebracht werden, dann ist die Dogmatik dem Wandel der sozialen Verhältnisse entsprechend $\mathrm{zu}$ ändern $\left.{ }^{2 \mathrm{r}}\right)$.]

Dabei hat die Dogmatik Veränderungen in der sozialen Umwelt nicht immer erst im nachhinein zu berücksichtigen. Das Recht hat nicht nur Bezug zur Vergangenheit und Gegenwart, sondern ist immer zugleich auch ein Ordnungsentwurf in die Zukunft hinein. Seine Leitfunktion kann es in einer sich beschleunigt verändernden Welt nur verwirklichen, wenn die Dogmatik auch versucht, die in der Entwicklung angelegten Umweltveränderungen vorwegzunehmen. Insofern ist die Dogmatik auch "Zukunftswissenschaft". [Hier ist sie in besonderem Maße auf die sozialwissenschaftliche Forschung angewiesen.]

3. Soll die Normativität des Rechts nicht der Faktizität der Entwicklung weichen, dann muß die Fortentwicklung der Dogmatik Grenzen haben. Sie ergeben sich unter dem Grundgesetz aus dem Wortlaut der Verfassung und des demokratisch legitimierten Gesetzes. Denn in einer pluralistischen Gesellschaft, wie sie das Grundgesetz voraussetzt und konstituiert, kann sich die Verbindlichkeit dogmatischer Fixierungen nicht etwa auf eine teleologische Geschichtsphilosophie stützen ${ }^{20}$ ), sondern

20) Dazu jetzt auch Manfred Rehbinder, Einführung in die Rechtssoziologie, Frankfurt/M. 1971, S. 9 ff.

2) Vgl. auch die ähnliche Auffassung über die Rechtsdogmatik bei $H$. Ryffel, Rechts- und Staatsphilosophie, S. 47.

27) Die Dogmatik des Verwaltungsrechts hat diesem Zusammenhang von Norm und Wirklichkeit auch immer wieder Rechnung getragen, etwa mit dem Bedeutungswandel des Verwaltungsaktsbegriffes, dem Gedanken der Daseinsvorsorge und der Konstruktion des Verwaltungsprivatrechts oder der Zweistufentheorle. Vtelleicht geschah dies in einer methodisch weniger reflektierten Weise. Jedenfalls läßt sich der Einwand, die Rechtswissenschaft beziehe inre Institute nicht auf die Probleme der Umwelt, in dieser Absolutheit gerade für das öffentliche Recht nicht aufrechterhalten. Dazu F. Wieacker, Rechtsdogmatik, S. 316; vgl. dagegen N. Luhmann, Theorie der Verwaltungswissenschaft, S. 59 1.

25) Das im Unterschied zu Staaten, deren Rechtsordnung etwa auf den marxistischen Sozialismus gegründet ist. Hier ermöglicht der dem Christentum seit Augustinus vertraute Gedanke einer sinn- 
allein auf die von dem demokratischen Gesetzgeber getroffenen Wertungen. Daher ist die Dogmatik in der BRD auch in ihrer Ausrichtung auf die Zukunft notwendigerweise systemstabilisierend ${ }^{24}$ ). Konfliktlösungen, die sich nicht mehr aus der positivierten Rechtsordnung entnehmen lassen, scheiden damit nicht aus der rechtswissenschaftlichen Reflexion aus; sie besitzen aber keine Rechtsverbindlichkeit und sind daher als reine „Rechtspolitik" zu kennzeichnen ${ }^{25}$ ). [Sie gehören in den Bereich

haften, geschichtlichen Entwicklung in der Form der „sozialist1schen Gesetzlichkeit" eine größere Flexibilität der Dogmatik. Deren Auseinanderfallen in subjektive Meinungen kann dadurch gesteuert werden, daß eine Einheitspartei das jeweilige Stadium des geschichtlichen Entwickiungsprozesses präzisiert. Dazu Th. Viehweg, Zwei Rechtsdogmatiken, S. 108 ff.

24) Dieser verfassungsrechtliche Bezug wird bei der programmatischen Forderung nach einer „Rechtswissenschaft als Zukunftswissenschaft", wie sie vor allem Werner Maihofer, Realistische Jurisprudenz, in: G. Jahr und W. Maihofer, Rechtstheorie, Beiträge zur Grundlagendiskussion, Frankfurt 1971, S. $427 \mathrm{ff}$. (430 ff.), wegweisend erhoben hat, leicht übersehen. Die dadurch bedingte $\mathbf{A b}-$ grenzung zwischen der Rechtsdogmatik im dargelegten Sinne und einer rechtlich unverbindlichen Rechtspolitik im Sinne einer Gesetzgebungswissenschaft wird hier nicht immer deutlich. So verweist Maihofer, S. 432, den in "Legislative, Exekutive und Justiz" bei der Gestaltung und „Handhabung des Rechts" tätigen Juristen auf seine Funktion als "Produzent von Recht und Kritiker der Gesellschaft" kraft seiner Vorbildung durch Wissenschaft zu rationaler Argumentation aus intersubjektivem Konsens. Andererseits grenzt er (S. 433) die Rechtsdogmatik von der "Rechtspolitik, insbesondere der Gesellschaftsgestaltung durch "Gesetzgebung" ab. Wenn er weiter (S. 460 ff.) den Maßstab für die Rechtsfortbildung der "Unumkehrbarkeit der Entwicklung" entnimmt, so folgt er letztlich einer teleologischen Geschichtsphilosophie, deren Verbindlichkeit, wie erwähnt, in der vom Grundgesetz pluralistisch verfaßten Gesellschaft der BRD kaum zu begründen ist. Sie ist zumindest in dieser Fassung auch zweifelhaft, wie das Beispiel der in den verschiedenen Verfassungsepochen (etwa Absolutismus, Wirtschaftsliberalismus des 19. Jahrhunderts, Jetztzeit) außerordentlich divergierenden Sozialbindung des Grundeigentums zeigt. Das schließt nicht aus, daß rechtspolitische Erwägungen auch auf diese Weise für die Gesetzgebung rational aufbereitet werden. Zur Abgrenzung von Rechtspolitik und Rechtsdogmatik vgl. auch die folgende Anm.

25) Der Begriff der „Rechtspolitik“ ist wie der der „Rechtsdogmatik" in der Rechtswissenschaft noch keineswegs präzisiert. Er wird daher oft in unterschiedlichem Sinne gebraucht und je nachdem, ob man die eigenständige Wertung des gesetzesanwendenden Juristen oder seine "Gesetzestreue" betont, auch auf die Rechtskonkretisierung angewandt oder den Gesetzgebungswissenschaften vorbehalten. Zweifellos muß gerade eine teleologische Gesetzesinterpretation, die nach dem "objektivierten Willen des Gesetzgebers" (Vgl. etwa BVerfG v. 21. 5. 1952, BVerfGE 1, 299 (312); v. 17. 5. 1960, BVerfGE 11, 126 (129 f.)) fragt, also den Sinn und Zweck eines Ge- 
der "Gesetzgebungswissenschaft", ein bislang vernachlässigtes Gebiet der Rechtswissenschaft ${ }^{20}$ ), das aber von der Rechtsdogmatik zu scheiden ist.]

Aus dieser Position ergibt sich die Notwendigkeit, die überkommene verwaltungsrechtliche Dogmatik in ihrer geistesgeschichtlichen und sozialen Bedingtheit herauszuarbeiten und aus der Konfrontation mit den Veränderungen in der Gegenwart die notwendigen Konsequenzen für ihre Fortentwicklung zu ziehen.

II.

1. Die herkömmliche Verwaltungsrechtslehre ist durch folgende Eigentümlichkeiten gekennzeichnet:

Im Mittelpunkt steht der an der Eingriffshandlung entwikkelte Begriff des Verwaltungsaktes als Äußerungsform der öffentlichen Gewalt ${ }^{27}$ ). Schwerpunkte bilden die Fragen der Ge-

setzes vom Standpunkt der Gegenwart aus ermitteln und verwirklichen will, soziologisch vorgehen. Sie muß einerseits diejenigen Interessen und Einflüsse feststellen, die zur Normblldung gefuhrt haben, um den Sinn der Norm in seiner Bewertung dieser Interessen zu erkennen; sie muß andererseits die tatsächliche Wirkung der Norm auf das Sozialleben erforschen, um diejenige Auslegung wählen zu können, die in ihrer Auswirkung die mit der Norm verfolgten Ziele trifft. Erkennt man den „politischen“ Charakter der Gesetzgebung, weil sie wirtschaftliche, soziale oder kulturelle Probleme zu regeln versucht (vgl. Hermann Heller, Staatslehre, 4. Aufl., Leiden 1970, S. 242), und definiert man Rechtspolitik als die Frage und Entscheidung, "welche sozialen Ziele mit welchen rechtlichen Mitteln und auf welchem rechtlichen Wege erreicht werden sollen" (Ernst E. Hirsch, Recht im sozialen Ordnungsgefüge, Berlin 1966, S. 45), so kann man eine solche Rechtskonkretisierung eine "rechtspolitische" nennen. Da sie jedoch am Gesetz orientiert ist und thre Grenze im Wortlaut des Gesetzes findet, nämlich dort, wo die Interpretation in eindeutigem Widerspruch zu den möglichen Textgehalten steht, der Wortlaut also nicht so verstanden werden kann (F. Müller, Normstruktur, S. 160), ist hierfür der Ausdruck „soziologische Interpretation" vorzuziehen. Der Begriff der Rechtspolitik bleibt dann in Abgrenzung zur Rechtsdogmatik den Gesetzgebungswissenschaften vorbehalten. (Vgl. auch den entsprechenden Wortgebrauch bei $M$. Rehbinder, Einführung in die Rechtssoziologie, S. 9 f.).

20) Dazu W. Maihofer, Realistische Jurisprudenz, bes. S. $462 \mathrm{ff}$.

27) Es geht hier um eine bewußt pointlert formulierte Analyse der Strukturen der herkömmlichen verwaltungsrechtlichen Dogmatik. Diese haben sich im Laufe der Entwicklung mehr und mehr in dieser Eigenheit herausgebildet, sind darin aber berelts bei Otto Mayer angelegt. Dieser übernahm zwar mit dem Begriff des „öffentlichen Unternehmens", insbesondere in der Form der "Anstalt" als dauernder "Veranstaltung “ aus dem französischen Recht den Gedanken des service public, verengte inn aber auf einen Teil der Verwaltungstätigkeit, indem er die Polizei sowie den Fiskus davon ausnahm, und hob im übrigen neben der Idee des „Dlenstes“ den Ge- 
setzmäßigkeit und des Individualrechtsschutzes. Das Bild der Verwaltung wird dadurch von ihrer "vollziehenden Funktion" her bestimmt, die als „Gesetzesanwendung“ allzu leicht mit logischer Subsumtion und starrer Gebundenheit identifiziert wird. Die Dogmatik ist so vor allem an der einen richtigen Entscheidung ausgerichtet. Die "Gestaltungsfunktion" der Verwaltung, verfahrens- und organisationsrechtliche Fragen treten dahinter weit zurück ${ }^{28}$ ).

danken der Machtäußerung des Staates, etwa in der Anstaltsgewalt und der Anstaltssatzung, hervor. Der Grund dafür ist vermutlich weniger in dem Einfluß der Gerber-Laband-Schule zu sehen als in dem Umstand, daB der Arrêt Blanco zwar bereits 13 Jahre vor dem Erscheinen sogar von Otto Mayers Theorie des französischen Verwaltungsrechts, Straßburg 1886, ergangen war, der Gedanke des service public aber erst später seinen Siegeszug im französischen Recht angetreten hat, so daß Otto Mayer nicht auf eine fundierte Lehre des service public zurückgreifen konnte. Auch in Otto Mayer, Deutsches Verwaltungsrecht, 1. und 2. Band, 2. Aufl., München 1914 und 1917, 3. Aufl. 1924, Nachdruck Berlin 1969, zählt der Verwaltungsakt im allgemeinen Teil $z u$ den „Grundzügen der Verwaltungsrechtsordnung“ (vgl. 1. Band, 2. Aufl., S. 95 ff.; 3. Aufl., S. 92) und bildet auch im besonderen Teil als "Polizeibefehl" (1. Band, 2. Aufl., S. 235; 3. Aufl., S. 226), als "Finanzbefehl" (1. Band, 2. Aufl., S. $363 ; 3$. Aufl., S. 348) und selbst im Bereich der öffentlichen Unternehmen die zentrale Handlungsform der Verwaltung. Enteignungen und Nutzungsverleihungen erfolgen durch Verwaltungsakt; öffentliche Dienstpflichten werden durch ihn begründet und öffentliche Lasten durch ihn auferlegt (vgl. 2. Band, 2. Aufl., S. 6, 180, 256, 393; 3. Aufl., S. 4, 95, 144, 233). Die zentrale Stellung des Verwaltungsaktes wurde in den Werken von $F$. Fleiner und $W$. Jellinek erweitert und gefestigt, indem etwa auch Gebrauchserlaubnisse, Zulassungen zur öffentlichen Anstalt und Widmungen als Verwaltungsakte angesehen wurden (vgl. Fritz Fleiner, Institutionen des Deutschen Verwaltungsrechts, 8. Aufl., Tübingen 1928, 2. Neudruck, Aalen 1963, S. 186, 336, 379, 409; Walter Jellinek, Verwaltungsrecht, 3. Aufl., Berlin 1931, S. 239). Dazu wie auch zum Begriff der öffentlichen Gewalt und zur weiteren Entwicklung der Dogmatik in dieser Frage vgl. im einzelnen W. Brohm, Strukturen der Wirtschaftsverwaltung, S. $168 \mathrm{ff}$., bes. $S$. $171 \mathrm{f}$. und $S .179 \mathrm{ff}$. (183 f.) m. 2ahlr. N. Zur Ablehnung des öffentlich-rechtlichen Vertrages durch $O$. Mayer zugunsten des Verwaltungsaktes als umfassende Handlungsform der Eingriffsverwaltung wie der hoheitlich geübten Leistungsverwaltung und zu den Hintergründen hlerfür vgl. Martin Bullinger, Vertrag und Verwaltungsakt, Stuttgart 1962, bes. S. 241 ff. m. w. N.

$\left.{ }^{28}\right)$ Bezeichnend hierfür ist die vielfach übliche Charakterisierung der Verwaltung als "Vollziehung" (vgl. etwa F. Fleiner, Institutionen, S. 4, 133 und passim). Die daneben erwähnte Regierungsfunktion der Verwaltung wird in den Erörterungen fast völlig von der Vollzugsfunktion verdrängt. Diese beherrscht durchweg die Bemühungen in der verwaltungsrechtlichen Dogmatik, gleichgültig, ob das Gesetzmäßigkeitsprinzip als Grundlage oder als Begrenzung der Verwaltungstätigkeit verstanden wird. Bereits Albert Haenel, 
In dieser Ausrichtung hat das Verwaltungsrecht einen eigenartigen individualistischen und punktuellen Charakter. Auf der einen Seite steht der Staat bzw. die Verwaltung als eine geschlossene, dem Individuum vergleichbare Rechtsperson, auf der anderen Seite findet sich der einzelne, ebenfalls isoliert als Individuum mit seinen gegen den Staat gerichteten Freiheitsrechten. In gleicher Weise wird die Verwaltungstätigkeit punktuell gesehen, wie es für den fallweisen Vollzug von Normen bei relativ unkomplizierten Sachverhalten auch typisch ist ${ }^{20}$ ).

So ist die Dogmatik in ihrer Grundausrichtung statisch. Sie erfaßt mit dem Begriff des Verwaltungsaktes nur den End-

Studien zum deutschen Staatsrechte, Bd. II: Das Gesetz im formellen und materiellen Sinne, Leipzig 1888, S. 186, hat die Bezeichnung „Vollziehung" kritisiert, die man jeder gewissenhaften Analyse zuwider mißbraucht habe, um die reiche und vielgestaltige Tätigkeit des Staates, die der Gesetzgebung gegenüberstehe, mit logischer Subsumtion und starrer Gebundenheit zu identifizieren. Dazu auch Erich Kaufmann, Art.: Verwaltung und Verwaltungsrecht, in: Stengel-Fleischmann, Wörterbuch des deutschen Staatsund Verwaltungsrechts, Bd. III, Tübingen 1914, S. 688 ff., jetzt in: Gesammelte Schriften, Bd. I, Göttingen 1960, S. 75 ff. (76); Thomas Ellwein, Formierte Verwaltung - autoritäre Herrschaft in einer parlamentarischen Demokratie, in: Kritik, Bd. 3, Parlamentarismus ohne Transparenz, Opladen 1971, S. 48 ff. (50); Ellwein-GörlitzSchröder, Parlament und Verwaltung, Teil 1, Gesetzgebung und politische Kontrolle, Stuttgart 1967, S. 74. Entsprechend betont Ernst Forsthoff, Lehrbuch des Verwaltungsrechts, 9. Aufl., München 1966, S. $16 \mathrm{~m}$. Anm. 2, daß die normativ orientierte Verwaltungsrechtswissenschaft der Regierungsfunktion kein besonderes Interesse abgewinnen konnte. - Die Dominanz der Vollzugsfunktion in der verwaltungsrechtlichen Dogmatik und deren Orientierung an der einen richtigen Entscheidung ist durch den Ausbau des verwaltungsgerichtlichen Rechtsschutzes weiter befördert worden. In der Konzentration auf die Vollzugsfunktion der Verwaltung liegt wohl auch der Grund für die Vernachlässigung des Organisations- und Verfahrensrechtes. Denn wenn die Verwaltung, zumindest in ihrer für die Dogmatik relevanten Tätigkeit, vorwiegend Im Gesetzesvollzug besteht, ist es - jedenfalls bei der Vorstellung einer Gesetzessubsumtion - relativ gleichgültig, welche Instanz in welcher organisatorischen Ausgestaltung damit betraut wird. Vgl. dazu auch $\boldsymbol{N}$. Luhmann, Theorle der Verwaltungswissenschaft, S. 89.

20) Der "punktuelle“ Charakter der gegenwärtigen Verwaltungsrechtslehre tritt gerade in neueren Untersuchungen unter den verschiedensten Aspekten mehr oder weniger deutlich hervor; vgl. etwa Peter Badura, Verwaltungsrecht im liberalen und im sozialen Rechtsstaat, Tübingen 1966, S. 10 und passim; Fritz Ossenbïhl, Verwaltungsvorschriften und Grundgesetz, Bad Homburg v. d. H. 1968, S. 51, 59, 60 f., 192; Klaus König, Erkenntnisinteressen der Verwaltungswissenschaft, Berlin 1970, S. $16 \mathrm{ff}$; Elmar Stachels, Das Stabilitätsgesetz Im System des Regierungshandelns, Berlin 1970, S. 103; Rupert Scholz, Wirtschaftsaufsicht und subjektiver Konkurrentenschutz, Berlin 1971, S. 14, $35 \mathrm{ff}$., $41 \mathrm{ff}$. 
punkt eines Entscheidungsprozesses, nicht aber den Prozeß selbst. Sie sieht den Verwaltungsakt weiter nur isoliert, als Regelung gegenüber dem einzelnen Bürger, und nicht in der breiten Wirkung, die er oftmals entfaltet, und in den Handlungszusammenhängen, in denen er vielfach steht. Insofern fehlt der herkömmlichen Dogmatik weithin die räumliche und die zeitliche Dimension.

Im Zusammenhang damit stehen die oftmals starren Fixierungen der dogmatischen Formtypik, die Abstufungen - etwa in der Verbindlichkeit der Anordnungen oder in der Intensität des subjektiven Rechts und seines Schutzes - nicht kennen und dadurch einer flexibleren Handhabung des Rechts entgegenstehen ${ }^{30}$ ).

Diese Charakterisierung der herkömmlichen Dogmatik ist bewußt pointiert erfolgt, um die Grundstrukturen schärfer hervortreten zu lassen. Auf Modifikationen kommt es in diesem Zusammenhang nicht an.

2. Der punktuelle Charakter der überkommenen Dogmatik läßt sich auf mehrere Umstände zurückführen: auf den Einfluß des vom Naturrecht geprägten Zivilrechts ${ }^{31}$ ), auf die staatspolitische Konzeption des bürgerlichen Liberalismus mit ihrer Trennung von Staat und Gesellschaft als eigengesetzliche Sphären und der weitgehenden Beschränkung der staatlichen Tätigkeit auf die Gefahrenabwehr ${ }^{32}$ ) und schließlich auf die relativ überschaubaren sozialen Verhältnisse jener Zeit.

30) E. Kaufmann, Art.: Verwaltung und Verwaltungsrecht, S. 139 1., führt dies auf die Eliminierung des Zwecks in der juristischen Formtypik durch die „juristische“ Methode zurück. Dazu auch schon A. Haenel, Gesetz, S. 207.

s1) Dazu im einzelnen E. Kaufmann, Art.: Verwaltung und Verwaltungsrecht, S. $139 \mathrm{f}$.

s2) Dazu insbes. Peter Badura, Das Verwaltungsrecht des liberalen Rechtsstaates, Göttingen 1967, bes. S. 51 ff.; ders., Verwaltungsrecht im liberalen und im sozialen Rechtsstaat, S. $16 \mathrm{ff}$. und passim. - Es soll hier nicht übersehen werden, daß der Staat des ausgehenden 19. Jahrhunderts die Beschränkung seiner Tätigkeit auf die Gefahrenabwehr und die Besteuerung längst wieder aufgegeben hatte. In der verwaltungsrechtlichen Dogmatik aber wurde dem zunächst weniger Rechnung getragen. Daraus erklärt sich die Bedeutung, die erst die Schrift von Ernst Forsthoff, Die Verwaltung als Leistungsträger, Stuttgart 1938, und der darin geprägte Begriff der "Daseinsvorsorge" - übrigens erst lange Zeit nach deren Erscheinen - erlangte (dazu auch E. Forsthoff, Verwaltungsrecht, S. 342 f. unter Hinweis auf die Behandlung dieser Problematik bel $O$. Mayer, $F$. Fleiner und $W$. Jellinek). Die Nachwirkungen dieser staatspolltischen Konzeption zeigen sich weiter in der geringen Beachtung der Gestaltungsfunktion der Verwaltung, worauf im folgenden näher einzugehen sein wird. 
Unter diesen Bedingungen vermochte sich das Interesse der verwaltungsrechtlichen Dogmatik im wesentlichen auf die individuelle, fallweise Verhaltenskorrektur zu beschränken. Der Verwaltungsakt als obrigkeitliche Handlungsform der Verwaltung konnte so zu einem zentralen Begriff des Systems werden, mit dem über die Anwendbarkeit des öffentlichen Rechts, die Erforderlichkeit des Gesetzesvorbehaltes, die Verbindlichkeit der Anordnung, die Fragen der Fehlerhaftigkeit und deren Folgen, die Rechtsverletzung und den gerichtlichen Rechtsschutz und vieles andere mehr entschieden wurde.

3. Dieses System war elastisch genug, auch die Probleme der Leistungsverwaltung, wie sie i. a. mit dem Begriff der „Daseinsvorsorge" im Sinne einzelner Leistungsverhältnisse umschrieben wird, bewältigen zu können. Der Verwaltungsakt wurde vom Befehl zur hoheitlichen Regelung, die hoheitlichobrigkeitliche Verwaltung um die schlicht-hoheitliche bereichert, die öffentlich-rechtlichen Maßstäbe über die Zweistufentheorie oder das Verwaltungsprivatrecht in einer elastischen Weise auf die schlichte Hoheitsverwaltung anwendbar gemacht und individuelle Teilhaberechte über die Ausdehnung des subjektiven öffentlichen Rechts begründet" $\left.{ }^{23}\right)$.

Diese Umgestaltung ist noch nicht zum Abschluß gekommen. Zahlreiche Fragen sind noch umstritten. So das Verhältnis zwischen mitwirkungsbedürftigem Verwaltungsakt und Vertrag, die Ausgestaltung der Dauerrechtsbeziehungen mit gegenseitigen Rechten und Sorgfaltspflichten, die Problematik des doppelten Rechtsweges bei der Zweistufentheorie u. a. m." ). Indessen sind diese Fragen im Wege der Anpassung und Ergänzung des verwaltungsrechtlichen Instrumentariums zu lösen, ohne daß dadurch die Dogmatik in ihrer Grundstruktur verändert werden müßte. Das hat seinen Grund darin, daß auch bei der Erbringung einzelner begrenzter Versorgungsleistungen der Vollzugscharakter und der Individualbezug der Verwaltungstätigkeit gewahrt bleiben. Selbst das Eingriffsdenken läßt sich beibehalten - und wird teilweise ja auch beibehalten —, kann

ss) Dazu im einzelnen W. Brohm, Strukturen der Wirtschaftsverwaltung, insbes. S. 179 ff. m. zahlr. w. N.

s4) Vgl. dazu insbes. die Referate von Wilhelm Henke und Wolfgang Rüfner, Rechtsformen der sozialen Sicherung und das Allgemeine Verwaltungsrecht, VVDStRL 28 (1970), S. $149 \mathrm{ff}$. und $187 \mathrm{ff}$., bes. S. 156 ff., 158, 161, 191, 204, 214 ff., 235. Zur Problematik des öffentlich-rechtlichen Vertrages: Martin Bullinger, Zur Notwendigkeit funktionalen Umdenkens des öffentlichen und privaten Vertragsrechts im leistungsintensiven Gemeinwesen, in: Gedächtnisschrift Hans Peters, Berlin 1967, S. 667 ff. (bes. S. 680); Hans Peter Ipsen, Rechtsstaatliche Erdölkonzessionierung, ebd., S. 686 ff. (702). 
man doch die Verweigerung der beanspruchten Leistung als einen "Eingriff" in das Teilhaberecht werten ${ }^{35}$ ). Zwar hat die Verwaltung im Rahmen der Daseinsvorsorge auch eine "Gestaltungsfreiheit" in der Frage etwa, ob sie eine Leistungsinstitution errichten und in welcher Weise sie sie ausgestalten will. Aber diese Fragen wurden bislang als wenig problematisch empfunden ${ }^{36}$ ). Das Interesse galt in erster Linie der Nutzung dieser Einrichtungen, und hier konnte der punktuelle Vollzugscharakter nach Maßgabe der Anstaltsordnung gewahrt bleiben.

4. Inzwischen sind wir - idealtypisch gesprochen ${ }^{37}$ ) - in eine neue Phase der Entwicklung eingetreten, die der Tätigkeit der Verwaltung neue Möglichkeiten und neue Dimensionen gibt und auch nicht ohne Rückwirkung auf ihre organisatorische Struktur sein wird. Die moderne Industriegesellschaft kann mit den Grundphänomenen der sich beschleunigenden Veränderung, der Verwissenschaftlichung und der nahezu totalen Interdependenz aller Tätigkeiten und Zustände charakterisiert werden ${ }^{20}$ ).

25) Repräsentativ etwa der Diskussionsbeitrag von Ferdinand Kopp, VVDStRL 28 (1970), S. 253.

so) Das gilt etwa für die Fragen der Errichtung und des Standorts solcher Einrichtungen. Diese werden nach der herkömmlichen Auffassung in den Bereich rechtlich unkontrollierbarer Politik verwiesen und scheiden damit aus den dogmatischen Bemühungen aus. Typisch etwa die Literatur und die Kommentierung zu der in den Gemeindeordnungen statuierten Aufgabe der Kommunen, innerhalb der Grenzen ihrer Leistungsfähigkeit die für die wirtschaftliche, soziale und kulturelle Betreuung ihrer Einwohner erforderlichen öffentlichen Einrichtungen zu schaffen. Vgl. etwa Hans $J$. Wolff, Verwaltungsrecht II, 3. Aufl., München 1970, \& 98 III; Hans Körner, Gemeindeordnung Nordrhein-Westfalen, Köln 1970, Rdnr. 2 zu \$ 18; Kottenberg-Rehn, Gemeindeordnung für das Land NordrheinWestfalen, 9. Aufl., Siegburg 1970, \& 18 I und II; Zuhorn-Hoppe, Gemeinde-Verfassung, 2. Aufl., Siegburg 1962, S. $91 \mathrm{ff}$; HelmreichWidtmann, Bayerische Gemeindeordnung, 3. Aufl., München 1966, Anm. 1 zu Art. 57. - Probleme sind hier bislang nur vereinzelt aufgetreten, etwa bei der Ausgestaltung der Benutzungsordnungen. Vgl. dazu BVerwG v. 8. 11. 1963, BVerwGE 17, 119; v. 16. 12. 1966, BVerwGE 25, 364; E. Forsthoff, Verwaltungsrecht, S. 388 f. m. w. N.; H. J. Wolff, Verwaltungsrecht II, \& 99 II e; Otto Bachof, Rechtsnatur, zulässiger Inhalt und Anfechtung von Friedhofsordnungen, AöR 78 (1952/53), S. $83 \mathrm{ft}$. (87 ff.).

37) Historisch betrachtet reichen die Wurzeln auch dieser Entwicklung bereits ins 19. Jahrhundert hinein.

3) Das ist oft beschrieben worden. Vgl. etwa allgemein die Zusammenstellung bei Hartmut $v$. Hentig, Systemzwang und Selbstbestimmung, 3. Aufl., Stuttgart 1970, S. $78 \mathrm{ff}$. Aus staatsrechtlicher Sicht: Ernst Forsthoff, Der Staat der Industriegesellschaft, München 1971 , bes. S. $30 \mathrm{ff}$. Speziell unter dem Gesichtspunkt der Wirtschaftsaufsicht: $R$. Scholz, Wirtschaftsaufsicht und subjektiver Konkurrentenschutz, S. 39 und passim. 
Das hat zur Folge, daß vielfach schon die herkömmlichen Vollzugsmaßnahmen der Verwaltung ihren individuell begrenzten Charakter verlieren. So betreffen z. B. die Typengenehmigungen im Kraftfahrzeug- oder Baustoffgewerbe ${ }^{30}$ ) nicht nur den Antragsteller, sondern ganze Wirtschaftszweige, die an der Herstellung des Produktes beteiligt oder auf seine Nutzung angewiesen sind.

Vor allem aber fehlt der punktuelle Charakter regelmäßig bei den Sozialgestaltungen der Verwaltung. Typische Beispiele sind die Planungen in der Wirtschafts- und Sozialpolitik oder in der Raumordnung und im Städtebau ${ }^{40}$ ).

Bei diesen Gestaltungsaufgaben gibt es zunächst keine gesetzlichen Tatbestände, die man fallweise gegenüber einem einzelnen anzuwenden hätte. Der Verwaltung wird vielmehr das Ziel eines Gestaltungsprozesses genannt, zu dessen Verfolgung sie auch ein bestimmtes Instrumentarium zur Wahl erhält. Der Weg zum Ziel steht ihr dabei frei. Er ließe sich auch gar nicht im voraus berechnen. Denn bei der planenden Gestaltung sind die verschiedensten Unterzwecke [zu beachten, und was auf der einen Ebene als Mittel erscheint, ist auf der anderen der Zweck für weitere Mittel. Je höher dabei die $\mathrm{Ab}$ straktionsebene, desto harmonischer erscheinen die Zwecke miteinander vereinbar. Je konkreter die Planung wird, desto schärfer treten oft die Zielkonflikte hervor $\left.{ }^{41}\right)$. Dann ist eine widersprüchliche Zielverfolgung allenfalls im zeitlichen Nacheinander möglich. Insofern hat die Verwaltung bei ihren Maßnahmen die Möglichkeiten der Zweck-Mittel-Vertauschung, der

\footnotetext{
s9) Dazu Christian Heinze, Allgemeine Zulassung von Fabrikaten, Stuttgart 1971, bes. S. $12 \mathrm{ff}$.

10) Es geht hier also um die aktiv gestaltenden Maßnahmen des Staates, zu denen er heute nicht nur auf Grund der sozialen Gegebenheiten gezwungen, sondern als "Sozialstaat" (Art. 20 I GG) auch nach der Verfassung angehalten ist. Wenn $E$. Forsthoff, Verwaltungsrecht, S. 59, den Sozialstaat als einen reaktiv, aus der jewelligen Situation heraus handelnden Staat charakterisiert, so hat sich die Verfassungswirklichkeit in der Bundesrepublik, legitimlert durch diesen verfassungsrechtlichen Auftrag, in den letzten Jahren erheblich gewandelt. Die Beiträge etwa in den Sammelbänden von Joseph H. Kaiser (Hrg.), Planung I-V, Baden-Baden 1965-1971, geben dem Ausdruck. Dazu auch Hans Joachim Arndt, Der Plan als Organisationsfigur und die strategische Planung, PVS 1968, S. 177 ff. (178).

4) Daher wäre es ein Trugschluß, wollte man annehmen, daß aus der Angabe des obersten Zieles die weiteren Ziele im Wege fortlaufender Konkretislerung logisch gefolgert werden könnten. Dazu Rolf-Richard Grauhan, Zur Struktur der planenden Verwaltung, Stadtbauwelt 1969, S. 132 ff. (134).
} 
opportunistischen Zweckverwirklichung ${ }^{42}$ )] wie auch die rasche Veränderlichkeit der Umweltdaten mit zu berücksichtigen. Die Verwaltung muß sich daher in der Verfolgung des ihr gesteckten Zieles laufend selbst programmieren. Gegenüber dieser eigenen Zwecksetzung und Programmierung im Rahmen vorgegebener Ziele ist dann der Vollzug des Programms im Einzelfall von untergeordneter Bedeutung. Die Würfel sind dann meist schon gefallen. Das ist für den Rechtsschutz, etwa im Bauplanungsrecht, schon mehrfach hervorgehoben worden ${ }^{43}$ ).

Oft kommt es nicht einmal zu einem verbindlichen Vollzug gegenüber den Betroffenen, oder es ergeht zwar eine Regelung gegenüber einzelnen, aber ihre Wirkung reicht viel weiter und gilt meistens auch ganz anderen als den Adressaten. Das ist vor allem bei der Wirtschaftslenkung der Fall. Wenn z. B. die Bundesbank die Mindestreservesätze erhöht, dann trifft diese Maßnahme nicht nur die Geschäftsbanken, sondern darüber hinaus auch die kreditabhängigen Unternehmen. Schließt sie aus konjunkturpolitischen Gründen die Wechsel bestimmter Wirtschaftszweige von der Rediskontierung aus ${ }^{44}$ ), oder stellt die öffentliche Hand die Vergabe von Aufträgen ein, so fehlt es überhaupt an einer „Regelung“ gegenüber dem Bürger, und doch ist die Wirkung dieser Maßnahmen einer entsprechenden Anordnung gleichzustellen ${ }^{45}$ ).

42) Dazu N. Luhmann, Zweckbegriff, 2. B. S. 29, 31.

43) Vgl. etwa Winfried Brohm, Rechtsschutz im Bauplanungsrecht, Stuttgart 1959, S. $75 \mathrm{ff}$. und passim; ders., Art.: Städtebau (III), Staatslexikon, 6. Aufl., 3. Ergänzungsband, Freiburg 1970, Sp. $339 \mathrm{ff}$. (347); Willi Blümel, Raumplanung, vollendete Tatsachen und Rechtsschutz, in: Festgabe für Ernst Forsthoff, München 1967, S. $133 \mathrm{ff}$., bes. S. $139 \mathrm{~m}$. zahlr. w. N.; Richard Bartlsperger, Die Bauleitplanung als Reservat des Verwaltungsstaates, DVBl. 1967, S. $360 \mathrm{ff}$. (369).

4) Zum Ausschluß von Bau- und Teilzahlungswechseln vgl. z. B. die Beschlüsse des Zentralbankrates vom 12. 10. 1955 und 21. 3. 1956 im Geschäftsbericht der Bank Deutscher Länder für das Jahr 1956, Frankfurt 1957, S. 116.

15) Vgl. allgemein zu dieser Problematik: Joseph H. Kaiser, Exposé einer pragmatischen Theorie der Planung, in: ders., (Hrg.), Planung I, Baden-Baden 1965, S. 11 ff. (23 f.); Hans Peter Ipsen, Fragestellungen zu einem Recht der Wirtschaftsplanung, ebd., S. $35 \mathrm{ff}$. (59 f.); ders., Rechtsfragen der Wirtschaftsplanung, in: J. H. Kaiser, Planung II, Baden-Baden 1968, S. 63 ff.; Ernst Forsthoff, Uber Mittel und Methoden moderner Planung, in: J. H. Kaiser, Planung III, Baden-Baden 1968, S. 21 ff., 33 und passim; Hans Heinrich Rupp, Zur Problematik öffentlich-rechtlicher Machtpotenzierung durch Funktionenkombination, NJW 1968, S. 569 ff.; Peter Badura, Auftrag und Grenzen der Verwaltung im sozialen Rechtsstaat, DOV 1968, S. 446 ff. (447); Karl Heinrich Friauf, Offentlicher Haushalt und Wirtschaft, VVDStRL 27 (1969), S. 1 ff. (7 f., 10 f. und 
Insofern ist die zentrale Stellung des Verwaltungsaktes problematisch geworden und mit ihr die an diesem Begriff orientierte Dogmatik, angefangen beim Vorbehalt des Gesetzes bis zu den Handlungsmaßstäben und dem Rechtsschutz.

Die Diskussion dieser Probleme hat im Planungsrecht gerade erst begonnen. Dabei standen bislang - bedingt durch die Vordringlichkeit des Rechtsschutzes - die herkömmlichen Fragestellungen der Gesetzmäßigkeit und des Individualrechtsschutzes im Vordergrund. Der punktuelle Charakter der Dogmatik wurde allenfalls bei der Frage nach der Drittbetroffenheit angetastet. Die anderen Aspekte der planenden Gestaltung blieben jedoch weithin außerhalb der rechtswissenschaftlichen Erörterung, so etwa die Fragen nach der Organisation und Struktur des Entscheidungsprozesses, nach der Rationalität der Zwecksetzung der Verwaltung, nach der optimalen Selektion alternativer Möglichkeiten, nach der Einordnung der Zwecksetzungen in die gesamte staatliche Sozialgestaltung, nach ihrer Adaption an die sich laufend verändernden Datenkonstellationen oder nach der Mitwirkung der Betroffenen und einer effektiven Kontrolle der Zwecksetzung und nicht nur ihres Vollzuges.

Diese Fragen sind nicht nur soziologisch von Belang. Vielmehr muß die Rechtsdogmatik die Voraussetzungen dafür schaffen, $\mathrm{da} B$ dieser Proze $B$ der Entscheidungsbildung optimal verläuft, optimal nicht nur im Sinne technischer Perfektion, sondern auch im Sinne der vom Recht intendierten zukünftigen Ordnung. Denn die Organisation und das Verfahren sind für den Inhalt einer Entscheidung von eminenter Bedeutung. Bei der Vollzugsfunktion der Verwaltung spielen diese Faktoren eine geringere Rolle; um so stärker treten sie bei der Gestaltungsfunktion hervor.

Diese Feststellung lenkt den Blick auf die andere Seite des Rechtsverhältnisses zwischen Staat und Bürger, auf die Verwaltung. Auch hier wird die überkommene individualisierende Sicht fragwürdig. Die gestiegene Umweltkomplexität, die Zunahme der Verwaltungsfunktionen und die Verwissenschaftlichung unseres Lebens zwingen die Verwaltung zu immer

passim); Heinz Wagner, Offentlicher Haushalt und Wirtschaft, ebd., S. $47 \mathrm{ff}$. (bes. S. $62 \mathrm{ff}$.). - Versuche, die rechtlich bislang nur schwer erfaßbaren indirekten und die nicht-hoheitlichen Einwirkungsmöglichkeiten der rechtlichen Beurtellung zuzuführen, finden sich etwa bei $W$. Brohm, Strukturen der Wirtschaftsverwaltung, S. 53 ff. und 228 ff., und für die staatliche Aufsicht bei Martin Bullinger, Staatsaufsicht in der Wirtschaft, VVDStRL 22 (1965), S. 264 ff. (294 f., 301 und passim). 
stärkeren institutionellen und funktionellen Differenzierungen ${ }^{46}$. Dadurch verliert sie ihre straff gegliederte Einheit und pluralisiert sich in eine Vielzahl mehr oder weniger selbständiger Behörden und Verwaltungseinheiten.

Verselbständigungstendenzen sind bereits innerhalb der Hierarchie der Allgemeinen Verwaltung bemerkbar. Das überkommene hierarchische Prinzip hat seine unbestreitbaren Vorzüge für die herkömmliche Vollzugsfunktion. Denn diese war - und ist es weithin auch heute noch - eine vorwiegend routinierte Tätigkeit bei festen und fortdauernden Verwaltungszwecken und relativ überschaubaren Sachverhalten. Das hierarchische Prinzip ist aber weniger geeignet für Tätigkeiten, die Flexibilität und innovatorische Fähigkeiten verlangen ${ }^{47}$ ). Deshalb haben sich in der Verwaltungspraxis - was die Kritik leicht übersieht - neue Institutionen herausgebildet, die eine gemeinsame Arbeit verschiedener hierarchisch über- oder gleichgeordneter Stellen erlauben. [Diese bislang noch informellen Einrichtungen werden sich weiter ausdehnen. Das bedeutet, daß die Kontakte zur Außenwelt und zu anderen Ressorts nicht mehr immer über die Verwaltungsspitze laufen. Denn der Dienstweg ist viel zu langwierig und die Führungsspitze gar nicht in der Lage, alles zu überschauen und selbst zu entscheiden.] So entwickeln sjch in zunehmendem Maße in den hierarchischen Ebenen relativ selbständige Teilsysteme ${ }^{48}$ ).

Hinzu kommt die Ausdifferenzierung der Verwaltung in eine Vielzahl faktisch unabhängiger Sonderbehörden und selbständiger Verwaltungseinheiten. [Die Bundesaufsichtsämter, die Einfuhr- und Vorratsstellen, die Filmbewertungsstelle, das Institut für Bautechnik ${ }^{40}$ ), regionale Planungsverbände - oft sogar in privatrechtlicher Organisationsform - sind Beispiele dafür.]

\footnotetext{
19) Allgemein zur Notwendigkeit der Innendifferenzierung auf Grund höherer Umweltkomplexität: Niklas Luhmann, in: J. Habermas, N. Luhmann, Theorie der Gesellschaft oder Sozialtechnologie, Frankfurt/M. 1971, S. 22 f., 147, 156.

7) $\mathrm{Zu}$ den Vorzügen und Nachteilen des hierarchischen Prinzips, das Max Weber, Wirtschaft und Gesellschaft, 4. Aufl., Tübingen 1956, unübertroffen geschildert hat, vgl. im einzelnen Niklas Luhmann, Zweck - Herrschaft - System. Grundbegriffe und Prämissen Max Webers, Der Staat 3 (1964), S. 129 ff. (139 ff.); besonders kritisch: Reinhard Höhn, Verwaltung heute. Autoritäre Führung oder modernes Management, Bad Harzburg 1970; Frieder Lauxmann, Die kranke Hierarchie, Stuttgart 1971.

18) Dazu im einzelnen N. Luhmann, Der Staat 3 (1964), S. 141 if. 27 if.

19) Dazu Ch. Heinze, Allgemeine Zulassung von Fabrikaten, S.
} 
Mit dieser Pluralisierung der Verwaltung geht vielfach aus Gründen besonderer Fachkunde oder politischer Abstimmung - eine Verzahnung mit den gesellschaftlichen Kräften einher, sei es, daß die Verwaltung sie institutionell eingliedert, sei es, daß sie sie in anderer Form an ihrem Entscheidungsprozeß beteiligt oder ihnen Aufgaben zur selbständigen Erledigung überträgt.

Aus diesen Veränderungen in der organisatorischen und personellen Struktur ergeben sich neue Probleme für die Koordination und Kooperation wie auch für die Beurteilung der Entscheidungsprozesse selbst.

Lassen Sie mich diese hier im Uberblick aufgezeigten Fragen an sinigen Beispielen weiter verfolgen. Dabei möchte ich zunächst auf das Wirken der Verwaltung im gesellschaftlichen Raum eingehen, danach die Formen der internen Entscheidungsbildung und schließlich einige Fragen der Organisation des' Entscheidungsprozesses behandeln. [Diese Fragenkreise stehen, wie gesagt, miteinander in Wechselwirkung; sie lassen sich daher nur bedingt nach diesen Gesichtspunkten einteilen.]

\section{III.}

1. Die Verwaltung verfügt heute für ihr Handeln im gesellschaftlichen Raum über eine Vielzahl hoheitlicher und fiskalischer, verbindlicher und unverbindlicher Formen. Die funktionale Äquivalenz dieser Einwirkungsmöglichkeiten macht es unmöglich, das öffentliche Recht und das Privatrecht nach den Handlungsformen der Verwaltung abzugrenzen.

Es kann für die Anwendbarkeit öffentlich-rechtlicher Maßstäbe keinen Unterschied machen, ob die Verwaltung ihre Aufgaben durch streng verbindliche Anordnungen oder durch Imperativ- oder Indikativrichtlinien ${ }^{50}$ ) verfolgt oder ob sie ihre Zwecke über die finanzielle Beteiliguing an einem Unternehmen oder durch eine mit entsprechenden Auflagen verbundene Subventionierung durchsetz $t^{s 1}$ ). Ebenso müssen die Vergabe von Aufträgen oder der Einsatz öffentlicher Unternehmen zur Wirtschaftslenkung ${ }^{s 2}$ ) nach öffentlichem Recht beurteilt wer$\left.\operatorname{den}^{53}\right)$.

so) Dazu im einzelnen W. Brohm, Strukturen der Wirtschaftsverwaltung, S. $234 \mathrm{ff}$. m. zahlr. w. Hinweisen und Beispielen.

s1) Zur funktionalen Aquivalenz dieser Mittel vgl. etwa Volker Emmerich, Das Wirtschaftsrecht der öffentlichen Unternehmen, Bad Homburg v. d. H. 1969, S. 42 I.

s2) Die wirtschaftspolitischen Möglichkeiten mit Hilfe des öffentlichen Haushalts sind bekannt und werden heute in der Staatspraxis auch weithin wahrgenommen (vgl. die Nachweisungen oben in Anm. 45). Offentliche Unternehmungen hat man bei uns bislang 
Da die Handlungsform kein ausreichendes Kriterium mehr bietet, versucht man neuerdings wieder auf die Rechtsform der

kaum zu interventionistischen Zwecken eingesetzt, obgleich sie infolge ihrer Konzentration auf einige wesentliche Wirtschaftszweige dazu geeignet wären. (Dazu aus der neueren Literatur Klaus Vogel, Die wirtschaftliche Betätigung öffentlicher Verwaltungsträger in Handel und Industrie und ihre rechtliche Regelung, in: Deutsche Landesreferate zum VII. Internationalen Kongreß für Rechtsvergleichung in Uppsala 1966, hrg. v. Ernst v. Caemmerer und Konrad Zweigert (Sonderveröffentlichung von Rabels Zeitschrift für ausländisches und internationales Privatrecht), Berlin-Tübingen 1967, S. 461 ff.; Wolfgang Rïfner, Formen öffentlicher Verwaltung im Bereich der Wirtschaft, Berlin 1967, S. $176 \mathrm{ff}$ (182 ff.); Hans $H$. Klein, Die Teilnahme des Staates am wirtschaftlichen Wettbewerb, Stuttgart 1968, S. 38 ff. (51 f.); Günter Püttner, Die öffentlichen Unternehmen. Verfassungsfragen der wirtschaftlichen Betätigung der öffentlichen Hand, Bad Homburg v.d. H. 1969, etwa S. 96, 274 ff.). Darauf mag es zurückzuführen sein, daß auch von volkswirtschaftlicher Seite die Frage nach der Möglichkeit eines effizienten Einsatzes öffentlicher Unternehmen zur Wirtschaftslenkung noch nicht in zureichendem Maße untersucht ist. Kurzfristige konjunkturpolitische Zielsetzungen dürften über eine antizyklische Investitionspolitik nur bei nicht-kapazitätswirksamen Maßnahmen zu erreichen sein; kapazitätswirksame Investitionen dagegen werden sich im allgemeinen auf das Gesamtangebot nur auswirken, wenn die öffentlichen Unternehmen eine Monopolstellung innehaben. Auch hier ist ihr Wirkungsradius nur begrenzt. Einer Preispolitik der öffentlichen Unternehmen wird noch geringere Bedeutung für den Konjunkturverlauf beigemessen. Als gewichtiger wird der Einsatz öffentlicher Unternehmen zu langfristigen Beeinflussungen des wirtschaftlichen Geschehens, insbesondere zu strukturpolitischen Zielsetzungen angesehen. Dazu Franz Gsell, Die öffentlichen Unternehmen der BRD im Dienste der Sozial- und Wirtschaftspolitik (Möglichkeiten und Grenzen), Diss. rer. pol. München 1962, S. 18 ff.; Helmut $v$. Natzmer, Die wirtschaftliche Betätigung der öffentlichen Hand in der Bundesrepublik Deutschland, in: Gemeinwirtschaft in Westeuropa, hrg. v. Wilhelm Weber, Göttingen 1962, S. $466 \mathrm{ff}$.; Margret Dieck, Die gemeinwirtschaftlichen Unternehmen in der Bundesrepublik Deutschland - Untersuchung ihrer Stellung in der deutschen Wirtschaft und ihres Einsatzes als Mittel der Wirtschaftsund Gesellschaftspolitik, Annalen der Gemeinwirtschaft, 37. Jg. (1968), bes. S. 407; Helmut Stukenberg, Offentliche Unternehmen als Instrumente planender Verwaltung, dargestellt am Beispiel der staatlichen Eisenbahnen, in: J. H. Kaiser (Hrg.), Planung III, BadenBaden 1968, S. 353 ff.; vgl. ferner in diesem Band die Beiträge insbes. von Gert Nicolaysen und Michel Fromont.

ss) Im Ergebnis übereinstimmend für die Auftragsvergabe: Hans J. Wolff, Verwaltungsrecht I, 8. Aufl., München 1971, § 23 II a 1; Ernst Forsthoff, Der Staat als Auftraggeber, Stuttgart 1963, S. 16; a. A. etwa W. Rüfner, Formen öffentlicher Verwaltung, S. 407, der allerdings auf die wirtschaftspolitische Funktion des Haushalts nicht eingeht. 
Organisation abzustellen ${ }^{54}$ ). Dann aber müßte alles Handeln der Verwaltung dem öffentlichen Recht unterstehen - was zu Recht überwiegend abgelehnt wird ${ }^{\text {ss }}$. Umgekehrt würde der Einsatz öffentlicher Unternehmen zur Wirtschaftspolitik dann nicht dem öffentlichen Recht unterliegen, wenn diese unter der Flagge des Gesellschaftsrechts agierten; anders wäre es, wenn sie in öffentlich-rechtlichen Formen organisiert wären. Diese Unterscheidung entspricht zwar der herrschenden Meinungse), ist aber zu formal und materiell nicht $\mathrm{zu}$ begründen ${ }^{87}$ ).

Angesichts der erweiterten Handlungsmöglichkeit der Verwaltung können öffentliches Recht und Privatrecht nicht mehr ausschließlich nach formalen Kriterien voneinander abgegrenzt werden; vielmehr ist letztlich die Funktion entscheidend, die die öffentliche Hand mit ihrer Handlung verfolgt. Obrigkeitliche Handlungen zeigen an, da $B$ eine hoheitliche Funktion oder "Hoheitskompetenz" wahrgenommen wird. Ebenso bringt die öffentlich-rechtliche Organisationsform zum Ausdruck, daß die dieser Organisation übertragenen Aufgaben hoheitlichen Charakter haben. Die hoheitliche Natur einer Kompetenz kann sich aber auch aus der Verfassung oder gesetzlichen Bestimmung ergeben, wie es z. B. bei der Raumplanung und der Wirtschaftslenkung der Fall ist ${ }^{58}$ ). Das hat zur Folge, daß etwa fiskalische

54) Herbert Krüger, Allgemeine Staatslehre, 2. Aufl., Stuttgart 1966, S. 323 ff.; vgl. auch W. Henke, VVDStRL 28 (1970), S. $149 \mathrm{ff}$. (151). Zum Stand der Meinungen über die Bedeutung der Rechtsform der Organisationen für die Qualifizierung der Handlungsformen: W. Brohm, Strukturen der Wirtschaftsverwaltung, S. $134 \mathrm{ff}$.

55) Vgl. etwa H. J. Wolff, Verwaltungsrecht I, \& 23; G. Dïrig, in: Maunz-Dürig-Herzog, Grundgesetz, Kommentar, Loseblattausgabe, München, Stand August 1971, Rdnr. 136 zu Art. I GG, Jeweils m. w. N.

so) Repräsentativ V. Emmerich, Das Wirtschaftsrecht der öffentlichen Unternehmen, S. $144 \mathrm{ff}$. und passim; H. J. Wolff, Verwaltungsrecht I, \$23 II; $W$. Rüfner, Formen öffentlicher Verwaltung, S. $358 \mathrm{ff}$., jeweils $\mathrm{m}$. w. N.

57) Dahinter steht entweder eine formale Betrachtungsweise oder aber das Bestreben, wenigstens die öffentlichen Unternehmen in privater Rechtsform dem Kartellrecht zu unterstellen und damit ihren Einsatz zur Wirtschaftslenkung unmöglich zu machen. Dieses am Modell des Wirtschaftsliberalismus orientierte Vorverständnis ist verfassungsrechtlich nicht abgesichert.

s8) Zum Begriff der Hoheitskompetenz und den damit verbundenen rechtlichen Konsequenzen vgl. im einzelnen: W. Brohm, Strukturen der Wirtschaftsverwaltung, S. $39 \mathrm{ff}$., $155 \mathrm{ff}$., $164 \mathrm{ff}$., $183 \mathrm{ff}$., $197 \mathrm{ff} ., 211$ ff. und passim. Entscheidend für dieses Verständnis ist die Erkenntnis, daß jede Rechtshandlung nach Art und Wirkung erst von der Rechtsordnung ermöglicht und bestimmt wird, also auch die Möglichkeiten der Privatautonomle eine (Privat-)Kompetenz des einzelnen voraussetzen. In der Abgrenzung dazu ergibt sich der Terminus „Hoheitskompetenz“. Mit der Wahrnehmung von 
Hilfsgeschäfte dem Privatrecht unterliegen, wenn sie allein der Bedarfsdeckung dienen, da $\beta$ sie aber nach öffentlich-rechtlichen Maßstäben zu beurteilen sind, wenn sie vorwiegend zur Wirtschaftslenkung eingesetzt werden. Entsprechendes gilt für das Marktverhalten der öffentlichen Unternehmen, unabhängig von ihrer öffentlich-rechtlichen oder privatrechtlichen Organisationsform.

2. Die Frage, welche öffentlich-rechtlichen Maßstäbe für die gestaltende Verwaltung gelten, ist allerdings schwer zu beantworten. Denn auch die herkömmlichen rechtsstaatlichen Sicherungen des Gesetzesvorbehaltes, der Grundrechte und der allgemeinen Handlungsmaßstäbe sind am punktuellen Eingriffsakt orientiert und lassen sich nicht ohne weiteres auf die Gestaltungsfunktionen der Verwaltung übertragen.

a) Nach der herkömmlichen Vorstellung vom Vorbehalt des Gesetzes legt der Gesetzgeber im Eingriffsbereich die MittelZweck-Relation im einzelnen fest, so daß der Verwaltung nur der "unpolitische“ Vollzug verbleibt.

Für die Gegenwart besitzt diese Vorstellung nur noch bedingte Gültigkeit. Im Verfassungsrecht ist schon mehrfach darauf hingewiesen worden, daß bei der Gesetzgebung Parlament

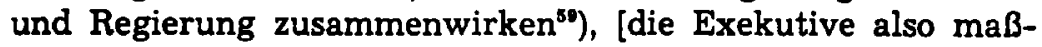

Hoheits- oder Privatkompetenzen verbindet die Rechtsordnung, sofern sie nicht ausnahmsweise eine einheitliche "Sachbereichsregelung" getroffen hat, unterschiedliche Rechtswirkungen und Legitimationsprinzipien. So beurteilt sich die Ausübung von Hoheitskompetenzen zumindest in ihrem "Kernbereich" nach den Maßstäben des öffentlichen Rechts. Die Entscheidung, welche rechtlichen Befugnisse und Möglichkeiten dem einen oder anderen Bereich zufallen, trifft in einzelnen Fällen und in den äußersten Grenzen die Verfassung, im übrigen aber der Gesetzgeber in deren Rahmen und nach deren Maßgabe. Jedenfalls bedarf es einer solchen Entscheidung. Daher kann für die Anwendung öffentlich-rechtlicher Maßstäbe nicht an die unmittelbare Wahrnehmung "öffentlicher Interessen" oder (materiell bestimmter) "öffentlicher Aufgaben" angeknüpft werden, vielmehr muß aus der Rechtsordnung (der Verfassung oder gesetzlichen bzw. untergesetzlichen Regelungen) entnommen werden, ob eine Zuweisung zum hoheitlichen Funktionsbereich in verfassungsrechtlich zulässiger Weise erfolgte. Vgl. auch H. J. Wolff, Verwaltungsrecht I, \& 23 II b; Fritz Ossenbühl, Die Erfullung von Verwaltungsaufgaben durch Private, VVDStRL 29 (1971), S. $137 \mathrm{ff}$., bes. S. $150 \mathrm{ff}$.

6) Dazu Ernst Friesenhahn, Parlament und Regierung im modernen Staat, VVDStRL 16 (1958), S. $9 \mathrm{ff}$. (33 ff.); Roman Herzog, Gesetzgeber und Verwaltung, VVDStRL 24 (1966), S. $183 \mathrm{ff}$. (201 ff.); vgl. auch Ulrich Scheuner, Politische Koordination in der Demokratie, in: Festschrift für Gerhard Leibholz, Bd. II, Tübingen 1966, S. 899 tf. (916 t.); ders., Das Gesetz als Auftrag der Verwaltung. DOV 1969, S. 585 ff.; Walter Leisner, Quantitative Gewaltenteilung, 
geblichen Einfluß auf die Zweck-Mittel-Relationen des Gesetzgebers ausübt. Das wird für eine moderne parlamentarische Demokratie zutreffend als verfassungsgemäß angesehen. Die Mitwirkung der Exekutive beschränkt sich dabei nicht auf den politischen Führungsstab der Regierung, sondern umfaßt auch die Verwaltung bis zu den unteren Verwaltungsstellen, die $\mathrm{Da}-$ ten melden und die Notwendigkeit von Planungen oder Planungskorrekturen aufzeigen. Gerade bei den sozialgestaltenden Maßnahmen werden diese Rückkoppelungsverfahren in $\mathrm{Zu}$ kunft noch wesentlich intensiviert werden müssen ${ }^{60}$ ).]

b) Wenn sich heute die gestaltende Verwaltung im Rahmen der ihr gesteckten Ziele selbst programmiert, insoweit also gesetzgeberische Funktionen übernimmt, dann gilt es, diese Erkenntnis des Zusammenwirkens von Parlament und Verwaltung bei der Gesetzgebung auch auf die Gesetzesverwirklichung durch die gestaltende Verwaltung zu übertragen.

aa) Die Ansicht, daß der Vorbehalt des Gesetzes nicht auf unmittelbare Eingriffe beschränkt sei, sondern auch für die indirekten Einflußnahmen gelten müsse, ist zu Recht im Vordringen begriffen ${ }^{61}$ ). Man müßte sonst auch die Geltung der Grundrechte gegenüber mittelbaren Rechtsbeeinträchtigungen verneinen $^{\text {(z) }}$. Das hätte die Konsequenz, daß gerade die folgenreichsten Funktionen der Verwaltung weitgehend aus den Gewährleistungen des Rechtsstaates herausfielen.

Auf der anderen Seite können die Ermächtigungen zur planenden Gestaltung nicht in vollem Umfange den Bestimmtheitsanforderungen des Art. 80 I 2 GG genügen. Auf die Notwendigkeit, $\mathrm{da} B$ die Verwaltung im Prozeß $\mathrm{der}$ Zielverwirklichung selbst Zwecke setzt und sich selbst programmiert, habe ich bereits hingewiesen ${ }^{\text {(s) }}$. Aus diesem Grunde können die Zielnormen auch nur zur Vornahme der Gestaltungsmaßnahmen

DOV 1969, S. $405 \mathrm{ff}$. (409 f.). - Aus der politikwissenschaftlichen Literatur vgl. etwa Thomas Ellwein, Das Regierungssystem der Bundesrepublik Deutschland, 2. Autl., Köln 1965, S. $207 \mathrm{ff.}$

o) Zur Notwendigkeit einer solchen Rückkoppelung vgl. etwa auch $R$. $R$. Grauhan, Stadtbauwelt 1969, S. 132 ff. (137); zur bislang noch einseitigen Akzentuierung der Administrativfunktion in den Ministerien: E. Stachels, Stabilitätsgesetz, S. 168.

11) Klaus Vogel, Gesetzgeber und Verwaltung, VVDStRL 24 (1966), S. 125 ff. (bes. S. $151 \mathrm{ff}$.) m. zahlr. w. N.

os) Dazu unten im Text III. 3.

*5) Siehe oben im Text II. 4.; vgl. auch $R$. Scholz, Wirtschaftsaufsicht und subjektiver Konkurrentenschutz, S. 107, der wegen des "dynamischen Bereiches des Wirtschaftsrechts" das Aufstellen von „strikten und unbeweglichen Inhaltserfordernissen" für unmøglich hält. 
ermächtigen, nicht aber zu den Rechtsbeeinträchtigungen, die in ihrem Gefolge eintreten können. Diese lassen sich gar nicht in vollem Umfange vorhersehen. Wollte man hier auf einer strengen Einhaltung des Bestimmtheitsgrundsatzes bestehen, so müßte man auf die planende Gestaltung überhaupt verzichten, was mit dem Prinzip des Sozialstaates unvereinbar wäre.

bb) Das zeigt, daß der Bestimmtheitsgrundsatz nur auf Ermächtigungen zum Erlaß genereller Verhaltensregelungen uneingeschränkt anwendbar ist. Für die Gestaltungsfunktion der Verwaltung kann er nur sinngemäß gelten, vor allem in seiner Funktion, die grundlegenden politischen Entscheidungen dem Parlament vorzubehalten ${ }^{64}$ ). Die Rechtsprechung hat daraus allerdings mehr pragmatisch als theoriegeleitet - längst die Konsequenz gezogen, an die Bestimmtheit der Ermächtigung bei wirtschaftslenkenden Gesetzen nicht so strenge Anforderungen zu stellen ${ }^{65}$ ). [Das bedeutet eine flexiblere, nach den Funktionen abgestufte Handhabung dieser Bestimmung.]

4) Art. 80 I 2 GG enthält sowohl eine rechtsstaatliche wie eine demokratische Komponente, wobei diese Unterscheidung allerdings nicht in einer strengen Gegensätzlichkeit verstanden werden darf. Die rechtsstaatliche Komponente bezweckt in Verbindung mit dem herkömmlichen Rechtssatzbegriff, Eingriffe in Freiheit und Eigentum von der Zustimmung des Parlaments abhängig und für den einzelnen vorhersehbar zu machen sowie eine gerichtliche Kontrolle darüber zu ermöglichen. Diese Funktion kann, wie ausgeführt, bei Ermächtigungen zur planenden Gestaltung nicht in demselben Umfange erfüllt werden wie bei Ermächtigungen zum Erlaß von Verhaltensvorschriften. Um so wichtiger ist es, die planende Gestaltung für den einzelnen transparenter zu machen und die Geltendmachung seiner Rechte - insbesondere auch durch entsprechende Beteiligungsformen etwa im Rahmen des rechtlichen Gehörs - wirksamer zu gestalten, wie es in den folgenden Abschnitten versucht wird. Die demokratische Komponente des Art. 80 I 2 GG liegt in dem Verbot an das Parlament, sich der Verantwortung, d. h. den grundsätzlichen politischen Entscheidungen zu entziehen. Auch dieser Funktion kann bei Ermächtigungen zur gestaltenden Verwaltung nicht in vollem Umfange entsprochen werden; hier liegt die Kompensation in der im folgenden darzulegenden "demokratischen Rückkoppelung". Zu den Funktionen des Art. 80 I 2 GG vgl. etwa Friedrich Klein - Ulrich Scheuner, Die Ubertragung rechtsetzender Gewalt im Rechtsstaat, Frankfurt/M. 1952, S. 49, 70, 68 ff.; Horst Ehm$k e$, Wirtschaft und Verfassung. Die Verfassungsrechtsprechung des Supreme Court zur Wirtschaftsregulierung, Karlsruhe 1961, S. 77 m. w. N.; Konrad Hesse, Grundzüge des Verfassungsrechts, 4. Aufl., Karlsruhe 1970, S. 210 f.; sowie die Diskussionsbeiträge von Badura, Bachof, Ehmke und Zacher, VVDStRL 24 (1966), S. 213, 225 f., 231, 234; a. A. Hans Heinrich Rupp, Grundfragen der heutigen Verwaltungsrechtslehre, Tübingen $1965, \mathrm{~S} .133,135 \mathrm{~m}$. w. N., der das rechtsstaatliche Moment isoliert betrachtet.

as) Vgl. etwa BVerfG v. 12. 11. 1958, BVerfGE 8, 274 (307 ff.); v. 15. 12. 1959, BVerfGE 10, 251 (255 ff.); v. 5. 5. 1965, BVerfGE 19, 17 
cc) Dabei kann es jedoch nicht sein Bewenden haben. Wenn Art. 80 I 2 GG in seiner Funktion nicht ausgehöhlt werden soll, muß das Zusammenwirken von Parlament und Regierung beim Erlaß der Zielnormen auch auf die Fortführung der Zwecksetzung durch die Verwaltung übertragen werden. In dem $\mathrm{Maße}$, in dem die Lenkungsfunktion auf die Verwaltung übergeht, ist der Kompetenzverlust des Parlaments ${ }^{00}$ ) durch eine entsprechende "demokratische Rückkoppelung" auszugleichen. M. a. W.: Eine Lockerung der Anforderungen des Bestimmtheitsgrundsatzes in Art. 80 I 2 GG ist nur zulässig, wenn sie durch entsprechende Mitwirkungs- und Kontrollrechte des Parlaments kompensiert wird. Das Stabilitätsgesetz hat diesen Anforderungen bereits entsprochen, wenn es die konjunkturpolitischen Maßnahmen der Regierung einem Zustimmungs- und Kassationsrecht des Parlaments unterwarf ${ }^{07}$ ).

Es ist zu erwägen, ob diese "Kompensation" immer durch eine „Rückkoppelung“ an das Parlament oder nicht bei einem begrenzten Wirkungskreis der Verwaltungsmaßnahmen auch durch die Mitwirkung der Betroffenen erfolgen kann. Schließlich wenden wir zu Recht Art. 80 I 2 GG nicht auf den Erlaß von Satzungen an, sofern sie ihre demokratische Legitimation durch das Bestimmungsrecht eines körperschaftlich verfaßten „Verbandsvolkes“ erfahren ${ }^{68}$ ). Entsprechende Mitwirkungsfor-

(30); v. 18. 10. 1966, BVerfGE 20, 296 (303 ff.); v. 21. 5. 1968, BVertGE 24, 1 (15 ff.).

ob) Dazu oben III. 2. a, b. - Vgl. auch Klaus Stern, in: SternMünch, Gesetz zur Förderung der Stabilität und des Wachstums der Wirtschaft, Kommentar, Stuttgart 1967, S. 55; Hans Heinrich Rupp, Die Dogmatik des Verwaltungsrechts und die Gegenwartsaufgaben der Verwaltung, DVBl. 1971, S. $669 \mathrm{ff}$. (671 ff.).

67) Genauer geht es um das Recht des Parlaments, dem ErlaB zuzustimmen oder die Aufhebung einer erlassenen Verordnung zu verlangen. Vgl. Art. 109 IV GG sowie etwa \$§ 8 I, 26 Nr. 3 Gesetz zur Förderung der Stabilität und des Wachstums der Wirtschaft v. 8. Juni 1967 (BGBl. I S. 581).

e) Dazu im einzelnen W. Brohm, Strukturen der Wirtschattsverwaltung, S. 245 ff. (248-262). Die Möglichkeit einer eigenständigen demokratischen Legitimation für organisationsinterne Gestaltungen betonen auch Ernst $v$. Hippel, Vom Wesen der Demokratie, Bonn 1947, S. 48; Roman Herzog, Allgemeine Staatslehre, Frankfurt/M. 1971, S. 220 ff.; Herzog gebraucht in diesem Zusammenhang, wohl in Anlehnung an Hans Kelsen, Allgemeine Staatslehre, Berlin 1925, Neudruck Bad Homburg v. d. H. 1966, S. 180 f., den Terminus ,Tellvolk"; hier wird die Bezeichnung "Verbandsvolk" vorgezogen, weil es für die demokratische Legitimation nicht ausreicht, daß irgendein Teil des Staatsvolkes mitwirkt, sondern das "ganze Volk" der betreffenden Organisation, d.h. die Einheit der diesem Ordnungsbereich eingegliederten Personen diese Befugnis besitzen muß. Der Begriff „Verbandsvolk" bringt weiter zum Ausdruck, daB die el- 
men ließen sich, rechtspolitisch gesprochen, auch für einzelne Planungsmaßnahmen denken ${ }^{60}$ ).

genständige Legitimation durch die Verbandsmitglieder sich nur auf Anordnungen beziehen kann, die sich auf die Mitglieder beschränken und nicht außenstehende Dritte betreffen. Diese Auffassung deckt sich im Ergebnis mit der von Herzog. Wenn er aber aaO. meint, öffentlich-rechtliche Körperschaften könnten nur Organisationen mit „Zwangsmitgliedschaft" sein, so ist diese Bestimmung des Verbandsvolkes allzu formal. Sie trifft nicht die Staatswirklichkeit, die seit jeher eine Vielzahl öffentlich-rechtlicher Körperschaften ohne Zwangsmitgliedschaft kannte und bis heute kennt (ohne daß darin eine Verletzung des Gleichheitssatzes gesehen werden könnte) und reduziert letztlich die hoheitlichen Funktionen auf die Zwangsgewalt, womit man den leistenden und gestaltenden Aufgaben des gegenwärtigen Sozialstaates kaum gerecht wird. Auch kann nicht jede irgendwie verfügte Personengruppierung eine demokratische Legitimationsbasis abgeben; dazu bedarf es einer gewissen "sozialen Homogenität" der Betroffenen, einer Interessengemeinschaft, die Voraussetzung dafür ist, daß die Angehörigen der Organisation die von der staatlichen Rechtsordnung gestellten Aufgaben als ihre eigenen und deren Gestaltung durch die Organisation als ihre eigenen Regeln empfinden. Fehlt es daran, so ist an diesem Punkte im Hinblick auf die Herrschaftsbefugnis der Organisation die Problematik des Art. 3 GG angesprochen. Dazu im einzelnen W. Brohm, Strukturen der Wirtschaftsverwaltung, aaO.

o) Insofern stehen die verschiedenen Formen und Möglichkeiten demokratischer Legitimation nicht isoliert nebeneinander, sondern vermögen sich auch gegenseitig zu ergänzen. Voraussetzung für eine eigenständige demokratische Legitimation durch die Betroffenen bleibt (wie in der vorangehenden Anmerkung erwähnt), daß die Betroffenen im Hinblick auf die wahrzunehmende Aufgabe als eine etnheitliche Gruppe angesehen werden können, die insoweit elgene Angelegenheiten erledigt. Das ist auch möglich, wenn sich die Zusammengehörigkeit auf einen begrenzten $Z$ weck von $u$. $U$. kürzerer Dauer und begrenztem räumlichen Wirkungsradius beschränkt. Dle allenthalben festzustellende organisatorische Differenzierung und Spezlalisierung erfaßt in steigendem Maße den einzelnen nur für spezifische Zwecksetzungen und in wenigen, eng begrenzten Beziehungen. Die Grenzen in der Annahme organisierter Einheiten sind dabel fließend und müssen weit gesteckt werden. (Dazu Renate Mayntz, Soziologie der Organisation, Reinbek b. Hamburg 1963, bes. S. $36 \mathrm{ff}$.). Die Rechtsdogmatik hat diesen Gegebenheiten Rechnung zu tragen, indem sie die Möglichkeiten eigenständiger demokratischer Legitimation entsprechend weit faßt. Das Grundgesetz gibt hierfür nicht zuletzt in den Art. 28 I, II, 87 II, III ausreichende Anhaltspunkte. Daß hierbei verschiedene Formen demokratłscher Mitwirkung, insbesondere auch plebiszitäre Varianten zulässig sind, ist anerkannt. (Vgl. Th. Maunz, in: Maunz-DürigHerzog, Rdnr. 22 zu Art. 28 GG). Je mehr die Gesetzgebung an Allgemeinheit verliert und konkrete und damit abgrenzbare Gestaltungsmaßnahmen bezweckt, läßt sich so die demokratische Legitimation von Herrschaft, wie sle in dem politischen Gesetzesbegriff angesprochen ist, auf die wirklich Betroffenen begrenzen. Das gilt vor allem für die konkreteren Durchführungsplanungen, weniger für die Planungen im Makrobereich. Allerdings darf in Anbetracht 
Rechtsdogmatisch bestehen gewisse Beteiligungsrechte bereits auf Grund einer verfassungsrechtlich gebotenen Ausweitung des subjektiven öffentlichen Rechtes ${ }^{70}$ ). [Diese ergibt sich aus folgenden Erwägungen.]

3. a) Wie erwähnt, gewinnt die Ansicht, daß subjektive Rechte auch durch eine mittelbare Einwirkung verletzt werden können, immer mehr Anhänger ${ }^{11}$ ). [Sie ist aus demselben Grun-

der starken Interdependenz aller Lebensverhältnisse der praktische Anwendungsbereich dieser rechtlichen Möglichkeiten nicht überschätzt werden. Gestaltungsmaßnahmen, die über den Lebenskreis der zur eigenständigen Legitimation berufenen Gruppe hinausrelchen, müssen durch das Gesamtvolk des Staates oder zumindest derjenigen größeren Einheit, auf die sie sich auswirken, legitimiert seln. Indessen genügt es, wenn Festlegungen nur insoweit, als der begrenzte Wirkungsbereich überschritten wird, durch das Gesamtvolk erfolgen. Für die Ausgestaltungen im einzelnen bleiben dann immer noch Möglichkeiten dezentralisierter Legitimation. So wäre es z. B. dem Gesetzgeber möglich, die Präzisierungen für die Sanierung eines Stadtteils oder die Modalitäten zur Durchführung der Frdölbevorratung oder einer Beschränkung der unternehmerischen Aktivität auf dem Heizölmarkt den damit unmittelbar angesprochenen und auch besonders fachkundigen Kreisen zu überlassen, wenn nur das $Z$ iel und die wesentlichen für die Allgemeinheit bedeutsamen Grundentscheidungen in der Gemeindesatzung oder in dem Parlamentsgesetz fixiert sind. Befürchtungen, daß über eine eigenständige Legitimation durch die Betroffenen die Einheit des politischen Gemeinwesens und das öffentliche Wohl verfehlt werden könnten, sind bei der Einführung solcher Möglichkeiten mit zu berücksichtigen. Sie können jedoch so lange zurückgestellt bleiben, als der Aufgabenkreis begrenzt ist und die grundlegenden, über einen begrenzten Wirkungskreis hinausreichenden Entscheidungen in der Hand des Gesamtvolkes verbleiben. Weiter besteht auch immer die Möglichkeit, daß die Vertretung des Gesamtvolkes die Entscheidung wieder an sich zieht oder korrigierend eingrelft. Dazu noch unten unter $\mathrm{V}$.

70) Diese Beteiligungsmöglichkeiten folgen aus rechtsstaatlichen Gewährleistungen, wie dem Anhörungsrecht der konkret Betroflenen und dem gerichtlichen Rechtsschutz ihrer Rechte. Insolern sind sie dogmatisch von den zuvor erwähnten Formen demokratischer Legitimation zu unterscheiden. Sie werden jedoch zuglelch dem Demokratiegebot in seiner Ausrichtung auf Transparenz und dauernde Konsenswerbung gerecht. Dazu unten Nr. 5.

i1) Hans-Ulrich Gallwas, Faktische Beeinträchtigungen im Berelch der Grundrechte. Ein Beitrag zum Begriff der Nebenwirkungen. Berlin 1970, S. $21 \mathrm{ff}$., $49 \mathrm{ff}$. und passim m. zahlr. N. auch aus der Rechtsprechung; Rudolf Bernhardt, Zur Anfechtung von Verwaltungsakten durch Dritte, JZ 1963, S. 302 ff.; Wilhelm Henke, Das subjektive öffentliche Recht, Tübingen 1968, bes. $S$. 71 If.; $\boldsymbol{R}$. Scholz, Wirtschaftsaufsicht und subjektiver Konkurrentenschutz, $\mathbf{S}$. 46 ff. m. zahlr. w. N.; E. Stachels, Stabllitätsgesetz, S. 20 if.; a. A. H. Wagner, VVDStRL 27 (1969), S. $47 \mathrm{fl}$. (63 ff. und Leitsatz 16) im Hinblick auf globalsteuernde Maßnahmen. 
de zu bejahen wie die Ausweitung des Gesetzesvorbehaltes. Auch die Rechtsprechung schließt sich neuerdings dieser Auffassung an, wenn sie Klagen der Drittbetroffenen, der Nachbarn oder Konkurrenten, zuläßt ${ }^{72}$ ).] Es kommt also für die Aktualisierung eines subjektiven öffentlichen Rechtes nicht mehr auf das Vorliegen eines Eingriffsaktes an, sondern allein auf die Rechtsbeeinträchtigung, gleichgültig, durch welche Handlungsmodalität der Verwaltung sie hervorgerufen wur-

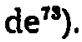

b) Allerdings ist bislang noch unklar, wann normative Festlegungen subjektive Rechte gewähren. Man kann bezweifeln, ob die Entgegensetzung von objektivem und subjektivem Recht in einem demokratischen Rechtsstaat überhaupt noch ihren Platz hat. [Schließlich begründet hier die gesamte Rechtsordnung die Rechtsstellung des einzelnen als Rechtssubjekt, so daß eine Rechtsverletzung immer auch seine Rechte tangiert. Der Ausschluß der Popularklage ${ }^{74}$ ) wäre dann lediglich eine prozessuale Einschränkung, die nach der faktischen Beschwer zu beurteilen wäre $\left.{ }^{75}\right)$.]

Hält man prinzipiell an dieser Unterscheidung fest, so ist sie jedenfalls durch die Grundrechte wesentlich relativiert. Denn nach Art. 2 I GG als allgemeines Freiheitsrecht oder rach den speziellen Freiheitsrechten braucht der einzelne eine Beeinträchtigung nicht hinzunehmen, wenn sie nicht in materieller wie formeller Hinsicht mit den Normen der Rechtsordnung übereinstimmt ${ }^{78}$ ). Diese vom Bundesverfassungsgericht mit dem

72) Zahlreiche Nachweisungen aus der Rechtsprechung zur Rechtsposition des Drittbetroffenen im Personenbeförderungs-, Bau- und Subventionsrecht bei: $R$. Bernhardt, JZ 1963, S. 302 ff.; $R$. Scholz, Wirtschaftsaufsicht und subjektiver Konkurrentenschutz, S. 57 ff.; H. J. Wolff, Verwaltungsrecht I, \& 43 I b; vgl. ferner BVerwG v. 30. 8. 1968, BVerwGE 30, 191 (196 f.), DVBl. 1969, S. 365 m. Anm. v. K. H. Friauf.

79) Dazu im einzelnen H.-U. Gallwas, Faktische Beeinträchtigungen, S. 25 ff. und passim; R. Scholz, Wirtschaftsaufsicht und subjektiver Konkurrentenschutz, S. 76 ff. m. w. N.

74) Darin liegt nach allgemeiner Meinung die Bedeutung des Erfordermisses der Verletzung in "eigenen" Rechten in Art. 19 IV GG und \$ 42 II VwGO.

73) Das ist letztlich die Position von W. Henke, Das subjektive öffentliche Recht, vgl. etwa S. 54. Die spätere Einschränkung (ebd., S. 60), daß das gesetzwidrige Verhalten der Verwaltung den Bürger in "seinen eigenen Angelegenheiten" betreffen müsse, ergibt sich deshalb bei ihm nur aus objektiven Gegebenheiten bzw. tatsächlichen Auswirkungen.

76) Das gilt für imperative wie faktische Beeinträchtigungen. Ob im letzteren Fall die speziellen grundrechtlichen Gewährleistungen die allgemeinen verdrängen, braucht hier nicht erörtert zu werden. 
Elfes-Urteil ${ }^{77}$ ) eingeleitete Entwicklung ist für den Adressaten der Verwaltungshandlung heute unbestritten; sie beginnt sich allmählich auch für den Drittbetroffenen, [den Nachbarn des Bauherrn oder den Konkurrenten des begünstigten Unternehmers,] durchzusetzen ${ }^{78}$ ). Dabei ist noch vieles ungeklärt ${ }^{70}$ ). Jedenfalls kann in Parallele zur verfassungsgerichtlichen Rechtsprechung festgehalten werden, daß es nicht im Belieben des Gesetzgebers liegen kann, subjektive öffentliche Rechte zu gewähren oder vorzuenthalten, sondern daß jede Nichteinhaltung der gesetzlichen Vorschriften oder Rechtsgrundsätze, samt der dazugehörenden Kompetenz- und Verfahrensvorschriften, auch Dritte in ihren Rechten verletzt, sobald sie nur selbst durch die Maßnahme der Verwaltung betroffen sind ${ }^{\mathrm{B}}$ ).

$\mathrm{Zu}$ dieser Streitfrage vgl. einerseits Hans $F$. Zacher, Verwaltung durch Subventionen, VVDStRL 25 (1967), S. $308 \mathrm{ff}$. (368 f.), andererseits H.-U. Gallwas, Faktische Beeinträchtigungen, S. 68 m. Anm. 83 .

17) BVerfG v. 16. 1. 1957, BVerfGE 6, 32 (38).

78) Es war wenig verständlich, wenn bislang bei Anfechtungsklagen des Adressaten eines Verwaltungsaktes die Klagebefugnis wegen der Einschränkung seines "allgemeinen Freiheitsrechtes" ohne weiteres angenommen wurde, so daß er auch die Verletzung von Kompetenzvorschriften oder allgemeinen Rechtsgrundsätzen, wie des Ubermaßverbotes, rügen konnte, während der Drittbetroffene diese Rechtsposition nur haben sollte, wenn eine gesetzliche Norm bestand, die zumindest auch seinem Interesse zu dienen bestimmt war. Zur gegenwärtigen Rechtsauffassung im einzelnen vgl. R. Bernhardt, JZ 1963, S. 302 ff. (306 f.); G. Dürig, in: Maunz-DürigHerzog, Rdnr. 26 zu Art. 2 I GG und Rdnr. 36 zu Art. 19 IV GG m. w. N.; H.-U. Gallwas, Faktische Beeinträchtigungen, S. 142 f. und passim; Markus Wiebel, Wirtschaftslenkung und verwaltungsgerichtlicher Rechtsschutz des Wirtschafters nach dem ErlaB des Stabilitätsgesetzes, Stuttgart 1971, S. 57 f.; Richard Bartlsperger, Subjektives öffentliches Recht und störungspräventive Baunachbarklage, DVBl. 1971 , S. 723 ff. (731 f.); H. J. Wolff, Verwaltungsrecht I, $\S 43 \mathrm{I} \mathrm{b} 2 \mathrm{~m}$. zahlr. w. N.

70) So etwa die Frage, wie weit Art. 2 I und Art. 3 I GG bzw. die speziellen Grundrechtsnormen auch bei Leistungsgewährungen reichen. Der Gedanke, daß die Grundrechte durch die Gesetze ausgestaltet werden (vgl. etwa Peter Häberle, Die Wesensgehaltsgarantie cies Art. 19 Abs. 2 GG, Karlsruhe 1962; Walter Leisner, Von der Verfassungsmäßigkeit der Gesetze zur Gesetzmäßigkeit der Verfassung, Tübingen 1964) bietet hierfür einen Ansatzpunkt, bedarf aber noch der weiteren Präzisierung in dieser Frage. Dazu auch die folgende Anm.

80) Insofern müssen auch diese Erwägungen praktisch zur Aufhebung des Gegensatzes von objektivem und subjektivem Recht führen. $O b$ überhaupt Fälle denkbar sind, in denen diese Unterscheidung noch eine praktische Bedeutung erlangen kann, müßte an Hand einzelner Fallgruppen untersucht werden. In eine solche Untersuchung wäre auch die Abgrenzung von "innen" und „außen“, von Kompetenz- und Verhaltensrecht einzubeziehen, mit der vielfach funktional äquivalente Wirkungen erzielt werden. Das muß 
c) Diese Ausweitung des subjektiven öffentlichen Rechts wirkt sich auf den Gerichtsschutz allerdings im wesentlichen nur bei den Vollzugsfunktionen aus ${ }^{81}$ ). Denn die Gestaltungsfunktionen lassen sich vom Recht nur in den Randzonen eines evidenten Mißbrauches erfassen ${ }^{02}$ ). Bei ihnen hat die Ausweitung des subjektiven öffentlichen Rechts vor allem verfahrensrechtliche Bedeutung. Auf beide Fragen ist zunächst weiter einzugehen.

4. Auch die Handlungsmaßstäbe der Verwaltung sind an der isolierten Vollzugsentscheidung orientiert ${ }^{\text {(s) }}$ ).

späteren Ausführungen vorbehalten bleiben. Die Nivellierung der Unterscheidung von objektivem und subjektivem Recht zwingt dazu, die Frage der Klagebefugnis als spezielles prozeßrechtliches Problem des Ausschlusses der Popularklage zu verstehen und dafür Maßstäbe zu finden. Das BVerfG, das infolge des unbestrittenen Charakters der Grundrechte als subjektiver Rechte die Unterscheidung zwischen objektivem und subjektivem Recht nicht treffen konnte, hat deshalb auch speziell für die Klagebefugnis Kriterien der Beschwer entwickelt. Danach muß der Kläger durch die beanstandete Maßnahme selbst, gegenwärtig und unmittelbar betroffen sein (vgl. bereits BVerfG v. 19. 12. 1951, BVerfGE 1, 97 (101)). Die Unmittelbarkeit aber wird angenommen bei einer rechtlichen Bindung wie auch bei elner „faktischen" Rechtsbeeinträchtigung, sofern eine "besondere Beziehung zum Sachverhalt" vorliegt. Dazu im elnzelnen $M$. Wiebel, Wirtschaftslenkung und verwaltungsgerichtlicher Rechtsschutz, S. 82 f. m. w. N. aus der Rechtsprechung. Diese Abgrenzung deckt sich weithin mit den Kriterien, mit denen im französischen. Recht, das weniger auf das Vorliegen eines subjektiven Rechtes abstellt, die Popularklage ausgeschlossen wird. Vgl. André de Laubadère, Traité Elémentaire de Droit Aministratif, Bd. I, 5. Aufl., Paris 1970, S. 483 ff.; J.-M. Auby/M. Drago, Traité de Contentieux Administratif, Bd. II, Paris 1962, S. $495 \mathrm{ff}$.

81) Etwa im Anspruch auf die Einhaltung einer verbindlich festgestellten Durchführungsplanung im Einzelfall.

8:2) Hier bleibt den Betroffenen im Regelfalle nur ein "Dulde und Liquidiere“, wobei die Sozialgebundenheit des Eigentums gerade bei Planungen auch Abstufungen in der Entschädigungsleistung zuläBt. Vgl. speziell am Beispiel der Stadtplanung: W. Brohm, Art.: Städtebau, Staatslexikon, 3. Ergänzungsband, Sp. 339 ff. (346, 348 f).

88) Das zeigt sich auch dort, wo der Verwaltung, wie beim Ermessen, ein Entscheidungsspielraum eingeräumt ist. So weist $E$. Forsthoff, Verwaltungsrecht, S. 69, auf den Unterschied zwischen den „normativ geregelten Ermessensbetätigungen" und dem "gestaltenden Ermessen" hin. Ebenso betont $H$. J. Wolff, Verwaltungsrecht I, \& 31 II a, III, daß Ermessen nur i. S. einer Unbestimmtheit der Rechtsfolge, nicht aber des Begriffs oder gar der Beliebigkeit einer Tatbestandssetzung verstanden werden dürfe. Entsprechend Klaus Stern, Ermessen und unzulässige Ermessensausübung, Berlin 1964, etwa S. 22, 15. 
So vermag das Prinzip der Erforderlichkeit im Sinne eines möglichst geringen Eingriffes ${ }^{84}$ ) noch relativ eindeutige Entscheidungen herbeizuführen, wenn der Handlungszweck und die Handlungswirkung begrenzt und überschaubar bleiben ${ }^{85}$ ). Härteklauseln und Optionsmöglichkeiten der Betroffenen vermögen überdies auszugleichen, was im einzelnen Fall an intersubjektivem Wertkonsens oder einem umfassenden Uberblick über die Handlungsalternativen fehlen mag. Je breiter aber die Wirkungen der Verwaltungsmaßnahmen sind und je mehr die Verwaltung im Rahmen von Zielnormen die Unterzwecke selbst setzt, desto mehr verliert dieser Maßstab an Präzision. Denn es fehlt eine transitive und konsistente Wertskala, die eine erste Voraussetzung für eindeutige Entscheidungen wäre. [Sie könnte auch gar nicht aufgestellt werden, weil die Datenkonstellationen $z u$ komplex und $z u$ veränderlich sind und außerdem die Flexibilität des Systems dadurch viel $\mathrm{zu}$ 'sehr beeinträchtigt würde ${ }^{30}$ ).] Insofern kann sich eine Rechtskontrolle nur darauf beschränken, ob sich die Zwecksetzungen und Präferenzen der Verwaltung im Rahmen der Verfassung und der gesetzlichen Zielnormen halten und nicht gerade als willkürlich erscheinen ${ }^{87}$ ).

84) Zum Übermaßverbot mit seinen Elementen der Geeignetheit, Erforderlichkeit und Verhältnismäßigkeit vgl. insbes. Rupprecht $v$. Krauss, Der Grundsatz der Verhältnismäßigkeit in seiner Bedeutung für die Notwendigkeit des Mittels im Verwaltungsrecht, Hamburg 1955; Peter Lerche, Uberma $B$ und Verfassungsrecht, Köln $1961 ; H$. J. Wolff, Verwaltungsrecht I, $\$ 30$ II b 1.

B5) Man muß sich darüber im klaren sein, daß auch bei der Beurteilung der Erforderlichkeit einer Maßnahme nicht die Mittel, sondern die Schäden (der tatsächlich drohende und der durch den „Eingriff“ bewirkte Schaden) miteinander verglichen werden, was sofort die Probleme der Transitivität der Wertskala, der menschlichen Informationsverarbeitungskapazität und andere Fragen aufwirft, die vor allem in den wirtschaftswissenschaftlichen Entscheidungstheorien im Zusammenhang mit dem ökonomischen Prinzip diskutiert werden. Vgl. etwa Gerard Gäfgen, Theorie der wirtschaftlichen Entscheidung, 2. Aufl., Tübingen 1968, bes. S. 95 ff.; N. Luhmann, Zweckbegriff, S. 22, 59, 64 und passim. Diese Probleme treten bel den "Vollzugsfunktionen" der Verwaltung im allgemeinen nicht so entscheidend hervor, weil der Wirkungsradius des Verwaltungshandelns und der vorgegebene Zweck relativ begrenzt und überschaubar bleiben. Daß dies nicht immer der Fall ist, hat die Anordnung des Schußwaffengebrauchs beim „Münchener Banküberfall" erst jetzt wieder drastisch vor Augen geführt.

86) Dazu im einzelnen G. Gäfgen, Theorie der wirtschaftlichen Entscheidung, S. 145 ff., $271 \mathrm{ff}$.

87) Das Erforderlichkeitsprinzip spielt dabel Insofern eine Rolle, als Je nach der Mittelwahl auch andere Zwecke $u$. U. besser verfolgt werden könnten. 
Mit der Zwecksetzung aber entscheidet die Verwaltung zugleich auch über die Mittel. Selbst diese Zweck-Mittel-Entscheidung läßt sich mit dem Erforderlichkeitsprinzip nicht eindeutig bestimmen. Denn es übersteigt die menschliche Fähigkeit, alle Handlungsalternativen und Folgewirkungen im Hinblick auf den Adressaten und die Drittbetroffenen ${ }^{88}$ ) zu überschauen und nach dem Minimierungsprinzip zweifelsfrei einzustufen ${ }^{80}$ ). [Das gilt erst recht, wenn sich bei sozialgestaltenden Maßnahmen die Auswirkungen auf die gesellschaftliche Entwicklung im vorhinein nicht genau abschätzen lassen.]

Die Entscheidungssituation kompliziert sich noch, wenn man bedenkt, daß gerade die sozialgestaltenden Maßnahmen nicht isoliert für sich betrachtet werden können, sondern als Systemproblem erfaßt werden müssen. Das besagt folgendes:

Die modernen Organisationstheorien verstehen Entscheidungen als Ergebnis eines Informationsverarbeitungsprozesses, der dadurch zustande kommt, daß in das Verwaltungssystem an der Inputgrenze Informationen eingegeben werden, die nach ihrer Verarbeitung an der Outputgrenze mit einem Mehr an Information wieder ausgegeben werden. Dieses Modell macht deutlich, daß die Outputgrenzen in zeitlicher und räumlicher Hinsicht verschoben werden können. Das System braucht seine Reaktionen nicht mehr und nicht sofort an derselben Stelle zu zeigen, es kann den Output auch auf andere Gebiete lenken und damit diese zeitlich oder überhaupt vorziehen ${ }^{00}$ ). Insofern müßten bei umfassenderen Gestaltungen in die Erforderlichkeitsprüfung die alternativen und variablen Zielsetzungen des gesamten Systems einbezogen werden. Damit aber verliert das Erforderlichkeitsprinzip für Gesamtgestaltungen jede Schärfe. [Es kann allenfalls in deren Rahmen beim Vollzug

89) $\mathrm{DaB}$ auch in dieser Dimension das Ubermaßverbot zu beachten ist, ergibt sich aus der Ausdehnung des subjektiven öffentlichen Rechts. Vgl. in diesem Sinne ausdrücklich etwa H.-U. Gallwas, Faktische Beeinträchtigungen, S. 80 .

89) Vgl. Herbert A. Simon, Models of Man, Social and Rational: Mathematical Essays on Rational Human Behavior in a Social Setting, New York-London 1957, S. $196 \mathrm{ff.,} 241$ ff.; James G. March/ Herbert A. Simon, Organizations, New York-London 1958, S. 140 f.; Karl W. Deutsch, The Nerves of Government, New York 1966, S. 51 ff.; Frieder Naschold, Systemsteuerung, 2. Aufl., Stuttgart 1971, S. 43 f.; N. Luhmann, Zweckbegriff, S. 18, $77 \mathrm{f}$.

10) Zum Ganzen N. Luhmann, Zweckbegriff, S. 171 ff. und passim. Zur Verfeinerung des Input-Output-Modells in Anlehnung an David Easton, A Systems Analysis of Political Life, New York 1965: Frieder Naschold, Vernachlässigte Aspekte der Regierungs- und Verwaltungsreform in der Bundesrepublik Deutschland, Kommunikation V/4, 1969, S. $191 \mathrm{ff}$. 
gegenüber einzelnen Betroffenen kleinere Feineinstellungen bewirken.]

Entsprechendes ließe sich zu Art. 3 GG ausführen. [Wie gering seine Aussagekraft für die planende Gestaltung ist, wurde an Hand der Subventionsproblematik schon unter den verschiedensten Gesichtspunkten dargetan ${ }^{01}$ ).]

Die Situation der gestaltenden Verwaltung kommt so derjenigen der wirtschaftslenkenden Gesetzgebung nahe, auch wenn sich die Verwaltung im allgemeinen präziseren Zielvorstellungen gegenübersieht als der Gesetzgeber ${ }^{82}$ ). Wenn sich in diesem Bereich das Bundesverfassungsgericht allmählich darauf beschränkt hat, nur die. Vertretbarkeit bzw. eine eventuelle Willkür bei der Zielsetzung ${ }^{03}$ ) und neuerdings auch bei der Geeignetheit und Erforderlichkeit ${ }^{04}$ ) zu überprüfen, so geschah das aus pragmatischen Erwägungen heraus. Sie zeigen aber die Richtigkeit der entscheidungstheoretischen Erkenntnis, da $B$ allenfalls "brauchbare“ oder „befriedigende“, nicht aber „optimale" oder "einzig richtige" Entscheidungen zu erzielen sind ${ }^{\text {s) }}$ "). Die Verwaltungsgerichte werden diesem Umstand mehr als bisher Rechnung tragen müssen ${ }^{97}$ ). [Denn es geht hier um ein funk-

11) Vgl. etwa Volkmar Götz, Recht der Wirtschaftssubventionen, München 1966, S. 264 ff.; Hans Peter Ipsen, Verwaltung durch Subventionen, VVDStRL 25 (1967), S. 257 ff. (303); H. F. Zacher, VVDStRL 25 (1967), S. 308 ff. (369); Günter Dürig, Diskussionsbeitrag, VVDStRL 25 (1967), S. 416; Hans Huber, Die Gleichbehandlung der Gewerbegenossen, in: Festschrift für Walter Hug, Bern 1968, S. $447 \mathrm{ff}$. (466); H. Wagner, VVDStRL 27 (1969), S. 47 ff. (70); Heiko Faber, Anmerkung zum Urteil des BVerwG v. 20. 6. 1969, JZ 1970, S. $220 \mathrm{ff}$.

$\left.{ }^{22}\right) \mathrm{Zu}$ den Zielvorschriften für den Gesetzgeber auf Grund „dirigierender Verfassungsnormen" vgl. $P$. Lerche, UbermaB, $S$. $61 \mathrm{ff}$. und passim.

23) Vgl. BVerfG v. 17. 7. 1961, BVerfGE 13, 97 (107); v. 22. 5. 1963, BVerfGE 16, 163 (167 ff.); v. 14. 12. 1965, BVerfGE 19, 330 (337 ff.); ständige Rechtsprechung.

94) Dazu insbes. BVeriG v. 9. 3. 1971, BVerfGE 30, 250 (263 If.) m. w. N.

95) Dazu etwa Niklas Luhmann, Kann die Verwaltung wirtschaftlich handeln? VerwArch. 51 (1960), S. 97 ff. (105); F. Naschold, Systemsteuerung, S. $52 \mathrm{~m}$. w. N.

9) Die Kritik an dieser Rechtsprechung (vgl. neuerdings etwa Michael Klöpfer, Das Geeignetheitsgebot bei wirtschaftslenkenden Steuergesetzen, NJW 1971, S. 1585 ff.) mag zwar in Einzelheiten hinsichtlich der Begründung, die das Gericht gegeben hat, gerechtfertigt sein. Im Ergebnis wird man dieser Rechtsprechung jedoch angesichts der entscheidungstheoretischen Erkenntnisse zustimmen müssen, solange keine Kriterien für eine größere Kontrolldichte gefunden sind. Dazu auch die folgende Anm.

07) Das gilt gerade im Hinblick auf dle neuerdings verfolgte Tendenz, allgemein bei unbestimmten Rechtsbegriffen der Verwaltung 
tionell-rechtliches Problem. Wo die rechtliche Eindeutigkeit aufhört, beginnt im Verhältnis zur Gerichtsbarkeit die Letztverantwortlichkeit der Verwaltung. Die Exekutive ist auf Grund ihrer personellen und organisatorischen Struktur besser zur Entscheidung solcher Fragen ausgerüstet.] Dabei ist zu beachten, daß die Handlungsspielräume der Verwaltung durch eine unterschiedliche rechtliche Verdichtung im Einzelfall er-

keinen Beurteilungsspielraum mehr zuzuerkennen (vgl. dazu die Nachweisungen bei $H$. J. Wolff, Verwaltungsrecht $I, \$ 31$ I c 3, S. 181) wie auch auf diesem Wege das bislang als besonders weit anerkannte Planungsermessen der Verwaltung mehr und mehr gerichtlich "nachzuprüfen". Vgl. etwa BVerwG v. 12. 12. 1969, BVerwGE 34, 301 und die viel beachtete Floatglasentscheidung des VG Gelsenkirchen v. 4. 7. 1971, DB 1971, S. 1518. Die Lehre vom „Beurteilungsspielraum" (dazu grundlegend Otto Bachof, Beurteilungssplelraum, Ermessen und unbestimmter Rechtsbegriff im Verwaltungsrecht, JZ 1955, S. 97 ff.; entsprechend die "Vertretbarkeitstheorie" von Carl Hermann Ule, Zur Anwendung unbestimmter Rechtsbegriffe im Verwaltungsrecht, Gedächtnisschrift für Walter Jellinek, München 1955, S. 309 ff.) wird allein den oben erwähnten entscheidungstheoretischen Erkenntnissen gerecht. Daß es anstrebenswert ist, den gerichtlichen Rechtsschutz gerade auch im Bereich der gestaltenden Verwaltung zu verstärken, soll damit nicht bestritten werden. (Vgl. etwa auch Werner Hoppe, Rechtsschutz bei der Planung von Straßen und anderen Verkehrsanlagen, München 1971). Doch müssen dazu erst die Gestaltungsfunktionen der Verwaltung juridifizierbar gemacht oder zumindest die Willkürgrenzen eingeengt und besser präzisiert werden können. Hierfür Kriterien zu finden, ist eine der Wissenschaft und Praxis vordringlich gestellte Aufgabe. Solange es aber schon an der Möglichkeit fehlt, die dabei angesprochenen qualitativen Erfordernisse zu quantifizieren und so etwa die Lärmstruktur für Bebauungspläne zu ermitteln, sind die Gerichte auf die Nachprüfung äußerster Willkürgrenzen beschränkt. Sie setzen sonst ihr "Ermessen" an die Stelle des Ermessens oder der Gestaltungsfreiheit der Verwaltung, wozu sie nicht legitimiert sind. Immerhin hat das Bundesverwaltungsgericht in der angeführten Entscheidung im Ergebnis die Maßnahme der Rechtsaufsichtsbehörde gebilligt und damit deren Beurteilungsspielraum respektiert. Anders das VG Gelsenkirchen, das eine Bauleitplanung für rechtswidrig und nichtig ansah, weil nicht alle "wesentlichen" Belange in die Abwägung "zutreffend eingestellt" worden seien. Angesichts der unübersehbaren Vielzahl von Belangen, die bei einer Planung berücksichtigt werden müssen, und mangels allgemein verbindlicher Maßstäbe und feststehender Wertungen kann eine solche Argumentation - wenn es sich nicht um extreme und daher evidente Mißgriffe der Verwaltung handelt nur dazu führen, daß das Gericht seine rechtlich nicht meßbare abweichende Wertung für letztverbindlich erklärt und damit die Kompetenz des demokratisch stärker legitimlerten Planungsträgers an sich zieht. Kritisch zu diesem Trend in der Rechtsprechung auch Konrad Redeker, Sozialstaatliche Gestaltung und rechtsstaatliche Bindung, DVBl. 1971, S. 369 ff.; ders., Fragen der Kontrolldichte verwaltungsgerichtlicher Rechtsprechung, DOV 1971, S. 757 ff. (758). 
heblich variieren können. Davon war beim Vorbehalt des Gesetzes bereits die Rede. Insofern ergeben sich für die Gerichte auch unterschiedliche Grenzen des Willkürverbotes. Innerhalb dieser Grenzen aber verbleibt ihnen nur die Kontrolle des Verfahrens.

5. Je mehr eine Verwaltungsentscheidung sich von dem Bilde des reinen Gesetzesvollzuges entfernt, desto größere Bedeutung gewinnt die Beteiligung der Betroffenen am Entscheidungsproze $B$. Information und rechtliches Gehör, Begründungszwang und Akteneinsichtsrecht, aber auch die Einhaltung der Bestimmungen über die behördliche Zuständigkeit, die Mitwirkung anderer Behörden oder die Unparteilichkeit und Unbefangenheit der Amtsträger können den Inhalt der Entscheidung erheblich beeinflussen. Verfahrensgrundsätze werden daher in zunehmendem $\mathrm{MaBe}$ als Rechte der einzelnen anerkannt ${ }^{98}$ ). [Sie vermögen in gewissem Maße auszugleichen, was der gerichtliche Rechtsschutz derzeit nicht zu leisten vermag, weil die Verwaltung bei der Planung in zeitlicher und faktischer Hinsicht die Vorhand hat und die Gestaltungsbefugnisse sich nicht in ausreichendem Maße juridifizieren lassen. Verfahrensgarantien bilden daher die notwendige Ergänzung der klassischen Abwehrrechte. Von ihnen darf nur in den Ausnahmefällen eines legitimen öffentlichen Interesses abgewichen werden ${ }^{(5)}$.]

Diese Aussage über die Verfahrensgrundsätze läßt sich dogmatisch begründen mit der Ausweitung des subjektiven öffentlichen Rechts und dem verfassungsrechtlichen Erfordernis rechtlichen Gehörs und effektiven Rechtsschutzes. Sie folgt wei-

๑) Dazu Ferdinand Kopp, Verfassungsrecht und Verwaltungsverfahrensrecht, München 1971, m. zahlr. w. N. aus der umfangreichen Literatur und Rechtsprechung zu den einzelnen Verfahrensgrundsätzen. Vgl. welter Carl Hermann Ule - Franz Becker, Verwaltungsverfahren im Rechtsstaat, Köln 1964, S. 40 f., 43; K. Redeker, DVBl. 1971, S. 369 if. (372); Christian-Friedrich Menger, Höchstrichterliche Rechtsprechung zum Verwaltungsrecht, VerwArch 54 (1963), S. 286 If. (293 f.); Jörn Pipkorn, Auskunftsansprüche gegenüber Verwaltungsbehörden, DOVV 1970, S. 171 ff. (175). - Allgemein zur Bedeutung des Verwaltungsverfahrens Klous Stern, Verwaltungslehre - Notwendigkeit und Aufgabe im heutigen Sozialstaat, in: Gedächtnisschrift Hans Peters, Berlin 1967, S. 219 ff. (241); Franz Mayer, Verfahrensgrundsätze der Verwaltung, BayVBl. 1960, S.332 ff.

m) Wann eine solche Ausnahme angenommen werden kann, bedarf noch der näheren Untersuchung und Präzisierung. Zu eng wohl J. Pipkorn, DOV 1970, S. 171 ff. (175), der verlangt, daß das ausschlleßende öffentliche Interesse ausdrücklich in der Verfassung festgelegt sein müsse. 
ter auch aus dem Demokratiegebot der Transparenz und der Konsensherstellung ${ }^{100}$ ).

[Angesichts der sozialen Interdependenzen und der dadurch bedingten Breitenwirkung zahlreicher administrativer Maßnahmen ist der Kreis der Betroffenen für die Verwaltung vielfach nicht genau abzusehen ${ }^{101}$ ). Versäumt sie daher, einzelne Betroffene von sich aus am Verfahren $z u$ beteiligen, so muß es der Initiative der Ubergangenen überiassen bleiben, ihre Beteiligungsrechte bei der Verwaltung und notfalls vor Gericht geltend zu machen. Für Maßnahmen der Verwaltung, die in ihrer Wirkung den Rechtsnormen nahekommen, ist eine öffentliche Bekanntmachung zu fordern, wie sie der Entwurf für ein Verwaltungsverfahrensgesetz ausdrücklich vorsieht und wie sie bei Allgemeinverfügungen und zahlreichen Planungsverfahren heute schon erforderlich sein $\mathbf{k a n n}^{108}$ ).

Möglichkeiten, sich auf Grund der Betroffenheit in eigenen Rechten am Verfahren der Verwaltung zu beteiligen, bestehen vor allem im Mikrobereich, bei Planungen also im Bereich der Durchführungsplanung. Im Makrobereich läßt sich die rechtliche Betroffenheit des einzelnen als Individuum in der Regel nicht mehr hinreichend präzisieren. Anders mag es um eine konkrete Rechtsbetroffenheit bei größeren, mit eigenen Rechten ausgestatteten Einheiten stehen, wie etwa bei den Gemeinden in Fällen der Raumplanung ${ }^{103}$ ). Die Gefahr, daß gerade bei

100) Konsensherstellung wird hier im Sinne eines Gebotes verstanden, sich laufend um einen intersubjektiven Konsens $\mathrm{zu}$ bemühen und die institutionellen Voraussetzungen dafür zu schaffen. Der Gedanke des "government by consent", d.h. die Vorstellung, daß sich die Verwaltung auch beim Vollzug der Gesetze gegenüber dem einzelnen und der Allgemeinheit täglich neu zu legitimieren habe, gewinnt nicht nur in der Demokratiediskussion des Verfassungsrechts an Boden, sondern liegt auch der in der Rechtstheorie vertretenen Anerkennungstheorie über die Geltung der Rechtsnormen zugrunde. - Zur Ableitung der Verfahrensgrundsätze, die der Wahrung der Gesetzmäßigkeit der Verwaltung dienen, aus dem Grundsatz der Demokratie, vgl. auch F. Kopp, Verfassungsrecht und Verwaltungsverfahrensrecht, S. $180 \mathrm{ff}$.

101) Vgl. die entsprechende Problematik bei $\S 65$ VwGO.

102) Vgl. \$ 31 III, VI EVwVerfG, BT Drucks. VI/1173; § 2 VI Bundesbaugesetz v. 23. Juni 1960 (BGBl. III Nr. 213-1).

105) Zum Anhörungsrecht der kommunalen Gebietskörperschaften, das parallel zum Recht des einzelnen auf rechtliches Gehör aus dem Rechtsstaatsprinzip in Verbindung mit der Selbstverwaltungsgarantie folgt, vgl. für den Fall der Eingemeindungen: Hubert Görg - Gerhard Seibert, Anmerkung zum Urteil des VG Köln vom 31. 5. 1968, DVBl. 1968, S. 851 ff. (853); Carl Hermann Ule, Zwangseingemeindungen und Verfassungsgerichtsbarkeit, VerwArch 60 (1969), S. 101 If. (121); VerfGH Rh.-Pf. v. 17. 4. 1969, DOV 1969, S. $560 \mathrm{ff}$. 
den wichtigen Gestaltungen im Makrobereich nur Großorganisationen $\mathrm{zu}$ Wort kommen und das nichtorganisierte Interesse ausgeschaltet bleibt, ist also rechtsdogmatisch über die rechtsstaatlichen Grundsätze der Verfahrensbeteiligung der Betroffenen nicht auszuschließen; hier bleiben nur rechtspolitische Lösungen $\left.{ }^{104}\right)$.]

Allerdings dürfen [auch] die [dargelegten] Möglichkeiten der Beteiligung nicht überschätzt werden. Das zeigt die geringe Effizienz der Einwendungsverfahren, etwa bei den Stadt- und Fachplanungen. Der Stil der Verwaltungsbehörden ist oft nicht dazu angetan, den einzelnen von dem Nutzen seiner Beteiligung zu überzeugen ${ }^{105}$ ). Es kommt daher darauf an, Möglichkeiten zu schaffen, die einen rechtlich gesicherten Einfluß auf den Inhalt der Entscheidung gewährleisten. Rechtsdogmatisch ist das in begrenztem $\mathrm{MaBe}$ zu erreichen, wenn man bereits die verschiedenen Stufen des Entscheidungsprozesses der rechtlichen Wertung zugänglich macht. Das läßt sich durch eine Ausweitung des Begriffes des Verwaltungsaktes im Wege des "verwaltungsgerichtlichen Vorverfahrens" erreichen.

6. a) Verwaltungsakt und Rechtsnorm als die beiden Handlungsformen des Staates schlossen nach ihrer herkömmlichen Eegriffsbestimmung sozialgestaltende Maßnahmen aus. Denn mit der Festlegung der eingreifenden Verwaltung auf den Gesetzesvollzug und mit der Definition des Rechtssatzes durch die Eigentums- und Freiheitsklausel sowie das Erfordernis der generell abstrakten Regelung war die äußerste Grenze der staatlichen Regelungsmöglichkeiten umrissen. Auch die Verwaltung war nicht in der Lage, den offenen Bereich konkreter Rechtsetzung auszufüllen ${ }^{100}$ ). Daraus resultieren die heutigen

(567); OVG Münster v. 5. 5. 1969, DOV 1969, S. 570. Allein auf die Selbstverwaltungsgarantie stützen das Anhörungsrecht: Fritz Ossenbühl, Rechtliches Gehör und Rechtsschutz im Eingemeindungsverfahren, DOV 1969, S. 548 ff. (551); Gerhard Seibert, Selbstverwaltungsgarantie und kommunale Gebietsreform, Frankfurt/M. 1971, S. $41 \mathrm{f}$; Franz-Ludwig Knemeyer, Das Anhörverfahren im Rahmen der bayerischen Gebietsreform, BayVBl. 1971, S. $371 \mathrm{ff}$. Eine Abweichung von den oben genannten Ansichten ist darin wegen der einer individualrechtlichen Rechtsposition vergleichbaren Stellung der Gemeinde letztlich nicht zu sehen.

104) Dazu unten unter V., wo hierfür etwa ein Gesetzespostulationsrecht vorgeschlagen wird.

105) W. Blïmel, Raumplanung, vollendete Tatsachen und Rechtsschutz, S. 133 ff.; W. Brohm, Art.: Städtebau, Staatslexlkon, 3. Ergänzungsband, Sp. $339 \mathrm{ff}$. (345).

${ }^{106)}$ Die Freiheits- und Eigentumsklausel behält bestimmte Regelungsbereiche dem Gesetzgeber vor; der generell-abstrakte Charakter beschränkt dabel den Gesetzgeber auf eine Allgemeinheit der Regelungen, wie sie sozialen Gestaltungen nicht eigen ist. Indem 
Schwierigkeiten, konkret generelle und abstrakt individuelle Handlungsformen sachgerecht zu erfassen ${ }^{107}$ ). Begriffsbildungen wie Vollzugsnorm ${ }^{108}$ ), dingliche Verwaltungsakte ${ }^{100}$ ), adressatlose Verwaltungsakte ${ }^{110}$ ) oder gar Verwaltungsakte an wen es angeht ${ }^{111}$ ) beweisen das.

Insofern sind Verwaltungsakt und Rechtsnorm begrifflich nur in den klassischen Fällen generell-abstrakter Verhaltensregelung oder punktueller Verhaltenskorrektur klar zu trennen. Staatstheoretisch ist die Unterscheidung auf Verwaltungsebene überholt. Denn angesichts der Gestaltungsfunktionen der Verwaltung können die Begriffe des Verwaltungsaktes und der Rechtsnorm nicht mehr als Ausdruck verschiedener Staatsfunktionen angesehen werden; sie sind vielmehr beide Handlungsformen der Verwaltung ${ }^{112}$ ).

diese Einteilung noch mit der Unterscheidung von Rechtsetzung und Rechtsanwendung kombiniert wurde, vermochte die Verwaltung den offengelassenen Raum konkreter Rechtsetzung nicht auszufüllen. Dazu Ernst-Wolfgang Böckenförde, Gesetz und gesetzgebende Gewalt, Berlin 1958, S. 339; Richard Thoma, Grundbegriffe und Grundsätze, HdbDStR Bd. II, Tübingen 1932, \& 71, S. $108 \mathrm{ff}$. (124 ff.); Konrad Huber, Maßnahmegesetz und Rechtsgesetz, Berlin 1963, S. 172 ff.; E. Stachels, Stabilitätsgesetz, S. 109.

107) Zahlreiche Beispiele aus der umfangreichen Rechtsprechung hierzu bei Otto Bachof, Verfassungsrecht, Verwaltungsrecht, Verfahrensrecht in der Rechtsprechung des Bundesverwaltungsgerichts, Bd. II, Tübingen 1967, Nr. $335 \mathrm{ff}$.

109) W. Brohm, Rechtsschutz im Bauplanungsrecht, S. 52 ff. (61); R. Bartlsperger, DVBl. 1967, S. 360 ff. (362, 369).

109) Norbert Niehues, Dingliche Verwaltungsakte, DOV 1965, S. $319 \mathrm{ff}$; $H$. J. Wolff, Verwaltungsrecht I, \& 46 VIII m. w. N.

110) E. Forsthoff, Verwaltungsrecht, S. $355 \mathrm{f}$.

111) Dazu BVerwG v. 28. 6. 1968, JZ 1969, S. 69 (Subventionsrückforderung gegen Zwischenhëndler wegen zweckwidriger Verwendung von Handelsdünger durch den Abnehmer). Die Konstruktion war notwendig, weil eine Rechtsetzung der Verwaltung im AuBenverhältnis noch nicht anerkannt ist. Auch mit Hilfe des Vertrages hätte sich der Fall nicht besser lösen lassen. Das verkennt Ludwig Renck, Verwaltungsakt und verwaltungsrechtlicher Vertrag, JuS 1971 , S. $77 \mathrm{ff}$. Denn auch der öffentlich-rechtliche Vertrag hätte öffentlich-rechtliche Bindungen nur zu dem Hersteller, nicht aber zu dessen Abnehmer bewirken können. Insofern erweist sich der öffentlich-rechtliche Vertrag auch hier der herkömmlichen Form des Verwaltungsaktes unter Auflage nicht überlegen.

112) Dazu W. Brohm, Strukturen der Wirtschaftsverwaltung, S. 229 ff. m. w. N. Neuerdings hat dies Axel Görlitz, Politlsche Funktionen der Lehre vom Verwaltungsakt, PVS 1971, S. 71 ff., noch einmal ausführlich dargetan, wobei er offenbar davon ausgeht, daß die Rechtswissenschaft diesen Funktionswandel noch nicht bemerkt habe. MiBverständnisse dieser Art sind heute keine Seltenheit. Sle geben Anlaß zu der grundsätzlichen Bemerkung, daß sich manche Polemik von Soziologen und Politologen gegen die Rechtswissen- 
In der Rechtspraxis werden die Unterschiede in den Voraussetzungen und Wirkungen von Verwaltungsakt und Rechtsnorm auch zunehmend abgeschliffen; [so in den Anforderungen an die Bestimmtheit der gesetzlichen Ermächtigung, in den Formen der Kundmachung und neuerdings auch in den Fehlerfolgen ${ }^{113}$ ). Auch der Rechtsschutz kann, wie gezeigt, nicht von der Handlungsmodalität abhängen. Der Ausschluß der abstrakten Normenkontrolle für untergesetzliche Normen in einigen Ländern verstößt daher gegen Art. 19 IV GG $^{114}$ ). Dennoch lassen sich einzelne Unterschiede angesichts der positiven Rechtslage nicht ganz aufgeben. Sie sind für die klassischen Handlungsformen in gewisser Beziehung durchaus sinnvoll.] Für die Zwischenformen [jedoch] müssen weitere Differenzierungen gefunden werden.

Auch hinsichtlich der Verbindlichkeit, die beiden Handlungsformen gemeinsam ist, sind heute Relativierungen notwendig. So wird vielfach das Merkmal der "verbindlichen Regelung" bis zur Unkenntlichkeit ausgeweitet, weil man Indikativrichtlinien, Normativkontingente, Auskünfte, Zusagen, Berichte oder Bescheinigungen den Rechtsnormen oder Verwaltungsakten einordnen und nicht jeder rechtlichen Erfassung entgleiten lassen will $\left.{ }^{115}\right)$.

schaft als überflüssig erwiese, wenn man durch bessere interdisziplinäre Kontakte wenigstens über den jeweiligen Forschungsstand der Nachbardisziplin unterrichtet wäre.

${ }^{113}$ ) Dazu im einzelnen m. zahlr. w. N. W. Brohm, Strukturen der Wirtschaftsverwaltung, $S$. $231 \mathrm{f}$.

114) Vgl. Klaus Obermayer, Die verwaltungsgerichtliche Normenkontrolle, in: 10 Jahre Verwaltungsgerichtsordnung, Schriftenrelhe der Hochschule Speyer, Bd. 45, Berlin 1970, S. 142 ff. (157 t.); OlafRoman Baron von Engelhardt, Der Rechtsschutz gegen Rechtsnormen, Berlin 1971, S. 244 ff. (255). - Im Ergebnis übereinstimmend mit unterschiedlichen Lösungen für eine aus Art. 19 IV GG geforderte Klagemöglichkeit: Hartmut Maurer, Rechtsschutz gegen Rechtsnormen, in: Tübinger Festschrift für Eduard Kern, Tübingen 1968, S. $275 \mathrm{ff}$. (294 f.); Rainer Wilken, Rechtsschutz gegen Normen und verwaltungsgerichtliche Normenkontrolle, DOV 1969, S. 532 tf.

115) Vgl. zu den Indikativrichtlinien und Normativkontingenten: W. Brohm, Strukturen der Wirtschaftsverwaltung, S. $239 \mathrm{ff}$. und 241 ff. Zur Auskunft und Zusage: Karl Zeidler, Empfiehlt es sich, die bestehenden Grundsätze über Ausküntte und Zusagen in der öffentlichen Verwaltung beizubehalten? Gutachten für den 44 . Deutschen Juristentag, Tübingen 1962; Klaus Obermayer, Der Verwaltungsakt als Gegenstand von Zusagen und Rechtsausküntten, NJW 1962, S. $1465 \mathrm{ff}$. (1468); Nikolaus Pfander, Dle Zusage Im ötfentlichen Recht, Berlin 1970, S. 263 I.; Goswin Pieper, Dle öffentllchrechtliche Zusage, VerwArch 59 (1968), S. 217 if.; sowle BVerwG v. 25. 2. 1969, BVerwGE 31, 301, das die Namensnennung eines Informanten des Verfassungsschutzamtes im Unterschled zur Namensnennung in anderen Fallen als Verwaltungsakt ansieht. Bescheint- 
b) Auf diese verschiedenen Zwischenformen lassen sich die Voraussetzungen und Wirkungen, die herkömmlich mit den Begriffen des Verwaltungsaktes oder der Rechtsnorm verbunden werden, nicht einheitlich übertragen. Es ist vielmehr jeweils nach dem Sinn und Zweck der einzelnen Vorschrift zu prüfen, ob und in welchem Maße sie bei dem einen oder anderen Handlungstypus zur Wirkung kommen kann.

So können die Grundsätze über den Widerruf und die Rücknahme von Verwaltungsakten nur für punktuell begrenzte Maßnahmen gelten ${ }^{16}$ ), nicht aber für Planfeststellungsbeschlüsse im Rahmen der Fachplanungen, die wir ebenfalls den Verwaltungsakten zuordnen. [Angesichts der breiten Wirkung und der Bedeutung dieser Maßnahmen sind hier andere Regeln zum Vertrauensschutz zu erarbeiten. Das zeigen die dogmatischen Bemühungen um die Plangewährleistungsansprüche ${ }^{117}$ ). Sie müssen zur Anwendung kommen, gleichgültig ob man diese Pläne als Verwaltungsakte oder als Rechtsnormen qualifiziert.] Anders wiederum ist der Widerruf von Anordnungen durch Verkehrszeichen zu beurteilen.

Auch die formelle Bestandskraft kommt bei diesen Verwaltungsakten nur begrenzt zur Wirkung ${ }^{119}$ ); [sie müßte in Anbetracht der Breitenwirkung dieser Maßnahmen analog der Ausschlußfrist nach § 93 II BVerfGG geregelt werden ${ }^{10}$ ).] Die Konstruktion eines "dinglichen Verwaltungsaktes" ist dafür nur

gungen werden als Verwaltungsakte angesehen, wenn sie gesetzliche Voraussetzung für die Inanspruchnahme von Rechten oder Vergünstigungen sind; so schon BVerwG v. 28. 9. 1955, BVerwGE 2, 212 und v. 30. 11. 1955, BVerwGE 2, 353; dazu auch Jürgen Simon, Behördliche Bescheinigungen als Verwaltungsakte, DVBl. 1956, S. 355 ff. (356). Berichte des Luftfahrtbundesamtes sind nach Ansicht des OVG Lüneburg v. 26. 1. 1961, OVGE 16, 442 und von Peter Wendt, Uber die Rechtsnatur der Untersuchungsberichte des Luftfahrtbundesamtes, DOV 1963, S. 89 ff. (90 f.) Verwaltungsakte; anders BVerwG v. 20, 7. 1962, BVerwGE 14, 323.

110) Inwieweit hier nicht auch weiter nach den einzelnen Verwaltungsbereichen zu differenzieren wäre, kann in diesem Zusammenhang dahingestellt bleiben.

117) Vgl. Martin Oldiges, Grundlagen eines Plangewährleistungsrechts, Bad Homburg v. d. H. 1970; Jürgen Egerer, Der Plangewährleistungsanspruch, Baden-Baden 1971, jeweils m. zahlr. w. N.

118) Auch die Jahresfrist nach $\S 58$ II VwGO beginnt erst nach der Bekanntgabe gegenüber dem Betroffenen zu laufen. (Für Drittbetroffene hat dies das BVerwG im Urteil v. 14. 2. 1969, DVBl. 1969, S. 362 ausdrücklich bekräftigt). Maßnahmen mit Breitenwirkung könnten also von neu davon Betroffenen noch nach Jahrzehnten angefochten werden.

119) Nach der gegenwärtigen Rechtslage ist eine solche Annahme allerdings kaum zu begründen, da die landesrechtlichen Vorschriften über die Normenkontrolle nur die herkömmlichen Verhaltens- 
eine Verlegenheitslösung ${ }^{120}$ ), die zudem auf Planungen mit Koordinationswirkung schon nicht mehr übertragbar ist.

[Entsprechendes gilt für die Problematik der aufschiebenden Wirkung bei Anfechtungsklagen und die Anordnung des sofortigen Vollzuges. Sie wäre etwa bei Planungen auf die einzelnen in dem Plan enthaltenen Teilentscheidungen $\mathrm{zu}$ beschränken $\left.^{121}\right)$.]

Ebenso erfüllen nicht alle Verwaltungsakte eine Titelfunktion; Auskünfte oder Bescheide über Leistungsgewährungen sind nicht vollstreckbar, und Pläne bedürfen dazu vielfach erst noch eines Vollzugsaktes.

Weiter gilt der Nachrang des Verwaltungsaktes gegenüber Rechtsnormen nicht etwa für Planfeststellungsbeschlüsse, die als Verwaltungsakte die Bebauungspläne als Satzungen durchbrechen ${ }^{122}$ ). Ähnliches gilt für die Imperativ- und Indikativrichtlinien $^{123}$ ). Die Beispiele ließen sich beliebig vermehren.

c) Sind demnach in Zukunft die Handlungsformen im Hinblick auf die damit verbundenen Rechtswirkungen vielfach zu differenzieren und neu zu typisieren, so ist zu erwägen, ob der Begriff des Verwaltungsaktes nicht auf einer höheren Abstraktionsebene definiert werden sollte. Nachdem er seinen spezifischen Konnex mit dem subjektiven öffentlichen Recht verloren

normen im Auge haben und daher solche AusschluBfristen nicht kennen. Für Extremfälle bleibt u. U. der Rückgriff auf die Verwirkung, vgl. Eyermann-Fröhler, Verwaltungsgerichtsordnung, Kommentar, 5. Aufl., München 1971, Rdnr. 13 zu \& 58 VwGO m. w. N.

${ }^{120}$ ) Sie dient vor allem auch dem Zweck, eine formelle Bestandskraft herbeizuführen (so Ferdinand Kopp, Der dingliche Verwaltungsakt, BayVBl. 1970, S. 233 ff. (236)). Indessen dürfte der Versuch, die Verbindlichkeit für die davon betroffenen Personen mit sachenrechtlichen Konstruktionen $z u$ erklären, dem öffentlichen Recht kaum angemessen sein. Vgl. dazu schon Georg Jellinek, System der subjektiven öffentlichen Rechte, 2. Aufl., Tübingen 1905, Nachdruck Darmstadt 1963, S. 10; ders., Allgemeine Staatslehre, 5. Neudruck der 3. Aufl., Berlin 1929, Nachdruck Darmstadt 1960, S. 398 ff.; $H$. H. Rupp, Grundfragen der heutigen Verwaltungsrechtslehre, S. 166 ff. m. w. N.; Joachim Martens, Zur Begriffsbestimmung des Verwaltungsaktes, DVBl. 1968, S. 322 ff. (329).

121) Darin liegt ein wesentliches Anliegen der Qualifizierung rechtsverbindlicher Pläne als "Vollzugsnorm". Dazu W. Brohm, Rechtsschutz im Bauplanungsrecht, S. $52 \mathrm{ff}$. und $73 \mathrm{ff}$.

122) Dazu Rüdiger Breuer, Die hoheitliche raumgestaltende Planung, Bonn 1968, S. 176 ff., dessen Thesen mit der Rechtsnatur der einzelnen Handlungsformen begründet werden und daher bisweilen eigentümlich anmuten.

125) Dazu im einzelnen W. Brohm, Strukturen der Wirtschaftsverwaltung, S. 234 ff. 
hat $\left.{ }^{124}\right)$, ließe er sich als "Entscheidung" im Sinne der modernen Entscheidungstheorien ${ }^{125}$ ) verstehen. Allerdings ist die sozialwissenschaftliche Definition der Entscheidung als Ergebnis eines Informationsverarbeitungsprozesses zu einseitig. Sie setzt die Rationalität des Entscheidungsprozesses absolut und vernachlässigt so das Machtproblem ${ }^{126}$ ). Berücksichtigt man beide Momente, so könnte man den Verwaltungsakt neu bestimmen als den "für die Verwaltung verbindlichen Abschluß eines Willensbildungs- und Informationsverarbeitungsprozesses im Rahmen der Wahrnehmung ihrer Hoheitskompetenzen, unabhängig davon, ob er eine Regelung gegenüber dem Bürger enthält oder nicht ${ }^{\text {(1127) }}$.

124) Wie oben unter III. 3. a) und 6. a) mit Anm. 114 gezeigt, kommt es für die Aktualisierung eines subjektiv-öffentlichen Rechts allein auf die „Rechtsbeeinträchtigung“ an, nicht aber auf die Handlungsmodalität, durch die sie hervorgerufen wird. Die gegenwärtige Lehre dagegen erfaßt den Begriff des Verwaltungsaktes gerade unter diesem Gesichtspunkt, indem sie eine „Regelung“ vor allem dann annimmt, wenn eine "Rechtsbeeinträchtigung" vorliegt, so z. B. bei reinen Tathandlungen, wie der Erteilung von Auskünften, Berichten oder Bescheinigungen (dazu die Nachweisungen oben Anm. 115), aber auch bei der Abgrenzung von Verwaltungsakt und innerdienstlichem Rechtsakt im Rahmen sog. „besonderer Gewaltverhältnisse" (dazu etwa Winfried Brohm, Verwaltungsvorschriften und besonderes Gewaltverhältnis, DOV 1964, S. 238 ff. (244 1.) m. w. N.) und der Qualifizierung von Organisationsakten als Verwaltungsakte (dazu etwa BVerwG v. 31. 1. 1964, BVerwGE 18, 40).

${ }^{125)}$ Dazu zusammenfassend $F$. Naschold, Systemsteuerung, S. 30; ders., Organisation und Demokratie, 2. Aufl., Stuttgart 1971, S. 56; K. König, Erkenntnisinteressen, S. 252 ff., jewells m. w. N.

$\left.{ }^{120}\right)$ Damit kommt sie zwar dem arbeitsteiligen und z. T. maschtnell bewirkten Entscheidungsprozeß näher als das voluntaristische Verständnis. Doch bleiben bei den vielfältigen Entscheidungen der Verwaltung nach wie vor auch volitive Elemente bestimmend.

127) Durch eine solche Neudefinition des Verwaltungsaktes wird dessen verfahrensrechtliche und materiell-rechtliche Funktion (letztere sehe Ich, wie im folgenden ausgeführt wird, mit Klaus Vogel, Diskussionsbeitrag, VVDStRL 28 (1970), S. 269, u. a. in einer Klarstellungsfunktion) nicht beseitigt, sondern nur auf eine höhere $A b-$ straktionsebene verlegt und damit in den Beziehungen aufgegeben, in denen er sle nach der aufgezeigten Entwicklung der Dogmatik längst verloren hat. Das ist einmal der Fall in der Abgrenzung zur Rechtsnorm bei den konkret-generellen und abstrakt-individuellen Handlungsformen. (Dazu oben Anm. 106-114; vgl. auch Ludwig Renck, Verwaltungsakt und Feststellungsklage - BVerwGE 26, 161, JuS 1970, S. $113 \mathrm{ff}$. (118), der unter Hinweis darauf, daß Wasserschutzgebiete durch Rechtsverordnung, Parkzonen durch Verwaltungsakt, Skihauptabfahrtsstrecken durch Rechtsverordnung, Wasserskistrecken durch Verwaltungsakt festgesetzt werden, meint, das könne kein Jurist, geschweige denn ein Laje verstehen; das sei nur noch zu glauben). Der Verwaltungsakt hat weiter seine Funktion verloren in der Abgrenzung zu den Tathandlungen, wo die 
Die Markierung eines solchen „Fixpunktes" im Entscheidungsprozeß $B$ der Verwaltung ist notwendig, um an dieser Stelle die Fragen der Legitimation, Kontrolle und Verantwortlichkeit anknüpfen zu können ${ }^{128}$ ). Diese wären dann je nach dem Typus der Verwaltungsentscheidung $u$. $U$. verschieden $z u$ beurteilen. So bildeten die generell-abstrakten Regelungen lediglich einen Sonderfall der Verwaltungsentscheidung, der gewisse Verfahrens- und Rechtsschutzmodalitäten bedingt. Die Unterscheidung zum Einzelakt fiele also nicht weg, sie wäre aber relativiert, so da $B$ alle Zweifelsfälle ohne diffizile Erörterungen dem Verwaltungsakt als Auffangbegriff zugeordnet werden könnten.

Die Differenzierungen der Zwischenformen nach den Voraussetzungen und Wirkungen von Rechtsnorm und Verwaltungsakt würden erleichtert, weil zunächst eine Vermutung für die Regeln über den Verwaltungsakt spräche. Eine Modifikation müßte daher im Einzelfall mit der Funktion dieser Regeln und der besonderen Eigenart der Verwaltungsmaßnahme gerechtfertigt werden.

Vor allem aber bekäme bei dieser Neuformulierung des Verwaltungsaktes die Dogmatik mehr Spielraum, neue, sachgerechte Typisierungen als Unterfall der Verwaltungsentscheidung zu entwickeln, da der Verwaltungsakt geringeren gesetzlichen Formbindungen unterliegt ${ }^{129}$ ).

Ein weiterer Vorteil läge darin, daß sich zahlreiche Diskussionen um das Vorliegen einer "Regelung " erübrigten. [Denken Sie an die jüngsten Entscheidungen der Gerichte zur Namensnennung von Informanten, zum Schuldspruch des Bundesober-

gegenwärtige Rechtsdogmatik das Kriterium der "Regelung“ gegenüber dem Bürger nach der "Rechtsbetroffenheit" beurteilt (dazu die Nachweisungen oben Anm. 115 und 124 sowie unten 130), auf die es, wie oben III. 3. a) gezeigt, in diesem Zusammenhang aber nicht ankommt. Mit der vorgeschlagenen Neudefinition bleiben also die heute dem Verwaltungsaktsbegriff allgemein noch zukommenden spezifischen Problemlösungen erhalten, durch thre größere $A b-$ straktheit wird aber gleichzeitig der Weg zu weiteren sachgerechten Differenzierungen frei.

128) Zu diesem Bedürfnis vgl. auch $A$. Görlitz, PVS 1971, S. 71 it. (84 f.), der allerdings im Ergebnis den herkömmlichen Begriff des Verwaltungsaktes samt der „Regelung" gegenüber dem Bürger belbehält und ihn lediglich in einer organisations- und entscheidungstheoretischen Terminologie definiert.

129) Aus diesem Grunde wäre eine Legaldefinition des Verwaltungsaktes, wie sie in $\S 27$ des EVwVerfG (BT Drucks. VI/1173) vorgesehen ist, sehr unzweckmäBig. Sie würde den derzeitigen Entwicklungsstand der Dogmatik unnötig zementleren. 
seeamtes, zur Ausstellung von Bescheinigungen ${ }^{130}$ ) ${ }^{131}$ ) oder zu innerdienstlichen Weisungen und Organisationsakten $\left.{ }^{132}\right)$.]

130) Vgl. etwa BVerwG v. 25. 2. 1969, BVerwGE 31, 301 (306), wonach die Namensnennung eines Informanten kein Verwaltungsakt sei, wenn sie vom Einwohnermeldeamt erfolge, dagegen als Verwaltungsakt gewertet werden müsse, wenn sie vom Verfassungsschutzamt erfolge, weil dieses dabei seine Ermessensentscheidung zum Ausdruck bringe. Mit dieser „Begründung“ konnte die Klage wegen Fristablaufs abgewiesen werden. Vgl. ferner BVerwG v. 18. 4. 1969, JZ 1970, S. 137, BVerwGE 32, 21, wonach Sprüche des Bundesoberseeamtes, die das schuldhafte Verhalten eines Beteiligten nach \& 25 SUG (Gesetz über die Untersuchung von Seeunfällen v. 28. September 1935 (RGBl. I S. 1183 ff.)) feststellen, keine Verwaltungsakte seien. Aus diesem Grunde wurde in diesem Falle der Rechtsschutz völlig versagt. Dazu kritisch die Anmerkung von Walter Schick, ebd., S. 139. - Ferner BVerwG v. 28. 11. 1969, BVerwGE 34, 248: Die Anordnung der Verwaltungsbehörde gegenüber dem Inhaber einer Fahrerlaubnis, das Gutachten einer medizinisch-psychologischen Untersuchungsstelle über seine Eignung zum Führen von Kraftfahrzeugen vorzulegen, soll als Vorbereitung für den eventuellen Entzug der Fahrerlaubnis kein Verwaltungsakt sein. Die Frage, ob der Betroffene durch eine solche Anordnung in seinen Rechten beeinträchtigt ist, bleibt natürlich bestehen. Sie ist aber zu bejahen, wenn z. B. die Voraussetzungen des $\S 3$ II StVZO (AnlaB zur Annahme der Nichtgeeignetheit) nicht gegeben sind. Dagegen ist die Tötung eines streunenden Hundes oder die Anwendung unmittelbaren Zwangs durch den Einsatz von Hiebwaffen ein Verwaltungsakt, vgl. BVerwG v. 9. 2. 1967, BVerwGE 26, 161. Weitere Nachweisungen zu diesem widersprüchlich beurteilten Fragenkreis oben Anm. 115.

Nach der hier vertretenen Auffassung wären auch Glückwunschtelegramme, bloße Ankündigungen, Meinungsäußerungen, Belohnungen, Warnungen und Untersuchungsberichte des Luftfahrtbundesamtes als Verwaltungsakte $\mathrm{zu}$ werten. $\mathrm{Ob}$ sie im konkreten Fall Rechte einzelner beeinträchtigen und daher angefochten werden können, ist eine andere Frage. Insofern kehren viele, aber bei weitem nicht alle Fragestellungen, die gemeinhin beim Verwaltungsaktsbegriff erörtert werden, wieder, aber sie werden unter dem zutreffenden Gesichtspunkt, nämlich der Klagebefugnis, und für den jeweils zur Entscheidung stehenden Fall erörtert. Das dient nicht nur der dogmatischen Klarheit, sondern auch einer sachgerechteren Beurteilung. - Gegen die Einengung des Verwaltungsaktsbegriffs durch das Merkmal der „Regelung" wenden sich auch Eyermann-Fröhler, Verwaltungsgerichtsordnung, Rdnr. $14 \mathrm{ff}$. zu 842 VwGO, die alle hoheitlichen Amtshandlungen, auch die tatsächlichen, als Verwaltungsakt auffassen; allerdings verlangen sie an anderer Stelle (Rdnr. 26 zu \& 42 VwGO) als „Wesensmerkmal des Verwaltungsaktes", daß die Behörde dem Dritten gegenüber für ihr Handeln Verbindlichkeit beanspruche, und gehen somit doch wieder von einer "Regelung" aus. Das zeigen auch die dort angegebenen Beispiele.

131) Als Realakte erschienen dann nur noch Handlungen, denen, wie etwa Unfällen, keine Entscheidung zugrunde läge. Die allgemeine Leistungsklage dürfte bei dieser Lösung entbehrlich sein. Sie 
Ferner könnten alle Maßnahmen, die nicht eine generellabstrakte Regelung oder deren Vorstadium beträfen, erst nach Abschluß des Vorverfahrens vor Gericht gerügt werden. Das entspräche nicht nur dem Sinn der Verwaltungsgerichtsordnung, sondern prinzipiell der funktionell-rechtlichen Aufgabenverteilung zwischen Verwaltung und Gerichtsbarkeit ${ }^{235}$ ).

Schließlich würde deutlicher, daß der Rechtsschutz nicht vom Vorliegen einer rechtlichen Regelung, sondern allein von dem Vorhandensein einer hoheitlich verursachten Rechtsbeeinträchtjgung abhängt.

\section{IV.}

1. In den Fragen der Bestandskraft und der Berücksichtigung veränderter Rechts- und Sachlagen für den Zeitpunkt der gerichtlichen Entscheidung, für den Folgenbeseitigungsanspruch oder für Plangewährleistungsansprüche hat die verwaltungsrechtliche Dogmatik dem Faktor Zeit in dem Fortwirken der durch den Verwaltungsakt begründeten Rechtsfolgen mehr und mehr Gewicht beigemessen. In ihrer Fixierung auf die "Regelung" gegenüber dem Bürger aber orientiert sie sich an dem Endergebnis der Verwaltungsentscheidung. Dabei entgeht ihr der Prozeß der Entscheidungsbildung.

Solange sich die Verwaltungsentscheidungen auf relativ unkomplizierte Vollzugshandlungen beschränkten, bestand daran auch kein besonderes Interesse. Mit der Komplizierung der Verhältnisse aber werden langwierige und verzweigte Entscheidungsprozesse notwendig. In den verschiedenen Verfahrensstadien der technischen Prüfung, der Datenerhebung und

ist als prozessualer Notbehelf entwickelt und wenig systemgerecht. (Dazu auch Eyermann-Fröhler, Ranr. 14 zu \$42 VwGO). Die gegen die hier vertretene Lösung noch möglichen Einwände aus dem prozessualen Vollstreckungsrecht überzeugen nicht. Wenn nach \& 167 II VwGO Verpflichtungsurteile nur wegen der Kosten vorläufig vollstreckbar sind, weil das hoheitliche Handeln bedingungsfeindlich sei, so müßte dasselbe - abgesehen von der Fragwürdigkeit der Argumentation - auch für hoheitliches Handeln gelten, das keine „Regelung" enthält. Die \$\$ 170, 171 VwGO schlfeßlich gelten für alle Urteile auf Zahlungen, im übrigen aber auch nicht für Leistungsurteile anderer Art. Hier bleibt es also auch bel den Urteilen auf Grund allgemeiner Leistungsklagen bei der Vollstreckung nach $\S 172$ VwGO. Vgl. zu den Einwänden und ihrer Widerlegung im einzelnen: OVG Münster v. 22. 2. 1961, DOV 1961, S. 469 f. elnerseits und Rolf Schweickhardt, Der Verwaltungsakt als Anknüpfungspunkt im VerwaltungsprozeB, DOV 1965, S. $795 \mathrm{ff}$. andererseits.

192) Vgl. die Nachweisungen oben in Anm. 124.

139) Dazu auch $R$. Schweickhardt, DOV 1965, S. 795 ff. (801); Karl August Bettermann, Anm. zum Urteil des BVerwG v. 25. 2. 1969, DVBl. 1969, S. $703 \mathrm{ff}$. 
Datenselektion wird die endgültige Entscheidung nicht unerheblich vorgeprägt. Daher läßt sich oft nicht lokalisieren, an welcher Stelle des Systems die Entscheidung überhaupt fällt.

Es dient weder der Entscheidungsrationalität noch der Verfahrensökonomie, geschweige denn einem effektiven Rechtsschutz des Betroffenen, wenn die Dogmatik erst an den Abschluß des Entscheidungsprozesses anknüpft. Sie muß vielmehr versuchen, den Prozeß selbst transparent und kontrollierbar zu machen. Das ist möglich, indem man die einzelnen Verfahrensstufen rechtlich zu erfassen sucht. Das Verständnis des Verwaltungsaktes als verbindlicher $A b s c h l u B$ eines Informationsverarbeitungs- und Willensbildungsprozesses könnte diesen Ansatz erleichtern. Denn es käme für seine Annahme nur darauf an, $\mathrm{da} B$ bei einem Teilsystem der Verwaltung ein Verfahren verbindlich abgeschlossen wäre ${ }^{13}$ ). Hält man dagegen an dem herkömmlichen Erfordernis einer Regelung fest, so läßt sich diese, wie etwa bei der verbindlichen Zusage ${ }^{125}$ ), über den Gedanken der Teilregelung begründen ${ }^{180}$ ).

Diese These bedeutet zunächst, daß die Beteiligung anderer Behörden in Form von Zustimmung und Einvernehmen als Verwaltungsakt zu qualifizieren ist. Als Teilentscheidung kann sie bereits Rechte der Betroffenen tangieren. Daher greifen schon in diesem Stadium die angeführten Grundsätze des Verwaltungsverfahrens, etwa über das rechtliche Gehör der Betroffenen, ein. Für eine Klage braucht deswegen noch kein Rechtsschutzinteresse zu bestehen; vielmehr hängt es vom Einzelfall ab, ob dem Betroffenen das Zuwarten bis zur Endentscheidung zuzumuten ist.

Diese Feststellungen gelten aber auch für rechtlich unverbindliche Mitwirkungsformen, wenn sachlich abgrenzbare Teilfragen von einer anderen Instanz kraft besonderer Sachkunde abschließend behandelt werden ${ }^{197}$ ). Eignungsgutachten des TUV

134) Von einem Teilsystem in diesem Sinne kann immer dann die Rede sein, wenn von einer bestimmten Stelle ein bestimmter abgrenzbarer Fragenbereich eigenverantwortlich bearbeitet wird.

195) K. Zeidler, Gutachten, DJT 1962, S. $47 \mathrm{f}$. und passim, sieht in der Zusage die "Vorabregelung eines Tellkomplexes" und qualifiziert sie als Verwaltungsakt. Entsprechend spricht Norbert Achterberg, Der Verwaltungsvorakt, DOV 1971, S. 397 ff. vom „Verwaltungsvorakt" und "Verwaltungsendakt". In den Bauordnungen der Länder ist vielfach ein Bauvorbescheid als eine solche Tellregelung gesetzlich vorgesehen (vgl. \$ 84 LBO NW); er wird allgemein als Verwaltungsakt qualifiziert.

190) Zur Notwendigkeit von Teilregelungen im Subventionsverfahren vgl. $H$. F. Zacher, VVDStRL 25 (1967), S. 308 ff. (347).

197) Das Argument, die letztentscheidende Behörde trage die Verantwortung für die gesamte Entscheidung, ist wenig realistisch. 
für die Erteilung der Fahrerlaubnis oder amtsärztliche Gesundheitszeugnisse vor Ernennung des Beamten sind daher nach den allgemeinen Verfahrensgrundsätzen als Teilentscheidungen zu behandeln und z. B. dem Betroffenen bekanntzugeben, so daß er bereits in diesem Stadium Einwände dagegen vorbringen kann.

[Der Einwand liegt nahe, durch diese Theorie der "stufenweisen Entscheidung" verliere der Innenbereich der Verwaltung seine feste Abgeschlossenheit. Indessen ist die hier vertretene dogmatische Lösung nur eine Folge der Komplizierung der Entscheidungsvorgänge und der Pluralisierung des Gesamtsystems. Klare Verantwortlichkeiten, rechtliches Gehör und effektiver Rechtsschutz lassen sich nur gewährleisten, wenn die Fechtsdogmatik ihre Sonde bereits dort ansetzt, wo die betreffenden Fragen, sei es auch nur im Teilbereich, tatsächlich entschieden werden. Darauf ist um so mehr abzustellen, je weiter sich die Tätigkeit der Verwaltung von einem reinen Gesetzesvollzug entfernt und daher im Prozel der Entscheidungsbildung den einzelnen Entscheidungsstadien besonderes Gewicht für die Endentscheidung zukommt. Das gilt nicht zuletzt für die Gestaltungsfunktionen der Verwaltung. Hier kann überhaupt nur eine frühzeitige Beteiligung der Betroffenen die Gewähr dafür bieten, daß der einzelne sich letztlich nicht vollendeten Tatsachen gegenübergestellt sieht. Daß hierbei die rechtsstaatlich geforderten Beteiligungsformen nicht nur individualrechtliche Schutzfunktionen zu erfüllen vermögen, sondern gleichzeitig auch den Horizont der Entscheidungsgremien erweitern und damit einer den realen Bedürfnissen der Bevölkerung besser entsprechenden Gestaltung dienen können, bedarf keiner besonderen Hervorhebung.]

Im Einzelfall mögen legitime öffentliche Interessen einer frühzeitigen Beiziehung der Betroffenen entgegenstehen ${ }^{136}$ ); dann ist das Beteiligungsverfahren sobald wie möglich nachzuholen ${ }^{130}{ }^{140}$ ).

Schließlich wurde die Arbeitsteilung gerade zur Verantwortungsentlastung eingeführt. Dazu auch N. Luhmann, Der Staat 3 (1964), S. 129 ff. (152).

139) Diese Problematik ist in der Diskussion um das Offentlichkeitsprinzip bereits ausführlich zur Sprache gekommen. Vgl. etwa Wolfgang Martens, Offentlich als Rechtsprinzip, Bad Homburg v. d. H. 1969, S. 70 t.; Peter Häberle, Offentllches Interesse als juristisches Problem, Bad Homburg v. d. H. 1970, bes. S. 565 ff., jeweils $\mathrm{m}$. w. N.

130) Vgl. auch die entsprechende Regelung in 857 des österreichtschen AVG. Dazu F. Kopp, Verfassungsrecht und Verwaltungsverfahrensrecht, $S .28$ f. und passim. 
2. Die Erkenntnis, daß die Entscheidung in einem stufenweisen Proze $B$ der Informationsverarbeitung und Willensbildung oft über viele Stellen hinweg gebildet wird, zeigt eine neue Dimension des Rechtsinstituts der Beleihung auf. Bislang haben sich die dogmatischen Bemühungen auf die unmittelbare Hoheitstätigkeit Privater gegenüber dem Bürger konzentriert. Die Einschaltung von Privatpersonen und privaten Organisationen in den Entscheidungsproze $\beta$ der Verwaltung fiel damit aus den rechtlichen Uberlegungen heraus. Selbst wenn Private nur als Berater oder Sachverständige in das Verfahren zur Wahrnehmung einer Hoheitskompetenz eingeschaltet sind, entscheiden sie in der Sache mit. Denn durch das Gewicht ihres Sachverstandes haben sie einen ganz anderen Einfluß auf den Entscheidungsproze $B$ als etwa die am Verfahren beteiligten Parteien. Je komplizierter die Sachverhalte werden, desto weniger kann sich die Verwaltung dem Argument des Sachverständigen verschließen. $\mathrm{Daß}$ in die Selektion und Bewertung der Fakten und in andere Momente auch subjektive Wertvorstellungen des Sachverständigen einfließen, ist besonders bei den Gestaltungsfunktionen der Verwaltung unvermeidlich. Alles das zwingt dazu, den Gedanken der Beleihung auch auf die am Entscheidungsprozeß beteiligten Privaten auszudehnen. Fragen der Inkompatibilität, der Befangenheit, der Verschwiegenheitspflicht und andere Grundsätze werden daher auch hier von Belang. Auch die Gründung und Organisation von "Beratungsgremien" der Verwaltung in privatrechtlichen Formen ${ }^{141}$ ) wird unter diesem Gesichtspunkt einer Utberprüfung bedürfen.

140) Ist in Gesetzen oder Verwaltungsvorschriften die Mitwirkung anderer Stellen vorgesehen, weil die letztentscheidende Stelle bestimmte Fragenbereiche aus eigener Sachkenntnis nicht entscheiden kann, so macht das Fehlen einer solchen Mitwirkung die Endentscheidung fehlerhaft und anfechtbar (a. A. die h. M., vgl. $H$. J. Wolff, Verwaltungsrecht II, $\S 77 \mathrm{~V}$ a 1). Die Notwendigkeit, eine in Verwaltungsvorschriften geregelte Mitwirkung einer entsprechenden gesetzlichen Regelung gleichzusetzen, ergibt sich daraus, daß die Verwaltung durch die Regelung in der Verwaltungsvorschrift zum Ausdruck bringt, daß die letztentscheidende Stelle für die Entscheidung nicht voll kompetent ist. Kompetenzregelungen, gleichgültig in welcher Form sie erfolgen, sind mit der zunehmenden Differenzierung der Verwaltung für den Inhalt der Entscheidung und die Rechte des Bürgers von eminenter Bedeutung. Ihre Einhaltung kann daher, wie ausgeführt, von den Betroffenen erzwungen werden. Im übrigen läßt sich über die Anfechtbarkeit kompetenzwidriger Akte die in ihrer Funktionsfähigkeit vielfach beeinträchtigte Staatsaufsicht mit Hilfe der Gerichte ergänzen.

141) Z. B. gehen viele Städte dazu über, die Schwierigkeiten einer Altstadtsanierung einer von ihnen beherrschten oder auch einer allein von privaten Kräften getragenen Gesellschaft des Handels- 
[Alle diese Fragen erfordern eine differenzierende Beurteilung, die sich etwa an dem politischen Gewicht der anstehenden Entscheidung und der Intensität der Einschaltung der Privaten orientieren müßte. Daraus können sich dann neue Grundsätze und Typisierungen ergeben.]

\section{V.}

Angesichts der Gestaltungsfunktion und der Pluralisierung der Verwaltung wird die Organisation der Zielbestimmung, Koordination und Kooperation zu einem zentralen Problem.

1. Die Verwaltungsrechtslehre hat bislang versucht, die "Einheit des Staates“ bzw. der Verwaltung im wesentlichen über das hierarchische Modell zu gewährleisten ${ }^{142}$ ). Innerhalb des Staatsapparates vertraute man auf das Weisungsrecht und den Dienstweg. Selbständige Verwaltungsträger wurden über das staatliche Aufsichtsrecht mit seinen verschiedenen Einwirkungsmöglichkeiten in dieses System einbezogen. Denn die staatliche Aufsicht gilt nach der herkömmlichen Dogmatik als wesensmäßig mit der Ausübung von Hoheitsbefugnissen verbunden ${ }^{133}$ ). Diese Konstruktion ist rechtsdogmatisch nicht 2 wingend und verfehlt in der Wirklichkeit in zunehmendem Maße ihren Zweck.

a) Zahlreiche organisationssoziologische Untersuchungen haben gezeigt, daß es unmöglich ist, in hochdifferenzierten Organisationen bei komplexen Fragestellungen alle relevanten Informationen und Wertungen an zentraler Stelle zu übersehen, abzuwägen und sachgerecht zu selektieren ${ }^{144}$ ). Mit der Kom-

rechts zu übertragen, um auf diese Weise ihren politischen Gremien die Schwierigkeiten der Auseinandersetzung mit den Betroffenen zu ersparen. Ebenso erfolgt die Konzeption neuer Städte und Stadtteile heute vielfach durch private Gesellschaften und daher ohne öffentliche Kontrolle. Die Gemeinden, die diese Gesellschaften oft unter erheblichem Kostenaufwand mit der Erstellung solcher Pläne beauftragen, sind danach faktisch an diese gebunden.

142) Vgl. etwa $H$. J. Wolff, Verwaltungsrecht II, \& 77 I.

$\left.{ }^{143}\right)$ Repräsentativ $E$. Forsthoff, Verwaltungsrecht, S. 456; Ernst Rudolf Huber, Wirtschaftsverwaltungsrecht, Bd. I, 2. Aufl., Tübingen 1953, S. 544 f.; ebenso Werner Weber, Die Körperschaften, Anstalten und Stiftungen des öffentlichen Rechts. Eine Darstellung ihrer gegenwärtigen Ordnung, 2. Aufl., München 1943, S. 23 f.; ders., Art.: Juristische Personen des öffentlichen Rechts, HDSW Bd. 5, Stuttgart 1956, S. 449 ff. (452); ders., Art.: Körperschaften, HDSW Bd. 6, Stuttgart 1959, S. $38 \mathrm{ff}$. (41).

14.) J. G. March / H. A. Simon, Organizations, S. 199 If.; Charles $E$. Lindblom, The Intelligence of Democracy: Decision Making through Mutual Adjustment, New York 1965, S. $167 \mathrm{Hf}$; $N$. Luhmann, Zweckbegriff, S. 18, 77 ^.; Frieder Naschold, Organisation und Demokratie, 2. Aufl., Stuttgart 1971, S. 65; ders., Systemsteuerung, 5 . 50 tf., jeweils $m$. w. N. 
plizierung der Verwaltungstätigkeit und ihrer Organisation werden daher auch hier die Chancen einer zentralen Steuerung geringer $\left.{ }^{145}\right)$. Das gilt vor allem wieder für die Gestaltungsfunktionen der Verwaltung. Auf die dadurch ausgelösten Verselbständigungstendenzen innerhalb der Staatsbürokratie habe ich bereits hingewiesen ${ }^{146}$ ). [Entsprechend entziehen sich auch die selbständigen Verwaltungsträger einer effektiven Einflußnahme der staatlichen Organisationsspitze. Wenn immer wieder festgestellt wird, daß die staatliche Aufsicht in der Gegenwart versage, dann dürfte das nicht nur auf rechtliche und politische Gegebenheiten, sondern auch auf diesen Umstand zurückzuführen sein.]

b) Schon aus diesem Grunde besteht keine Notwendigkeit, an einem Prinzip der begriffsnotwendigen Staatsaufsicht über Hoheitsträger festhalten $\mathrm{zu}$ wollen, das sich verfassungsrechtlich kaum abstützen läßt. [Denn das Argument von der Einheit des Staates und der Staatsgewalt übersieht, daß die Verwaltung nicht der einzige Garant der staatlichen Einheit ist. Außerdem kann die Ausübung von Privatkompetenzen die staatliche Einheit ebenso gefährden wie die von Hoheitskompetenzen. Schließlich vermag der Hinweis auf die parlamentarische Verantwortlichkeit der Regierung ebenfalls nicht zu überzeugen. Denn diese kann sich natürlich nur auf diejenigen Bereiche beziehen, die dem Weisungsrecht der Regierung unterstehen.] Zu Recht setzt sich daher allmählich die Auffassung durch, daß nicht alle Inhaber von Verwaltungskompetenzen automatisch einer Staatsaufsicht unterstehen müßten ${ }^{147}$ ).

c) Aus dem Rechtsgedanken der Art. 80 I 2, 81 III GG muB man jedoch entnehmen, daß sich die Volksvertretung nicht ihrer politischen Gesamtverantwortung entziehen darf. Daraus ergibt sich ein dem politischen Gesetzesbegriff entsprechender

145) Erfahrungen in der-Kriegsproduktion des 2. Weltkrieges in England und in den USA zeigen, daß es z. B. nicht einmal innerhalb der Flugzeugproduktion möglich war, alle Fragen des Einsatzes der Arbeitskräfte, der Rohstoffe, des Fabrikbaues, der Zuteilung der Geldmittel etc. zu überschauen. Dazu Robert A. Dahl / Charles E. Lindblom, Politics, Economics and Welfare, New York 1963, S. 372 fl. (378); vgl. dazu auch J. G. March / H. A. Simon, Organizations, S. $205 \mathrm{ff}$.

140) Vgl. oben im Text unter II. bel Anm. $46 \mathrm{ff}$.

147) Vgl. Jürgen Salzwedel, Staatsaufsicht in der Verwaltung, VVDStRL 22 (1965), S. 206 ff. (256.f.); Otto Bachof, Verfassungsrecht, Verwaltungsrecht, Verfahrensrecht, Bd. I, 3. Aufl., Tübingen 1966, S. 116. Zum Ganzen W. Brohm, Strukturen der Wirtschaftsverwaltung, S. $218 \mathrm{ff}$. Weitere Nachweisungen zur Streitfrage des "mlnisterlalfreien Raumes" bel Th. Maunz, in: Maunz-Dürig-Herzog, Rdnr. 22 zu Art. 88 GG. 
„politischer Kontrollbegriff“. Das Parlament kann keine Aufgaben von größerer politischer Tragweite weisungsunabhängigen Stellen überlassen, wenn diese damit der parlamentarischen Kontrolle mehr oder weniger entzogen würden. Allerdings braucht die parlamentarische Kontrolle nicht über ein staatliches Aufsichtsrecht der Verwaltung gewährleistet zu werden; sie könnte auch in Formen direkter parlamentarischer Aufsicht, etwa durch spezielle Parlamentsausschüsse erfolgen. [Die Beschränkung des parlamentarischen "Interpellations-“ oder "Zitierungsrechts" auf die Mitglieder der Regierung geht noch von einer monolithischen Struktur der Verwaltung aus. $\mathrm{Je}$ mehr in einer pluralisierten Verwaltung die Verantwortlichkeit der Regierung ihren realen Bezug verliert, desto mehr müssen neue Formen parlamentarischer Kontrolle auch im Bereich der Verwaltung gefunden werden. Auf Regierungsebene haben wir bereits Ansatzpunkte dazu in der Zusammenarbeit von Regierung und Fachausschüssen des Parlaments ${ }^{148}$ ).]

2. a) Im Hinblick auf die Mängel des hierarchischen Prinzips vor allem für die komplexen Gestaltungsfunktionen wird in der modernen Organisationstheorie weithin bilateralen bzw. multilateralen Entscheidungs- und Kontrollmechanismen das Wort geredet. In diesen Modellen geht man von einer Vielzahl von Subsystemen aus, die als selbständige Entscheidungsträger rasch und spezifisch auf die auftretenden Umweltprobleme reagieren. Gleichzeitig halten sie sich gegenseitig in Schach und passen so ihre Zielsetzungen laufend einander an. Durch dieses Prinzip der "wechselseitigen Anpassung" („mutual adjustment") soll die Notwendigkeit einer zentralen Steuerung entfallen. Das Gesamtsystem werde von den Problemen der Untersysteme entlastet und das allgemeine Wohl stelle sich gleichsam von selbst ein ${ }^{140}$ ).

Was hier in neuer Terminologie erscheint, sind weithin die bekannten Argumente für eine dezentralisierte Organisation, die in der Tat in einer komplexen Welt besonderes Gewicht er-

143) Dazu Wilhelm Kewenig, Staatsrechtliche Probleme parlamentarischer Mitregierung am Beispiel der Arbeit der Bundestagsausschüsse, Bad Homburg v. d. H. 1970, S. $13 \mathrm{ff}$. und passim.

140) Vgl. Ch. E. Lindblom, The Intelligence of Democracy, S. 205 If., 274 ff.; Richard M. Cyert / James G. March, Behavloural Theory of Organizational Objektives, in: M. Haire (Ed.), Modern Organization Theory, New York 1959, S. $76 \mathrm{ff}$; Jean Miller, Die Rolle des Sachverständigen in der politischen Willensbildung und im Entscheidungsproze $B$, Hamburg 1970, S. 26 ff. m. w. N.; eine entsprechende Argumentation findet sich bel Adalbert Podlech, Diskussionsbeitrag, VVDStRL 28 (1970), S. 263 f. 
halten $\left.{ }^{150}\right)$. Allerdings werden sie hier mit der Vorstellung eines sich selbst steuernden Systems verbunden, eine deutliche Parallele zur pluralistischen Demokratietheorie. [Indessen wird man sich fragen müssen, ob der Einsicht in die mangelnde Steuerungsfähigkeit des hierarchischen Prinzips dadurch Rechnung getragen werden kann, da $B$ man die zentrale Lenkung einfach ersatzlos streicht.] In dem Harmonieglauben dieser These wird das Machtproblem allzusehr vernachlässigt. Indessen läßt sich das Modell mit zentralen Koordinationsmechanismen kombinieren. Es bleibt das Verdienst dieser Lehre, die Notwendigkeit und Effektivität multilateraler Entscheidungsund Kontrollformen herausgestellt zu haben. Sie werden in $\mathbf{Z u -}$ kunft noch größere Bedeutung erlangen.

b) Vielfältige Ansatzpunkte haben wir bereits in der Gegenwart in der Zusammenarbeit von Bund, Ländern, Gemeinden und gesellschaftlichen Kräften auf den verschiedensten Ebenen. Sie erfolgt in unterschiedlichen Formen, angefangen bei formlosen Beratungen und Abstimmungen über Anhörungs- und Zustimmungsrechte bis zu den institutionellen Verfestigungen in Kooperativorganisationen und Gemeinschaftseinrichtungen $\left.^{151}\right)$. Das Planungsrecht bietet dafür eine Fülle an Beispielen $^{152}{ }^{153}$ ). Diese Formen werfen Probleme der Beleihung ${ }^{154}$ ),

150) Dazu W. Brohm, Strukturen der Wirtschaftsverwaltung, $\mathbf{S}$. 248 ff., und unter Systemaspekten S. 285 f.

151) Dazu im einzelnen $H$. J. Wolff, Verwaltungsrecht, Bd. II, $\$ 77$ $V, \S 75$ III b 3.

132) Vgl. z. B. die Abstimmungs-, Auskunfts- und Beratungspflichten der verschiedenen Planungsträger auf den verschiedenen Planungsebenen (Bauleitplanung, Regionalplanung, Landesplanung, Bundesraumordnung) nach $\$ \S 1$ IV, 4 V, 7, 8 und 10 BROG mit dem begrenzt wirksamen Widerspruchsrecht bestimmter Bundesbehörden gegen raumplanerische Maßnahmen der Länder in $\$ 6$ BROG, ferner $\$ \S 44,48,49$ und 52 BBahnG, $\$ \S 31$ II, 36 I BBauG oder die institutionellen Verfestigungen in kommunalen Arbeitsgemeinschaften, kommunalen Verwaltungsgemeinschaften, Zweckverbänden (vgl. etwa $\$ \S 2$ f., 27, 4 ff. GKG NW), Planungsverbänden (vgl. $\$ 4$ BBauG), regionalen Planungsgemeinschaften, Landesplanungsgemeinschaften (für die Erarbeitung von Gebietsentwicklungsplänen und Flächensicherungsplänen vgl. etwa \& 7 LPG NW), oder Entwicklungsgesellschaften (z.B. die Entwicklungsgesellschaft Wulfen m. b. H. oder Sennestadt GmbH zur Planung und Entwicklung dieser Städte).

159) Weniger der wechselseitigen Anpassung als einer technisch bedingten Zentralisation dienen Gemeinschaftseinrichtungen oder Einrichtungen eines Landes unter Beteiligung anderer Länder, wie z. B. das ZDF, die Filmbewertungsstelle oder das Institut für Bautechnik.

154) Das ist auch dann der Fall, wenn gesellschaftliche Kräfte in körperschaftlicher oder anstaltlicher Organisationsform an der Ent- 
der Mischverwaltung ${ }^{153}$ ) und der interkommunalen Zusammenarbeit ${ }^{156}$ ) auf. [Dabei ist $\mathrm{zu}$ beachten, daß sich diese Rechtsfragen nicht nur ergeben, wenn die Mitwirkungsformen rechtsverbindlichen Charakter haben, sondern auch dann, wenn sie „unverbindliche" Abstimmungen, Planungen oder Richtlinienbeschlüsse betreffen ${ }^{157}$ ). Denn auch dann handelt es sich um Formen der Mitentscheidung. Die Lage ist hier nicht wesentlich anders als bei der bereits erörterten Mitwirkung von Sachverständigen an behördlichen Entscheidungen.]

Die Staats- und Verwaltungspraxis hat sich weitgehend neben den Grundsätzen der Dogmatik entwickelt $\left.{ }^{138}\right)$. Soll sie nicht

scheidung beteiligt werden. So ist es etwa problematisch, gesellschaftlichen Kräften über die Körperschaftsform ein Satzungsrecht verleihen zu wollen. Dazu im einzelnen W. Brohm, Strukturen der Wirtschaftsverwaltung, S. 202 ff., S. $264 \mathrm{ff}$. und pasșim.

${ }^{155)}$ So wenn verschiedene Länder oder Bund und Länder bei der Entscheidung zusammenwirken. Dazu Th. Maunz, in: Maunz-DürigHerzog, Rdnr. 36 und 57 ff. zu Art. 83 GG; Arnold Köttgen, Der Einwand der Mischverwaltung und das Grundgesetz, DOV 1955, S. 485 ff. (487 ff.); Erich Gerner, Zur Frage der "Mischverwaltung" zwischen Bund und Ländern, BayVBl. 1955, S. $193 \mathrm{ff}$. (194 ff.); Fü $\beta$ lein, Mischverwaltung oder Mitverwaltung?, DVB1. 1956, S. 1 if.; H. J. Wolff, Verwaltungsrecht II, $\$ 77 \mathrm{~V}$ a 2; Richard Bartlsperger, in: Bonner Kommentar, Rdnr. 51, 95 f. zu Art. 90 GG (Zweitbearbeitung 1969); Hans Schneider, Körperschaftliche Verbundverwaltung, AöR 83 (1958), S. 1 ff. (3 ff.); ders., Verträge zwischen Glledstaaten im Bundesstaat, VVDStRL 19 (1961), S. 1 ff. (22); Walter Leisner, Schwächung der Landesparlamente durch grundgesetzllchen Föderalismus, DOV 1968, S. 389 ff. (391 f.); Rolf Grawert, Verwaltungsabkommen zwischen Bund und Ländern in der Bundesrepublik Deutschland, Berlin 1967, S. 206 ff.; Gunter Kisker, Kooperation im Bundesstaat, Tübingen 1971, S. $46 \mathrm{ff}$. (bes. S. $166 \mathrm{ff}$.). Zur Problematik bel der Bundesauftragsverwaltung vgl. Willi Blimel, Bundesstaatliche Aspekte der Verwaltungsvorschriften, AöR 93 (1968), S. $200 \mathrm{ff}$.

150) Ahnliche Bedenken wie gegen die "Mischverwaltung" werden auch gegenüber diesen Formen erhoben. Dazu Klaus Stern Günter Püttner, Grundfragen zur Verwaltungsreform im Stadtumland, Berlin 1968, S. 22 und passim; H. J. Wolff, Verwaltungsrecht II, $877 \mathrm{~V}$.

${ }_{157}$ ) Anders die h.M., 2. B.: Werner Weber, Gegenwartsprobleme der interkommunalen Ordnung, in: $W$. Weber $-H$. A. Berkenhoff, Die Gemeinden im nachbarschaftlichen und bundesstaatlichen Spannungsfeld, Göttingen 1962, S. 1 ff. (8); K. Stern - G. Piittner, Grundfragen zur Verwaltungsreform, S. 35; W. Blümel, AöR 98 (1968), S. 200 ff. (225); ferner auch Th. Maunz, in: Maunz-DürlgHerzog, Rdnr. 61 zu Art. 83 GG; A. Köttgen, DOV 1955, S. 485 ff. (487); vgl. aber W. Leisner, DOV 1968, S. 389 If. (392 1.).

158) Rücksichten auf die Dogmatik in der Form, daß man, wie bei der Filmbewertungsstelle und dem Institut für Bautechnik, statt elner Gemeinschaftseinrichtung eine Institution bei einem Lande schafft, die dann für die anderen Länder mit tätig wird („Beteili- 
völlig über die Dogmatik hinweggehen, so wird man sich in der Frage der verfassungsrechtlichen Zulässigkeit nicht auf ein "aut-aut" versteifen können, sondern versuchen müssen, [wie es hier beim Vorbehalt des Gesetzes und dem staatlichen Aufsichtsrecht über selbständige Verwaltungsträger unternommen wurde,] mit größerer Flexibilität und in neuen Formen die heute noch gültigen Rechtsgedanken zur Wirksamkeit zu bringen.

[So wäre zu berücksichtigen, daß die Beschränkungen der Eigenständigkeit der Länder und der kommunalen Selbstverwaltungseinheiten durch entsprechende Mitwirkungsformen kompensiert werden. Grenzen dieser Kompensation wären etwa nach dem politischen Gewicht des kooperativ betreuten Gegenstandes, nach der Intensität der Bindung und nach dem bereits bestehenden Ausmaß der Beeinträchtigung zu bestimmen $^{159}$ ). Die Probleme der parlamentarischen Verantwortlichkeit wiederum ließen sich etwa bei Zustimmungsformen über die stufenweise Betrachtung des Entscheidungsprozesses und bei institutionellen Verbindungen über die Möglichkeit ihrer jederzeitigen Aufkündigung lösen. Die Problematik ist zu komplex, als daß sie hier im einzelnen erörtert werden könnte. Es ging mir nur darum, auf die Notwendigkeit einer dogmatischen Typisierung und rechtlichen Steuerung der verschiedensten Formen multilateraler Entscheidungs- und Kontrollmechanismen hinzuweisen.]

3. Für die daneben weiterhin erforderliche zentrale Zielsetzung und Koordination kommt der Verfassung und der staatlichen Rechtsetzung wachsende Bedeutung $\left.\mathrm{zu}^{100}\right)$. Die Grundrechte und die allgemeinen Rechtsgrundsätze erfüllen in einer pluralisierten Verwaltung mit ihrer differenzierten Tätigkeit eine vereinheitlichende und bewahrende Funktion ${ }^{101}$ ). Kompe-

gungsverwaltung"), sind nur formale Scheinlösungen der eigentlichen Probleme. Mit der Einfügung der neuen Art. 91 a und $91 \mathrm{~b}$ sowie 104 a IV GG wird versucht, die Rechtslage wenigstens im Verhältnis zwischen Bund und Ländern der Entwicklung anzupassen.

159) Dazu G. Kisker, Kooperation im Bundesstaat, S. $144 \mathrm{ff} ., 165 \mathrm{ff}$.

100) Diese Funktion wird leicht bei der negativen Beurteilung von Erscheinungen wie die der Maßnahmegesetze übersehen; vgl. etwa J. Esser, Vorverständnis, S. 82 f.; im obigen Sinne Otto Bachof, Grundgesetz und Richtermacht, Tübingen 1959, S. 28 f1.; F. Kübler, Juristenausbildung im Zielkonflikt, S. 14.

111) Das zeigt sich bei allen Grundrechten. Eine größere Bedeutung wird man in diesem Zusammenhang in Zukunft auch Art. 3 GG zumessen müssen. Seine Anwendbarkeit im Vergleich verschiedener Verwaltungseinheiten miteinander ist noch nicht anerkannt. Die Pluralisierung der Verwaltung bedingt jedoch eine Pluralität 
tenzregelungen reduzieren die Gefahr widersprüchlicher $\mathrm{Maß}$ nahmen. Planungsgesetze koordinieren die Aktivität der staatlichen Verwaltungen wie der gesellschaftlichen Kräfte.

Zur Durchsetzung dieses Rechts tritt neben die staatliche Aufsicht vor allem die staatliche Gerichtsbarkeit.

a) Insofern dienen die dargelegte Ausdehnung des subjektiven öffentlichen Rechts und die rechtliche Erfassung der einzelnen Entscheidungsstufen nicht nur dem Individualrechtsschutz, sondern sie erfüllen zugleich auch Systemfunktionen ${ }^{102}$ ).

Dabei gilt es zu beachten, daß Rechtsbeeinträchtigungen des einzelnen nicht nur durch ein aktives Handeln der Verwaltung, sondern auch durch ein Unterlassen ausgelöst werden können, etwa wenn die Verwaltung gegen die Verletzung von Schutzvorschriften nicht einschreitet oder dringende Planungen unterläßt. Strafanzeigen wegen Umweltverschmutzung gegen Unbekannt haben nur provokatorische Bedeutung. Bestehen aber gesetzliche Regelungen, die den Freiheitsraum des einzelnen ausgestalten oder diese Ausgestaltung durch die Verwaltung vorsehen, so ergeben sich hier Möglichkeiten, mit Hilfe der Verwaltungsgerichtsbarkeit die Verwaltung zum Handeln zu

von Gruppenordnungen und Verwaitungsübungen, die erhebliche Unterschiede in den Leistungen der öffentlichen Hand wie in den Belastungen des einzelnen in gleichartigen Lebenssituationen hervorrufen können. Solange die Verwaltungspraxis von der Vollzugsfunktion geprägt war und sich das Weisungsrecht der staatlichen Hierarchie voll auswirken konnte, beschränkten sich unterschiedliche Verwaltungspraktiken im wesentlichen auf unerhebliche Auslegungsverschiedenheiten im Einzelfall. Soweit die Ungleichheiten zwischen verschiedenen Selbstverwaltungseinheiten bestanden, waren sie mit spezifischen lokalen und statusbedingten Gegebenheiten zu erklären. Unter diesen Umständen ließ sich der Satz der Dogmatik aufrechterhalten, daß das Gleichbehandlungsgebot nur für die jeweilige Verwaltungsstelle gelte. Im egalisierenden Sozialstaat aber wird dieser Grundsatz in vfeler Hinsicht zweifelhaft. Zwar wird man ihn nicht ganz aufgeben können, will man nicht den Pluralismus der Verwaltung für verfassungswidrig halten. Indessen ließe sich über Art. 3 GG ein Mindeststandard erarbeiten, der sich aus dem durchschnittlichen Verhalten der Behörden ergibt. Ubermäßige Belastungen der einzelnen Verwaltungseinheiten könnten im Wege eines umfassenden Finanzausgleichs berücksichtigt werden. Dazu auch W. Brohm, Strukturen der Wirtschaftsverwaltung, S. 283 und passim.

101) Das ist gerade auch für die verschledenen Planungsstufen von Bedeutung. - Weniger positiv wird diese Systemfunktion der Gerichtsbarkeit beurtellt von Christian-Friedrich Menger, Rechtsschutz im Bereich der Verwaltung. Versuch einer Bllanz, DOV 1969, S. 153 ff. (160), der hierin eine Fehlentwicklung sleht. Vom Standpunkt einer Konzeption multilateraler Entscheidungs- und Kontrollmechanismen ist diese Ansicht nicht zu tellen. 
veranlassen. Das Opportunitätsprinzip wird dadurch nicht beseitigt; es wird aber rechtlich beschränkt, und zwar nicht nur im allgemeinen Polizeirecht, wo es allmählich anerkannt ist ${ }^{105}$ ), sondern in allen Rechtsbereichen, etwa auch im Bauplanungsrecht.

b) Fraglich bleibt, ob die Koordination mit Hilfe der Gerichte allein dem Eigeninteresse des einzelnen überlassen werden kann. In seiner Abhängigkeit von der Verwaltung wird er sich allzuoft mit ihr zu arrangieren suchen. Hier jst jedoch zu berücksichtigen, da $\beta$ auch private Interessenverbände die Beeinträchtigung der von ihnen verfolgten Zwecke als eigene Rechtsverletzung rügen können $\left.{ }^{104}\right)$. Das ist nicht nur der Fall, wenn die Tätigkeit der Vereinigung selbst in Frage steht - wie in der "Lumpensammler-Entscheidung" des Bundesverfassungsgerichts ${ }^{105}$ ) - , sondern auch dann, wenn die Vereinigung - wie bei den örtlichen Interessengemeinschaften - nach ihrem Zweck die Individualrechte aller ihrer Mitglieder ,in Gemeinschaft" ausübt, [also als Sachwalterin für die gemeinsamen Individualrechte der hinter ihr stehenden Personen auftritt. Nach diesem Kriterium werden öffentlich-rechtliche Organisationen für grundrechtsfähig gehalten. Ebenso muß man Organisationen des Privatrechts in diesem Falle eine entsprechende Rechtsposition und ihre prozessuale Durchsetzungsmöglichkeit zubil-

103) Dazu Volkmar Götz, Allgemeines Polizei- und Ordnungsrecht, Göttingen 1970, S. $60 \mathrm{ff}$.; Franz Mayer, Das Opportunitätsprinzip in der Verwaltung, Berlin 1963; Otto Bachof, Anmerkung zum Urteil des BVerwG v. 18. 8. 1960, DVBl. 1961, S. $128 \mathrm{ff}$.

104) Das gilt auch dann, wenn sie keine juristischen Personen sind und Art. 19 III GG daher auf sie nicht unmittelbar zutrifft; vgl. etwa BVerfG v. 16. 10. 1968, BVerfGE 24, 236 (243).

105) Vgl. BVerfG v. 16. 10. 1968, BVerfGE 24, 236 („Aktion Rumpelkammer" der kath. Landjugend). - Auf diese Fälle beschränkt letztlich auch Manfred Wolf, Die Klagebefugnis der Verbände. Ausnahme oder allgemeines Prinzip?, Tübingen 1971, die Klagemöglichkeit der Verbände. Wolf will neben der Verfolgung individueller Rechte des Verbandes die Wahrnehmung von Gruppeninteressen nur zulassen, wenn der Gesetzgeber diese als selbständige schutzwürdige Rechte anerkannt habe, d. h. der Schutzzweck „gerade auf die vom Individuum abstrahierenden Merkmale des jeweiligen Interesses gerichtet" sei, und wenn der Gesetzgeber weiter die Verbände als Träger dieser Rechte vorgesehen habe (S. $36 \mathrm{ff}$., $42,45,47 \mathrm{ff}$. (51)). Indessen müssen Verbände nach ihrem Verbandszweck auch eine "gemeinschaftliche Rechtsverfolgung" von Individualrechten, z. B. der Ehre, durchführen können, wenn diese generalisierbar sind, wie etwa das Ansehen einer Gruppe bzw. Personengemeinschaft. Allerdings wird man in vielen Fällen dieser Art im Wege einer weiten Interpretation als Schutzgut des Gesetzes auch ein über das Individualinteresse hinausgehendes Interesse begründen und so dann zum selben Ergebnis kommen können. 
ligen $\left.{ }^{100}\right)$. Der einzelne ist also nicht darauf angewiesen, generalisierbare Individualrechte allein zu verfolgen; er kann sich zu diesem Zwecke auch in Interessengemeinschaften zusammenschließen, und diese können in eigenem Namen diese Rechte geltend machen, so daß dem einzelnen das Prozeßrisiko nicht allein aufgebürdet wird und ihm der Schutz der Anonymität verbleibt. Einer Popularklage wird damit der Weg nicht geöffnet, weil die Organisationen keine Rechtsbeeinträchtigung von einzelnen Mitgliedern oder gar von Nichtmitgliedern verfolgen können, sondern immer nur die gemeinschaftlichen Anliegen aller Mitglieder ${ }^{187}$ ).] Die Rechtslage ist hier nicht wesentlich anders als im französischen Recht $\left.{ }^{108}\right)$.

Damit ist allerdings die Grenze erreicht, im Rahmen der Dogmatik die Gerichte zu System-Zwecken einzuschalten. Sie wäre überschritten, wollte man ein Klagerecht grundsätzlich auch den Inhabern von Hoheitskompetenzen zugestehen. Denn der allgemeine Gerichtsschutz ist nach unserem Recht an der Beeinträchtigung von Individualrechten orientiert. [Diese Konzeption kann man nicht mit der These umgehen, das einzelne Organ habe zwar keine eigenen Rechte, könne aber das Interesse der Gesamtorganisation am ordnungsgemäßen Funktionsablauf geltend machen ${ }^{100}$ ). Da sich die Kompetenzen im allge-

160) Dazu auch G. Dürig, in: Maunz-Dürig-Herzog, Rdnr. 36 und 46 zu Art. 19 III GG; für private Organisationen vgl. weiter Rdnr. 3 mit Bezugnahme auf Art. 9 I GG.

107) So wäre es verfehlt, etwa die Klage örtlicher Aktionsgemeinschaften gegen die in ihrem Bezirk geplanten raumordnerischen Neugestaltungen von vornherein für unzulässig zu halten. Anders wären Klagen $z u$ beurteilen, die etwa der Bund der Steuerzahler im eigenen Namen gegen fehlerhafte Steuerbescheide erhöbe, die gegenüber einzelnen seiner Mitglieder ergangen sind. Ebenso wäre ein Rechtsmittel unzulässig, mit dem die Vereinigung Amnesty International die Rechte einzelner Inhaftierter verfolgen wollte.

168) Dazu Michel Fromont, Rechtsschutz gegenüber der Verwaltung in Deutschland, Frankreich und den europäischen Gemeinschaften, Köln 1967, S. 213 f. Danach hat in Frankreich z. B. der Interessenverband der Grundeigentümer oder Steuerpflichtigen eines Stadtviertels die Möglichkeit, gegen den Präfekten vorzugehen, der sich weigert, eine konzessionierte Verkehrsgesellschaft zur Beachtung ihrer Pflichten zu zwingen. Die "Société pour l'esthétique de la France" kann gegen Verwaltungsentscheidungen vorgehen, die ein Landschaftsbild beeinträchtigen. Allerdings darf eine Vereinigung nur diejenigen Interessen vertreten, zu deren Wahrnehmung sie errichtet worden ist, sonst kann sie sich nicht auf die besondere Lage ihrer Mitglieder berufen.

109) Werner Hoppe, Organstreitigkeiten vor den Verwaltungs- und Sozialgerichten, Siegburg 1970, bes. S. 175 m. Anm. 24, 185, $195 \mathrm{ff}$. (203), will über diese Konstruktion zu einer allgemeinen Klagemöglichkeit der Kompetenzinhaber gegen Beeinträchtigungen ihrer Kompetenz kommen. Er geht davon aus, daß der Begriff des sub- 
meinen nicht über die Grundrechte zu subjektiven Rechten ausweiten lassen ${ }^{170}$ ), kann ein Klagerecht des Kompetenzinhabers nur dann angenommen werden, wenn ihm die Rechtsordnung die Kompetenz als quasi eigenes Recht etwa zur Erfüllung einer Kontrastrolle zugewiesen hat $\left.{ }^{171}\right)$.]

4. Die zentrale Lenkung muß sich, wie erwähnt, bei der planenden Gestaltung in der Regel auf Zielangaben und Planungsgrundsätze beschränken. Die köordinierende Funktion der Gerichte ist daher auf extreme Abweichungen beschränkt. Sie wirkt außerdem nur punktuell.

Bezieht man die geminderte staatliche Aufsicht in die Betrachtung mit ein, so kann man heute schon die Verwaltung nicht mehr als einen einheitlich gesteuerten Organismus im Sinne des Maśchinenmodells ansehen. Vielmehr verbleibt den Subsystemen jener erhebliche Handlungsspielraum, den die modernen Organisationstheorien im Interesse der Flexibilität, Innovations- und Anpassungsfähigkeit für erforderlich halten. Indessen können sich daraus erhebliche Uberschneidungen und

jektiv-öffentlichen Rechts eng mit dem Rechtssatzbegriff zusammenhänge. $\mathrm{Da}$ das Recht im Innenbereich der Verwaltung nicht wie im Außenberelch Rechts- und Interessensphären abgrenze, sondern eine zusammenordnende Funktion habe, könne es keine Individualoder Partikularrechte der Organe geben. Intrapersonale Rechtsbeziehungen beständen überhaupt nur zwischen der juristischen Person als Rechtssubjekt nach innen und den Organen oder Organteilen als Pflichtsubjekten. Das Interesse der Gesamtorganisation als nach innen gerichtetes Ordnungsinteresse aber sel ein auf ein Rechtssubjekt bezogenes Individualinteresse. Es könne von jedem Organ geltend gemacht werden, das auf Grund der arbeitsteiligen Funktionsgliederung der Organisation von der Kompetenzverletzung mitbetroffen sei.

Dieser Argumentation steht $\mathrm{m}$. E. vor allem entgegen, daß auch im Außenbereich das Recht nicht nur abgrenzende, sondern auch zusammenordnende Funktion hat (vgl. etwa schon $A$. Haenel, Gesetz, S. $82 \mathrm{ff}$.). Weiter führt diese Argumentation zur Authebung von objektivem und subjektivem Recht innerhalb des Kompetenzbereiches. Diese These müßte noch begründet werden, da hier eine ausdehnende Interpretation mit Hilfe der Grundrechte im allgemeinen nicht möglich ist.

170) Insbesondere kann hierzu nicht das allgemeine Grundrecht des Art. 2 I GG herangezogen werden, wie es im Außenbereich möglich ist. $\mathrm{Ob}$ spezielle Grundrechte im Einzelfall zum Zuge kommen können, etwa Art. 5 III GG für Theater in der Form nicht rechtsfähiger Anstalten, mag hier dahinstehen. Vgl. Rolf Dïnnwald, Dle Rechtsstellung des Theaterintendanten, Diss. jur., Köln 1964, S. 53; Wolfgang Knies, Schranken der Kunstfreiheit als verfassungsrechtliches Problem, München 1967, S. 202 if.

171) Dazu Gunter Kisker, Insichprozeß und Einhelt der Verwaltung, Baden-Baden 1968, bes. S. $36 \mathrm{ff}$. Zu eng H. H. Rupp, Grundfragen der heutigen Verwaltungsrechtslehre, S. 100. 
Reibungen im Einzelfall ergeben. Ferner können die zentralen Zielsetzungen unbedachte Auswirkungen in der sozialen Umwelt zeitigen oder durch neue Präferenzen einer Änderung bedürfen.

Deshalb muß die Möglichkeit gewährleistet bleiben, mit Hilfe des Gesetzes notwendige zentrale Lenkungen durchzuführen oder Fehlabläufe zu korrigieren, [sei es, daß der Gesetzgeber einzelne Planungsträger auflöst $\left.{ }^{172}\right)$, sei es, daß er ihre Planungen im Rahmen der verfassungsrechtlichen Kompetenzen und Gewährleistungen an sich zieht oder stärker bindet.] Voraussetzung dafür ist, daß der Gesetzgeber frühzeitig mit den sich anbahnenden Konfliktsituationen konfrontiert wird. DaB dieser Innovations- und Rückkoppelungsprozeß auch im Rahmen des hierarchischen Modells gleichsam im Gegenstromverfahren möglich ist, habe ich eingangs bereits erwähnt ${ }^{173}$ ). Solange er auf einem langwierigen Dienstweg von Stufe zu Stufe mehr verwässert wird, wird er - wenn überhaupt - nur noch in geringer Konzentration beim Gesetzgeber angelangen. Deshalb müssen Formen gefunden werden, daß die mit der Sache befaßten Stellen und Gruppen direkt die Zielbestimmung und Koordination des Gesetzgebers anzuregen vermögen. Das wäre etwa über ein Gesetzespostulationsrecht der Subsysteme und der betroffenen Gruppen zu erreichen, wie ich es an anderer Stelle näher ausführen werde ${ }^{174}$ ). [Es geht hierbei darum, nicht nur den institutionalisierten Großorganisationen Einfluß auf die Gesetzgebung zu geben, sondern auch den nichtorganisierten Interessen bzw. ad hoc gebildeten Gruppen. Diese sind angesichts der starken Interdependenzen und Anpassungsbedürfnisse heute allerdings weniger denn je imstande, einen Gesetzentwurf selbst $z u$ formulieren, wie es in den Volksbegehren herkömmlicher Art verlangt wurde und verlangt wird $\left.{ }^{178}\right)$. Daher muß es genügen, diesen Gruppen ab einem bestimmten Beteiligungsquorum, für das wiederum ab einer bestimmten Anzahl von Befürwortern über die Massenmedien geworben werden dürfte, die Möglichkeit zu eröffnen, über das Parlament der Ministerialbürokratie den Auftrag zur Ausarbeitung eines th-

178) Sie bedürfen, auch wenn sie in privatrechtllcher Form organisiert sind, nach den obigen Ausführungen über die Belelhung einer gesetzlichen Grundlage.

173) Dazu auch Rolf-Richard Grauhan, Modelle politischer Verwaltungstührung, PVS 1969, S. 269 ff.

174) Das geschieht in einem Beitrag: „Sachverständige und Politik", in: Festschrift für E. Forsthoff, München 1972.

175) Vgl. z. B. Art. 73 III Weim. RV, Art. 69 11. LV Bremen, Art. 71, 124 LV Hessen, Art. 68 LV NW, Art. 109 LV Rh.-PI., Art. 74 LV Bayern; oder im Kommunalrecht \$ 21 GO BW. 
ren Zielen entsprechenden Gesetzentwurfes zu erteilen.] Ein solches Gesetzespostulationsrecht hätte den Vorteil, daB die Bedürfnisse begrenzter Konfliktsituationen mit dem Anliegen der Gesamtheit abgestimmt werden könnten und die Letztentscheidung bei Regierung und Parlament verbliebe, aber öffentlich verantwortet werden müßte.

\section{VI.}

Ich habe versucht darzulegen, daß unsere verwaltungsrechtliche Dogmatik die durch die technischen und sozialen Interdependenzen verursachte Komplexität der Verwaltungsorganisation und ihrer Wirkungsweise nur noch bedingt zu meistern vermag.

Diese Komplexität [der Umwelt wie des Verwaltungssystems] erfordert eine stärkere Differenzierung der Dogmatik. Sie muß vor allem im Hinblick auf die Gestaltungsfunktion der Verwaltung zu tiefgreifenden Änderungen führen. Wichtiger als eine Einteilung [nach „Eingriffs-“ und "Leistungsverwaltung ${ }^{\text {(176) }}$ oder] nach den Verwaltungszwecken der Ordnungsund Leistungsverwaltung ${ }^{177}$ ) scheinen mir für diese Differen-

176) Die Einteilung in Eingriffs- und Leistungsverwaltung kann nicht als systembildend angesehen werden. Einmal wird bei dem Begriff der Eingriffsverwaltung auf die Rechtsform des Handelns, bei dem Terminus Leistungsverwaltung aber auf den Zweck abgestellt. Zum zweiten sind Eingriff und Gewährung vertauschbar; so können dieselben Ziele der Wirtschaftslenkung durch eine entsprechende Steuergesetzgebung wie durch die Gewährung von Subventionen erreicht werden. Im übrigen hat die Unterscheidung im wesentlichen nur noch Bedeutung für den Vorbehalt des Gesetzes und ist auch hier, wie gezeigt, schon wegen der Breitenwirkung vieler Maßnahmen fragwürdig geworden. Entsprechendes gilt für die Abgrenzung von begünstigenden und belastenden Verwaltungsakten. Vgl. auch BVerwG v. 12. 7. 1968, BVerwGE 30, 132; dazu Meinhard Schröder, Grenzen der nachträglichen Abänderung belastender Verwaltungsakte, BVerwGE 30, 132, JuS 1970, S. 615 ff.

177) Dafür plädiert im Anschluß an $P$. Badura, Verwaltungsrecht im liberalen und im sozialen Rechtsstaat, S. $22 \mathrm{ff}$., etwa auch Walter Schmidt, Die Programmierung von Verwaltungsentscheidungen, AöR 96 (1971), S. 321 ff. (322 f.). - Indessen ist zweifelhaft, ob dieser Einteilung in Ordnungs- und Leistungsverwaltung eine über eine äußere Gliederung des Stoffes hinausgehende, systembildende Wirksamkeit zugemessen werden kann. Schließlich sind diese Zwecke weithin gegeneinander austauschbar und damit ununterscheidbar geworden. Die Subventionsverwaltung als Leistungsverwaltung verfolgt auch strukturpolitische Zwecke wie Fragen der Gefahrenabwehr, etwa bei Subventionen im Interesse des Umweltschutzes. Mit guten Gründen werden daher von den einen die herkömmlichen Ordnungsfunktionen als Leistungsverwaltung qualifiziert (so etwa Erich Becker, Verwaltung und Verwaltungsrechtsprechung, VVDStRL 14 (1956), S. $96 \mathrm{ff}$. (109 ff.)) und von den anderen 
zierung die Gesichtspunkte der „Vollzugsfunktion“ und der „Gestaltungsfunktion" zu sein. Beide sind sowohl für die Ordnungs- wie für die Leistungsverwaltung bedeutsam. Sie sind am Grad der rechtlichen Determiniertheit der Verwaltung orientiert, der allerdings durch die Aufgabenstellung mitbedingt ist. Beide Funktionen können auch nicht scharf voneinander abgegrenzt werden. Sie sind vielmehr lediglich Pole, zwischen denen die verschiedensten Abstufungen möglich sind. Das muß bei der Rechtskonkretisierung im Einzelfall wie bei Neutypisierungen beachtet werden. Insofern verfehlen feste begriffliche Formen in einer komplexen und sich beschleunigt verändernden Welt ihre Funktion. Es wird mehr denn je notwendig sein, den in der Dogmatik festgelegten Wertungen durch neue, flexiblere Formen zur Wirksamkeit zu verhelfen.

Der Begriff der Gestaltungsfunktion macht dabei deutlich, daß die Unterscheidung zwischen Legislative und Exekutive nicht nur im Rahmen des Gesetzgebungsverfahrens, sondern auch bei der Verwaltungstätigkeit problematisch geworden ist. Daher können hier auch die herkömmlichen rechtsstaatlichen Sicherungen nur noch eine begrenzte Wirkung entfalten. Aufgabe des Rechts ist es zu gewährleisten, daß die Zweckset-

die Gegenstände der Leistungsverwaltung als Ordnungsverwaltung deklariert (so etwa Karl Heinrich Friauf, Bemerkungen zur verfassungsrechtlichen Problematik des Subventionswesens, DVBl. 1966, S. 729 ff. (732, 736 f.)). Es wäre aber verfehlt, aus einer solchen Einordnung dogmatische Konsequenzen ziehen zu wollen, etwa damit den Vorbehalt des Gesetzes für das Subventionsrecht zu begründen (a. A. wohl K. H. Friauf, ebd., S. 736 f.). Badura verweist aaO. für seine These auf die Wirtschaftslenkung durch Steuern, die an Art. 12 GG gemessen werden müsse. Diesem Ergebnis ist zuzustimmen. Nur wäre dasselbe auch anzunehmen, wenn Steuern zum Zwecke der Ordnungsverwaltung, etwa des Umweltschutzes, auferlegt würden. Im übrigen ist das Beispiel wenig beweiskräftig, weil die Steuern, obwohl sie Belastungen sind, nach dem herkömmlichen rechtsstaatlichen Verständnis nicht an den Grundrechten gemessen werden. Die Frage wäre umgekehrt zu stellen, ob nicht auf die Deckung des staatlichen Finanzbedarfs prinzipiell die Grundrechte anwendbar sind. Hier mag dann der mit der Steuer verfolgte $Z$ weck eine unterschiedliche Eingriffsintensität rechtfertigen. Insofern soll nicht bestritten werden, daß die verschiedenen Verwaltungszwecke für die Anwendung des einen oder anderen Rechtsgrundsatzes Bedeutung haben können. Rechtsstaat, Sozialstaat und Demokratie sind Grundprinzipien unseres gesamten Gemeinwesens, aber keine spezifischen der Verwaltung. Sie haben für die Verwaltung und ihre einzelnen Institutionen erhebliche Bedeutung, brauchen damit aber nicht für das Verwaltungsrecht und seine Dogmatik systembildend zu wirken. Hierfür läge es näher, auf die Unterscheidung der Staatsfunktionen zu rekurrieren. Dazu im folgenden. 
zungen der Verwaltung nicht nur in technischer Hinsicht, sondern auch im Rahmen der Zielsetzungen der Verfassung, des Gesetzgebers und eines dauernden demokratischen Konsenses optimal erfolgt. $\mathrm{Da}$ dies in weitem Maße noch durch eine Fortentwicklung der Dogmatik des geitenden Rechts erreicht werden kann, habe ich an einigen Beispielen zu zeigen versucht. Rechtspolitische Vorschläge habe ich mit Rücksicht auf die Themenstellung auf ein Minimum beschränkt ${ }^{178}$ ).

179) $\mathrm{Zu}$ der hier getroffenen Abgrenzung der Rechtsdogmatlk von der Rechtspolitlk vgl. im einzelnen oben I., insbes. Nr. 3. 
Leitsätze des Mitberichterstatters über:

\section{Die Dogmatik des Verwaltungsrechts vor den Gegenwartsaufgaben der Verwaltung}

I.

1. Die verwaltungsrechtliche Dogmatik kann wie jede Rechtsdogmatik als ein innersystematisch erarbeitetes Gefüge juristischer Begriffe, Institutionen, Grundsätze und Regeln verstanden werden, die als Teil der Rechtsordnung Anerkennung und Befolgung für sich beanspruchen.

Die Dogmatik dient damit

- der Entlastung bei der Rechtskonkretisierung, ohne ein Reflexionsverbot zu sein,

- der Rationalisierung, sofern man sich des Zweckcharakters ihrer Formen bewujt bleibt,

- der Einheit der Rechtsordnung als Aufgabe,

- der Systemflexibilität,

- der Kontrolle und autonomen Verbesserung der Selektionsleistung.

2. Möglichkeit und Grenzen, die Rechtsdogmatik fortzuentwickeln, ergeben sich einerseits aus dem Wirklichkeitsbezug des Rechts und andererseits aus seiner Normativität. Sie gehen je nach der staatlichen Verfassung verschieden weit.

Die Rechtsdogmatik ist auch „Zukunftswissenschaft". Soll das Recht in einer sich beschleunigt verändernden Welt eine Leitfunktion behaupten, so darf die Dogmatik die Umweltveränderungen nicht nur im nachhinein berücksichtigen.

In ihrem Realitätsbezug ist die Dogmatik auf die sozialwissenschaftliche Forschung angewiesen. Sie hat jedoch ihren eigenständigen Charakter als normative Wissenschaft zu wahren.

3. Konfliktlösungen, die sich nicht mehr aus der positivierten Verfassungs- und Rechtsordnung entnehmen lassen, gehören zum Bereich der "Gesetzgebungswissenschaft", ein bislang vernachlässigtes Gebiet der Rechtswissenschaft, das aber von der Rechtsdogmatik zu scheiden ist. 
II.

4. Im Mittelpunkt der herkömmlichen Verwaltungsrechtslehre steht der an der Eingriffshandlung entwickelte Begriff des Verwaltungsaktes als Äußerungsform der öffentlichen $\mathrm{Ge-}$ walt. Schwerpunkte bilden die Fragen der Gesetzmäßigkeit der Verwaltung und des Individualrechtsschutzes. Damit steht die „Vollzugsfunktion" der Verwaltung im Vordergrund. Die "Gestaltungsfunktion", das Organisations- und das Verfahrensrecht werden als zweitrangig angesehen.

In dieser Ausrichtung hat die verwaltungsrechtliche Dogmatik einen individualistischen und punktuellen Grundzug. Es fehlt weithin die räumliche und zeitliche Dimension.

Feste und starre Rechtskategorien scheinen Abstufungen und Zwischenformen nicht zuzulassen.

5. Grund dieser Eigentümlichkeiten ist neben dem Einfluß des vom Naturrecht individualistisch geprägten Zivilrechtes die staatspolitische Konzeption des bürgerlichen Liberalismus und die geringere Komplexität der realen Gegebenheiten jener Zeit.

6. Das überkommene verwaltungsrechtliche Instrumentarium hat sich als elastisch genug erwiesen, um unter den veränderten rechts- und sozialstaatlichen Anforderungen auch der Leistungsverwaltung im Sinne der „Daseinsvorsorge" gerecht zu werden.

7. Durch die Veränderungen in der technischen und sozialen Welt und die Notwendigkeit staatlicher Sozialgestaltung erhält die Wirksamkeit der Verwaltung neue Möglichkeiten und andere Dimensionen. Die am einzelnen Vollzugsakt orientierte Dogmatik läßt sich vor allem auf die Gestaltungsfunktion der Verwaltung als Zwecksetzung im Rahmen gesetzlich zugewiesener (oder selbst gewählter) Aufgaben nur sehr bedingt übertragen.

Die Problematik der Gestaltungsfunktion wird bislang im Planungsrecht vornehmlich am Prinzip der Gesetzmäßigkeit und des Individualrechtsschutzes erörtert. Systemtheoretische und entscheidungstheoretische Fragen kommen dabei zu kurz.

Die Ausdifferenzierung der Verwaltung führt zu Änderungen ihrer organisatorischen. und personellen Struktur. Sie zeigen sich in Verselbständigungstendenzen innerhalb der Verwaltungshierarchie, in der Zunahme faktisch und rechtlich selbständiger Sonderverwaltungen und in der Beteiligung gesellschaftlicher Kräfte. Diese "Pluralisierung der Verwaltung“ 
wirft organisationsrechtliche Probleme der Zielbestimmung, Koordination und Kooperation auf.

III.

8. Für die Unterscheidung von öffentlichem Recht und Privatrecht ist heute weder die Handlungsform noch die Organisationsform entscheidend. Vielmehr muß darauf abgestellt werden, ob mit der Maßnahme der Verwaltung eine Hoheitskompetenz wahrgenommen wird. Auch fiskalische Hilfsgeschäfte und das Marktverhalten öffentlicher Unternehmen können daher unter die Maßstäbe des öffentlichen Rechts fallen.

9. Der Vorbehalt des Gesetzes gilt auch für mittelbar verursachte Rechtsbeeinträchtigungen insofern, als eine allgemeine Handlungsermächtigung für die Verwaltung vorhanden sein muß. Die Anforderungen des Art. 80 I 2 GG sind in einem strengen Sinne nur auf Ermächtigungen zu generell-abstrakten Verhaltensregelungen anwendbar. Für die Gestaltungsfunktionen der Verwaltung werden sie durch das Sozialstaatsprinzip modifiziert. Das Zusammenwirken von Verwaltung und Parlament bei der Gesetzgebung ist auf die Gesetzesverwirklichung zu erstrecken. Der durch die Zwecksetzung der Verwaltung bedingte Kompetenzverlust des Parlaments ist durch eine entsprechende "demokratische Rückkoppelung" auszugleichen. Diese kann bei abgrenzbaren Wirkungin unter Umständen auch durch die Mitwirkung der Betroffenen oder ihrer Repräsentanten kompensiert werden.

10. Die "Verletzung“ subjektiver öffentlicher Rechte setzt keinen "Eingriffsakt", sondern allein eine durch eine hoheitliche Maßnahme verursachte "Rechtsbeeinträchtigung" voraus.

Die verfassungsrechtlich gebotene Ausweitung des subjektiven öffentlichen Rechts gilt auch für "Dritte". Auch sie sind gegen Beeinträchtigungen geschützt, die mit dem Recht, einschließlich der Kompetenz- und Verfahrensvorschriften wie der allgemeinen Rechtsgrundsätze, nicht übereinstimmen.

Die Ausdehnung des subjektiven öffentlichen Rechts bedeutet eine effektive Erweiterung des Gerichtsschutzes im wesentlichen nur bei der Vollzugsfunktion. Bei der Gestaltungsfunktion wirkt sie sich vor allem auf die Verfahrensbeteiligung aus.

11. In dem Maße, in dem die Zwecksetzung und die Breitenwirkung administrativen Handelns zunimmt, vermögen die an der punktuellen Verwaltungshandlung orientierten Handlungsmaßstäbe die Maßnahmen der Verwaltung nur noch bedingt zu determinieren. Das gilt auch für das Ubermaßverbot (Transiti- 
vität und Konsistenz der Wertskala, Informations- und Werterfassungskapazität, Systemaspekt). Ebenso vermag der Gleichheitsgrundsatz nur eine fragmentarische Kontrollfunktion zu entfalten.

12. Angesichts der weiten Handlungsspielräume der gestaltenden Verwaltung gewinnt die Einflußnahme der „Betroffenen" auf den Entscheidungsprozeß an Bedeutung. Die Notwendigkeit einer umfassenderen Verfahrensbeteiligung folgt aus dem Gebot effektiven Rechtsschutzes und der demokratischen Forderung nach Transparenz und permanentem Konsensstreben. Eine effektive Verfahrensbeteiligung setzt rechtlich gesicherte Einwirkungsmöglichkeiten auf den Inhalt der Entscheidung voraus. Diese lassen sich in begrenztem Umfange über die rechtliche Erfassung der einzelnen Stufen des Entscheidungsprozesses erreichen.

13. Die Unterscheidung zwischen Verwaltungsakt und Rechtsnorm ist begrifflich nur in den klassischen Fällen generell-abstrakter Verhaltensregelung und punktueller Verhaltenskorrektur durchzuführen. Als Kennzeichnung verschiedener Staatsfunktionen hat sie ihren Sinn verloren. Die gesetzlich festgelegten Unterschiede in den Voraussetzungen und Wirkungen sind für die Zwischenformen weiter zu relativieren. Beide Handlungsformen bedürfen der Abstufung in der Verbindlichkeit.

Angesichts der Notwendigkeit größerer Differenzierungen muß erwogen werden, den Begriff des Verwaltungsaktes auf einer höheren Abstraktionsebene zu bilden. Als „Entscheidung “ bezeichnet er dann den verbindlichen Abschluß des Willensbildungs- und Informationsverarbeitungsprozesses der Verwaltung im Rahmen der Wahrnehmung ihrer Hoheitskompetenz, unabhängig davon, ob er eine Regelung gegenüber dem Bürger enthält oder nicht.

IV.

14. Im Interesse der Entscheidungsrationalität, der Verfahrensökonomie und eines effektiven Rechtsschutzes sind in einer pluralisierten Verwaltung bereits die abgrenzbaren Stufen des Entscheidungsprozesses als "Teilentscheidungen" rechtlich zu erfassen. Der Entscheidungsproze $\beta$ wird dadurch transparenter und die Beteiligung der Betroffenen auf die einzelnen Entscheidungsstufen vorverlegt.

15. Die Erkenntnis eines sich in Stufen vollziehenden Entscheidungsprozesses gibt dem Rechtsinstitut der Beleihung eine neue Dimension. Private, die in den Entscheidungsproze $\beta$, sei 
es auch nur als Berater oder Sachverständige, eingeschaltet werden, bestimmen die Entscheidung mit. Der Gedanke der Beleihung ist daher auf sie entsprechend anzuwenden. Das gilt auch für die Gründung privatrechtlicher Organisationen der Verwaltung zur Entscheidungsvorbereitung.

\section{V.}

16. Die zentrale Steuerung nach dem hierarchischen Modell verliert besonders bei den Gestaltungsfunktionen der Verwaltung an Wirksamkeit. Die selbständige Ausübung von Hoheitskompetenzen setzt ein staatliches Aufsichtsrecht nicht begriffsnotwendig voraus. Für Tätigkeiten von größerer politischer Tragweite muß jedoch grundsätzlich die parlamentarische Verantwortlichkeit gewährleistet sein (,politischer Kontrollbegriff"). Sie braucht nicht über ein Aufsichtsrecht der Verwaltung vermittelt zu werden, sondern kann auch in neuen Formen direkter parlamentarischer Kontrolle bestehen.

17. Die organisationssoziologischen Theorien sich selbst steuernder Systeme vernachlässigen zu sehr das Machtproblem. Multilaterale Entscheidungs- und Kontrollmechanismen vermögen eine zentrale Zielsetzung und Koordination nicht völlig $z u$ ersetzen, sind aber in der Kombination damit notwendig und werden in Zukunft noch größere Bedeutung erlangen.

Die Staats- und Verwaltungspraxis hat verschiedenste Formen der Kooperation weitgehend neben der Dogmatik entwickelt. Neue Typisierungen, die in einer flexibleren Art den rechtlichen Problemen der Beleihung, der Mischverwaltung und der interkommunalen Zusammenarbeit gerecht werden, müssen im Interesse der Leitfunktion des Rechts erarbeitet werden.

18. Für die daneben notwendige zentrale Zielbestimmung und Koordination kommt der Verfassung und der staatlichen Rechtsetzung wachsende Bedeutung zu. In ihrer Durchsetzung wird die staatliche Aufsicht durch die Gerichtsbarkeit ergänzt. Insofern erfüllen die Ausdehnung des subjektiven öffentlichen Rechts und die rechtliche Erfassung der einzelnen Stufen des Entscheidungsprozesses auch Systemfunktionen.

Diesen Funktionen dient auch ein Klagerecht der Interessenverbände bei einer Beeinträchtigung der von ihnen verfolgten Zwecke, die auch in der Wahrnehmung der Individualrechte der Gesamtheit ihrer Mitglieder bestehen können. Dagegen läßt es die rechtliche Festlegung auf den Individualrechtsschutz nicht zu, prinzipiell auch den Inhabern von Hoheitskompetenzen eine Klagebefugnis für Verletzungen ihres Funktionsbereiches zuzubilligen. Diese besteht nur in besonderen Fällen. 
19. Eine zentrale Zielbestimmung und Korrektur durch den Gesetzgeber ist auf den Rückkoppelungsproze $\beta$ und die Initiierung "von unten“ angewiesen. Diese Möglichkeiten bestehen auch im Rahmen des hierarchischen Modells, sind aber bei dessen gegenwärtiger Ausgestaltung weniger effektiv. Eine wirksame Ergänzung wäre ein Gesetzespostulationsrecht der Subsysteme wie ad hoc gebildeter gesellschaftlicher Gruppen.

VI.

20. Die zunehmende Bedeutung der Gestaltungsfunktion der Verwaltung läßt die Grenze zwischen Gesetzgebung und Verwaltung, zwischen Zwecksetzung und Vollzug, zwischen Verfassungs- und Verwaltungsrecht auch im Bereich der Verwaltungstätigkeit verschwimmen. In der Ausbildung von Formen, T'ypen und Grundsätzen, die dieser Funktion nicht nur eine technische, sondern auch eine den Vorstellungen der rechtsund sozialstaatlichen Demokratie entsprechende Wirksamkeit verleihen, liegt die Hauptaufgabe der gegenwärtigen Verwaltungs- und Verwaltungsrechtswissenschaft. 


\section{Die Dogmatik des Verwaltungsrechts vor den Gegenwartsaufgaben der Verwaltung}

\section{Aussprache und Schlußworte}

Ipsen: Gestern war ich aus Gründen familienrechtlicher Inkompatibilität arg gehemmt. Sie können sich vorstellen, wie mir schwer gefallen ist zu schweigen. Deswegen haben Sie bitte Verständnis, daß ich heute als Erster spreche - schon, um meine Statistik zu retten.

Zunächst eine Vorbemerkung, die mir wesentlich erscheint für die Zuordnung der beiden Referate zueinander: Herr Bachof hat in These 22 apodiktisch formuliert, ein "Neubau" der Dogmatik sei nicht geboten. Herr Brohm hat zu diesem Thema mit vielen Anregungen einen anderen Weg eingeschlagen. Ich bin geneigt, in entscheidenden Zügen Herrn Brohm zu folgen. Ich unterstreiche auch seinen Hinweis in der These 2, wonach eine Dogmatik eine zukunftswissenschaftliche Funktion und Aufgabe besitzt. Deswegen meine ich, wenn ein "Neubau" nicht geboten ist, dann aber - um im Bilde zu bleiben Modernisierung, Sanierung und Einfügung in neue Funktionen und neue Aufgabenbewältigung. Deshalb würde ich die beiden Referate einander zuordnen mit der Formulierung: was der Korreferent angeregt hat im Verhältnis zu Herrn Bachof, ist nicht revolutionär, sondern evolutionär zu begreifen. Die Referate stehen zueinander im Verhältnis realistischer und aufgeklärter Kontinuität. Ich bin deshalb auch keineswegs der Meinung - im Gespräch fiel das Wort -, Herr Brohm habe schockierend gewirkt - auf mich jedenfalls nicht. Jedem das Seine! Insgesamt möchte ich zu vier Punkten sprechen.

Erstens zu der Diagnose der Gegenwartsaufgaben Bachof-These 19. Ich bin mit ihm der Meinung, daB Planung, Lenkung und vergleichbare Begriffe solche heuristischer $\mathrm{Na}$ tur sind. Ihr rechtlicher Aussagewert ist für das, was wir dogmatisch benötigen, gering, denn sie besitzen nicht hinreichende Konturen. Das habe ich leidvoll erfahren, als ich mich (Kaiser, Planung, Bd. I) darum bemühte, Fragestellungen zur Wirtschaftsplanung zu sammeln, weshalb sie dann eben auch nur Fragestellungen geblieben sind. Andererseits müssen wir diese Begriffe inhaltlich ausfüllen mit dem dogmatischen Ertrag aus dem Bestand „à la Bachof" unter Verwendung der vor- 
handenen und bewährten Rechtsfiguren, aber unter Abwandlung und Veränderung in der Schwerpunktbildung ihres funktionellen Einsatzes, z. B. des Verwaltungsaktes unter Offnung hin zu vertraglichen Formen, zu Verständigungsformen. Ich verweise auf den schönen Aufsatz von Herrn Kaiser über industrielle Absprachen im öffentlichen Interesse (NJW 1971, S. 585), der uns solche Erscheinungen vor Augen geführt hat. Ich erinnere an die Aufsätze von Herrn Krüger über die Auflage im Deutschen Verwaltungsblatt, wo er uns gezeigt hat, welche Funktion die Auflage im modernen Wirtschaftslenkungsrecht hat. In dieser Weise sollten wir versuchen, bewährte Figuren anzupassen, einzufügen, um die Konturlosigkeit neuer Bereiche zu überwinden.

Damit komme ich zum zweiten Punkt, zum Verwaltungsakt. Herr Bachof - wahrscheinlich ist er Fotograf - hat das prächtige Bild gebraucht, der Verwaltungsakt sei eine Art Momentaufnahme. Das trifft den Nagel auf den Kopf. Herr Brohm hat sich in der Sache gleichartig geäußert, indem er von seinem punktuellen Grundzug sprach. Ich verweise auf Bachof-These 24 und die von Herrn Brohm unter Nr. 4. Herr Brohm hat hinzugefügt, der Verwaltungsakt entbehre des räumlichen und zeitlichen Bezuges und der entsprechenden Dimensionen. In der Tat: sie fehlen, wir benötigen sie aber, um verwaltungsrechtliche Beziehungen gehörig rechtlich auszufüllen. Eine kleine Nebenbemerkung zur These 23 von Herrn Bachof, der Verwaltungsakt sei in den Mittelpunkt unserer Dogmatik erst nach dem Kriege gerückt mit der Erneuerung und Intensivierung des Verwaltungsrechtsschutzes. Gewiß, in manchem mag das zutreffen, und die Impulse, die die Neuordnung der Verwaltungsgerichtsbarkeit der Rolle des Verwaltungsaktes gegeben hat, sind evident. Es hat aber schon vorher eine Zeit gegeben, in der der Verwaltungsakt nicht weniger dogmatisch im Mittelpunkt stand. Als ich promovierte, glaubte ich wissenschaftlich überhaupt nur hoffähig werden zu können, wenn ich mich mit dem Verwaltungsakt beschäftigte - deshalb der „Widerruf gültiger Verwaltungsakte" von 1932 . Als unsere Tagungen nach dem Kriege wieder begannen, habe ich in der Annahme, diese Periode sei dogmatisch überwunden, unserem Kollegen Winkler gegenüber gemeint, über den Verwaltungsakt, den man bei ihm Bescheid nennt, könne man sich eben auch nur noch in Osterreich habilitieren. Das hat er mir nie verziehen. Mittelpunkt ist der Verwaltungsakt heute nicht mehr, er darf es nicht mehr sein. Deshalb unterstreiche ich nachdrücklich - für die Fortentwicklung halte ich das für ein Essentiale des Bachof-Referats, These 25 - seine Aufwertung des Rechtsverhältnisses, 
obwohl Herr Bachof es zu meinem Leidwesen unterlassen hat, mein Subventionsrechtsverhältnis und mein Planungsrechtsverhältnis zu zitieren. Aber meinen Plangewährleistungsanspruch hat er dann noch angebracht. Wir brauchen - das entspricht auch den Thesen 7 und 11 von Herrn Brohm - einen Kodex (auch ohne Kodifikation) von Rechtssätzen, die die Zivilisten die Lehre von den Leistungsstörungen nennen. Es ist nötig, die Dauerhaftigkeit und die Kontinuität einer Rechtsbeziehung des Verwaltungsrechts rechtlich zu charakterisieren. Hierzu kann ich anzeigen, daß in Hamburg Herr HoffmannRiem sich habilitandi causa mit den Rechtsverhältnissen des öffentlichen Rechts befaßt, wovon ich mir einiges verspreche. Soviel zu der Frage „Rechtsverhältnis" (These 25 von Herrn Bachof, Thesen 7 und 11 von Herrn Brohm).

Dritter Punkt: Verfahrensbeteiligungen im Entscheidungsprozeß (These 12 von Herrn Brohm). Inwieweit hier Beziehungen zu dem Gedanken prozessualer Art von Herrn Häberle von gestern bestehen, wird die Diskussion vielleicht noch ergeben. Ich erinnere daran, da $\mathrm{B}$ uns das Thema schon beschäftigt hat, als wir uns in unserer Vereinigung über den verwaltungsrechtlichen Plan unterhielten. Das geschah in Erlangen im Jahre 1959 im Anschluß an das Referat von Herrn Imboden, wo vergleichbare Gedankengänge, wie sie in der These 12 von Herrn Brohm entwickelt werden, bereits zur Verwaltungsplanung in der Diskussion erörtert worden sind. Dieses System der Verwaltungsbeteiligungen im Entscheidungsproze $B$ halte ich für wesentlich unter zwei Gesichtspunkten. Die Intention dieser Methode sehe ich einmal in ihrem rechtsstaatlichen, zum anderen in ihrem demokratischen Gehalt. Die beiden wichtigsten Zielvorstellungen unseres Verfassungsrechts würden sich in einer solchen Entwicklung unseres Verwaltungsganges unter dogmatischen Gesichtspunkten verwirklichen.

Das gibt die Anknüpfung, zum letzten Punkt überzugehen. Ihn zu erörtern, fühle ich mich erleichtert, weil Herr Bachof mir in der These 30 dazu eine Ermächtigungsgrundlage geliefert hat. Herr Bachof hat mit Recht unterstrichen, die Entwicklung des europäischen Gemeinschaftsrechts nötige zu gewissen dogmatischen Anpassungen. Der Weg dorthin führt zwangsläufig zu wechselseitigen dogmatischen tberprüfungen und Befruchtungen. Wir vergeben uns nichts, wenn wir an dieser Stelle einmal erwähnen, welchen Beitrag zu dieser Aufgabe deutsche Juristen in den Gemeinschaftseinrichtungen leisten. Ich will - als Stellvertreter für sie alle - nur einen Namen nennen: der seit Beginn der Integration in Luxemburg tätige deutsche Generalanwalt Karl Roemer hat mit seinen Schluß- 
anträgen $z u$ den Entscheidungen des Europäischen Gerichtshofs wesentliche Beiträge methodischer und sachlicher Art geliefert für das, was Herr Bachof in seiner These 30 "geboten" genannt hat. Diese Befruchtung wird stattfinden in einem ständigen ProzeB, der an Intensität zunimmt. Weil dem so ist und ich diesen Prozeß aufmerksam verfolge, erklärt sich auch, daß ich die Anregungen von Herrn Brohm nicht schockierend empfinde. Ich will dafür zum Schluß zwei Beispiele nennen: Herr Brohm hat in These 17 hingewiesen auf die Notwendigkeit einer multilateralen Entscheidungspraxis und entsprechender Kontrollmechanismen. Das sind Verfahrensregelungen, die das Gemeinschaftsrecht entwickelt hat, und zwar nicht nur im Widerspiel von Rat und Kommission, sondern auch unter Beteiligung anderer Einrichtungen und Organe. Ein zweites Beispiel: Herr Brohm hat in These 13 einer dogmatischen Sicht das Wort geredet, die die Unterscheidung des Verwaltungsaktes als des Einzelaktes von der Norm mindestens schrittweise überwindet und abschwächt. Das ist geschehen im Gemeinschaftsrecht, und zwar sicherlich unter französischem Einfluß (insofern ist die Definition des Verwaltungsaktes von Otto Mayer Band I Seite 93 - mit diesem Zitat pflege ich noch heute Studenten zu imponieren, hier scheint das keinen Eindruck zu machen keineswegs französisch orientiert). Im Gemeinschaftsrecht ist auch jenes Kriterium wesentlich für die Differenzierung, das Herr Brohm in These 13 vorgeschlagen hat, nämlich in den Fechtsakten $\mathrm{zu}$ unterscheiden nach dem $\mathrm{MaB}$ der ihnen innewohnenden Verbindlichkeit, nicht aber nach der Individualwirksamkeit, der Einzelaktnatur und der Generalität. Art. 189 des EWG-Vertrages, von dem auch das Bundesverfassungsgericht schon Kenntnis genommen hat, sortiert sein Quintett der gemeinschaftsrechtlichen Rechtshandlungen säuberlich in den Absätzen II bis V nach dem Grade ihrer Verbindlichkeit.

Quaritsch: Ich möchte mit der Feststellung von Herrn Bachof beginnen, das Verwaltungsrecht sei im Vergleich zu anderen Rechtsgebieten dogmatisch weniger ausgeformt. Die dafür dargelegten Gründe sind plausibel. Vergleicht man indes die Lehrbücher des Verwaltungsrechts mit denen des Zivil- und Strafrechts, so muß jene Feststellung doch in Zweifel gezogen werden. Nach der Lektüre des dreibändigen Lehrbuchs von Hans Julius Wolff frage ich mich jedenfalls: wie dogmatischer soll es denn noch werden? Im Gegenteil: in die neueren Lehrbücher des Zivilrechts sind über die Generalklauseln sehr starke impressionistische Züge hineingelangt, deren das Lehrbuch von Hans Julius Wolff durchaus und nicht zu seinem Nachteil ent- 
behrt. - Nach den Attacken auf Ernst Forsthoff ist eines hier festzuhalten: Allen anderen Gebieten unseres Rechts fehlt ein Lehrbuch von der Art des "Forsthoff“, das die Institutionen in die Bedingtheiten des 19. und 20. Jahrhunderts hineinstellt und durch sie erklärt. Diese Funktion der Aufklärung mangelt den Lehrbüchern benachbarter Fächer mit dem Ergebnis, daß sich das, was sich seit einigen Jahren als „kritische Justiz“ geriert, vorzüglich und nicht ganz zu Unrecht in den Bereichen des Zivil- und Strafrechts tummelt. Das war und ist im Verwaltungsrecht unmöglich, weil die historischen Bedingtheiten von Verwaltungsakt, Gesetzesvorbehalt usw. seit der ersten Auflage des "Forsthoff“ hinreichend deutlich waren. Als kürzlich in einer politikwissenschaftlichen Zeitschrift ein Aufsatz über die "politische Funktion des Verwaltungsakts" erschien, so konnte das bei denjenigen, die in das Lehrbuch von Ernst Forsthoff hineingeblickt hatten, doch nur das große Gähnen auslösen; dergleichen war nun wirklich bekannt und brauchte nicht repetiert zu werden.

Herr Brohm hat in seinen ersten fünf Leitsätzen Erkenntnisse ausgebreitet, denen ich nur zustimmen kann. Zu seinem Referat im übrigen habe ich jedoch einige Fragen. Seine Darlegungen bewegen sich auf einem hohen Abstraktionsniveau und dort läßt sich leicht Verständigung erzielen - auf der Ebene der Praxis gibt es Schwierigkeiten. Zunächst: Was soll Leitsatz 8 besagen? Was bedeuten die Ausführungen zur Unterscheidung von öffentlichem und privatem Recht? Soll die Sentenz des Ulpian in Dig. 1.1.1.2. wiederbelebt werden? Handelt es sich hier um eine Reprise der Interessentheorie? Deren Problematik ist uns allen geläufig. Zweitens: Im Leitsatz 9 wird von einem Zusammenwirken von Verwaltung und Parlament bei der Gesetzgebung gesprochen. Das erscheint mir etwas zu unscharf. Ist schon das durch einen Regierungsentwurf ausgelöste parlamentarische Gesetzgebungsverfahren ein solches „Zusammenwirken"? Und was bedeutet in diesem Zusammenhang „Kompetenzverlust des Parlaments"? Diese Aussage bedarf der Begründung. Und inwiefern kann der angebliche Kompetenzverlust des Parlaments durch die Mitwirkung der Betroffenen oder deren Repräsentanten „kompensiert" werden? Ist das wirklich ein tauglicher Ersatz? Das Parlament, die politischen Parteien vertreten etwas anderes als die Betroffenen und deren Repräsentanten, die einen vertreten das Allgemeine, die anderen das Besondere. Das ist keine idealistisch-weltfremde Auffassung, sondern das Resultat praktischer Erfahrung aus der Beobachtung des politischen Lebens. Die führenden Parlamentarier sind nicht (mehr) Interessenvertreter; würden sie es sein, 
wären sie nicht mehr führend. - Die Leitsätze 12-15 sind getragen von einem ungemein sympathischen rechtsstaatlichdemokratischen Impetus. Auf dem Reflexionsniveau von Herrn Brohm erscheinen mir alle Leitsätze als zustimmungsfähig. Im Detail ergeben sich indes einige Fragen. So schlägt Herr Brohm vor, die "rechtliche Regelung" aus dem Begriff des Verwaltungsakts herauszunehmen. Otto Mayer definierte den Verwaltungsakt als einen obrigkeitlichen Ausspruch, der dem Bürger sagt, was für ihn rechtens sein soll. Unsere heutigen vier oder fünf Merkmale des Verwaltungsakts sind nur Ubersetzungen in gefälligere Termini. Wird die "rechtliche Regelung" aus dem Begriff eliminiert, verliert der Verwaltungsakt seine herkömmliche Funktion. Der Verwaltungsakt wurde durch Otto Mayer und seine Nachfolger so bestimmt, daß der Rechtsschutz erst dann einsetzt, wenn der Bürger in seinen Rechten betroffen worden ist - eben dazu bedarf es einer "rechtlichen Regelung“. Wer meint, der Bürger werde schon vorher „betroffen“, müßte sich Gedanken darüber machen, ob ein anderes als das bisherige Verständnis der rechtlichen Regelung notwendig ist. Eine der wesentlichen Aufgaben der Rechtsordnung ist es, die Komplexität zu reduzieren (Luhmann). Die begriffliche Bestimmung des Verwaltungsakts, die damit verbundene ausschnittsartige Erfassung des Verwaltungshandelns, das den Bürger in seinen Rechten berührt, um es der Rechtskontrolle zugänglich zu machen, ist ein klassischer Fall der Reduktion von Komplexität. Hat diese Reduktion seit Otto Mayer wirklich ihre Aufgabe verfehlt? Die Rechtsprechung hat manche Beispiele verkrampft wirkender Ausdehnungen geliefert Herr Brohm nannte als Beispiel die amtsärztlichen Gutachten -,um möglichst viele Fälle dem Begriff des Verwaltungsakts subsumieren zu können. Spätestens seit 1960 sind solche Ausdehnungen für den verwaltungsgerichtlichen Rechtsschutz überflüssig geworden. Wegen einer Fehlentwicklung - vielleicht verursacht durch Schaeffers Grundriß des Verwaltungsrechts - sollte nicht das Institut des Verwaltungsakts aus den Angeln gehoben werden. - Nach Leitsatz 15 sollen private Berater und Sachverständige, die am Entscheidungsproze $B$ der Verwaltung mitwirken, zu "Beliehenen" erhoben werden. Auf einen uns alle angehenden praktischen Fall angewendet: Gewohnheitsrecht und neuerdings auch Gesetz verpflichten die Fakultäten, Gutachten auswärtiger Gelehrter für das Berufungsverfahren einzuholen und dem Minister vorzulegen. Sind diese Gutachten, die von den also „Beliehenen“, z. B. von unseren Kollegen Scheuner, Ipsen und Kaiser, erstattet werden, abgeschlossene Teilaspekte, Teilentscheidungen der Verwaltung, 
die aus rechtsstaatlich-demokratischen Gründen den Betroffenen, nämlich den Bewerbern, mitzuteilen sind und dann von diesen der verwaltungsgerichtlichen Kontrolle unterworfen werden können?

Zacher: Herr Quaritsch, meinen Sie nicht, daß das wieder im Schaeffer als Fehler dann stehen würde, wenn der Beliehene in diesem Punkt schon der Kontrolle unterstellt würde?

Quaritsch: Ob das im Schaeffer steht, weiß ich nicht. Jedenfalls ist auch auf den von Herrn Brohm in Leitsatz 14 erwähnten Gesichtspunkt der "Verfahrensökonomie" zurückzugreifen. Dieser Aspekt scheint mir hinter der Entscheidung des Bundesverfassungsgerichts zu stehen, daß Personalentscheidungen von Kollegialorganen einer Begründung nicht bedürfen ein Segen für unsere Berufungsverfahren. Mit allgemeinen Leitsätzen ist hier nicht getan. Es muß vielmehr für jedes einzelne Gebiet des Verwaltungsrechts entschieden werden, ob unter rechtsstaatlichen, demokratischen und verfahrensökonomischen Gesichtspunkten die Transparenz der Verwaltung notwendig ist. - In Leitsatz 19 schlägt Herr Brohm vor, zur demokratischen Rückkoppelung den Gruppen oder auch nur ad hoc gebildeten Gruppen ein Gesetzespostulationsrecht einzuräumen. Das ist so sensationell nicht. Die Gewerkschaft OTV z. B. fordert, § 94 BBG dahin zu ändern, daß die Gesetzesinitiativen von Bundesregierung, Bundestag und Bundesrat etwa abweichende Normvorstellungen der Gewerkschaften einschließlich der maßgebenden Begründungen aufnehmen müssen und mit einer Stellungnahme der Initiatoren in das Gesetzgebungsverfahren einzubringen sind. Man kann diesen formalisierten Eingang für organisierte Interessen als praktisch ansehen; informell bekommen die Abgeordneten die Vorstellungen der Gewerkschaften ohnehin auf den Tisch. Aber das dürfte logischerweise nicht nur für Beamtengesetze gelten. Im Anhörungsverfahren zur Mehrwertsteuer sind mehr als ein halbes Hundert von Verbänden aufgetreten. Jedem Verband ein Gesetzespostulationsrecht einzuräumen, hieße die Bundesregierung bei Steuergesetzen z. B. verpflichten, ihre Vorlagen in mehreren Bänden einzubringen. Alles formell Eingebrachte hat einen moralischen und sehr bald einen rechtlichen $\mathrm{Zwang}$ zur Befassung und zur Widerlegung zur Folge. Unter dem Gesichtspunkt der Verfahrensökonomie ist ein solches Verfahren daher mißlich. Resumee: man kann die Dogmatik des Verwaltungsrechts nicht nur unter dem Blickwinkel des Anhörungsverfahrens in der Bauplanung betrachten. 
Brohm: Die Punkte von Herrn Quaritsch sind so zahlreich, daß ich gleich einige herausgreifen möchte, von denen ich glaube, daß sie in der weiteren Diskussion vielleicht nicht mehr aufgegriffen werden, aber dennoch beantwortet werden sollten.

Was den Hinweis auf "Schaeffers Grundriß" anbelangt, Herr Quaritsch, so darf ich Sie darauf aufmerksam machen, daß ich mich in meinen Ausführungen auf Entscheidungen des Bundesverwaltungsgerichts in den letzten Bänden (der amtlichen Sammlung) bezogen habe. Daß das Bundesverwaltungsgericht sein Wissen aus diesen Grundrissen bezieht, möchte ich nicht annehmen. Ich persönlich bin der Meinung, da $B$ wir einen Hauptteil unserer Vorlesungen dem Begriff des Verwaltungsaktes widmen, also der Frage, welche Handlungen Verwaltungsakte sind und welche nicht. Ich habe nur einmal zusammengestellt, was wir alles an Tathandlungen als Verwaltungsakte qualifizieren: z. B. den Schlag des Polizeibeamten auf den Störer in den Fällen des sofortigen Vollzugs, die Auskunft, das Armutszeugnis - d. h. die Ablehnung des Armutszeugnisses, nicht dagegen seine Ausstellung -, weiter die Stellungnahme der Filmbewertungsstelle, andere Bescheinigungen und schließlich die Namensnennung des Informanten. Gerade dazu hat das Bundesverwaltungsgericht in einem der letzten Bände ausführlich Stellung genommen. Danach ist die Namensnennung durch ein Einwohnermeldeamt kein Verwaltungsakt; sie ist es aber, wenn sie durch ein Verfassungsschutzamt erfolgt. Ich glaube also, die rationalisierende Funktion, die der Verwaltungsakt bei Otto Mayer hatte und die Sie ihm heute noch zusprechen, ist längst dahin. Sie retten nicht mehr viel, wenn Sie verlangen, $\mathrm{da} ß$ wir mit dem überkommenen Verwaltungsaktsbegriff argumentieren sollten. Vielleicht wäre es doch sinnvoller hier auf globalere Lösungen zu kommen. Das zu dem Punkt „Reduktion von Komplexität" durch die, wie Sie sagten, scharfe Bestimmung des Verwaltungsaktes.

Nun zum Gesetzespostulationsrecht. Hier können Sie mir zu Recht vorhalten, da $B$ ich meine Vorstellungen nicht näher ausgeführt habe. Das war aus zeitlichen Gründen nicht möglich. Ich muß hier auf eine spätere Publikation verweisen. Es geht mir kurz gesagt um folgendes: Ich glaube, wir können feststellen, $\mathrm{da} B$ allgemein in der Bevölkerung der Eindruck besteht, $\mathrm{da} \beta$ die Interessen bestimmter Gruppen im Parlament nicht mehr zur Sprache kommen. Das zeigen die zahlreichen Demonstrationen und andere Erscheinungen. Meine Vorstellung ist die, daß es möglich sein müßte, in das Parlament Interessen und Bedürfnisse ad hoc gebildeter Gruppen hineinzutragen. 
Das bedeutet nicht, daß diese dazu einen fertigen Gesetzentwurf benötigten. Die Möglichkeiten, die wir früher mit Volksbegehren und Volksentscheid hatten (und im Landesverfassungsrecht und im Kommunalrecht auch heute noch kennen), kamen nicht oder nur sehr wenig zur Wirkung, weil sie einmal einen fertigen Gesetzentwurf verlangten, der bei der heutigen Komplexität der Verhältnisse von Außenstehenden kaum erstellt werden kann, und weil sie weiter ein sehr hohes Quorum von Beteiligungen voraussetzten, was oft nicht zu erreichen ist. Ich könnte mir aber vorstellen - angesichts der technischen Mittel, insbesondere der Medien, die uns heute zur Verfügung stehen $\rightarrow, \mathrm{da} \beta$ eine Interessengruppe $a b$ einem bestimmten Quorum an Unterschriften für einzelne Bedürfnisse der Bevölkerung im Parlament einen Gesetzgebungsauftrag an die Ministerialbürokratie einbringen kann, der etwa dem entspricht, was heute auch schon die Abgeordneten tun, wenn sie der Regierung einen Gesetzgebungsauftrag erteilen, indem sie um den Entwurf einer bestimmten Vorlage ersuchen. Dann kann die Ministerialbürokratie bzw. die Regierung, die m. E. die fachkundige Instanz dafür ist, diese Fragen überprüfen und eventuell durch einen entsprechenden Gesetzentwurf reagieren oder auch sagen: nein, so geht es nicht. Dann aber ist sie im Parlament zur Begründung dieser Ansicht verpflichtet, und auf diesen Begründungszwang kommt es mir sehr wesentlich an. Ich würde Ihnen also nicht zustimmen, daß diese Lösung verfahrensökonomisch sehr mißlich und deshalb abzulehnen sei. Ich glaube vielmehr, es würde der Repolitisierung unseres Parlamentes dienen, wenn wir und jene Interessengruppen auf diese Weise erfahren könnten, warum ein solches Gesetz nicht durchkommt und warum andere Maßnahmen getroffen werden. Die Verfahrensökonomie hat $\mathrm{m}$. E. hinter dieses aus dem Demokratieprinzip abgeleitete Anliegen zurückzutreten.

Ich glaube, zu den anderen Punkten werden sich noch mehr Diskussionsbeiträge ergeben, so daß ich sie zurückstellen kann.

Bachof: Nur eine kurze Bemerkung zu dem ersten von Herrn Brohm angeschnittenen Punkt. Ich teile Herrn Brohms Ansicht, $\mathrm{da} B$ viele $\mathrm{Maßnahmen}$, die das Bundesverwaltungsgericht heute noch als Verwaltungsakte anspricht, tatsächlich keine Verwaltungsakte sind, und zwar weder im ursprünglichen Sinne Otto Mayers, noch bei einer vernünftigen Interpretation der heutiGesetze. Das Bundesverwaltungsgericht ist erst auf dem Wege zu dieser Einsicht, wir müssen es darin unterstützen. Viele Probleme lassen sich mit dem Institut des Rechtsverhältnisses, und prozessual mit der einfachen Leistungsklage oder mit der 
Feststellungsklage, ebenso gut oder besser bewältigen als mit dem überanstrengten Institut des Verwaltungsakts und der Anfechtungsklage. Was freilich das von Herrn Brohm angeführte Urteil zur Namensnennung betrifft, so scheint mir der methodische Ansatz gerade dieses Urteils manches für sich zu haben. Es wird dort nämlich scharf unterschieden zwischen einerseits solchen Auskunftsansprüchen, die sich ohne weiteres aus dem Gesetz ergeben und bei denen deshalb nichts zu „entscheiden“ und zu "regeln" ist - hier benötigt man also keinen Verwaltungsakt -, und andererseits solchen Auskunftsersuchen, bei denen der Auskunftserteilung erst eine Entscheidung darüber vorangehen muB, ob die Auskunft zu erteilen oder ob sie zu verweigern ist (Beispiel: Auskünfte des Verfassungsschutzamtes). Ich will damit nicht sagen, daß ich das Urteil für zwingend halte, aber jedenfalls ist der entscheidende Unterschied zwischen einem vorhandenen oder einem fehlenden Regelungsbedürfnis richtig gesehen. Ob etwas zu regeln oder ob nichts zu regeln ist, das scheint mir in der Tat ein wesentlicher Ansatzpunkt für die Frage zu sein, wo wir den Verwaltungsakt noch brauchen und wo wir ihn ad acta legen können.

Oppermann: Drei Bemerkungen mehr affirmativ ergänzender Natur, die sich nicht mit dem Verwaltungsakt befassen, zu den beiden eminenten Referaten, die mir - im Gegensatz zu dem knisternden Antagonismus gestern - in einem glücklichen Ergänzungsverhältnis zueinander zu stehen schienen.

Als erstes sehr̀ viel Zustimmung zu Herrn Bachofs Ehrenrettung unserer Vorfahren aus der konstitutionellen Monarchie von Otto Mayer bis Fritz Fleiner, das Reichsgericht von 1901 nicht $\mathrm{zu}$ vergessen. Persönlich habe ich vor einigen Jahren ganz dieselbe Erfahrung gemacht, als ich bei der Arbeit im Kulturverwaltungsrecht in einer Reihe von Lehrbüchern vom Ende des 19. Jahrhunderts und Anfang dieses Jahrhunderts gelesen habe. Da hat mich ebenfalls frappiert, welche Fülle von Aussagen sich hier im Kulturbereich zu dem finden, was wir heute die leistungsverwaltende oder sozialstaatliche Komponente nennen würden. Es steht unendlich viel darüber in Büchern, die über die Jahrzehnte nicht dieselbe Wirksamkeit entfaltet haben wie die beiden Stars Otto Mayer und Laband - wobei man bei Otto Mayer seinerseits das leistungsverwaltende Element durchaus entdecken kann, wie dies Herr Bachof gezeigt hat. Es steht eben unendlich viel in den Bibliotheken und wird einfach nicht mehr gelesen. Gewisse Vorurteile in dieser Richtung abzubauen, war sehr nützlich. Wahrscheinlich ist derjenige aus unserer Vereinigung, der in den letzten Jahren wohl am mei- 
sten in dieser älteren Literatur gearbeitet hat, nämlich Ernst Rudolf Huber mit seiner "Verfassungsgeschichte der Neuzeit", nicht ganz zufällig zu einer grundsätzlich ähnlichen Bewertung jener Epoche gekommen wie sie heute bei Herrn Bachof im Anfang seines Referates anklang.

Als Zweites mit Herrn Bachof Ziffer 14 und 28 und mit Herrn Brohm Ziffer 2 (und gegen Luhmann) dezidiert für ein "Hineinmischen" sozialwissenschaftlicher Erkenntnisse in die verwaltungsrechtliche Arbeit und gegen „reine" Lehren auf diesem Gebiet. Das gilt im besonderen Maße für das Organisationsrecht, wo man sich die Erkenntnisse der Organisationssoziologie in sehr viel stärkerem Maße zunutze machen sollte als es bisher gemeinhin geschieht. Wenn man etwa an das neuere Hochschulrecht denkt oder an den Entwurf des Betriebsverfassungsgesetzes und sich die Größe der verschiedenen Gremien näher ansieht, die dort geschaffen wurden bzw. geschaffen werden sollen und wenn man andererseits an ziemlich gesicherte Erkenntnisse der Organisationssoziologie denkt, nach denen Entscheidungsgremien maximal nicht mehr als 20 Personen, optimal 10-12 Personen umfassen sollen, ergibt sich aus solchem Theoriedefizit in der Gesetzgebungsarbeit beinahe automatisch das Plädoyer zugunsten der stärkeren Verwendung sozialwissenschaftlicher Erkenntnisse in der Verwaltungsrechtswissenschaft.

Als drittes und letztes zum Europarecht meine tberzeugung, daß es sich hier im Verhältnis zum innerstaatlichen Verwaltungsrecht um ein gegenseitiges Nehmen und Geben handelt, das im Grunde erst eingesetzt hat und von dem beide Seiten profitieren können. Das Europarecht ist sicherlich in mancher Hinsicht noch von der Differenziertheit unseres Verwaltungsrechtes - ich erinnere an die eben erfolgte Intervention von Herrn Quaritsch - ein gutes Stück entfernt. - Wenn man an ein Urteil denkt, wie das Leberpfennigurteil, in dem der Europäische Gerichtshof in einer souveränen Großzügigkeit über den Wortlaut des Art. 189 EWG-Vertrag hinweggegangen ist und aus Ihrem „Quintett“, Herr Ipsen, des Art. 189 mittlerweile nur noch ein Quartett oder Terzett gemacht hat, indem Richtlinie und Entscheidung mehr oder weniger in die Verordnung mit "hineingebügelt" wurden, so könnte hier etwas mehr präzise Dogmatik innerstaatlicher Qualität nur gut tun. Auf der anderen Seite - wenn ich noch einmal auf gestern zurückkommen darf - werden 2 war große "Grundrechtsfeste" in den europäischen Gemeinschaften nicht gefeiert. Man hat in diesem Bereich dafür manchmal, wenn man aus dem Staatsrecht ins Europarecht hinübertritt, das geradezu wohltätige Gefühl, daß auf europäischer Ebene anstelle gewisser Exzesse der deutschen 
Beschäftigung mit den Grundrechten eine nüchternere Betrachtungsweise vorherrscht. Grundrechte werden freilich z. B. als allgemeine Rechtsgrundsätze in dem Maße allmählich entwikkelt, in dem reale Bedürfnisse bestehen. Man ist aber nicht gerade auf etwas aus, was Herbert Krüger einmal als die Suche nach dem "Grundrecht auf Grundrechtserfindung" bezeichnet hat.

Vogel: Hinsichtlich des ersten, was ich ausführen wollte, kann ich jetzt eigentlich nur noch dem zustimmen, was Herr Oppermann schon gesagt hat. In unserer verwaltungsrechtlichen Dogmengeschichte ist bislang, vor allem was das Verwaltungsrecht der konstitutionellen Monarchie anbetrifft, verschiedenes bei weitem zu grob gezeichnet worden. Wir müssen deshalb Herrn Bachof sehr dankbar dafür sein, daß er sein Referat mit einer Uberprüfung mancher hartnäckig eingewurzelter Legenden begonnen hat. Falls jemand Sie deshalb, wie Sie es befürchtet haben, Herr Bachof, in die verfassungs- oder dogmengeschichtliche Rumpelkammer verweisen sollte, dann würde ich Sie sehr herzlich um die Erlaubnis bitten, in dieser Kammer neben Ihnen Platz nehmen zu dürfen. -

Damit darf ich mit dem Einverständnis des Herrn Diskussionsleiters zum nächsten Punkt unserer Diskussionsgliederung, zur Frage des verwaltungsrechtlichen Systems übergehen. Herr Bachof hat hierzu die Ansicht vertreten, daß gegenwärtig ein Neubau des verwaltungsrechtlichen Systems weder geboten noch auch nur möglich sei (These 22). Erlauben Sie mir dazu eine etwas ketzerisch klingende Frage: Haben wir denn eigentlich überhaupt schon ein verwaltungsrechtliches System? Daß wir eine verwaltungsrechtliche Dogmatik haben, hat Herr Quaritsch eben völlig zutreffend belegt; aber haben wir auch ein System, sei es ein „inneres“, sei es nur ein „äußeres System"? Nehmen wir doch nur einmal die gröbste Gliederung, nach der wir auch heute noch unsere Vorlesungen und unsere Lehrbücher einzuteilen pflegen, die Gliederung in "allgemeines" und "besonderes" Verwaltungsrecht: wissen wir denn überhaupt schon, was das ist, "besonderes Verwaltungsrecht"? Ich darf nur daran erinnern, daß die Zuordnung solcher Gebiete wie des Beamten- oder des Gemeinderechts immer wieder geschwankt hat; sie ist $\mathrm{m}$. E. bis heute nicht überzeugend geklärt. Vielleicht käme man überhaupt besser mit einer Dreiteilung an Stelle der bisherigen Zweiteilung weiter: der erste Teil würde die allgemeinen Grundsätze umfassen, der zweite das Recht der Verwaltungsorganisation und der Verwaltungsmittel, der dritte das Recht der Verwaltungstätigkeiten. Der 
mittlere Teil wäre dann "besonders" im Verhältnis zu den allgemeinen Grundsätzen, „allgemein“ aber im Verhältnis zum Recht der Verwaltungstätigkeiten. Dieses dritte Gebiet könnte man dann seinerseits vielleicht nach Verwaltungszwecken einteilen und somit auch ihnen im System des Verwaltungsrechts einen systematischen Ort zuweisen.

Als einen derartigen Bereich von Verwaltungstätigkeiten hat Herr Brohm den Bereich der "gestaltenden Verwaltung" genannt. Ich halte es für richtig, daß er in diesem Zusammenhang den zeitweilig beliebteren Ausdruck "planende Verwaltung“ vermieden hat. Planung ist im Prozeß der gestaltenden Verwaltung nur eine Phase: die Phase der Vorbereitung, allenfalls der Festlegung dessen, was jeweils geschehen soll. Demgegenüber ist der Planvollzug nicht mehr Planung; der zutreffende Oberbegriff hier ist deswegen der, den Herr Brohm verwendet hat. Herr Brohm hat nun gemeint, daß sich in diesem Bereich der "gestaltenden Verwaltung" die Unterscheidung zwischen Norm und Verwaltungsakt relativiere, und das ist als Befund, würde ich meinen, auch durchaus zutreffend. Dennoch habe ich Bedenken, ob dieser verwaltungsrechtstheoretische Befund auch zu einer entsprechenden Anpassung der Dogmatik nötigt, ob eine Definition des Verwaltungsakts auf einer höheren $\mathrm{Ab}$ straktionsebene, wie Herr Brohm sie verlangt hat, wirklich vertreten werden kann. Denn wir dürfen doch nicht verkennen, $\mathrm{da} \beta$ der Begriff des Verwaltungsakts neben seiner verfahrensrechtlichen Funktion, Ansatzpunkt für die verwaltungsrechtliche Anfechtungs- und Verpflichtungsklage sowie für das Widerspruchsverfahren zu sein, auch eine materiellrechtliche Funktion hat: der Verwaltungsakt schafft rechtliche Klarheit; sobald die Rechtsmittelfrist ungenutzt abgelaufen ist, kann seine Rechtmäßigkeit, außer in Extremfällen, vom betroffenen Bürger nicht mehr bestritten werden. Diese Klarstellung, ich habe darauf schon bei früherer Gelegenheit hingewiesen, ist im Großbetrieb der modernen Verwaltung unerläßlich; sie ist aber nur dann vertretbar, wenn der Adressat des betreffenden Akts im Zeitpunkt des Erlasses bereits feststeht, also Rechtsmittel einlegen kann - m. a. W. nur beim Einzelakt, nicht bei der Norm. Solange das materielle Verwaltungsrecht an jener Klarstellungsfunktion des Verwaltungsakts festhält, wird deshalb die Dogmatik des Verwaltungsrechts auch an der Unterscheidung zwischen Norm und Verwaltungsakt festhalten müssen.

Mit Recht hat Herr Brohm darauf hingewiesen, daß wir in Zukunft bei vielen Einzellösungen stärker als in unserer herkömmlichen Dogmatik werden differenzieren müssen, so etwa hinsichtlich der Grundsätze über die Rücknahme und den Wi- 
derruf von Verwaltungsakten. Hier hat man bislang wohl gelegentlich zu unterschiedliche Dinge über einen Leisten zu schlagen versucht. Unsere klassische Widerrufslehre, wie sie in den zwanziger Jahren entwickelt wurde, war, wenn man genauer zusieht, ja im wesentlichen am Vorstellungsbild der bauund gewerberechtlichen Polizeierlaubnis ausgerichtet, die Rechtsprechung des Bundesverwaltungsgerichts und die neuere Widerrufslehre dagegen am Vorstellungsbild des Leistungsbescheides. Für den Bereich der Leistungsbescheide kommt jene Rechtsprechung in der Tat, wenn man einmal den Vorhang der generalisierenden „Abwägungsformel“ durchstöBt und auf die Einzelergebnisse schaut, zu angemessenen Lösungen; für den Bereich der Polizei- und der verwandten Erlaubnisse verdient dagegen $\mathrm{m}$. E. nach wie vor die klassische Lehre den Vorzug. Was das Steuerrecht anbetrifft, haben schon die Klassiker, Otto Mayer, Fritz Fleiner usw. anerkannt, daß dort besondere Grundsätze gelten müßten. Wiederum andere Regeln gelten für rechtsgestaltende Akte. Was deshalb Herr Brohm zur Planfeststellung ausgeführt hat, fügt sich durchaus harmonisch in diese Vielfalt ein. Um so bedenklicher ist freilich die pauschalierende Regelung im Entwurf des Verwaltungsverfahrensgesetzes. Hier sollen Fragen gesetzlich geregelt werden, die in der Wissenschaft noch nicht genügend geklärt sind; wir werden, wenn wir dieses Gesetz erst haben, wohl gar nichts anderes machen können, als es, um den jeweils unterschiedlichen Situationen gerecht $\mathrm{zu}$ werden, von vornherein fortbildend, notfalls auch entgegen seinem Wortlaut auszulegen.

Ein letztes noch: Ich würde Herrn Brohm auch in dem beipflichten, was er in seinen Thesen 9 und 10 über die Ausdehnung des Gesetzesvorbehalts und des Eingriffsbegriffs auf mittelbare Rechtsbeeinträchtigungen ausgeführt hat. Ich würde hier jedoch noch einen Schritt weiter gehen; mir scheint, daß in diesen mittelbaren Beeinträchtigungen eine neue und für eine künftige Dogmatik des Verwaltungsrechtes notwendige Kategorie des Verwaltungshandelns steckt, die wir nur zögernd in den Griff zu nehmen wagen. Es ist doch so, daß die Verwaltung und auch der Gesetzgeber immer mehr dazu übergehen, bestimmte Folgen, die sie erreichen wollen, nicht einfach anzuordnen; sondern man setzt bestimmte Ursachen, von denen man dann aufgrund seiner empirischen Erfahrung erwarten kann, daß sie zu denjenigen Ergebnissen führen, die man "eigentlich“ will. Das schlagendste Beispiel ist nach wie vor die Regulierung des Wechselkurses durch Interventionen der Bundesbank. Die Bundesbank trifft keine Anordnung, sondern sie kauft oder verkauft Devisen - und trotzdem schlägt die Wirkung dieser 
Käufe und Verkäufe so durch wie die einer Anordnung. Diese "indirekte Determinierung" durch Maßnahmen einer Verwaltungsbehörde ist zunächst ein Problem des Staatsrechts, insofern die Frage gestellt werden muß, ob nicht auch für sie eine gesetzliche Ermächtigung notwendig ist; dazu hat Herr Brohm das seine gesagt. Wir werden aber beispielsweise auch zu erörtern haben, wie es mit dem Rechtsschutz gegen solche Maßnahmen steht. Für eine Dogmatik der verwaltungsrechtlichen Handlungsformen ist hier noch ein weites und fruchtbares Feld.

Badura: Herr Vorsitzender, meine Herren! Der Vorstand hat den Referenten ein sehr grundsätzliches Thema gestellt, sie haben es grundsätzlich behandelt, also müssen wir auch grundsätzlich sprechen. Die „Dogmatik des Verwaltungsrechts" sollte behandelt werden. Dogmatik des Verwaltungsrechts - das ist einmal der Versuch, für die Erfassung des Rechtsstoffes eine Hilfestellung zu geben und in dem Sinn also die unablässige Produktion des Gesetzgebers systematisch evident zu halten. Das besondere Verwaltungsrecht entwickelt derartige Grundsätze, Begriffe und Institutionen. Aber darauf beschränkt sich, wie ich glaube, die Bedeutung der Dogmatik des Verwaltungsrechts nicht. Es ist offenbar gerade im Verwaltungsrecht - und das sieht man an der Gestaltung des allgemeinen Verwaltungsrechts - ein besonderes Bedürfnis dafür vorhanden, den gegebenen Rechtsstoff mit der Verfassung und mit den allgemeinen Grundsätzen der Gerechtigkeit und Billigkeit zu vermitteln. Diese Funktion, zwischen der Partikularität des Rechtsstoffes und dem Verfassungsrecht, der Gerechtigkeit und der Billigkeit eine Vermittlung herzustellen, kommt dem allgemeinen Verwaltungsrecht zu. Das allgemeine Verwaltungsrecht hat in der Okonomie der öffentlich-rechtlichen Rechtsordnung deswegen eine besondere Funktion, die auch spezifisch rechtsstaatlichen Charakter haben kann und, wie gerade Otto Mayer zeigt, historisch besessen hat. Deswegen finde ich es erneut und immer wieder überraschend, wenn Begriffe wie "Daseinsvorsorge" als "soziologische Begriffe" bezeichnet werden, obwohl doch die Funktion dieser Begriffe gerade in der eben genannten Vermittlung besteht. Ich glaube, daß "Daseinsvorsorge" genausowenig ein "soziologischer" Begriff ist, wie etwa die von Herrn Häberle gestern genannten objektiven Dimensionen der Grundrechte einfach als "politisch" bezeichnet und damit der juristischen Betrachtung entzogen werden können. Rudolf Smend hat für den Bereich des Staats- und Verwaltungsrechts deutlich gezeigt, welche Funktionen der Dogmatik zukommen können. Da- 
bei ist die Dogmatik nicht beliebigen Einfällen ausgesetzt. Die Steuerung der durch sie erbrachten Leistungen geschieht durch die Verfassung und durch die Theorie von Verfassung und Verfassungsrecht. Diese besondere Verbindung von theoretischen Uberlegungen, prinzipiellen Vorstellungen und juristischen Normen ist die Schwierigkeit, die das allgemeine Verwaltungsrecht nicht anders wie das allgemeine Staatsrecht trifft. Die Staatsaufgaben und die Verwaltungszwecke, die Fortsetzung der Staatsaufgaben im Verwaltungsrecht, spielen dabei eine besondere Rolle. Das Verfassungsrecht wird also in dem Sinne im Verwaltungsrecht „konkretisiert", da $\beta$ diese Vermittlungsleistung erbracht wird, und nicht nur in dem Sinne, daß ein legaler Ableitungszusammenhang hergestellt oder überprüft wird.

Wenn wir die Realität von damals betrachten, besagt es wenig, daß die Zwecke des Verwaltungshandelns damals schon in vielfältiger Weise benannt und beschrieben worden sind, wie es Herr Bachof erneut geschildert hat. Es besagt auch wenig, daß der konstitutionelle Staat sich nicht auf Gefahrenabwehr und Besteuerung beschränkt hat. $\mathrm{DaB}$ das nicht so war, ist in dem letzten (vierten) Band von Ernst Rudolf Hubers Verfassungsgeschichte sehr deutlich gezeigt worden. Für die Frage der Dogmatik des Verwaltungsrechts aber ist es, wie ich glaube, wichtiger, da $B$ die Verfassungsidee des liberalen Rechtsstaates diesen Erscheinungen und Beobachtungen einen ganz bestimmten Stellenwert zugewiesen hat, der sich von dem unterscheidet, der heute diesen Gesichtspunkten und Handlungsweisen der Verwaltung zukommt. Verkürzt gesagt, muß die Verfassungsidee des sozialen Rechtsstaates auch für das allgemeine Verwaltungsrecht eine ganz andere systemleitende Konsequenz haben, als die Verfassungsidee des liberalen Rechtsstaates. Herr Bachof hat unter IV und V sehr ausführlich gezeigt, daB dem in der Tat so ist, und damit, glaube ich, Behauptungen, die er an anderer Stelle seines Referats aufgestellt hat, praktisch widerlegt. Es würde auch wundern, wenn der Autor eines der Bücher, das zu der skizzierten Vermittlungsfunktion des allgemeinen Verwaltungsrechts einen der wichtigsten Beiträge geleistet hat, nämlich der Autor von „Verfassungsrecht, Verwaltungsrecht, Verfahrensrecht in der Rechtsprechung des Bundesverwaltungsgerichts", diese Funktion nicht berücksichtigt haben würde. Aber für damals gesprochen: Wenn man Lorenz von Steins Buch und Otto Mayers Buch vergleicht, fällt doch ohne weiteres auf, da $B$ von den Prinzipien aus ganz unterschiedliche Einordnungen einzelner Beobachtungen und $\mathrm{Be}-$ griffe stattfinden. 
Es führt die konstitutionelle Dogmatik des Verwaltungsrechts weil sie sich am Rechts- und Machtzweck des Staates orientiert, in der Tat zu einer Zweckentleerung der Begriffe und Kategorien des Verwaltungsrechts, und zwar „Zweckentleerung" deswegen, weil Rechts- und Machtzweck des Staates nicht als Zweck, sondern als Wesen des Staates begriffen werden und dementsprechend gar nicht als Zweck in Erscheinung treten. Als Zweck erscheint dann nur das, was mit der Grundidee, dem Rechts- und Machtzweck des Staates, in Widerspruch tritt oder sich an ihrem Rande befindet, nämlich der Wohlfahrtszweck der Verwaltung, der eben in dem klassischen Verwaltungsrecht keine begriffs- und systemleitende Funktion besessen hat. Eine Verlegenheitskonstruktion wie das „schlicht hoheitliche" Verwaltungshandeln kann das sehr deutlich dokumentieren.

Für heute gesprochen, glaube ich nicht, daß die These, die Herr Bachof im letzten Satz von Nr. 4 aufgestellt hat, zutrifft, nämlich, daß bis heute nicht nur Rechtsprechung und Lehre, sondern auch die Gesetzgebung durch die Dogmatik des klassischen Verwaltungsrechts bestimmt werden. Das Korreferat von Herrn Brohm hat in vielfältigen Zusammenhängen auf diese Tatsache verwiesen und sie auch begründet. Ich brauche die Einzelheiten deshalb nicht in extenso zu wiederholen. Kurz nur folgendes. Das Problem von Norm und Vollzug muB sich natürlich heute anders stellen; denn der Begriff des Gesetzes wird anders definiert. Der Begriff des Verwaltungsaktes wird in vielfältiger Weise aufgefächert, wie Herr Brohm gezeigt hat. Der Verwaltungsakt mit Drittwirkung ist eine eigentümliche Rechtsfigur, die mit dem klassischen Begriff des Verwaltungsaktes nicht erfaßt werden kann. Der verwaltungsrechtliche Vertrag ist vorhin von Herrn Ipsen schon erwähnt worden. Um noch etwas hinzuzusetzen: Die öffentliche Anstalt als Begriff, wie sie Otto Mayer vorschwebte, ist heute mehr oder weniger zerfallen und gibt uns keine Leitung mehr, um Benutzungsverhältnisse oder sonstige Rechtsverhältnisse der Daseinsvorsorge zu erfassen.

Der Begriff des Gesetzes nimmt auch für die Dogmatik des Verwaltungsrechts eine Schlüsselstellung ein. Es ist deshalb, glaube ich, nicht möglich, ihn für das vorliegende Thema zu eliminieren, wie es Herr Bachof etwas vereinfachend unter These 6 getan hat, indem er auf die frühere Behandlung (Tagung in Würzburg, 1965) verweist. Denn das ganze Begriffssystem des Verwaltungsrechts ist ja notgedrungen bezogen auf eine bestimmte Vorstellung von dem, was das Gesetz ist. Dementsprechend ist auch der "Verwaltungsakt" Otto Mayers über- 
haupt nicht verständlich, wenn man ihn nicht mit dem damaligen rechtsstaatlichen Gesetzesbegriff im Zusammenhang sieht, worauf Forsthoff immer wieder hingewiesen hat. Der Einfluß von Demokratie und Sozialstaat - um diese beiden Prinzipien für eine Vielfalt von Erscheinungen zu verwenden - verändert den Begriff des Gesetzes, den Begriff des Gesetzesvorbehalts, aber eben auf diesem Wege auch die Kategorien und Begriffe des allgemeinen Verwaltungsrechts. Wenn Herr Brohm von "Gestaltung" spricht, die Zwecksetzung und Vollzug gewissermaßen umgreife, dann zeigt sich, daß eine Grundrelation des klassischen Verwaltungsrechts als überholt angesehen werden muß. Daß die Staatsaufgaben und Verwaltungszwecke von heute die Rechts- und Handlungsformen der Verwaltung verändern, hat Herr Bach of in These 25 selbst ausgedrückt, wenn er sagt, daß von einem bestimmten Ansatzpunkt aus sich Handlungsformen und Institute in jener Mannigfaltigkeit entwikkeln, „deren das Verwaltungsrecht bedarf, um allen Aufgaben der Verwaltung gerecht zu werden“. In der Tat, dieser Zusammenhang besteht. Er drängt sich ohne weiteres auf in der Wirtschaftsverwaltung etwa und im Bildungswesen, das im klassischen Verwaltungsrecht praktisch überhaupt keinen Ort hat. Die Schule als eine „öffentliche Anstalt" mit "besonderem Gewaltverhältnis" ist absurd, von den heutigen Problemen des Bildungswesens aus betrachtet. Das Auftragswesen der öffentlichen Hand ist nicht einfach "fiskalische Hilfstätigkeit" der Verwaltung; denn durch sein Volumen und die Art und Weise, wie es verwendet wird, gehört es in die so nicht richtig greifbaren Grundzusammenhänge des Staats- und Verwaltungsrechts hinein. Regierung und Verwaltung müssen unterschieden werden und diese Unterscheidung führt zu Konsequenzen. Die Programmtätigkeit spielt in Verwaltung und Finanzwirtschaft, in Wirtschaftslenkung, Raumordnung und im Bildungswesen eine zunehmende Rolle, ohne daß immer gleich im klassischen Sinne rechtlich greifbare Verwaltungshandlungen oder Rechtsformen in Erscheinung treten. Die Strukturpolitik beispielsweise ist ein merkwürdiges Konglomerat von Interventionen, Steuervergünstigungen und anderen Mitteln der Verwirklichung der Staatsaufgaben.

Die Schlüsselstellung des Verwaltungsaktes - um damit zu schließen - beruhte bei Otto Mayer nicht auf praktischen Gründen oder Gründen der Gliederung, sondern sie beruhte auf einem bestimmten Axiom über die Funktion des Verwaltungsrechts und der Verwaltung im damaligen liberalen Verfassungsstaat. Sie ist also nicht nur eine Äußerlichkeit und nicht nur aus Gründen der Verwaltungsgerichtsbarkeit nach 1945 in den 
Vordergrund getreten. Mit der Veränderung der Aufgaben des Staates und der Verwaltung mußte die methodische Veränderung eintreten, die den Verwaltungszwecken eine andere und neue Funktion für die von der Dogmatik des allgemeinen Verwaltungsrechts zu leistende Vermittlung einräumen mußte. Ein Neubau des verwaltungsrechtlichen Systems wird natürlich nicht die bewährten Grundlagen beseitigen, soweit sie unter den neuen Gesichtspunkten und unter dem neuen Verständnis der staatlichen Aufgaben der sozialen Gerechtigkeit erforderlich sind. Aber es ist eben, wie ich glaube, insofern ein Neubau, als der leitende Gedanke, das Axiom, von dem aus diese Dogmatik entwickelt werden muß und auch dauernd entwickelt wird, anders ist, und zwar prinzipiell anders als im klassischen Verwaltungsrecht.

König: Herr Bachof hat von den Kosten eines zu kurzen historischen Gedächtnisses gesprochen, und deswegen muß ich voraussetzen, daß ich selbst verkürze: Aber wenn die VorUrteile der Rechtsdogmatik diskutiert werden, sollte man auch über die Philosophie von der Einheit des juristischen Denkens sprechen. Denn wie wir wissen, besteht in der Jurisprudenz eine bestimmte Vorstellung von der Einheit von Theorie und Praxis, die - so meine ich - gerade für das Verwaltungsrecht und die Verwaltungsrechtslehre folgenreich ist. Wenn nun mal die Praxis im Rechtsleben das letzte Wort hat und wenn wir feststellen müssen, daß es der Theorie nur zu einem beschränkten Teil gelingt, die Praxis zu szientifizieren, muß man fragen: Welche Praxis ist denn für die Verwaltungsrechtslehre maßgeblich? Das ist unschwer festzustellen, schon in den Veröffentlichungen dieser Vereinigung nachzulesen, wo im $\mathrm{Zu}$ sammenhang mit der Verfassungsinterpretation vom Konsens aller Vernünftig- und Gerecht-Denkenden die Rede ist und es danach heißt, daß zu den Vernünftig-Denkenden die Rechtslehrer und die Richter gehören. Es wird deutlich, daß Richter nicht soziologisch als Bezugsgruppe angesprochen werden, sondern methodologisch gemeint sind. Das muß Konsequenzen haben. Die richterliche Betrachtungsweise muß maßgeblich werden für die Rechtsdogmatik. Die Systemgrenze Verwaltung/ Publikum muß spezifisch ins Blickfeld kommen; das Prozeßmoment muß eine spezifische Ausprägung erfahren usw. Prozeß wird zum Privileg des Richters. Die Verwaltung wird auf das Materielle beschränkt. Dabei - das zeigt die Rechtsvergleichung - ist das Prozeßmoment Bestandteil der Rechtskultur schlechthin, und ich bin befriedigt darüber, daß es hier cine Aufwertung für die Verwaltung erfährt. Ich halte diese 
Aufwertung auch aus demokratietheoretischen Utberlegungen - wie bereits angeklungen ist - für notwendig. Wir werden das Prozeßmoment noch brauchen, wenn sich im Leistungsstaat herausstellt, daß die individualisierte Zurechnung öffentlichrechtlicher Güter, daß das subjektive öffentliche Recht nur begrenzt möglich ist.

Wenn ich hier für die Auseinandersetzung mit gewissen rechtsdogmatischen Vorurteilen plädiere, dann möchte ich mich auf das Referat von Herrn Brohm beziehen, dem es nach meiner Meinung gelungen ist, einen einschlägigen Ansatz zu demonstrieren. Ich bin auch gar nicht so sicher, ob eine andere aktuelle Variante, nämlich die kritisch-dialektische Theorie, vor der Verwaltungsrechtsdogmatik Halt machen wird. Meines Erachtens muß man gerüstet sein für solche Ansätze, und ich halte sie darüber hinaus für notwendig, zum Beispiel im Hinblick auf das Effizienzproblem. Sicher hat das Effizienzproblem vor allem eine ökonomische Dimension. Aber es begegnet uns auch im Haushaltsrecht, und es ist Aufgabe der Verwaltungsrechtsdogmatik, die entsprechende rechtliche Ordnungsleistung nachzuweisen, ohne damit der Okonomie Konkurrenz machen zu müssen. Aber, Herr Brohm, wenn ich danach für weiterreichende Ansätze bin, so muß man doch auch die Konsequenzen solcher Versuche sehen. Diese Konsequenzen sind im Hinblick auf die Funktion der Rechtsdogmatik schon in anderen Diskussionsbeiträgen deutlich geworden. Man muß darauf achten, daß rechtsdogmatische Argumente auf spezifisch juristische Problemlösungen zugeschnitten sind, und der Verwaltungsakt hat sich eben als ein solches Argument im Zusammenhang mit pragmatischen Problemlösungsverfahren erwiesen. Ich habe Zweifel, wenn ich auf Ihre These 13 schaue, ob es möglich ist, den Entscheidungsbegriff rechtsdogmatisch einzusetzen. Ich meine, er liegt auf einer theoretischen Stufe über der Rechtsdogmatik. Insofern folge ich in einem anderen Punkt auch mehr Herrn Bachof: Ich bin sehr für eine Theorie der öffentlichen Aufgaben, bezweifle aber, wieweit sich eine solche Theorie unmittelbar in eine rechtsdogmatische Systematik umsetzen läßt.

Herr Bachof, ich möchte, indem ich für solche Differenzierungen spreche, mich nicht in einer Gegenposition zu Ihnen sehen. Ich sage, daß wir von verschiedenen Reflexionsebenen ausgehen müssen, und ich halte gerade Ihren Ausgangspunkt im Hinblick auf die Rechtsdogmatik für wichtig, weil er nämlich den spezifisch juristischen Argumentationszusammenhang aufrecht erhält. Ich bin dann jedoch grundsätzlich gegen Polarisierungen, wie sie in Gegenbegrifflichkeiten wie Dogmatik/ 
Zetetik oder auch im Vorwurf unreflektierter Aufnahme sozialwissenschaftlicher Erkenntnisse in die Rechtswissenschaft zum Ausdruck kommen können. Ich stimme Ihrer These $14 \mathrm{zu}$. Wir müssen einander zuarbeiten. Im Grunde genommen gelingt es uns heute immer besser, arbeitsteilige Verfahren durchzuführen. Es wird immer schwieriger, Arbeitsergebnisse zu integrieren, und das gilt wohl für die Verwaltungswissenschaften wie für die Verwaltungspraxis gleichermaßen.

Winkler: Zunächst ein Wort zu Herrn Ipsen. Ich kann sehr gut verstehen, daß Sie erbost waren, daß im Jahre 1956 jemand über den Verwaltungsakt schrieb, den Sie schon längst vorher "widerrufen" hatten. Aber das trennt uns nicht nur, das verbindet uns auch. Ich werde Ihnen daher auch in dieser Frage im Grundsätzlichen folgen und den Verwaltungsakt ausklammers.

Erlauben Sie mir nun, in Erinnerung an eine Begebenheit, die sich erst kürzlich ereignet hat, ein Wort an Herrn Bachof. Wie Sie, Herr Bachof, heute referiert haben, würden Positivisten österreichischer Provenienz auch sprechen. Ich hoffe, daß Sie das nicht als Kränkung empfinden. Ich habe kürzlich erst in Fünfkirchen in Ungarn über „Recht und Wirklichkeit" gesprochen und nachdem ich geendet hatte, sagte der dortige Dekan: So wie Kollege Winkler aus Wien jetzt über Sein und Sollen geredet hat, würden wir Marxisten auch über Sein und Sollen reden. Im Vergleich dazu, Herr Bachof, ist Ihre Einbeziehung in die Reihe der österreichischen Positivisten relativ weniger provokant.

In diesem Zusammenhang möchte ich gleich einen weiteren Punkt betonen. Es ist bereits eine gewisse Tradition, wenn auch eine immer wieder unterbrochene, daß ich mich genötigt sehe, mich in dieser Runde immer wieder zum einzelwissenschaftlichen Positivismus zu bekennen. Im Zusammenhang mit dem vorliegenden Thema muB ich es neuerdings tun. Man spricht von der Verwaltungsrechtsdogmatik. Und Verwaltungsrechtsdogmatik bedeutet eine bestimmte Art wissenschaftlicher Pflege eines vorgegebenen rechtlichen Gegenstandes. Dieser wird von uns nicht geschaffen; er wird von uns vorgefunden. Er wird von uns auch nicht eigentlich verbessert. Er wird von uns nicht in die Zukunft entwickelt: schon gar nicht unter dem Prätext „Verwaltungsrechtsdogmatik" mit der Denkweise der Verwaltungslehre und der Verwaltungspolitik.

Damit will ich zugleich eine Stellungnahme zu Herrn Brohm abgegeben haben. Weite Bereiche seines Referates fasse ich als Verwaltungslehre und Verwaltungspolitik auf. In dem Maße 
wie Herr Brohm die Zukunft der Verwaltungsrechtsdogmatik an die Wand malte, hat die Zukunft noch nicht begonnen. Im Gegenteil, in viel höherem Maße als Herr Brohm meint, dauert die Vergangenheit noch an, weil der Gegenstand "Verwaltungsrecht" relativ beständig ist.

Ich hoffe, da $B$ man mir nicht böse ist, da $\beta$ ich es nicht nur wage, mich als Positivisten vorzustellen, sondern auch noch Hans Kelsen zu zitieren: und zwar unverdächtigerweise, da doch jedermann weiß oder wissen kann, daß ich mich seit vielen Jahren in höchst kritischer Auseinandersetzung mit Kelsen befinde. Kelsen gibt im Vorwort zur Reinen Rechtslehre ein entscheidendes wissenschaftliches Bekenntnis ab. Er führt in der 1. Auflage aus - und zwar viel schärfer als in den Hauptproblemen - er wolle seine Lehre von der Theologie u. a. abheben. In der 2. Auflage sagt er, seine Reine Rechtslehre unterscheide sich wesensgemä $B$ von der Politik. Dabei ist es ihm ein entscheidendes Anliegen, die Rechtslehre von der Politik auch als Wissenschaft zu unterscheiden. - Ich möchte auf die vielfachen Bedeutungsgehalte des Begriffs „Politik" hier nicht eingehen. Es sind derer zu viele und man kann hier das Begriffliche auch gar nicht abklären. - Dieses Anliegen Kelsens ist nach wie vor gültig. Und zwar, sofern man der Meinung ist, da $B$ das positive Recht ein gegebener, unserer Erfahrung im großen und ganzen zugänglicher Gegenstand ist, den wir auf kritische, also wissenschaftliche Weise, in geordneter, also in systematischer Weise erfassen, erfahren, beschreiben und erklären können. So würde ich jedenfalls auch die Verwaltungsrechtsdogmatik verstehen.

Damit möchte ich zu einigen Aspekten kommen, die zum Teil in den Referaten beleuchtet worden und zum Teil in den Diskussionsbemerkungen angeklungen sind. Ich stelle mir vor, daß man das Verwaltungsrecht, die Verwaltungsrechtsordnung, als gegebenen Gegenstand, auf zwei Ebenen begreifen kann und muß: auf der Verfassungsebene, von der die Referenten gesprochen haben und die Herr Badura hervorgehoben hat, und auf der einfachrechtlichen Ebene. Diesen beiden Ebenen steht die Verwaltungswirklichkeit, das heißt das tatsächliche Verhalten der Verwaltung gegenüber. Dieses erweist sich dann als in Ubereinstimmung oder im Gegensatz zur Verwaltungsrechtsordnung. So kann man das Verwaltungsrecht erfassen, beschreiben, erklären, systematisch darbieten und zu der tatsächlichen Verhaltenswirklichkeit der Verwaltung kontrastieren. Wenn man isoliert vorgeht, dann kann man natürlich Gefahr laufen, das Spannungsverhältnis, das zwischen Verfassungsordnung und einfachgesetzlicher Ordnung zwangsläufig 
gegeben ist, schlechthin als politisches Verhältnis zu verstehen, weil die Verfassung ein ständiges Postulat gegenüber der einfachgesetzlichen Ordnung ist, weil sie die Verwaltung regelt und die Verwaltung an die Verfassung bindet.

Ich kann mir gewiß vorstellen, daß man das Verwaltungsrecht durchaus allein von der Ebene des einfachen Gesetzes und was darunter noch an Normativem liegt, erklären und zur Wirksamkeit des Verwaltungsverhaltens sowie zu den normativen Postulaten der Verfassung kontrastieren kann. Man kann und soll aber auch - hier stimme ich mit Herrn Badura überein - die Verfassungspostulate in eine Verwaltungsrechtsdogmatik einschließen. Dann ist es unausbleiblich, festzustellen, ob die einfachen Gesetze mit der Verfassung im Einklang stehen. Man kann ferner feststellen, ob auch die soziale Wirklichkeit mit dieser oder mit jener rechtlichen Ebene im Einklang steht.

Wenn man so unterscheidet und das Verwaltungsrecht als einen gegebenen rechtlichen Gegenstand begreift, dann ist die gedankliche Konzeption davon die Verwaltungsrechtsdogmatik. Sie ist nicht identisch mit dem Gegenstand. Sie ist vielmehr unser Denken über den Gegenstand, das einfachgesetzliche und auf sie gegründete normative Phänomene (Verordnung. Verwaltungsakt), wie verfassungsrechtliche genauso betrifft. Diese Unterscheidung von Erfahrungsobjekt und Erkenntnisobjekt habe ich sehr wohl bei Herrn Bachof gefunden, nicht aber bei Herrn Brohm.

Indem man fragt, was Verwaltungsrechtsdogmatik bedeutet, begibt man sich aber mit dem Denken auf eine weitere Ebene, die über dem Denken zum Gegenstand liegt, und analysiert dieses. Dabei fragt man sich vielleicht, ob dieses Denken gegenwartsbezogen, gegenstandsbezogen, vollständig, aktuell, modern, schön genug ist. Auch ästhetische Gesichtspunkte spielen in der Verwaltungsrechtdogmatik eine Rolle. Aus der Verbindung dieser beiden Denkebenen zeigt es sich deutlich, daß es Rechtsbegriffe und Wissenschaftsbegriffe gibt. Es ist eben nicht notwendigerweise so, daß ein Begriff, der nicht als Rechtsbegriff erkannt wird, ein soziologischer sein muß, er kann ein wissenschaftlicher Begriff sein. Damit gehört er einer anderen Ebene des Denkens an.

Nur wenn man die Fragestellung so auffaßt, kann man sinnvollerweise fragen, ob die heutige Verwaltungsrechtsdogmatik ihre Aufgabe erfüllt oder nicht. Das Recht ist dem Wandel unterworfen und die Verwaltungsrechtsdogmatik - sofern sie das Recht als einen gegebenen Gegenstand annimmt - muB dem Wandel des Rechts folgen. Das kann man feststellen. Na- 
türlich leistet man damit nicht genug. Damit hat aber die $\mathrm{Zu}-$ kunft noch nicht genug begonnen, Herr Brohm. Den sogenannten modernen Aspekten des Verwaltungsrechts müßte die Verwaltungsrechtswissenschaft gewiß viel mehr Rechnung tragen, als sie es tatsächlich tut. Wenn man eine Sachverhaltsaufnahme von der österreichischen Warte aus vornimmt, muß man sagen, daß noch nicht genug getan wird. Warum? Weil jeder von uns sein Arbeitsgebiet, sein Hobbygebiet hat - sei es auch der Verwaltungsakt. Weil man ferner auch verpflichtet ist, im Lehrplan der Hochschule einen bestimmten Gegenstand darzubieten und von dorther vielleicht die utopische Vorstellung hegt, es könnte ein vollständiges, ja sogar in sich geschlossenes, rechtsdogmatisches System, bezogen auf das Verwaltungsrecht geben. Wer wird schon mit seiner Vorlesung wirklich fertig? Ich sage von vornherein, daß ich gar nicht fertig werden will. Außerdem ist es ja auch so, daß man, wenn man vom System des Verwaltungsrechtes spricht oder sich mit der Systematik befaßt und Verwaltungsrechtsdogmatik meint, immer das allgemeine Verwaltungsrecht vor Augen hat und gar nicht eigentlich immer auch die in den besonderen Gebieten des Verwaltungsrechtes enthaltenen allgemeinen Gedanken. Die mangelnde Einbindung bestimmter Teilgebiete des Verwaltungsrechtes in das rechtsdogmatische Denken über das allgemeine Verwaltungsrecht oder in ein allgemeines Konzept wird zu Recht kritisiert.

Auf der anderen Seite bestimmen aber sowohl die subjektive als auch die objektive Wichtigkeit der Forschungsgebiete die verschiedenen Systeme. Der eine schreibt über diese Lieblingsgebiete, der andere über jene. Es gibt schließlich die Freiheit zur wissenschaftlichen Schwerpunktbildung. Und letzten Endes arbeitet man vielfach lieber in höchst aktuellen Bereichen, weil man diese für wichtiger hält.

Der Jurist darf sich den Anforderungen der Gesellschaft nicht entziehen und soll es auch gar nicht. Daher ist die rechtspolitische Fragestellung die interessantere, als etwa der fehlerhafte Verwaltungsakt, die Rechtswidrigkeit, die Schadenshaftung $u$. a. und viel häufiger in der modernen "Dogmatik" anzutreffen. Im übrigen begeht man nur zu leicht den Fehler, die höheren Bildungsanforderungen an den akademischen Lehrer auch noch in die Verwaltungsrechtsdogmatik miteinzubezieund mehr Methodik als Dogmatik zu pflegen. Man pflegt dann eigentlich nicht in puristischer Zurückhaltung und Bescheidenheit Rechtsdogmatik, sondern mehr Rechtstheorie, Erkenntnistheorie, Rechtsphilosophie, Staatslehre, Soziologie, Politik u. a. Das alles spielt eine große Rolle. 
Meine Vorstellungen von der Verwaltungsrechtsdogmatik möchte ich aber in einer allgemeinen Sinnbedeutung kurz andeuten: Verwaltungsrechtsdogmatik verstehe ich als eine systematische Erfassung des gesamten einschlägigen Stoffes. Darüber hinaus gibt es aber noch eine wichtige weitere Frage dogmatischer Grundeinstellung. In dieser Frage, so muß ich mit Bedauern feststellen, hat mir Herr König leider die Originalität abgelaufen. Ich meine das Verwaltungsdenken zum Fall, bei dem man nicht lehrmäßig systematisiert und folgert, sondern vielmehr den mühseligen Weg, oft durch Hunderte von Vorschriften beschreiten, seien sie einfachgesetzlicher Art oder verfassungsrechtlicher Natur, um letztlich in einer systematischen und auf die innere Widerspruchsfreiheit abzielenden Sinnermittlung und Klärung herauszufinden, was für den konkreten Fall Rechtens ist. Wenn es zünftig gemacht wird, dann ist das auf Anlaß und Sachverhalt bezogene Denken selbstverständlich auch rechtsdogmatisches Denken. Dabei erscheint natürlich vieles von dem, was heute gesagt wurde, sehr wichtig.

Entscheidend bleibt die grundsätzliche Utberlegung: Was ist der Gegenstand (Erfahrungsobjekt) und was ist die Gegenstandsauffassung (Erkenntnisobjekt). Eine Mehrschichtigkeit des Denkens auch in dieser Hinsicht ist unabweislich. Man kann ihr nicht entrinnen. Die volle Bewußtheit davon hindert daran, in einen Synkretismus zu verfallen, der wohl interessante Aspekte für einen Gegenstand vermitteln kann, nicht aber die rational zu begreifende Gegebenheit eines Gegenstandes. In diesem Sinn, würde ich sagen, hat weder die Vergangenheit aufgehört, noch die Zukunft begonnen. Denn darin zeigt sich die unveränderte Aufgabe der Rechtswissenschaft, die für das Verwaltungsrecht genauso Gültigkeit hat wie etwa für das Zivilrecht, für das Strafrecht u. a. Disziplinen.

Bullinger: Herr Brohm hat, glaube ich, das große Verdienst, daß er versucht hat, das Augenmerk der verwaltungsrechtlichen Dogmatik weniger auf die Rechtsform des Verwaltungshandelns als auf den Entscheidungsproze $\beta$ der Verwaltung zu lenken, der verwaltungsrechtlich bedeutsam ist, ob er schließlich zu einem privatrechtlichen oder öffentlich-rechtlichen Vertrag oder zu einem Verwaltungsakt führt. Damit wird zugleich, was Herr Bachof deutlicher gemacht hat als Herr Brohm, die Unterscheidung von öffentlichem Recht und Privatrecht für das Verwaltungshandeln weitgehend relativiert. Will man nämlich das Verwaltungsverfahren so gestalten, daß nach Möglichkeit Willkür vermieden wird, dann muß sich diese Uberlegung auch auf Verfahren beziehen, die nicht zum Erlaß eines Ver- 
waltungsaktes oder eines öffentlich-rechtlichen Vertrages, sondern zum Abschluß eines privatrechtlichen Vertrages führen. Deshalb ist das Verwaltungsverfahrensgesetz, das dem Musterentwurf folgend nunmehr vom Bunde erlassen werden soll, von vornherein antiquiert; denn was dort geregelt werden soll, ist eben nur das Verfahren, das mit einem Verwaltungsakt oder öffentlich-rechtlichen Vertrag enden soll, nicht dagegen das Verfahren, das einen privatrechtlichen Vertrag vorbereitet, z. B. die Vergabe eines öffentlichen Auftrags. Herr Badura hat schon hervorgehoben, da $B$ dieses wichtige Gebiet der öffentlichen Aufträge vom Verwaltungsrecht nicht übergangen werden darf.

Gerade für die öffentlichen Aufträge, speziell die Forschungsund Entwicklungsaufträge, aber auch für den Gesamtbereich der Planung ist etwas kennzeichnend, was Herr Brohm besonders herausgearbeitet hat, nämlich ein stufenförmiger Prozeß des Entscheidungsverfahrens. Welche rechtlichen Konsequenzen daraus gezogen werden können und müssen, zeigt anschaulich das Verfahrensrecht, das sich in den Vereinigten Staaten für Forschungs- und Entwicklungsaufträge der NASA entwickelt hat. In mehreren Verfahren wird jeweils ein zunächst abstrakt formuliertes Beschaffungsziel allmählich zu konkreten Zielen der Auftragsvergabe und zu Auftragsbeschreibungen verdichtet. In jeder Phase der Verdichtung wird das Ergebnis festgehalten, mit den Beteiligten erörtert und damit rechtsstaatlich wenigstens soweit kontrollierbar gemacht, wie es möglich ist. Ein derart abgestuftes Verfahren bietet sich auch für die Planung an. Die Planziele müssen fortschreitend zu konkreteren Planvorstellungen verdichtet, kundgetan und mit den Beteiligten erörtert werden, die damit am Entscheidungsproze $B$ teilnehmen und nicht darauf verwiesen werden, gegen die Endentscheidung vorzugehen. Ähnliches gilt auf dem Gebiet der Wirtschaftsaufsicht - ich hatte darüber früher einmal zu referieren. Nehmen Sie das Verfahren des Bundeskartellamts. Wenn das Kartellamt Begriffe wie „Mißbrauch“ handhaben muß, dann kann sich das nicht so vollziehen, daß die Auslegung dieses Begriffs auf bestimmte Wirtschaftspraktiken sogleich in einen Verwaltungsakt umgesetzt und dieser Verwaltungsakt dann gerichtlich darauf kontrolliert wird, ob er den rechtlichen Maßstäben genügt. Das Kartellamt, das ist auch die feste Praxis, verdichtet vielmehr solche allgemeinen Formeln zunächst zu konkreteren Maßstäben und erörtert sie mit den Beteiligten. Damit wird das stufenförmige Verfahren, das Herr Brohm dargelegt hat, realisiert und rechtsstaatlich nutzbar gemacht. 
Ich glaube also, daß das Referat von Herrn Brohm für die allgemeine verwaltungsrechtliche Dogmatik Wege aufgewiesen hat, die entscheidend weiterführen können.

Rupp: Meine sehr verehrten Herren! Erwarten Sie bitte nicht, daß ich mich hier mit meinem verehrten Lehrer Bachof anlege; andererseits ist es freilich nicht meine Art, mich in Verbeugungen vor meinem wissenschaftlichen Urgroßvater Otto Mayer oder vor von mir nicht minder verehrten Rechtslehrern wie Hans Kelsen oder Adolf Merkl zu erschöpfen. Ich stimme Herrn Badura und Herrn Quaritsch zu: Die These 8 Herrn Bachofs müßte wie folgt umformuliert werden:

„Richtig ist insbesondere die gängige Behauptung, die Dogmatik des deutschen Verwaltungsrechts entstamme einer Epoche des einseitig freiheitsverbürgenden (liberalen oder bürgerlichen) Rechtsstaates. Der deutsche Staat war zwar stets in erheblichem Umfang Wohlfahrtsstaat. Die auf Zurückdrängung wohlfahrtsstaatlicher Zwecke gerichtete Bewegung hatte zur Zeit Otto Mayers zwar längst ihren Höhepunkt überschritten und einer gegenläufigen Bewegung Platz gemacht, aber diese neue Bewegung hatte noch keinen spürbaren Niederschlag in der verwaltungsrechtlichen Dogmatik gefunden." Das allein ist unser Thema und nicht etwa eine Sammlung literarischer Einsichten über die Bedeutung wohlfahrtsstaatlicher Aufgaben in der damaligen Zeit.

Zum zweiten bin ich ja gewohnt, als "Buhmann" aufgebaut und falsch zitiert $z u$ werden, aber ich bin nachgerade diese Rolle leid: Es wird mir unterstellt, ich hätte der Regierung das Regieren bestritten. Das ist schlicht falsch. Ich habe gesagt, es seien immer noch Thesen im Umlauf, die allein der Regierung im organisatorischen Sinn das Regieren im Sinne des angelsächsischen government zuerkannt wissen möchten. Falsch ist auch, wenn mir unterstellt wird, ich lehnte das Verwaltungsermessen zugunsten der Theorie der eindeutigen Kognition ab. Was ich für verfehlt halte, ist gerade umgekehrt diese Scheidung und die auf dieser Scheidung beruhende deutsche Ermessenslehre. Wer sich die Mühe macht, meine einschlägigen Ausführungen nachzulesen, wird auch schnell feststellen, daß bei mir von einem totalen Gesetzesvorbehalt der Verwaltung nirgends die Rede ist, sondern daß ich zu Ergebnissen gekommen bin, die in jeder Tagung unserer Vereinigung von neuem bestätigt werden.

Zum dritten schließlich: Was mich besonders beschäftigt und was das ganze Referat von Herrn Brohm durchzogen hat ist die Frage: Wie kann der „Kompetenzverlust des Parla- 
ments", von dem Sie, Herr Brohm, sprechen, ausgeglichen werden durch andere Verfahren demokratischer Aktivierung und Partizipation? Hier kann ich nur das, was bereits Herr Quaritsch gesagt hat, unterstützen: Führt wirklich eine Beteiligung der „Betroffenen“ an Verwaltungsentscheidungen zu demokratischer Legitimation? Was hat eine solche Beteiligung mit "Transparenz" und mit demokratischem „Konsensstreben“ zu tun? Inwiefern ist dies eine Kompensation für nicht vorhandene oder gar abzubauende parlamentarische oder aufsichtsbehördliche Kontrolle? In welchem Verhältnis stehen Beteiligung der Betroffenen an Verwaltungsentscheidungen und subjektive Rechte des einzelnen gegen die Verwaltung? Wandeln sich subjektive Rechte in dem von Herrn Brohm vorgestellten Modell nicht zu ständestaatsähnlichen Kompetenzen von bestimmten Gruppen um? Inwiefern ist konfliktstheoretisch der erhoffte demokratische Konsensus durch Beteiligung herstellbar, ja ist überhaupt Demokratie identisch mit Konsenserzielung? Wenn ja, was bedeuten dann subjektive Individualrechte im Sinne des heutigen Verständnisses?

Ich möchte zu diesem Bündel von Fragen kein Wort mehr sagen. Ich meine, das Referat Herrn Brohms verdient es, daß darüber nachgedacht wird, ob durch solche oder ähnliche Strategien der Verlust an Demokratie aufgefangen oder gar ausgeglichen werden kann. Ich persönlich teile die Skepsis von Herrn Quaritsch.

Thieme: Ich möchte zu einer Frage Stellung nehmen, und zwar zur Idee von Herrn Brohm, die Sozialwissenschaften für die verwaltungsrechtliche Dogmatik fruchtbar zu machen. Das scheint mir in der Tat ein Angebot zu sein, über das wir ernsthaft nachdenken müssen. Wenn wir unsere Aufgabe hier so ansehen, daß es darum geht, die verwaltungsrechtliche Dogmatik up-to-date zu halten, damit wir sie als ein juristisches Instrument immer zur Verfügung haben, das uns gerechte Entscheidungen im Einzelfall zwar nicht schon liefert, aber bei der Lieferung solcher Entscheidungen helfen kann, so stellt sich die Frage, woher wir das Koordinatensystem dafür nehmen. Sicherlich, die Verfassung, die Europäischen Gemeinschaften und ihr Recht sowie manches andere Gebiet wird dafür sehr in Betracht kommen. Aber das Neue, das uns Herr Brohm heute gezeigt hat, scheint mir zu sein, daß unter Umständen auch die Sozialwissenschaften Hilfe leisten können.

Dabei würde ich allerdings nicht so vorgehen wie es Herr Winkler in seiner Skizze getan hat, als er da unten, auf der untersten Ebene, irgendwo die Verwaltungswirklichkeit mit 
einem Strich hingemalt hat. So eindimensional ist das Problem Sozialwissenschaften und Verwaltungswirklichkeit nicht! Sicherlich ist eine Untersuchung, die empirisch vorgeht, ohne vorher die Dinge selbst zu befragen, und dann meint, aus irgendwelchen stückweisen Untersuchungen die soziale Wirklichkeit in den Griff zu bekommen, völlig nutzlos für uns. Aber es ist doch die Frage, ob das, was uns die Sozialwissenschaften heute mit ihrer Systemtheorie und ihrer Entscheidungstheorie vorgezeichnet haben, nicht mehr ist, und ob es, wenn es sich durchsetzt, zugleich auch soziale Relevanz hat, weil hier nämlich mit dem wissenschaftlichen System, das hier aufgebaut ist, Probleme gezeigt werden, die in der sozialen Wirklichkeit Bedeutung haben.

Ist das aber so, so kann das System, das uns von der sozialwissenschaftlichen Theorie angeboten wird, für die Rechtswissenschaften durchaus Nutzen liefern. Wenn ich mir die Begriffe so überlege, die gefallen sind, also „Input-Output“, „Kosten-Nutzen“, „Information“, „Rückkoppelung", "System" usw., so möchte ich eigentlich, ohne das wegen der Zeitbegrenzung hier ausführen zu können, für jeden dieser Begriffe doch Beispiele anführen, die zeigen, daß wir in unserem Verwaltungssystem immer wieder vor Fragen stehen, wo wir gerade das, was da aufgezeigt wird, lösen müssen. Ich meine, wir können das heute sicher nicht irgendwie ausdiskutieren, aber ich halte es doch für ein wichtiges Forschungsvorhaben, sich einmal mit dieser Frage auseinanderzusetzen. Das wäre sicher des SchweiBes der Edlen wert, mag eine solche Forschung auch längere Zeit dauern.

Dagtoglou: Herr Vorsitzender, meine Herren! Zwischen den gestrigen Referaten und den heutigen besteht, so würde ich glauben, ein bedeutender gemeinsamer Punkt. Alle Referenten haben versucht, die Grundrechts- und Verwaltungsrechtsdogmatik mit allen sie beide verbindenden Elementen in eine veränderte soziopolitische Landschaft einzufügen, ohne die Traditionsbande zu zerreißen und den bewährten Boden völlig zu verlassen. Auch und gerade Herr Häberle gestern und Herr Brohm heute haben, wenn auch in unterschiedlicher Weise, aber ebenso eindrucksvoll, ein Beispiel gegeben, wie man mit souveräner Art Neues sucht und versucht und dabei natürlich nicht nur verdientes Lob erhält, sondern auch Kritik in Kauf nimmt. Die heutigen Referenten haben uns auf die Interdependenzen zwischen der Verwaltungsrechtswissenschaft und den Sozialwissenschaften aufmerksam gemacht. Herr Bachof hat in Leitsatz 14 auf die Notwendigkeit der Wiedereinbeziehung sozialwissen- 
schaftlicher Erkenntnisse in das Verwaltungsrecht hingewiesen und dabei den Vorwurf zurückgewiesen, ein Hineinmischen sozialwissenschaftlicher Erkenntnisse in die juristischen Auslegungs- und Entscheidungsverfahren widerspräche dem Sinn der Arbeitsteilung von Sozialwissenschaften und Entscheidungslogik. Es ist in der Tat merkwürdig, wie die Sozialwissenschaftler uns Staatsrechtlern einerseits vorwerfen, wir beachten die sozialwissenschaftlichen Erkenntnisse nicht; wenn wir es aber tun, dann verzeihen sie uns nicht und werfen uns vor, wir betreiben - so heißt es in einer Schrift - eine apokryphe Sozialwissenschaft, während wir uns auf die Kelsensche Argumentationsmethode zurückziehen müßten. (Ich darf mich dabei bei Herrn Winkler entschuldigen!) Damit allerdings die Verwaltungsrechtler die Erkenntnisse der Sozialwissenschaften berücksichtigen können, müssen sie sie zuerst verstehen. Dabei gibt es aber nicht selten erhebliche sprachliche Schwierigkeiten. Wenn manche Sozialwissenschaftler die Verwaltung als das Handlungssystem zur Reduzierung der Komplexität der Umwelt definieren und dabei ziemlich alles in eine neue Sprache übersetzen, so fragt man sich, ob die Komplexität der Umwelt nicht dadurch noch komplexer wird (von dem berechtigten Zweifel von Herrn Badura zum Komplexitätsbegriff ganz abzusehen). Freilich wird die Verständigung zwischen Sozialwissenschaftlern und Verwaltungsrechtlern nicht nur durch fachsprachliche und terminologische Unterschiede erschwert, sondern vor allem dadurch, daß viele Sozialwissenschaftler - ich darf auf das bereits in 2. Auflage erschienene und vielfach interessante Buch von Frieder Naschold „Organisation und Demokratie" hinweisen - die grundsätzliche Unterschiede zwischen Privatbetrieben und öffentlicher Verwaltung übersehen und dabei vergessen, daß wir trotz allem vom Establishment zum Management nicht so vollständig übergewechselt sind, sondern allenfalls zu einem managerial establishment - könnte man vielleicht sagen - allmählich übergehen. Viele Sozialwissenschaftler verkennen das Machtmoment - wie Herr Brohm zutreffend hervorgehoben hat. Deswegen finde ich seine Definition der Entscheidung im Leitsatz 13, so sehr sie dazu natürlich prädestiniert ist, kritisiert zu werden, sehr überlegungswert, zumal sie den neuen Entwicklungen der Rechtsprechung in ihrer originären Weise Rechnung trägt. Es gibt im übrigen zweifellos zahlreiche Zeichen für eine Krise oder jedenfalls Umformung des Verwaltungsaktes. Wenn die Rechtsangleichung im europäischen Raum nach dem EWG-Vertrag auch auf dem Gebiet des Verwaltungsrechts verwirklicht werden soll, so muß das wahrscheinlich vor dem britischen Beitritt 
geschehen, denn die junge britische Verwaltungswissenschaft kennt noch keinen allgemein anerkannten Begriff des Verwaltungsaktes!

Götz: Meine Bemerkung bezieht sich auf die Stellung und die Rolle der Verwaltungsaufgaben in der Systematik des Verwaltungsrechts. Herr Bachof, Sie betonen in Ihrer These Nr. 18 die Notwendigkeit einer zweck- und aufgabenorientierten Darstellung der Verwaltung, aber Sie sprechen dem Aufgabenkriterium doch die Eignung und den rechtlichen Aussagewert für das System des Verwaltungsrechtes ab. Dem in diesem Standpunkt meines Erachtens zutage tretenden Anliegen, für die Gesamtaufgaben der Verwaltung ein einheitliches begriffliches und institutionelles Instrumentarium zu erhalten, ist zuzustimmen. Aber ich glaube, da $\beta$ es eine unbedingte Notwendigkeit ist, stärker sowohl die rechtliche Relevanz der Verwaltungsaufgaben als auch ihre Bedeutung für das System hervorzuheben. Ein systematischer Ansatz bei den Verwaltungsaufgaben würde uns besonders davor bewahren, die so beliebte Aufgliederung unseres Verwaltungsrechtes in die Eingriffs- und die Leistungsverwaltung unkritisch zu übernehmen. Diese Einteilung sieht unser Verwaltungsrecht - und dieses Denken ist wohl nach wie vor sehr herrschend - nur von den Rechtswirkungen auf den einzelnen Bürger, vom Eingriff in seine Rechte oder der Vermehrung seiner Rechte und damit vom Bürger her. Eine solche Betrachtungsweise ist einmal rechtsstaatlich notwendig, aber zum anderen auch unvollständig und ist insofern eine Verkürzung. Sie bedarf meines Erachtens einer Ergänzung durch eine Betrachtung von den Verwaltungsaufgaben und damit von der Verwaltung her. Dann entsteht ein anderes Bild, und dann wird man etwa auch sehen, daß der Eingriff nicht etwa eine Verwaltungsaufgabe ist, sondern nur Mittel zur Erfüllung von öffentlichen Aufgaben, die ihrerseits vorsorgenden, leistenden Charakter haben. Die Beispiele dafür wären zahllos. Die Akte auf dem Gebiet des Umweltschutzes könnte man ebenso nennen wie etwa die nachbarschützende Baurechtsnorm. Und umgekehrt sind die Leistungen - das ist bekannt - durchweg mit Belastungen verbunden, sei es desjenigen, der die Leistung erhält, sei es Belastung eines Dritten. Insgesamt möchte ich also nicht glauben, da $B$ die Einbeziehung der Verwaltungsaufgaben in die Systematik des Verwaltungsrechts die Einheitlichkeit dieses Systems sprengt, sondern ich würde im Gegenteil meinen, daß diese Einbeziehung das System des Verwaltungsrechtes einheitlicher und ich meine auch, zutreffender hervortreten läßt. 
Kisker: Eine kurze Bemerkung in Ergänzung der Hinweise von Quaritsch und Rupp. Es ist in der Tat auffällig, daß nicht nur in dem Referat von Brohm heute, sondern auch gestern in dem Referat von Häberle der Rolle der Gruppenmitwirkung in dem Bereich der - ich würde mal sagen - "Globalsteuerung" eine so außerordentliche Rolle zugesprochen wurde. Brohm ist an das Problem vom Gedanken der Kompensation für eine Ausschaltung des Parlaments her herangegangen. Bei Häberle stand - das ist gestern etwas zu kurz gekommen - die Idee der Gruppenmitwirkung wohl hinter seiner Formel vom status activus processualis. Er hat diese Formel ja in Erwiderung auf eine Bemerkung von Schmitt Glaeser sehr stark pluralistisch interpretiert. - Ich muß mich, soweit es um die Erreichbarkeit der von Häberle und Brohm angesprochenen Ziele geht, weitgehend den Zweifeln anschließen, die Rupp und Quaritsch vorgetragen haben. Nur noch ein wichtiger Gesichtspunkt: Ein Problem wird ja wohl immer sein, daß man sich, um mitwirken zu können, einer Gruppe anschließen muß. Das läuft auf eine Art von Zunftzwang heraus, was ja doch nun gerade unter dem von Häberle betonten Aspekt des Grundrechtsschutzes eine sehr problematische Konsequenz wäre. - Ich glaube freilich, ob es uns paßt oder nicht, daß wir uns intensiver mit der Gruppenmitwirkung beschäftigen müssen. Wir werden nicht darum herumkommen, eine Art von Dogmatik der Gruppenmitwirkung im öffentlichen Bereich $\mathrm{zu}$ entwickeln. Bislang ist - glaube ich - davon noch sehr wenig da. Ich darf mich insoweit, da dies ja nicht das zentrale Thema des heutigen Tages ist, mit ein paar Stichworten begnügen: Mir scheint beispielsweise, daß die Frage der Zusammensetzung von pluralistisch konzipierten Gremien so gut wie noch gar nicht genauer angesprochen worden ist. Bisher hat man immer geglaubt, das ginge auch so gut. Aber der Krach etwa jetzt im ZDF zeigt ja deutlich, daß es zu kriseln beginnt. Ferner darf ich im Anschluß an eine mir sehr interessant erscheinende Bemerkung von Bachof - die dann auch von Quaritsch aufgenommen wurde darauf hinweisen, daß sich auch verwaltungsrechtlich ganz neuartige Probleme stellen. Stichwort: kein Begründungszwang. Es ist in der Tat unsinnig, von einem pluralistisch zusammengesetzten Gremium zu erwarten, daß es eine Begründung für seine Entscheidungen liefere. Die verschiedenen Beteiligten können höchst unterschiedliche Motive für ihr Votum gehabt haben. Aber wenn das der Fall ist, dann wird eine gerichtliche Kontrolle derartiger Maßnahmen außerordentlich erschwert. Das hat das Bundesverfassungsgericht in seinem höchst interessanten Beschluß zur Uberprüfbarkeit der Entscheidung des 
hamburgischen Richterwahlausschusses sehr deutlich gemacht. - Mein Plädoyer also geht darauf hinaus, in die neu zu formulierende Verwaltungsrechtsdogmatik ein System der Gruppenmitwirkung sehr bewußt und sorgfältig hineinzuarbeiten.

Blümel: Einige Bemerkungen zu drei Einzelfragen der Fortentwicklung der Dogmatik.

Es ist meines Erachtens Herrn Brohm in eindrucksvoller Weise gelungen, den theoretischen Unterbau für die von ihm vorgeschlagene Ausweitung des Verwaltungsaktsbegriffs zu liefern. Ich beziehe mich insoweit auf Leitsatz 13. Ich stimme Herrn Brohm, jedenfalls für den Bereich der Planung, auch in den Folgerungen in Leitsatz $14 \mathrm{zu}$, vor allem hinsichtlich der rechtlichen Erfassung von vorangegangenen Teilentscheidungen und hinsichtlich der Beteiligung der unmittelbar Betroffenen an den einzelnen Entscheidungsstufen. Ich bin jedoch nach wie vor skeptisch - und hier unterscheide ich mich etwa von Herrn Dagtoglou -, ob unsere wiederholten Bemühungen in dieser Richtung, ob also unsere Bemühungen um eine Effektuierung des gerichtlichen Rechtsschutzes und um eine Vorverlegung des Rechtsschutzes in das Verwaltungsverfahren in Rechtsprechung und Gesetzgebung in absehbarer Zeit honoriert werden. Herr Martens hat gestern schon darauf hingewiesen, $\mathrm{da} B$ es offenbar nicht zur Pflicht von Bundesrichtern gehört, die Veröffentlichungen der Vereinigung zu lesen. Ganz ähnlich habe ich bei einer neueren Entscheidung des Bundesverfassungsgerichts den Eindruck, da $B$ das Gericht die letzten 10 Jahre verschlafen hat. Ich beziehe mich hier auf den BeschluB vom 27. Juli 1971, der im nächsten Heft des Deutschen Verwaltungsblatts veröffentlicht wird*). Diese Entscheidung des Bundesverfassungsgerichts betrifft einen Normkontrollbeschluß des OVG Bremen in einem Verfahren nach $\$ 47$ der Verwaltungsgerichtsordnung. Das OVG Bremen hatte den Antrag nach $\S 47$ als unzulässig abgewiesen, weil es sich nicht für befugt hielt, im Rahmen dieses Verfahrens den Bebauungsplan am Maßstab des Bundesrechts zu prüfen. In der Entscheidung des Bundesverfassungsgerichts finden sich nun recht merkwürdige Ausführungen. Das Gericht lehnt es ab, obwohl es dazu Anla $B$ gehabt hätte, den Begriff der öffentlichen Gewalt in Art. 19 Abs. 4 des Grundgesetzes zu definieren. Es läßt die Frage offen, ob unter diesen Begriff auch das materielle Gesetz fällt. Das Gericht zieht sich in der Rechtsschutzfrage auf die längst überholte These zurück, daß es im gesamten Bereich der Pla-

*) Vgl. DVBl. 71, 740 (u. Anm. v. Umbach) 
nung auf den Vollzugsakt ankomme, daß also die Inzidentkontrolle genüge. Das Gericht geht so weit zu sagen, daß Art. 19 Abs. 4 des Grundgesetzes ein Verfahren etwa analog $\S 47$ der Verwaltungsgerichtsordnung nicht fordere. Das Verfahren nach $\$ 47$ der Verwaltungsgerichtsordnung sei ein zusätzliches Verfahren, aber wo es gesetzlich nicht vorgesehen sei, habe der einzelne eben keine entsprechende Möglichkeit. Ich halte diese Entscheidung für äußerst unglücklich, vor allen Dingen nachdem doch einige Kollegen darauf hingewiesen haben, daß man beim Rechtsschutz gegen Planungsentscheidungen unmittelbar auf Art. 19 Abs. 4 des Grundgesetzes rekurrieren kann.

Ein zweites Beispiel, und das betrifft die Gesetzgebung: Herr Bachof hat zurecht auf die Problematik des Städtebauförderungsgesetzes hingewiesen. Wir haben heute eindrucksvoll demonstriert bekommen, wie wichtig die Beteiligung der Betroffenen an den einzelnen Stufen ist. Wenn Sie nun einmal das Städtebauförderungsgesetz in die Hand nehmen, dann werden Sie feststellen, daß die wichtigste Entscheidung die Festlegung des Sanierungsgebietes ist. Diese Festlegung geschieht in der Form der Satzung. Wie steht es hier mit der Beteiligung der unmittelbar Betroffenen, also etwa der Eigentümer? Sie haben noch nicht einmal das Beteiligungsrecht, wie es etwa in $\S 2$ Abs. 6 des Bundesbaugesetzes vorgesehen ist. Welche Konsequenzen die Festlegung des Sanierungsgebietes hat, wissen Sie vielleicht. Das ganze Instrumentarium des Städtebauförderungsgesetzes steht nach der Festlegung den Gemeinden zur Verfügung. Aber dann ist für die Betroffenen der Zug bereits abgefahren. Ich warne davor, hier statt der aus rechtsstaatlichen Gründen notwendigen Anhörung bzw. Beteiligung der unmittelbar Betroffenen mit dem Schlagwort „Demokratisierung der Planung" zu operieren, das z. B. im Städtebaubericht 1970 der Bundesregierung auftaucht.

Ich bin der Meinung, daß diese „Demokratisierung“ keinen Ersatz für einen effektiven Rechtsschutz der unmittelbar Betroffenen im Verfahren darstellt, denn wie Abstimmungen in demokratisierten Gremien vonstatten zu gehen pflegen, dafür gibt es inzwischen genug Beispiele. Ich warne also vor einer Institutionalisierung in diesem Bereich. Wo die Betroffenen wirklich in ihren Interessen vehement beeinträchtigt werden, da organisieren sie sich auch heute bereits, ohne daß es dafür der Institutionalisierung bedarf. Ich denke etwa an Großbauvorhaben wie den Flughafen München II. In solchen Fällen werden die Rechte der Betroffenen in wirksamer Weise verfochten. Soviel zu diesem Bereich. 
Ein anderes Thema: Herr Bachof hat in Leitsatz 28 einige Bemerkungen zur Aufsicht gemacht. Er hat zutreffend darauf hingewiesen, daß hier noch vieles ungeklärt ist. Ich möchte nur die Frage aufwerfen, ob wir heute im Bereich der Staatsaufsicht noch von der ausschlieBlichen Geltung des Opportunitätsprinzips ausgehen können, oder ob es nicht vielleicht auch in Ausnahmefällen einen Rechtsanspruch des Betroffenen auf Einschreiten der Aufsichtsbehörden gibt. Denken Sie nur daran, daß gerade im Hochschulbereich einige Aufsichtsbehörden von ihren gesetzlich vorgesehenen Befugnissen überhaupt keinen Gebrauch machen, sondern den betroffenen Hochschullehrer auf den Rechtsweg verweisen. Der aber kann es sich vielleicht nicht leisten, von den allgemeinen Rechtsschutzmöglichkeiten Gebrauch zu machen, weil er anderweitigen Pressionen unterliegt.

Noch ein Einzelproblem, aber das nur ganz kurz: Herr Brohm hat mit Recht darauf hingewiesen, daß die Diskussion um die Mischverwaltung eigentlich erst beginnt. Ich habe dazu in meiner Berliner Antrittsvorlesung einiges ausgeführt. Ich bin der Meinung, daß unsere Dogmatik hier hinter der Staatspraxis etwa im Bereich der Planung zurückbleibt. Die ständig wiederholte These, da $B$ die Mischverwaltung zwischen Bund und Ländern schlicht verfassungswidrig sei, läßt sich heute nicht mehr unbesehen vertreten.

Kopp: Obwohl ich ebenfalls an einer österreichischen Hochschule lehre, möchte ich doch dem Urteil von Herrn Winkler über den Vortrag von Herrn Brohm nicht vorbehaltlos zustimmen. Ich habe erhebliche Zweifel, ob es möglich ist, eine Rechtsdogmatik allein voraussetzungslos auf positiv-rechtlicher Grundlage zu entwickeln, und zwar deshalb, weil gerade hier das allgemeine Verwaltungsrecht doch ganz erheblich hereinspielt und im allgemeinen Verwaltungsrecht jeder Jurist in Verlegenheit ist, wenn er gefragt wird, wo steht das, worauf sie nun ihre Ausführungen stützen. Es sind einfach überkommene Theorien, Auffassungen usw., und es gilt doch letztlich immer das bessere Argument. Man muß sicher das geltende Recht dabei zugrunde legen, aber wo es uns verläßt, bleibt wohl nichts anderes übrig, als hier nach dem besseren Argument zu suchen. Insoweit möchte ich Herrn Brohm Recht geben, daB auch er auf der Ebene des geltenden Rechts argumentiert und hier versucht, eine Rechtsdogmatik des Verwaltungsrechts zu entwikkeln. Trotzdem liegt mir persönlich die These von Herrn Bachof näher und ich möchte sie unterstützen, daß die Dogmatik des Verwaltungsrechts heute keinen grundlegenden Umbau erfor- 
dert, sondern allenfalls Ergänzungen und Fortentwicklungen. Ich darf vielleicht in diesem Zusammenhang auch darauf hinweisen, daß die Rechtsvergleichung uns zeigt, daß trotz ganz verschiedener Ausgangspunkte alle modernen Rechtsordnungen in dieselbe Richtung tendieren. Das ist besonders deshalb interessant, weil z. B. das anglo-amerikanische Rechtssystem und einige andere Rechtsordnungen von einem allgemeinen Klagensystem ausgehen, das im Zivilrecht entwickelt worden ist, also nicht von vornherein diese gewisse „Verengung" auf den Verwaltungsaktsbegriff gekannt haben. Ich glaube nicht, daß Herrn Dagtoglou hier zuzustimmen ist, daß das englische Recht hier eine Ausnahme macht. In der neueren Literatur und Rechtsprechung ist, soweit ich übersehen kann, der Verwaltungsakt auch hier in England in den Vordergrund getreten.

Wenn Sie mir verzeihen, daß ich nochmals auf den Verwaltungsaktsbegriff zurückkomme, der heute schon sehr strapaziert worden ist, so möchte ich gewisse Bedenken gegen die in These 13 von Herrn Brohm vorgeschlagene Ausweitung des Verwaltungsaktsbegriffs geltend machen. Es scheint mir wenig zweckmäßig, hier einen neuen weiteren Begriff, der auch Verordnungen mit umfaßt, zu entwickeln, wenn dann doch - wie es auch in These 13 heißt - wieder eine Differenzierung notwendig ist. Sicher gleichen sich Verwaltungsakt und Verordnung in mancher Hinsicht. Ich darf nur an das französische Recht und andere Rechtsordnungen erinnern, die hier auch bezüglich des Rechtsschutzes kaum Unterschiede kennen. Aber in Fragen der Bestandskraft usw. bestehen doch wesentliche Unterschiede. Auch bezüglich des Verfahrens ergeben sich gewisse Besonderheiten. Vor allem aber glaube ich, da $\beta$ eine zu weit gehende Abstrahierung dem Begriff des Verwaltungsaktes seine praktische Bedeutung und Brauchbarkeit als Instrument der Dogmatik nimmt und ihn farblos und inhaltslos werden läßt. $\mathrm{DaB}$ der Rechtsschutz des Bürgers die vorgeschlagene Ausweitung nicht erfordert, ist, glaube ich, allgemeine Meinung. Ich darf in diesem Zusammenhang auch an die heute bereits erwähnte Feststellungsklage erinnern, die - hier komme ich auf das, was Herr Blümel bereits gesagt hat, zurück - durchaus geeignet ist, auch gegenüber Verordnungen den Rechtsschutz zu verwirklichen, den Art. 19 Abs. 4 GG gewährleistet. Man kann mit Hilfe der Feststellungsklage zwar nicht die Gültigkeit einer Verordnung feststellen lassen, wohl aber eine Klärung herbeiführen, welche Rechte und Pflichten oder welche Rechtsstellung insgesamt sich daraus in der konkreten Situation für den Bürger ergeben. Das mag nicht dieselbe Wirksam- 
keit haben wie eine Klage nach $\S 47 \mathrm{VwGO}$, aber für den Rechtsschutz der Betroffenen reicht es vollkommen aus.

Ich möchte mich weiter auch gegen den Gedanken wenden, daß Verwaltungsentscheidungen nur vorbereitender Natur unterschiedslos in den Begriff des Verwaltungsaktes hineingenommen werden sollten. Ich war selbst als Richter an den vorhin erwähnten Entscheidungen zu den Planungsmaßnahmen für den Flughafen München II beteiligt. Ich glaube, daß man dem Bürger in solchen Fällen gar keinen Gefallen tut, wenn man jede einzelne Vorentscheidung im Planungsverfahren, die der endgültigen Planfeststellung vorausgeht, als Verwaltungsakt ansieht. Denn der Verwaltungsakt ist ja ein zweischneidiges Schwert. Die Nichtanfechtung führt zur Unanfechtbarkeit, sobald die Anfechtungsfristen versäumt sind, und damit zur Bestandskraft. Sieht man auch alle vorbereitenden Maßnahmen als Verwaltungsakte an, so ist der Bürger gezwungen, wenn er diese Folge vermeiden will, jede einzelne dieser Maßnahmen anzugreifen und damit mehrere Prozesse nebeneinander zu führen, statt sich nur gegen den letzten, abschließenden Akt zu wenden. Andererseits ist auch zu bedenken, daß die Verwaltung bei der Erfüllung ihrer Aufgaben übermäßig, und wie ich meinen möchte, unnötig, gehemmt wird, wenn die Gerichte ständig in laufende Verfahren einzugreifen gezwungen sind, obwohl noch nicht einmal feststeht, daß die Kläger durch die schließlich ergehende Sachentscheidung überhaupt beschwert werden. Soweit wirklich ein Rechtsschutzbedürfnis besteht, reicht meines Erachtens die vorbeugende Unterlassungs- und Feststellungsklage aus. Sie richtet sich aber ebenfalls nicht gegen diese vorläufigen Akte ohne abschließenden Regelungscharakter, sondern allein gegen das allenfalls befürchtete Endergebnis, durch das der Bürger ja letztlich allein betroffen wird.

Besonders begrüßen möchte ich andererseits die starke Betonung der sog. Mitwirkungsrechte des Bürgers in beiden Referaten. Mitwirkungsrechte müssen heute in der Tat einen groBen Teil dessen ausgleichen, was die Unbestimmtheit der gesetzlichen Ermächtigungen mehr oder wenger versündigt. Sie sind insofern zweifellos in gewissem Sinn ein Notbehelf. Aber sie sind andererseits doch nicht etwas ganz Neues, das bisher nicht bekannt war. Auch die Eingriffsverwaltung im herkömmlichen Sinn kennt ja diese Mitwirkungsrechte. Ich darf hier besonders auf die österreichischen Verfahrensgesetze hinweisen, die in ihren Grundgedanken zu einer Zeit entwickelt wurden, als die modernen Probleme, die wir heute zu sehen glauben, noch gar nicht in diesem Maße in den Blickpunkt des Interesses gerückt waren. Mitwirkungsrechte sind aber auch un- 
ter dem Gesichtspunkt des Rechtsschutzes gegen die bereits erwähnten Verwaltungsentscheidungen, die noch nicht endgültigen Charakter haben, im Planungsverfahren usw. heute von erheblicher Bedeutung, weil sie dem Bürger schon im Vorbereitungsstadium die Möglichkeit gegeben, seine Rechte und Interessen zu wahren und zu verhindern, daß abschließende Entscheidungen folgen, die ihn in seinen Rechten beeinträchtigen würden. Dasselbe gilt auch für Verordnungen. Ein bekannter amerikanischer Verwaltungsrechtler äußerte sich mir gegenüber erst vor einigen Wochen sehr erstaunt darüber, daß das deutsche Verwaltungsrecht für den $\mathrm{Erla} B$ von Verordnungen kein geordnetes rechtsstaatliches Verfahren kennt, da $B$ hier keine Anhörung der Betroffenen durchgeführt werden muß usw. Ich glaube, daß die Gesichtspunkte eines rechtsstaatlichen Verfahrens künftig auch beim Erlaß von Verordnungen stärker berücksichtigt werden müßten und ein allgemeines Verwaltungsverfahrensgesetz deshalb auch ähnliche Regelungen einführen sollte, wie sie heute in den Vereinigten Staaten, aber z. B. auch in Norwegen und zum Teil auch in Spanien für die Verordnungsgesetzgebung bestehen.

Eine letzte Anmerkung wäre - wenn Sie mir das noch erlauben - auch zur Abgrenzung des privaten und des öffentlichen Rechts zu machen. Ich glaube, man müßte die Begriffe etwas schärfer abgrenzen als dies in These 8 des zweiten Referates geschehen ist. Die Unterscheidung wird hier dahin umschrieben, daß es darauf ankommen soll, ob Hoheitskompetenzen wahrgenommen werden oder nicht. Die Frage der Hoheitskompetenzen indiziert aber grundsätzlich die Hoheitsverwaltung und umfaßt daher nicht ohne weiteres auch verwaltungsrechtliche Gleichordnungsverhältnisse, deren Zuordnung zum öffentlichen Recht jedoch nicht zweifelhaft sein kann. Die vorgeschlagene Definition ist daher schon aus diesem Grund meines Erachtens zu eng. Das entscheidende Kriterium für die $\mathrm{Ab}-$ grenzung von privatem und öffentlichem Recht kann nur sein, ob der Verwaltungsträger oder in Ausnahmefällen auch Private Sonderrechte für sich beanspruchen - das würde etwa der französischen Theorie entsprechen - wie sie unter Ausschaltung des bürgerlichen Rechts nur das öffentliche Recht einräumt. Damit ist freilich die Abgrenzung letztlich immer weitgehend Sache des positiven Gesetzgebers, dessen Entscheidung es überlassen bleibt, ob er der Verwaltung für die Erfüllung bestimmter Aufgaben besondere rechtliche Möglichkeiten an die Hand geben will. 
Frowein: Beiden Referaten war die starke Betonung des Verfahrens und der Organisation gemeinsam, in gewisser Abweichung der herkömmlichen Betrachtungsweise, und ich meine, das ist $\mathrm{zu}$ unterstreichen. Ich möchte mich einem Problem aus der Organisationssphäre zuwenden, nämlich der These 16 von Herrn Brohm, und hier einige Fragen stellen. Die erste Frage bezieht sich darauf, wieweit die Aufsicht in dem Rahmen der staatlichen Hierarchie hier wirklich abgeschafft oder vielleicht ersetzt werden kann. In These 17 deutet Herr Brohm an, daß der individuelle Rechtsschutz die staatliche Aufsicht ergänze. Kürzlich konnte man im Deutschen Verwaltungsblatt weitergehend lesen, daß die Aufsicht überhaupt unzulässig sei, wo Individualrechtsschutz bestehe. Herr Brohm will mit Sicherheit diese These nicht übernehmen, es scheint mir aber wichtig zu unterstreichen, welche Gefahren darin liegen, wenn man Aufsicht und Individualrechtsschutz miteinander vermengt. Nun meine Frage zum letzten Teil der These 16. Hiernach müsse für Tätigkeiten von größerer politischer Tragweite die parlamentarische Verantwortlichkeit gesichert werden. Wie sie aber gesichert wird, scheint mir hier noch nicht richtig geklärt zu sein. Interessanterweise scheint der Begriff der parlamentarischen Verantwortlichkeit hier nicht in der Weise benutzt zu werden, wie wir ihn wohl herkömmlich verwenden, nämlich der Verantwortung der Regierung gegenüber dem Parlament. Ich frage mich, ob nicht allein in diesem Zusammenhang der Begriff rechtlich aussagekräftig ist, weil nur in diesem Zusammenhang Sanktionen zur Verfügung stehen und der Ort der Verantwortung klargestellt werden kann. Wenn ich mir überlege, wie das Parlament sonst Verantwortung übernehmen könnte, so komme ich auf die vielfältigen Möglichkeiten der Einschaltung von Parlamentariern in Beiräten, die ja zunimmt, und ihre Interpretation als Wahrnehmung der parlamentarischen Verantwortlichkeit. Gegenüber dieser Tendenz habe ich erhebliche Zweifel. Schließlich scheint mir dahinter die Frage zu stehen, ob es demokratischen Konsens außerhalb des Parlaments überhaupt gibt. In Art. 28 II und 87 III ist er sicher für den echten Selbstverwaltungsbereich gewährleistet und festgelegt. Aber können wir ihn darüber hinaus durch Beteiligung der Betroffenen als verfassungsrechtlich genügend abgesichert ansehen?

Achterberg: Lassen Sie mich bitte zum Schluß der Aussprache den Blick auf ein Thema lenken, das heute noch nicht erörtert worden ist: Mir erscheint es als dringende Aufgabe der Verwaltungsrechtsdogmatik, einmal $\mathrm{zu}$ einer klaren Begriffsbil- 
dung der Verwaltung zu kommen. Solange wir nicht gewiß sind, was überhaupt Verwaltung ist, stehen wir auf schwankendem Boden. Die Subtraktionstheorie, nach der Verwaltung alles ist, was nicht zur Gesetzgebung und Rechtsprechung zählt, ermöglicht zum einen keine Definition, sondern nur eine Ausgrenzung, zum anderen nur eine höchst unsichere Ausgrenzung, da auch nicht gewiß ist, was man unter Gesetzgebung und Fechtsprechung zu verstehen hat. Welche logische Fehlschlüsse die Subtraktionstheorie nicht hindert, ergibt sich allein aus der vor einiger Zeit geführten Diskussion, ob der Wehrbeauftragte als vierte Staatsfunktion anzusehen ist. Bei Anwendung der Subtraktionstheorie ist es schlechterdings unmöglich, daß es eine solche gibt, weil der Kreis der Staatsfunktionen hiernach geschlossen ist. An der Ungesichertheit des Verwaltungsbegriffs nehmen im übrigen alle weiteren mit Attributen wie ordnende, leitende und lenkende versehene teil. Ich stimme Herrn Bachof darin $z u, d a ß$ es sich dabei um heuristische Begriffe und keine Rechtsbegriffe handelt. Uberdies handelt es sich nur um beschreibende und um keine definierenden Begriffe. Auch in einem anderen Punkt stimme ich Herrn Bachof zu: darin nämlich, daß er die Aufrechterhaltung des Begriffspaares Eingriffsverwaltung und Leistungsverwaltung nicht für sinnvoll hält. Aber wir kämen wohl noch einen Schritt darüber hinaus, wenn es uns gelänge, dereinst den Verwaltungsbegriff (positiv) zu definieren.

Ich möchte noch ganz kurz auf eine zweite Frage eingehen. Auch ich bin der Auffassung, da $\beta$ die verfassunggestaltenden Grundentscheidungen - Herr Bachof hat die Abhängigkeit des Verwaltungsrechts vom Verfassungsrecht wieder ganz deutlich hervorgehoben - für eine starke Kompetenzausweitung des Parlaments im Bereich der rechtsetzenden und der nichtrechtsetzenden Kontrolle der Verwaltung sprechen - und zwar nicht nur, um einen Kompetenzverlust des Parlaments zu vermeiden - wie Sie, Herr Brohm, es ausgeführt haben -, denn man kann nur etwas verlieren, was man einmal hatte. Ich bin der Meinung, daß das Parlament überhaupt erst den Kompetenzzuwachs bekommen muß, den es bisher nicht hatte. So bin ich sicher im Ergebnis (wenn auch nicht in der Begründung) mit Herrn Rupp darin einig, daß der Gesetzesvorbehalt ausgeweitet werden muß, weil der von Art. 19 Abs. 4 GG intendierte lückenlose Rechtsschutz nach meiner Auffassung nur dann möglich ist, wenn Maßstäbe vorhanden sind, an denen das Verwaltungshandeln gemessen werden kann - und zwar durchgehend, also im Bereich der Leistungsverwaltung ebenso wie im Bereich der Eingriffsverwaltung. Demgemäß meine ich 
auch, da $ß$ der parlamentarische Einfluß im Bereich der Plangebung oder auch der Richtlinienkompetenzbestimmung, wo wir ihn bisher kaum haben, erweitert werden muß. Der von Herrn Brohm vorgeschlagene Weg der Utbertragung von Kontrollaufgaben auf Ausschüsse scheint mir durchaus ein geeigneter Weg hierfür zu sein. Alles das hat erhebliche Auswirkungen auf das Verwaltungshandeln, und folgt man der Subtraktionstheorie vorläufig noch, so ergibt sich hieraus eine Reziprozität dergestalt, daß vom Umfang der parlamentarischen Kompetenzen der Aufgabenbereich der Verwaltung und damit zugleich der Verwaltungsbegriff mitbestimmt werden.

Brohm (Schlußwort): Meine Herren Kollegen! Es sind so viele Fragen aufgetaucht, daß es mir schwerfällt, zu allen - und gar noch ausführlich, wie Sie es vielleicht erwarten - Stellung zu nehmen. Lassen Sie mich auf einige Punkte eingehen, die mir besonders wichtig erscheinen. Vorausgehend möchte ich aber eines sagen: Ich hielt es für die Aufgabe des Referates, nicht einzelne Fragen der verwaltungsrechtlichen Dogmatik zu vertiefen oder gar abschließend zu lösen. Das scheint mir bei dem Umfang des Themas nicht möglich zu sein. Ich würde glauben, daß man über fast alle diese Fragen, die Herr Bachof und ich hier angeschnitten haben, eine spezielle Tagung abhalten könnte. Deshalb, scheint mir, kam es bei diesem Thema mehr darauf an, die uns heute gestellten Fragen einmal aufzuwerfen und im Zusammenhang darzustellen. Dabei hielt ich es für wichtig, darauf hinzuweisen, daß wir heute dadurch vor neuen Problemen stehen, daß erstens sich die Verwaltung außerordentlich stark ausdifferenziert hat, daß zweitens ihr Handeln eine viel breitere Wirkung besitzt als wir mit unserer Dogmatik bislang zu erfassen vermögen und schließlich, daß wir auch die zeitliche Dimension des Verwaltungshandelns nicht ganz in den Griff bekommen. Das waren eigentlich die Hauptprobleme, von denen ich ausgegangen bin.

Ich bin Herrn Ipsen, Herrn Oppermann und Herrn Vogel sehr dankbar für die ergänzenden Hinweise, daß einige meiner Thesen gerade im Hinblick auf die Angleichung an das Gemeinschaftsrecht von Bedeutung sind. Ich glaube, man könnte weiter noch darauf hinweisen, daß das ausgeweitete Klagerecht der Verbände, das ich hier vertreten habe, ja auch im französischen Recht bereits anerkannt ist.

Die Problematik, die in der Kritik angesprochen wurde, konzentrierte sich zunächst einmal auf die Frage: Sozialwissenschaften und Dogmatik. Das ist in der Tat eine sehr wichtige Frage, die nicht so leicht und auch nicht mit wenigen Sätzen 
beantwortet werden kann. Ich habe versucht, meine Position in meinen Ausführungen zu Leitsatz 3 anzudeuten. Ich glaubte, $\mathrm{da} B$ ich mit den Hinweisen auf die methodischen Arbeiten von Kriele, Friedrich Müller, Esser und anderen vielleicht doch zu erkennen gegeben habe, wo - wie ich meine - die Grenzen für die Einbeziehung der Sozialwissenschaften in die Dogmatik verlaufen. Es ist sehr schwierig, dem pauschal formulierten Einwand entgegenzutreten, ich hätte den Bereich der Dogmatik verlassen und hier "Sozialwissenschaft" betrieben. Ich war der Meinung, deutlich zum Ausdruck gebracht zu haben, wann ich rechtspolitische Vorschläge machte und wann ich innerhalb der der Dogmatik gesetzten Grenzen argumentierte. Wenn Herr Winkler vorhin meinte, daB die Dogmatik nicht fortentwickelt werden könne und Herrn Bachof in einem sehr positiven Sinne - dem ich mich, sofern er eine Anerkennung ausspricht, gerne anschließen möchte - als „Positivisten“ apostrophierte, dann möchte ich betonen, daß Herr Bachof gerade den Folgenbeseitigungsanspruch entwickelt hat, eine, wie ich glaube, ganz wesentliche Fortführung unserer Dogmatik!

Nun zu dem Einwand gegen die Neuformulierung des Verwaltungsaktsbegriffes: Das ist ein Punkt, über den ich mir selbst noch nicht ganz im klaren bin. Ich habe bewußt den Leitsatz so formuliert, daß dieser Vorschlag erwogen werden sollte, und ich habe in meinem Vortrag den Konjunktiv gebraucht. Aber ich glaube, diese Neufassung ist in der Tat erwägenswert. Herr König meinte, die Rechtsdogmatik habe spezifische Problemlösungen mit dem Begriff des Verwaltungsaktes verbunden. Das ist völlig richtig. Ich meine aber, daß - wenn man gerade die dogmatische Entwicklung dieses Begriffes beobachtet, und wenn man berücksichtigt, $\mathrm{da} B$ der Verwaltungsakt keinen Konnex mehr hat zum Rechtsschutz, zur Regelung und zum subjektiven öffentlichen Recht - es dann sinnvoller ist zu erwägen, ob hier nicht der Verwaltungsakt auf einer höheren $A b-$ straktionsebene angesiedelt werden sollte. Gerade die Klarstellungsfunktion des Verwaltungsaktes, die Herr Vogel herausstellte, scheint mir auf diese Weise erreichbar zu sein. Die Neuformulierung hätte natürlich noch weitere Vorteile; denn prozessual würden wir erreichen, da $\beta$ fast immer Vorverfahren durchgeführt werden müßten. Ich glaube, es wäre schon unter funktionellrechtlichen Gesichtspunkten wichtig, daß wir nicht der Verwaltungsgerichtsbarkeit, sondern zunächst einmal der Verwaltung, die auf Grund ihrer sachlichen und personellen Ausstattung viel besser zu solchen Entscheidungen in der Lage ist, das Wort geben. 
Dann kam der Einwand gegen die These des "stufenweisen Entscheidungsprozesses". Ich meine, da $B$ man gerade diesen Gedanken weiter verfolgen sollte. Es ist für die Verwaltung und ihre Effizienz keineswegs hinderlich, wenn sie bereits nach Abschluß bestimmter Verfahren Sicherheit erlangt, ob ihre Entscheidungen nun Bestand haben werden oder nicht. Für den Betroffenen ergibt sich daraus kein Nachteil, weil ja bekanntlich die Bestandskraft immer nur dann eintritt, wenn ihm der Verwaltungsakt vorher bekanntgegeben wurde. Was aus dieser Sicht eines sich in Stufen vollziehenden Entscheidungsprozesses weiter folgt, ist das Problembewußtsein für die Mitwirkung Privater bei diesem Entscheidungsprozeß. Hier möchte ich Herrn Quaritsch entschieden widersprechen. Ich glaube, wir dürfen das Problem nicht außer acht lassen. Außer den Beispielen, die ich in meinem Vortrag nannte, denke ich noch an ganz andere Fälle, etwa den, daß ganze Stadtplanungen heute durch private Institutionen durchgeführt werden und es den Gemeindeparlamenten dann gar nicht mehr möglich ist, solche Planungen irgendwie abzuändern. Wenn man aber berücksichtigt, daß solche Stadtplanungen nicht nur eine bauliche Anordnung darstellen, sondern daß sie politische Entscheidungen größten Ausmaßes beinhalten, etwa die Streuung der Siedlung, die gesellschaftliche Zusammensetzung der Bevölkerung durch Mischung der Gebäudearten usw., dann sollte man sich doch überlegen, ob sich diese Entwicklungen völlig außerhalb jeder öffentlichen Kontrolle vollziehen können. Ein anderes Beispiel wäre, $\mathrm{da} B$ die Gemeindeverwaltungen dazu übergehen, bei Stadtsanierungen die Aufgaben privatrechtlichen Gesellschaften, an denen sie nicht einmal beteiligt sind, zu übertragen, weil sie sich der Verantwortung und den Schwierigkeiten, die sich daraus ergeben, entziehen wollen.

Ein wichtiges Anliegen meiner Ausführungen war in der Tat - wie Herr Rupp hervorhob - die Frage: Wie kann man den Kompetenzverlust des Parlamentes ausgleichen? Ich glaube, daß das Parlament tatsächlich an Kompetenzen verloren hat und verliert. Das ist keine These, die ich hier neu vertrete; sie ist vielmehr vielfach und gerade auch auf der Würzburger Tagung über "Gesetz und Verwaltung" oft hervorgehoben worden. Worauf es mir ankam war, darauf hinzuweisen, da $B$ das Zusammenwirken von Regierung und Parlament sich in dem Moment auch in den verwaltungsrechtlichen Bereich hinein erstreckt, in dem die Verwaltung - und das wollte ich mit dem Begriff der Gestaltungsfunktion hervorheben - selbst Zwecksetzungen vornimmt. Inwieweit hier ein Ersatz durch die Mitwirkung von Betroffenen möglich ist, habe ich ausdrück- 
lich als Frage aufgeworfen und auch in jedem Falle auf einen eng begrenzten Kreis der Betroffenen beschränkt. Ich habe Ihnen als Beispiel genannt - und das ist ja allmählich anerkannt - daß eine solche Kompensation durch eine Organisation mit körperschaftlicher Verfassung möglich ist, wobei vorausgesetzt werden muß, daß die körperschaftliche Verfassung auch von einem homogenen Verbandsvolk getragen wird. Wichtiger erschien mir eigentlich die Forderung, daß in allen diesen Fällen eine Rückbindung an das Parlament erfolgen muß. Das ist die Idee, die ich mit der "demokratischen Rückkoppelung" und auch mit dem Gesetzespostulationsrecht verfolge.

Herr Frowein hat die Frage gestellt, ob ich die Aufsicht abschaffen wolle. Das liegt mir sehr fern. Ich will die Aufsicht auch nicht mit dem Individualrechtsschutz vermengen, aber ich glaube, daß eine Ausweitung des Rechtsschutzes über die Verwaltungsgerichte in der Tat eine Ergänzung der staatlichen Aufsicht bewirkt. Im Schrifttum ist schon oft hervorgehoben worden, daß die staatliche Aufsicht heute nicht mehr wirkungsvoll ist. Dafür gibt es politische, dafür gibt es rechtliche, dafür gibt es, wie ich glaube, auch soziologische Gründe. Die Frage ist: Wie kann man eine parlamentarische Verantwortlichkeit und das war der zweite Punkt, den Herr Frowein anschnitt gewährleisten, wenn man weisungsunabhängige Stellen zuläßt? Herr Frowein, wir haben heute schon viele weisungsunabhängige Instanzen: die Bundesbank, die Rundfunkanstalten, ich würde aber auch nicht zögern, etwa die Bundesaufsichtsämter hier zu nennen; diese sind zwar formal weisungsabhängig, aber diese Weisungsabhängigkeit wirkt sich faktisch doch nicht aus. Es ist also $\mathrm{m}$. E. unrealistisch zu sagen, wir hätten über das Aufsichtsrecht und die parlamentarische Verantwortlichkeit der Regierung eine effiziente Rückbindung an das Parlament. Man müßte vielleicht dem Gedanken, daß die Verwaltung sich mehr und mehr pluralisiert, auch dadurch Rechnung tragen, da $B$ man sich um neue Formen parlamentarischer Kontrolle bemüht. $\mathrm{Daß}$ ich Ihnen hier keine endgültigen Formen vorschlagen konnte, liegt daran, daß dieses Problem nur einen kleinen Punkt meines umfassenden Themas ausmachte.

Zum Schluß noch zur Frage der Hoheitskompetenz. Herr Quaritsch, ich identifiziere diesen Begriff nicht mit dem öffentlichen Interesse, sondern ich gehe davon aus, daß es keine abstrakt vorgegebenen staatlichen oder gesellschaftlichen Funktionen gibt, sondern daß wir unsere öffentlich-rechtlichen Maßstäbe immer nur dann anwenden können, wenn sich aus der Verfassung oder sonst aus der Rechtsordnung die Entscheidung ergibt, daß die öffentlich-rechtlichen Maßstäbe für diese Sach- 
verhalte zur Anwendung kommen sollen. Das ist das, was ich unter dem Begriff der Hoheitskompetenz im Vergleich zu den Privatkompetenzen darstellen wollte. Ich habe das nur kurz angedeutet, weil ich es in meiner Habilitationsschrift sehr ausführlich dargelegt habe.

Damit hätte ich sogar den umfangreichen Katalog von Herrn Quaritsch erledigt. Ich darf Sie vielleicht zum Schluß auf ein Wort von Arnold Köttgen hinweisen. Er sagte kurz vor seinem Ableben: „Am Anfang der wissenschaftlichen Arbeit steht immer noch die Monographie". Ich war in die Situation versetzt, am Anfang meiner wissenschaftlichen Arbeit eine umfassende und kritische Darstellung des gesamten verwaltungsrechtlichen Systems unter Einbeziehung sozialwissenschaftlicher Gesichtspunkte zu geben. Ich möchte daraus die Bitte an Sie ableiten: Nageln Sie mich in Zukunft nicht auf jede einzelne These fest, die ich hier vertreten habe. Meine Ausführungen waren vor allem als Anstöße für eine weitere Diskussion gedacht.

Bachof (Schlußwort): Meine Herren Kollegen! Auch ich kann aus der Fülle der Diskussionsbeiträge nur weniges herausgreifen; ich beschränke mich dabei im wesentlichen auf das, was mein Referat betraf.

Herr Ipsen hat gemeint, ich hätte zu apodiktisch die Notwendigkeit eines Neubaus der Dogmatik verneint. Dazu darf ich darauf hinweisen, da $\beta$ meine These 22 nicht nur aus diesem einen inkriminierten Satz besteht: sie fährt fort, möglich und zugleich geboten sei eine andere Verteilung der Gewichte innerhalb des Systems, seine Befreiung von überholten und seine Erweiterung um neue, dem Sozialstaat adäquate Bestandteile; im Referat sprach ich von einem notwendigen Umbau des Systems. In der Sache sind wir also wohl kaum auseinander; der von Herrn Ipsen geforderten „Modernisierung“ des Systems pflichte ich voll bei. - Herr Ipsen hat ferner der These 13 von Herrn Brohm (Relativierung der Unterscheidung von Verwaltungsakt und Norm) unter dem Gesichtspunkt zugestimmt, daB auch im Gemeinschaftsrecht unter französischem Einfluß nicht nach der individuellen oder generellen Wirksamkeit, sondern nach der Verbindlichkeit differenziert werde. Ich sehe noch nicht recht, wie man von diesem Ansatzpunkt aus, also von dem (an sich richtigen) Verständnis des Rechtsaktes als einer Entscheidung, als des verbindlichen Abschlusses eines Informationsverarbeitungsprozesses, differenzieren könnte. Norm und Verwaltungsakt sind gleichermaßen Abschluß eines Informationsverarbeitungsprozesses. Ich meine auch nicht, daß man die Unter- 
scheidung von Norm und Verwaltungsakt aufgeben oder auch nur relativieren sollte. Für das Gros der Verwaltungshandlungen stimmt die Unterscheidung auch heute noch. Es ist die Aufgabe einer Systematisierung, idealtypische Kategorien zu bilden. $\mathrm{Da}$ es Zwischenformen gibt, die sich solcher Einteilung entziehen, das wissen wir alle. Aber gerade darauf, da $B$ das nicht genügend berücksichtigt wird, beruhen manche Fehlentscheidungen. $\mathrm{DaB}$ etwa die $\mathrm{Be}-$ bauungspläne ebenso wie die Verkehrszeichen sich einer eindeutigen Einordnung in die eine oder andere Kategorie entziehen, steht außer Zweifel. Wenn der Gesetzgeber angeordnet hat, da $B$ der Bebauungsplan als Satzung erlassen wird, so ist damit keineswegs gesagt - das wird oft verkannt - daß der Plan wirklich eine Satzung im üblichen Sinne sei; vielmehr ist nur gesagt, da $B$ er in gewisser Weise wie eine Satzung behandelt werden solle. Der Gesetzgeber hat damit eine Streitfrage der Rechtspraxis entschieden, aber er hat keine dogmatische Frage entschieden. Es ist nur einer dogmatischen Streitfrage der Boden entzogen worden, und auch das nur in einer ganz bestimmten Hinsicht. Das verkennt die Rechtsprechung, wenn sie aus der gesetzlichen Regelung folgert, der Bebauungsplan müsse nun in jeder Hinsicht als eine echte Norm behandelt werden. Das führt zu ganz widersinnigen Ergebnissen, z. B. hinsichtlich der Gültigkeit oder Nichtigkeit sowie der Heilbarkeit oder Unheilbarkeit von fehlerhaften Bebauungsplänen. Ich kann das hier nicht näher ausführen, aber die falschen Folgerungen der Rechtsprechung zeigen, wie weit wir hier noch einer Begriffsjurisprudenz verhaftet sind: Aus dem Begriff "Satzung" werden Folgerungen gezogen, die durch den Sinn der betreffenden Regelung nicht intendiert sind, ja ihm geradezu zuwiderlaufen. Ahnlich ist es bei den Verkehrszeichen. Nachdem man sich nach langem Hin und Her nun entschlossen hat, sie als Verwaltungsakte $i$. S. des Rechtsschutzsystems anzusehen, meint man zu Unrecht, nun auch alle Konsequenzen ziehen zu müssen, die normalerweise aus einer Einordnung in die Kategorie Verwaltungsakt zu folgen pflegen. Ich meine demgegenüber: Solche idealtypischen Kategorien brauchen wir zwar; wir müssen uns aber immer bewußt bleiben, daß es mannigfache Zwischenformen gibt, bei denen die Kategorisierung nicht voll aufgeht. Die Entlastungsfunktion der Dogmatik, von der besonders Herr Brohm in seinem Referat gesprochen hat, kann also nur eine vorläufige sein. Wir müssen immer wieder auf die den dogmatischen Kategorien zugrunde liegenden Wertungen und $\mathrm{Zwecke}$ zurückgreifen, besonders dann, wenn etwas in die ideal-typisch konzipierten Schubladen nicht hineinpaßt. 
Aber die Schubladen als solche können wir, meine ich, nicht entbehren.

Zu Herrn Quaritsch: Sie haben meine These angezweifelt, die Dogmatik des Verwaltungsrechts sei weniger durchgebildet als diejenige des Zivilrechts, und haben dazu auf das Lehrbuch von $H$. J. Wolff verwiesen. Nun wird sicher niemand die hervorragende dogmatische Leistung dieses Werks in Frage ziehen. Aber das, was dieses Lehrbuch dogmatisch geleistet hat, ist zum erheblichen Teil Sichtung und Ordnung, ist Ausformung und Verfeinerung vorhandener Institute und Begriffe, weniger dagegen die Entwicklung neuer. Letzteres kann auch wohl kaum das Anliegen eines Lehrbuchs sein. Was ich mit meiner Feststellung meinte, ist das Fehlen einer Vielfalt an Institutionen und Formen, wie sie das bürgerliche Recht kennt. Denken Sie nur an eine dogmatische Entdeckung und Entwicklung wie das faktische Vertragsverhältnis. Ähnliche .Verhältnisse, 2. B. durch Realakte der Verwaltung entstanden, haben wir in Hülle und Fülle auch im Verwaltungsrecht; sie harren aber noch der dogmatischen Erschließung. Ich glaube deshalb, an meiner Auffassung von der geringeren Durchbildung der verwaltungsrechtlichen Dogmatik festhalten zu sollen. - Es lag mir völlig fern, Herr Quaritsch, die große Leistung Forsthoffs zu verkennen, die darin besteht, uns erstmals die historische Bedingtheit vieler unserer Institutionen deutlich vor Augen geführt zu haben. Ich habe seinerzeit diese Leistung in meiner Besprechung der ersten Auflage des Lehrbuchs nachdrücklich hervorgehoben. Worum es mir heute ging, war nur, zu zeigen, $\mathrm{da} B$ und warum diese Bedingtheiten $\mathrm{m}$. E. einen anderen Stellenwert haben, als Forsthoff ihn ihnen beimiBt.

Herrn Oppermann bin ich dankbar für seinen nachdrücklichen Hinweis auf das Kulturverwaltungsrecht. Ich habe dieses Gebiet nur mit einem Satz erwähnen können, aber in der Tat waren die staatlichen Aktivitäten dort ähnlich wie im Bereich der sozialen Verwaltung.

Herr Vogel hat die Frage aufgeworfen, ob wir überhaupt ein "System" besitzen. Er hat dazu auf die fragwürdige Einteilung in allgemeines und besonderes Verwaltungsrecht hingewiesen. Damit hat er recht. Ich habe in einigen beim mündlichen Vortrag meines Referats aus Zeitnot unterschlagenen Sätzen die Frage gestellt, wohin z. B. die Subvention gehöre; sei sie ein Begriff des allgemeinen oder des besonderen Verwaltungsrechts? Die Einteilung in allgemeines und besonderes Verwaltungsrecht ist in der Tat eine sehr grobe und unvollkommene. Auch sie ist nur eine Einteilung des äußeren Systems; denn das innere System, die Sinneinheit der Prinzipien, 
Grundsätze, Institute usw., wird von dieser Einteilung kaum berührt. Es ist ja interessant, daß auch im bürgerlichen Recht diese mehr äußere Einteilung in einen allgemeinen und einen besonderen Teil - obwohl sie sich dort sogar im Gesetz findet - von der Dogmatik mehr und mehr in Frage gestellt wird. $\mathrm{Ob}$ man freilich mit Herrn Vogel das Recht der Organisation und der Verwaltungsmittel als einen zwischen dem allgemeinen und dem besonderen Verwaltungsrecht liegenden dritten Bereich ansprechen kann, ist mir fraglich. Die Verwaltungszwecke haben ja nicht nur in diesem dritten Bereich, sondern im gesamten Verwaltungsrecht ihren legitimen Platz. - Auch die Unterscheidung von gestaltenden Akten und Vollzugsakten ist sicher richtig, aber ich würde auch das nur für heuristische Kategorien halten. Auch hier gibt es eine ganze Skala und Stufung von der totalen Gebundenheit reinen Vollzuges bis hin zur freiesten Gestaltung. Solche Unterscheidungen haben sicher einen wichtigen Erkenntniswert, aber eine scharfe Scheidung, die dogmatisch verwertbar wäre, ist hier kaum möglich.

Herr Badura hat in sehr grundsätzlicher Weise die Vermittlungsfunktion der Dogmatik zwischen der Verfassung und den Gerechtigkeitsprinzipien einerseits und der Partikularität des Rechtsstoffes andererseits betont. Insoweit volle Zustimmung. Aber ich sehe nicht, wieso dem die Kennzeichnung der Daseinsvorsorge als eines „soziologischen“ Begriffs entgegensteht. Auch scheint mir, als wenn Herr Badura in solcher Kennzeichnung eine Abwertung erblicke. Das ist es in meiner Sicht nicht. Ich habe den juristischen Sinn solcher Begriffe und vor allem ihre kritische Funktion, die uns nötigt, die Rechtsbegriffe und Rechtsinstitute immer wieder neu zu durchdenken, ausdrücklich betont. - Für die Realität, meint Herr Badura, besage es wenig, da 3 schon im 19. Jahrhundert die Zwecke des Verwaltungshandelns gesehen worden seien; denn die Verfassungsidee des liberalen Rechtsstaates habe den Erscheinungen eben einen anderen Stellenwert gegeben, als es heute diejenige des sozialen Rechtsstaates tue. Darin stimme ich ihm, jedenfalls zum Teil, zu. Ich darf vielleicht, als eine gewisse Ergänzung zu meinem heutigen Bericht, auf mein früheres Referat über den sozialen Rechtsstaat verweisen. Ich habe dort - dies zu Herrn Baduras Hinweis auf den klassischen Gesetzesbegriff - betont, wie sehr dieser Begriff ein politischer war. Ich bin durchaus der Ansicht, da $B$ wir den Gesetzesbegriff heute so nicht mehr verwenden können. Aber ich konnte auf diese Fragen nicht erneut eingehen, sonst hätte ich viel anderes streichen müssen.

Herr König hat in seinen Bemerkungen zur Einheit von Theorie und Praxis gemeint, für die Praxis sei letzten Endes 
die richterliche Denkweise maßgebend. In der Tat, das ist sie in erheblichem Umfange, aber keineswegs ausschließlich. Es scheint mir nun die Aufgabe gerade der Wissenschaft zu sein, dafür zu sorgen, daß jene Denkweise keinen AusschlieBlichkeitscharakter erlangt. Die Praxis würde dabei Schaden nehmen. Für das wichtige Effizienzproblem z. B. ist in richterlichen Entscheidungen nur wenig Gespür zu finden. Auf solche Umstände müssen wir kritisch hinweisen. Unser Verwaltungsrecht ist zwar weitgehend ein judge made law, aber es darf nicht nur dazu werden. Ich war erschrocken, kürzlich aus der Feder des derzeitigen Präsidenten des Bundesverwaltungsgerichts eine Polemik gegen die Wissenschaftsgläubigkeit der deutschen Richter zu lesen, in der als Vorbild die (angebliche) angelsächsische Praxis empfohlen wurde, derzufolge die Professoren nur zu lehren hätten, wie die Richter Recht sprechen (vgl. DOV 1971, 7). Ich meine demgegenüber, auf der Wechselwirkung von Theorie und Praxis, auf dem gegenseitigen Gedankenaustausch zwischen Wissenschaft, Rechtsprechung und Verwaltungserfahrung, darauf müssen wir bestehen.

Ich weiß nicht recht, ob ich meine Einbeziehung in die Reihe österreichischer Positivisten durch Herrn Winkler ausschließlich als Lob empfinden soll. Aus seinem Beitrag möchte ich nur zwei Dinge herausgreifen. Mich hat sehr gefreut, daß er auf die ästhetische Seite des Rechts solchen Nachdruck gelegt hat. Schon Erich Kaufmann hat sich einmal ähnlich geäußert; er hat gemeint, daß Otto Mayers Lehren sich nicht zuletzt deshalb so schnell durchgesetzt hätten, weil Otto Mayer neben und fast vor allen anderen Qualitäten diejenige eines Künstlers besessen habe. - Was das "Verwaltungsdenken zum Fall" betrifft: auf die Frage „Problem- oder Systemdenken“ habe ich leider - aus Zeitgründen nicht eingehen können. Unser Verwaltungsrecht ist weitgehend vom fallbezogenen Problemdenken geprägt und wird es auch bleiben müssen. Das macht es vor allem den Anwälten so unangenehm und unbequem; deshalb rufen gerade sie auch ständig nach einer Kodifizierung, in der Hoffnung, daß es dann künftig einen „VerwaltungsrechtsPalandt" geben werde, in dem sie nachblättern können, was die Gerichte zu diesem und jenem gesagt haben. Aber das Verwaltungsrecht mit seinem sich stets wandelnden Stoff wird sich nie in eine Kodifizierung umfassender Art einfangen lassen. Unser Recht ist und bleibt deswegen weitgehend ein Richterrecht. Ich habe versucht, jenem Mangel an "Nachschlagbarkeit" durch meine Rechtsprechungsberichte ein wenig abzuhelfen.

$\mathrm{DaB}$ ich mit Herrn Bullingers Relativierung des Unterschiedes von öffentlichem und Privatrecht voll einverstanden bin, 
dürfte aus meinem Bericht hervorgegangen sein. Das gilt vor allem für die in Herrn Bullingers Buch so eindringlich vorgetragene Einsicht, daß es ein Allgemeinrecht gibt, welches sich jener Einteilung von vornherein entzieht. Diese Einsicht muB aber erst durchgesetzt und die sich daraus ergebenden Folgerungen müssen erst erkannt werden. Das Bundesverwaltungsgericht hat zwar von Treu und Glauben zutreffend gesagt, hier handele es sich um einen Begriff nicht des öffentlichen und auch nicht des privaten, sondern des allgemeinen Rechts; daß es dann aber gefolgert hat, gerade deswegen (!) sei der Begriff nicht revisibel, zeigt, daß es die wahre Bedeutung jener Einsicht nicht erkannt hat.

Zu Herrn Rupps temperamentvollem Beitrag: Ich habe ihn gewiß nicht als Buhmann aufbauen wollen! Herr Rupp liebt temperamentvolle Äußerungen, und sie dürfen deshalb wohl auch temperamentvoll erwidert werden. Es tut mir leid, wenn er meint, ich hätte ihn ungenau zitiert. Ich habe seine Formulierung in "Das Bundesverfassungsgericht 1951-1971" jetzt nicht vor mir. Ich meine zu erinnern, daß sie etwa lautet: Der Regierung als Organisation komme die Funktion des Regierens nicht zu. Es mag sein, daß es zusätzlich heißt: Regieren „im Sinne des government"1). Ich würde der These aber auch mit diesem Zusatz widersprechen. Auch bei uns teilen sich Parlament und Regierung in diese Funktion, wie es etwa für den Bereich der Außenpolitik durch Art. 59 Abs. 2 GG (inzident anerkannte oder vorausgesetzte Prärogative der Regierung) deutlich wird.

Von Herm Götz glaube ich mich nicht wesentlich zu unterscheiden. Ich habe betont, daß eine Ausrichtung des äußeren Systems an den Zwecken und Aufgaben der Verwaltung notwendig ist, und ich habe weiter darauf hingewiesen, da $B$ dieses äußere System selbstverständlich auch das innere System beeinflußt. In Leitsatz 18 habe ich gesagt: "kann es beeinflussen"; ich hätte vielleicht besser gesagt: "soll es beeinflussen" oder "muß es beeinflussen." Gerade in solcher Beeinflussung kommt die kritische und didaktische Funktion einer Orientierung des äußeren Systems an Zwecken und Aufgaben zur Geltung.

Für Herrn Kiskers Hinweis auf das Urteil des Bundesverfassungsgerichts zum hamburgischen Richterwahlausschuß bin ich dankbar. Die fehlende Begründungsmöglichkeit bei den Entscheidungen pluralistisch zusammengesetzter Gremien ist ein weiteres Beispiel für die Notwendigkeit stärkerer Berücksichtigung der Verwaltungsorganisation; in dieselbe Richtung zielten

1) Vgl. dazu oben S. 195, N. 8 
meine Ausführungen über Wahlgremien usw. - Herrn Kiskers Bemerkungen über eine "Dogmatik der Gruppenmitwirkung“ sind ein Teilaspekt der von mehreren Diskussionsrednern erhobenen Forderung nach einer stärkeren Ausformung der Verfahrensbeteiligung. Hier unterscheide ich mich wohl von Herrn Brohm darin, daß ich zwar de lege ferenda alles unterschreiben kann, was er über die Notwendigkeit einer umfassenderen Verfahrensbeteiligung ausgeführt hat, aber manches davon doch mehr für eine Frage der Gesetzespolitik als der Dogmatik des geltenden Rechtes halte. Ich möchte freilich Herrn Blümel darin zustimmen, daß manche einschlägigen Probleme auch schon auf der Basis des geltenden Rechts dogmatisch gelöst werden können, etwa mit Hilfe des Grundsatzes des rechtlichen Gehörs. Wenn z. B. die Festsetzung der Sanierungsgebiete ohne Beteiligung der Betroffenen erfolgt, so kann man dem vielleicht beikommen, indem man das als Versto $B$ gegen jenen Grundsatz und damit gegen das Rechtsstaatsprinzip wertet und auf diese Weise dogmatisch in den Griff bekommt. $\mathrm{Ob}$ die darüber hinausgehenden, von Herrn Brohm aufgestellten Postulate schon als geltendes Recht begründbar sind, ist mir mindestens zweifelhaft.

Zum Schluß noch eine Bemerkung zu Herrn Achterbergs Forderung nach einer "klaren Begriffsbildung der Verwaltung“. Das ist ja ein sehr altes Problem. Ich meine, nicht ohne Grund hat Herr Forsthoff davor resigniert und in seinem Lehrbuch gesagt, Verwaltung lasse sich nicht definieren, sondern nur beschreiben. Wenn man dennoch auf einer "Definition" bestehen will, so läßt sie sich angesichts der außerordentlichen Fülle und Mannigfaltigkeit der Vorgänge, die wir unter Verwaltung verstehen, nicht anders geben als mit der herkömmlichen Subtraktionsmethode. Diese ist natürlich ein höchst armseliger Behelf. Aber gerade das zeigt, daß wir in der Tat Verwaltung wohl nur beschreiben und nicht wirklich definieren können.

Damit darf ich schließen. Allen Diskussionsrednern für die zahlreichen Anregungen herzlichen Dank!

Zacher: Meine Herren, ich darf damit die wissenschaftliche Arbeit dieser Tagung zum Abschluß bringen. Erlauben Sie mir noch ein subjektives Wort, vielleicht sehen es viele von Thnen anders. Ich selbst empfinde den Zustand der Dogmatik des Verwaltungsrechts oder empfand ihn bis heute in einem so großen Mißverhältnis zur Detailentwicklung des Verwaltungsrechts, zur Entwicklung der Verwaltungswirklichkeit und zur Entwicklung der rechtspolitischen Anforderungen an das Verwaltungsrecht, daß ich es quälend bezeichnen kann. Ich glaube, daß 
wir heute durch die beiden Referate und natürlich auch durch die Diskussion einen Schritt in dem Schließen dieser großen Lücke vorangekommen sind und dafür möchte ich den beiden Herren Referenten ganz besonders Dank sagen. 